\title{
Improving sexual and reproductive health care for poor and underserved girls : impact of a voucher program on access and quality of primary care in Nicaragua
}

Citation for published version (APA):

Meuwissen, L. E. M. M. (2006). Improving sexual and reproductive health care for poor and underserved girls : impact of a voucher program on access and quality of primary care in Nicaragua. [Doctoral Thesis, Maastricht University]. Universiteit Maastricht. https://doi.org/10.26481/dis.20060920lm

Document status and date:

Published: 01/01/2006

DOI:

10.26481/dis.20060920lm

Document Version:

Publisher's PDF, also known as Version of record

Please check the document version of this publication:

- A submitted manuscript is the version of the article upon submission and before peer-review. There can be important differences between the submitted version and the official published version of record. People interested in the research are advised to contact the author for the final version of the publication, or visit the DOI to the publisher's website.

- The final author version and the galley proof are versions of the publication after peer review.

- The final published version features the final layout of the paper including the volume, issue and page numbers.

Link to publication

\footnotetext{
General rights rights.

- You may freely distribute the URL identifying the publication in the public portal. please follow below link for the End User Agreement:

www.umlib.nl/taverne-license

Take down policy

If you believe that this document breaches copyright please contact us at:

repository@maastrichtuniversity.nl

providing details and we will investigate your claim.
}

Copyright and moral rights for the publications made accessible in the public portal are retained by the authors and/or other copyright owners and it is a condition of accessing publications that users recognise and abide by the legal requirements associated with these

- Users may download and print one copy of any publication from the public portal for the purpose of private study or research.

- You may not further distribute the material or use it for any profit-making activity or commercial gain

If the publication is distributed under the terms of Article 25fa of the Dutch Copyright Act, indicated by the "Taverne" license above, 


\section{Improving sexual and reproductive health care}

for poor and underserved girls

Impact of a voucher program on access and quality of primary care in Nicaragua 
ISBN-10: 90-9020895-X

ISBN-13: 978-90-9020895-4

\section{Copyright (C) 2006 Liesbeth Meuwisssen}

Cover Design: Liesbeth Meuwissen

Print: Universal Press

All rights reserved. No parts of this publication may be reproduced, stored in a retrieval system or transmitted, in any form or by any means, electronic, mechanical, photocopying, recording or otherwise, without the prior written permission of the author. Exceptions are allowed in respect of any fair dealing for the purpose of research, private study or review. 


\section{Improving sexual and reproductive health care for poor and underserved girls}

Impact of a voucher program on access and quality of primary care in Nicaragua

Het verbeteren van sexuele en reproductieve gezondheidszorg voor kansarme tienermeiden

Het effect van een voucher programma op toegankelijkheid en kwaliteit van de eerstelijnszorg in Nicaragua

Mejorar los servicios de salud sexual y reproductiva para adolescentes pobres y desatendidas

El impacto de un programa de bono en el acceso y la calidad de servicios de salud primaria en Nicaragua

\section{PROEFSCHRIFT}

ter verkrijging van de graad van doctor aan de Universiteit Maastricht, op gezag van de Rector Magnificus

Prof. mr. G.P.M.F. Mols

volgens het besluit van het College van Decanen, in het openbaar te verdedigen

op woensdag 20 september 2006 om 14.00 uur door

Louise Elisabeth Margaretha Magdalena Meuwissen 
Promotor:

Prof. dr. J.A. Knottnerus

Copromotor:

Dr. A.C. Gorter Instituto CentroAmericana de la Salud (ICAS), Managua,

Nicaragua

Beoordelingscommissie:

Prof. dr. G.G.M. Essed, voorzitter

Prof. dr. J.M. Bensing Universiteit Utrecht

Dr. G.D. Majoor

Prof. dr. J. van der Velden Universiteit Nijmegen

Dr. T. van der Weijden

The study presented in this thesis was conducted with support of the Care and Public Health Research Institute (CAPHRI) of the University of Maastricht, which participates in the Netherlands School of Primary Care Research (CaRe), acknowledged in 1995 by the Royal Netherlands Academy of Sciences.

The University of Maastricht and the Netherlands Institute for Health Care Research (NIVEL) are gratefully acknowledged for the financial support for the publication and dissemination of this thesis. 


\section{Content}

$\begin{array}{ll}\text { Foreword } & \text { iii }\end{array}$

$\begin{array}{lll}\text { Abbreviations } & \text { iv }\end{array}$

Affiliations Co-Authors iv

$\begin{array}{ll}\text { Chapter } 1 & 1\end{array}$

Introduction

Chapter 2

The illusion of innocence. Why sexually active teenage girls in Nicaragua do not use contraceptives while not wanting to conceive?

A literature search

\section{Chapter 3}

Sexual and reproductive health care for adolescents. Overview of Interventions in Latin America and description of health care in Nicaragua

\section{Chapter 4}

Competitive voucher programs. Description of the voucher program for adolescents and the design of the evaluation study

\section{Chapter 5}

Impact of accessible sexual and reproductive health care on poor and underserved adolescents in Managua, Nicaragua. A quasi-experimental intervention study

Meuwissen LE, Gorter AC and Knottnerus JA

Journal of Adolescent Health 2006 Jan 38(1); 56.e1-56.e9.

\section{Chapter 6}

Uncovering and responding to needs for sexual and reproductive health care among poor urban female adolescents in Nicaragua

Meuwissen LE, Gorter AC, Segura Z, Kester ADM, Knottnerus JA

Tropical Medicine and International Health (in press 2006) 
Chapter 7

Perceived quality of reproductive care for girls in a competitive voucher program, A quasi-experimental intervention study, Managua, Nicaragua

Meuwissen LE, Gorter AC, and Knottnerus JA.

International Journal for Quality in Health Care 2006; 18(1):35-42

Chapter 8

Can a comprehensive voucher program prompt changes in doctors' knowledge, attitudes, and practices related to sexual and reproductive health care for adolescents? A case study from Latin America

Meuwissen LE, Gorter AC, Kester ADM, Knottnerus JA

Tropical Medicine and International Health. 2006;11(6):889-98

\section{Chapter 9}

Does a competitive voucher program for adolescents improve the quality of reproductive health care? A simulated patient study in Nicaragua

Meuwissen LE, Gorter AC, Kester ADM and Knottnerus JA

BMC Public Health (in press 2006)

\section{Chapter 10}

General discussion

\section{Annex}

Nicaragua: Introducing a voucher scheme for disadvantaged adolescents' access to services in three districts

L Meuwissen, T Donaire, J Medina, Z Segura \& A Gorter Sexual Health Exchange 2004-3\&4,28-30

Summaries

Summary

Samenvatting

Resumen 


\section{Foreword}

When I was preparing for our move to Nicaragua, I contacted Anna Gorter. Anna had been working for 17 years in Nicaragua as a medical doctor and researcher. She had developed the concept of a competitive voucher program in an effort to provide sex workers with high quality and timely treatment for sexually transmitted diseases. She informed me about living and working in Nicaragua. She shared her experiences of seeking to improve health care among sex workers in Managua. She also told me about a voucher program, aimed at reducing the number of unwanted teenage pregnancies among adolescents that was about to start.

I was fascinated by the approach. Voucher programs could be capable of breaking through the impasse in which the poor and needy make less use of health services than the rich. Unmarried adolescents have even more problems due to taboos about their sexuality. This situation is not only present in Nicaragua. In the African countries where I had lived and worked, I had seen the same situation: unmarried adolescents did not attend sexual and reproductive health services, despite their questions and needs.

Nowadays more than ever, interventions are needed that are able to correct the inequity in access to health care. Differences between rich and poor have been aggravated, not only on a global scale, but also within most developing countries (1). The recent health sector reforms have resulted in further deterioration in the provision of services to the poor, and more people than ever before are left without basic health services $(1 ; 2)$. The voucher program might not only be a possible solution for adolescents, but also for other groups of underserved people.

So when I was invited to join the project as a researcher, I immediately agreed. I was curious to see if the voucher program was indeed an effective strategy to provide poor and underserved adolescents with adequate care. This task would enable me to become a researcher and to examine the impact of an intervention in a field where relevant information and analysis are scarce and much needed. It could contribute to improving access to sexual and reproductive health care for underserved adolescents and, as a consequence, to improving their opportunities in life. My interest and fascination in this approach remained, and I hope you will enjoy reading this dissertation as much as I enjoyed writing it.

\section{Reference}

1. Collins T. Globalization, global health, and access to healthcare. Int J Health Plann Manage 2003 Apr;18(2):97-104.

2. UNFPA. The State of World Population 2005. New York, USA: UNFPA, United

Nations Population Fund; 2005. 


\section{Abbreviations}

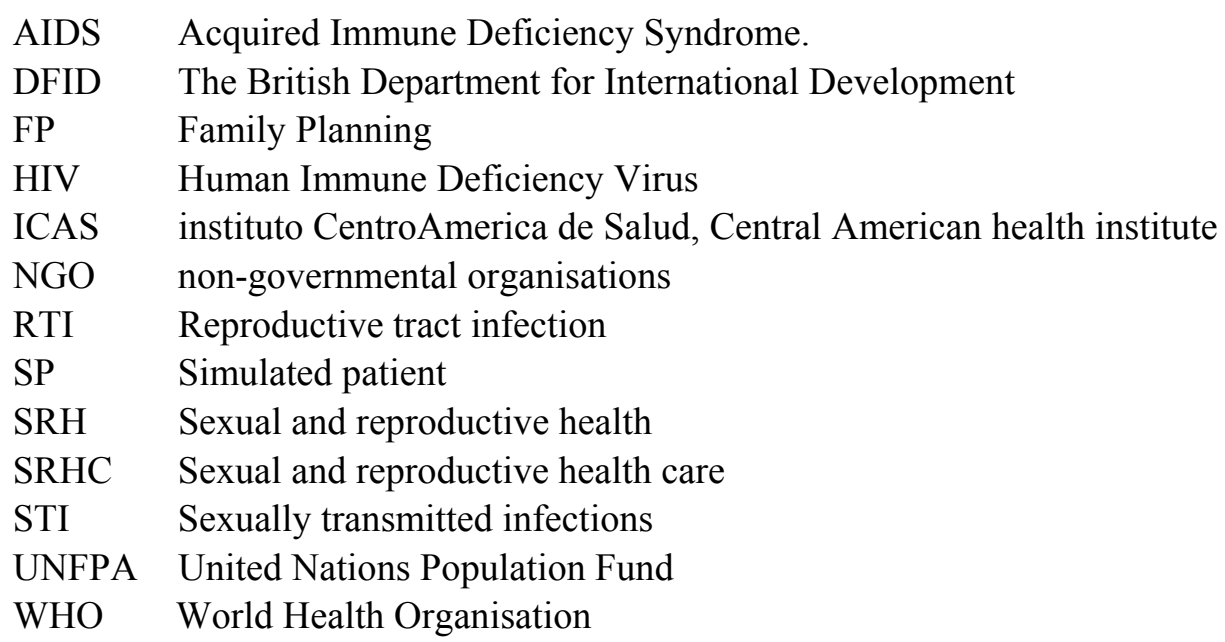

\section{Affiliations Co-Authors}

Anna C Gorter During the project: London School of Hygiene and Tropical Medicine. Currently: Instituto CentroAmericano de la Salud (ICAS), Apartado Postal 2234, Managua, Nicaragua.

Arnold DM Kester Department of Methodology and Statistics, University of Maastricht, Postbus 616, 6200 MD Maastricht, the Netherlands.

JA Knottnerus Professor of General Practice, University of Maastricht, Postbus 616, 6200 MD Maastricht, the Netherlands, and President of the Health Council of the Netherlands, The Hague, the Netherlands.

Zoyla E Segura Instituto CentroAmericano de la Salud (ICAS), Apartado Postal 2234, Managua, Nicaragua. 
Dedicated to:

All young people in Nicaragua 


\section{Chapter 1}

Introduction 


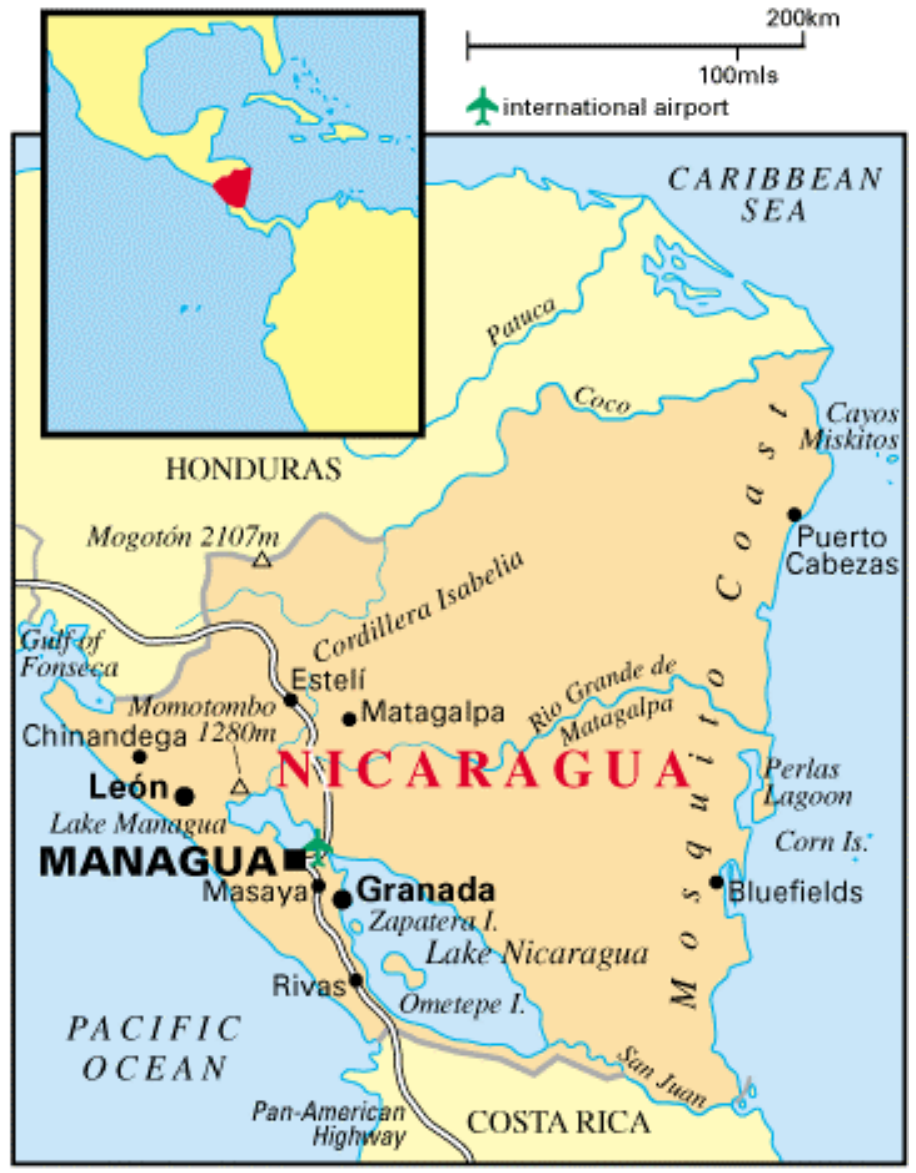

Figure 1 Nicaragua 


\subsection{Introduction}

In Latin America, adolescents ${ }^{1}$ are confronted with serious problems with respect to their sexual and reproductive health. Although widely recognized as serious public health problems, the response from health care services can be generally categorised as inadequate. Many adolescents lack access to sexual and reproductive health ( $\mathrm{SRH})$ care and the quality of care that is available is often poor. There is a dearth of rigorous research on what should be done to effectively address this situation. An urgent need exists to identify effective, low cost interventions that assist adolescents to protect themselves from unwanted or untimely pregnancies as well as sexually transmitted infections (STIs), including HIV. This is essential, whether considered from a women's health perspective, a rights based approach or from the public health priority list (1-5).

In Nicaragua, a concrete intervention has been developed and implemented, aimed at increasing access to and quality of SRH care for adolescents, and, as a result, reducing the rate of unwanted pregnancies and the risks of contracting STIs/HIV. The intervention involves the distribution of vouchers to any adolescent aged between 12 and 20, living in disadvantaged areas of Managua. Vouchers could be exchanged for a free-of-charge consultation relating to SRH care in one of 19 participating clinics.

Two main assumptions underlie this intervention. The first is that there is demand among adolescents to reduce the risks associated with sexual intercourse, but they do not have access to confidential personal advice and treatment. The second assumption is that the voucher program engenders improvements in the quality of care. Although there are indications that competitive ${ }^{2}$ voucher programs in the health sector have a strong potential to improve service quality $(6 ; 7)$, this has never been the subject of explicit research.

In this thesis, we sought to ascertain the effectiveness of this intervention during its pilot phase, between 2000 to 2002 . We focussed the evaluation on girls in part as a result of resource limitations but more importantly because we wanted to assess if girls could be supported to take control of their fertility without requiring the consent of parents or partner. In this introductory chapter, a description is given of the context of the intervention and the intervention itself, followed by an overview of the research and the outline of this thesis.

\footnotetext{
${ }^{1}$ Adolescence has been defined by the World Health Organisation as the period from 10 to 19 years of age We will use the term adolescents and teenager interchangeably to indicate people in this age group. The intervention however, comprised adolescents from 12 to 20 years.

2 The voucher program is competitive in the sense that it involves a number of different providers, with consumers able to choose between them. This encourages the providers to compete to attract and retain voucher holders. The program will be discussed in detail in chapter 4 .
} 


\subsubsection{Context}

Nicaragua lies in Central America (figure 1) and is one of the poorest countries of Latin America. Forty-five percent of the population lives on less than US\$ 1 a day and $80 \%$ on less than US\$ 2 dollars a day (8). Around one-fourth of the population lives in the capital Managua. In 2000, Managua had an estimated population of $1,025,000$ (9). Urban population growth is high due to high birth rates and internal migration, the latter caused by the lack of employment opportunities in rural areas. Approximately $25 \%$ of the population fall within the adolescent age group (9).

Teenage pregnancy is very common in Nicaragua. Each year, 119 per 1000 girls between 15 and 19 years old give birth (10). By the age of 19, $45 \%$ of the girls are either pregnant or have already given birth (figure 2) (10). Research from Leon, the second largest city in Nicaragua, showed that the latency period between first intercourse and the end of the first pregnancy is, on average, 21.5 months (11).

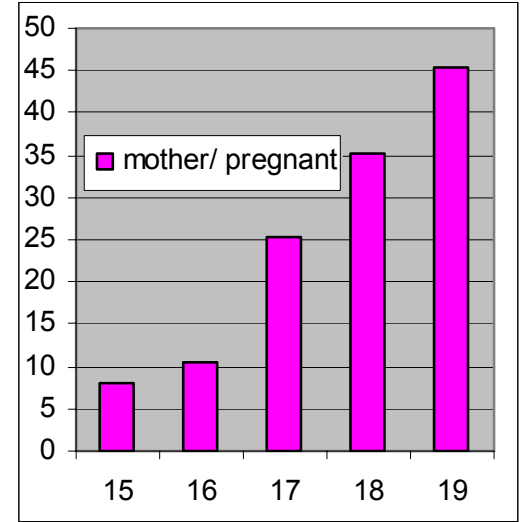

Figure 2 Percentage girls mothers or pregnant by age

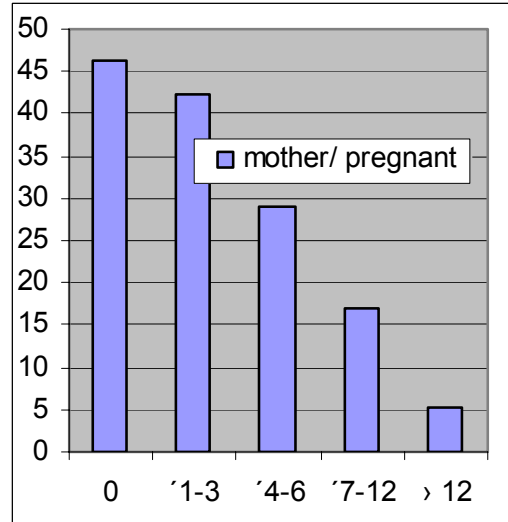

Figure 3 Percentage girls mothers or pregnant by number of years of education

High teenage fertility rates are associated with both low socio-economic status and low educational attainment (figure 3) (10). Although high rates of teenage pregnancy may still reflect the traditional pattern of life in rural areas, early pregnancy is very often unwanted or untimely. Furthermore, teenage pregnancy is frequently associated with school dropout, poverty, abusive relations, and poor health outcomes for both mothers and babies. These threats are associated with a low use of modern contraceptive methods and condoms among sexually active adolescents. Although $98 \%$ of 15-19 years olds could name at least one modern contraceptive method, only $7 \%$ of sexually active girls in this age group used a condom and $47 \%$ another modern method according to the 2001 Nicaraguan demographic health survey (10).

Increased use of modern contraceptives and condoms could dramatically reduce the 
teenage pregnancy rate. The background to the low use of contraceptives will be discussed in chapter 2.

\subsubsection{Interventions}

Until now, very few interventions aimed at increasing adolescents' use of sexual and reproductive (SRH)-care or contraceptives in Latin America have been evaluated and documented. This sparse literature will be discussed in the first part of chapter 3. However, it is important to note that none of these evaluations provided evidence of success in increasing adolescents' uptake of SRH care services or of contraceptives.

The provision of SRH care to adolescents in Managua is described in the second part of chapter 3 .

In Nicaragua, the Central American Health Institute (Instituto CentroAmericano de la Salud, ICAS) has used a competitive voucher scheme to successfully improve access to STI treatment among sex workers and, as a result, has contributed to reducing STI prevalence among this underserved group (6). Inspired by this success, ICAS developed, in collaboration with the London School of Hygiene and Tropical Medicine, a proposal to increase the access to and quality of SRH care for adolescents using a similar mechanism. The British Department for International Development (DFID) provided the funding for a pilot program from 2000 to 2002 . It is this pilot program that is the subject of the studies underlying this thesis. More information on competitive voucher programs and their characteristics is given in the first part of chapter 4.

Under the voucher program for adolescents in Nicaragua, vouchers were distributed to adolescents aged between 12 and 20 in disadvantaged areas of Managua. The vouchers entitled the holder to a free-of-charge consultation and follow-up visit for advice/counselling, contraception, treatment of STIs or reproductive tract infections (RTIs), pregnancy testing and/or antenatal care. Adolescents were able to attend without appointment to any one of four public, five private and ten non-governmental organisation clinics contracted by ICAS. A detailed description of the program and its (NGO) implementation is presented the second part of chapter 4. 


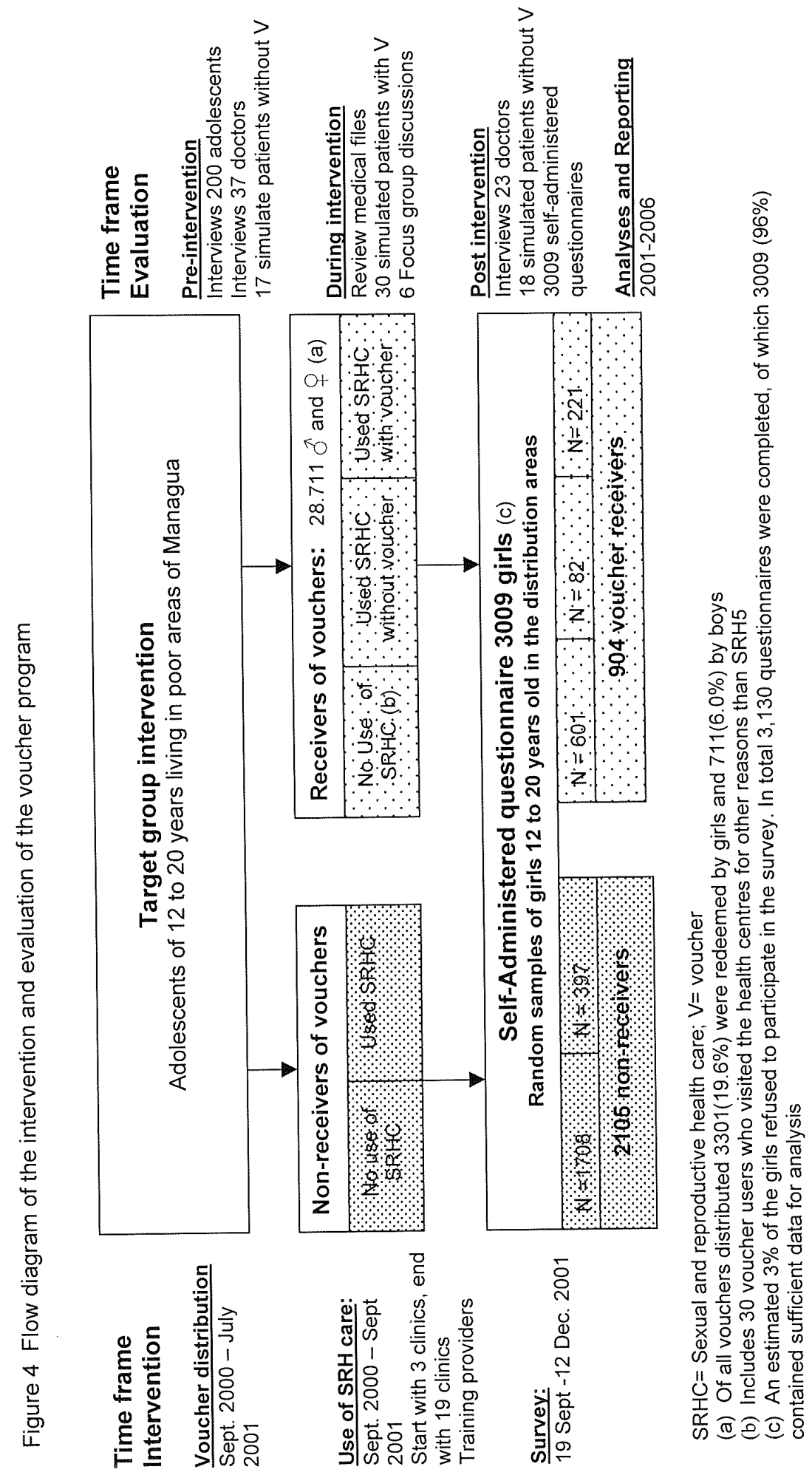




\subsection{An overview of the research}

An overview of the timeframe of the intervention and the evaluation is presented in figure 4. A detailed description of the design of the evaluation study can be the found in the third part of chapter 4.

The first main research question was: Did the voucher program increase adolescents' use of SRH care and their knowledge and use of contraceptives and condoms?

The specific questions formulated to measure impact were:

- Did the voucher receivers use SRH care services more frequently than nonvoucher receivers?

- $\quad$ Did the voucher receivers have a better knowledge of modern contraceptives and condoms than non-voucher receivers?

- Did the voucher receivers use modern contraceptives and condoms more frequently than non-voucher receivers?

- What is the nature of existing, but largely unmet needs for SRH care among female adolescents?

To be able to answer these questions, random samples of adolescents outside schools, at markets and in neighbourhoods completed self-administered anonymous questionnaires. Adolescents were approached in a representative sample of the sites where vouchers had been distributed. As such, a random sample was obtained of 3,009 female adolescents, of whom 904 had received a voucher (the intervention group), and 2,105 had not (the control group). In chapter 5, we present the results of this quasi-experimental design, in which the intervention and control groups are compared for use of SRH care and knowledge and use of contraceptives (12). In Figure 4 an overview is given of the study samples.

A descriptive study design is used to reflect the needs of the girls who used their voucher. For all 3,301 vouchers used by female adolescents, doctors completed a standardised medical form with details of the clients' background and reasons for seeking a consultation. Because the use of services increased substantially among voucher receivers, analysis of the medical records makes it possible to identify the nature of existing, but largely unmet needs for SRH care among adolescents. The results are described in chapter 6 (13).

The second main question was: Did the voucher program improve the quality of SRH care delivered to adolescents?

The specific questions we formulated with respect to the quality of care were:

- Were voucher users more satisfied with the care received than non-voucher users? 
- Did voucher users receive health care of good 'social' and technical quality?

- Were there any changes in the quality of care that were sustained after the intervention?

To evaluate the various aspects of the quality of care, we used the criteria for adolescent friendly services $(14 ; 15)$ and the concepts that have been developed to evaluate the quality of family planning services $(1 ; 16)$. The methods used were interviews with adolescents, revision of medical files, focus group discussions, simulated patients and interviews with doctors.

The user perspective received considerable attention because previous researchers had found that a client's decision to adopt or sustain contraceptive use is influenced by the quality of care provided $(1 ; 2 ; 17)$. The questionnaires distributed to adolescents included a number of questions on the quality of care received. From the 700 'users of SRH care', we were able to compare the perception of the quality of the SRH care between the 221 'users-with-voucher' and the 479 'users-withoutvoucher' (Figure 4). We assessed whether vouchers made a difference to perceptions of service quality and analysed the determinants of adolescents' satisfaction. The results are presented in chapter 7 (18).

Since providers have a central role in the delivery of health care, we were also very interested to study doctors' perspectives on serving adolescents. To assess whether any changes occurred as a result of participation in the program, a before-after design was used. All doctors were interviewed before and after the program, with questions relating to their knowledge, attitudes and practices. Answers are compared to assess and evaluate any changes in their knowledge, attitudes and practices. In chapter 8 we describe our findings (19).

A method that has proved to be reliable, valid, feasible and acceptable in assessing the performance of doctors in developed countries is the use of simulated patients (20-22). We used a before-during-after design to monitor the performance of participating doctors. This allowed us to evaluate the quality of the service that the adolescents voucher users received during the intervention, and to assess differences in the pre- and post-intervention performance of the doctors visited by girls without vouchers. The experiences of the simulated patients and our experiences using this method of analysis are discussed in chapter 9 (23).

Two assessment methods are not covered in a separate chapter. The first involved 200 interviews with adolescents prior to the intervention to estimate their knowledge of SRH services and contraceptives. Their answers helped us to design the intervention and to select the clinics. The second method involved focus group discussions. These were used to better understand the problems faced by adolescents and to determine their assessment of the quality of regular health care services compared with services delivered under the voucher program. The focus group discussions were used to monitor the voucher program and as input for 
design, analysis and interpretation in the evaluation studies.

In chapter 10 the conclusions of the different evaluation studies are drawn together to create a picture of the impact of the voucher program on the access to and quality of SRH care for adolescents. In addition, some methodological issues are discussed more fully, we compare the results of our studies with findings from other studies, and discuss the implications for further interventions and research.

After the pilot intervention ended, the Royal Dutch Embassy in Managua continued financing the adolescent health program until 2004. During this period, the program was extended to two departmental cities of Nicaragua. The Annex contains a review written by the adolescent health team of ICAS in 2004 (24). This paper provides a global overview of the main program features and our operational experiences.

The thesis is summarized in chapter 11 .

El resumen del tesis se encuentra en capitulo 12.

De Nederlandse samenvatting staat in hoofdstuk 13.

\section{References}

1. Bertrand JT, Hardee K, Magnani RJ, Angle M. Access, Quality Of Care and Medical Barriers in Family Planning Programs. Int Fam Plan Perspect 1995;21:64-9\&74.

2. RamaRao S, Mohanam R. The quality of family planning programs: concepts, measurements, interventions, and effects. Stud Fam Plann 2003 Dec;34(4):227-48.

3. Speizer IS, Magnani RJ, Colvin CE. The effectiveness of adolescent reproductive health interventions in developing countries: a review of the evidence. J Adolesc Health 2003 Nov;33(5):324-48.

4. UNFPA. The State of World Population 2003. Investing in Adolescents' Health and Rights. New York, USA: UNFPA, United Nations Population Fund; 2003.

5. WHO Department of Child and Adolescent Health and Development, UNAIDS Inter Agency Task Team on Young People. Adolescent Friendly Health Services, an agenda for change. 1-48. 2002. World Health Organisation Geneva, WHO/FCH/CHA/02.14.Ref. Type: Report.

6. Sandiford P, Gorter A, Salvetto M. Vouchers for Health, Using Voucher Schemes for Output-Based Aid. Public Policy for the Private Sector, Viewpoint. The World Bank Group; 2002. Report No.: 243.

7. Gorter A. Evidence of effectiveness of competitive voucher schemes on HIV prevention and care for young people. Background paper 'Global consultation on the health services response to the prevention and care of HIV/AIDS among young people'. Montreux, Swiss: WHO, UNFPA, UNAIDS and YouthNet; 2003.

8.UNDP. Poverty indicators of Nicaragua. http://hdr undp org/statistics/data/cty/cty_f_NIC html, accessed 11 September 20052006 January 12

9. Alcaldia de Managua. Managua a shared future (in Spanish) Plan General de Desarrollo Municipal. Alcaldia de Managua, Hermanamiento Amsterdam-Managua.; 2000. 
10. INEC Instituto National de Estadística Censos, Ministerio de Salud. Demographic Health Survey Nicaragua 2001 [in spanish]. Managua, Nicaragua: Instituto nacional de Estadística and Censos y Ministerio de Salud, Calverton, MD USA; Marco International/DHS+ Program; 2001.

11. Zelaya E, Marin FM, Garcia J, Berglund S, Liljestrand J, Persson LA. Gender and social differences in adolescent sexuality and reproduction in Nicaragua. J Adolesc Health $1997 \mathrm{Jul} ; 21(1): 39-46$.

12. Meuwissen LE, Gorter AC, Knottnerus AJ. Impact of accessible sexual and reproductive health care on poor and underserved adolescents in Managua, Nicaragua: a quasi-experimental intervention study. J Adolesc Health 2006 Jan;38(1):56.

13. Meuwissen LE, Gorter A, Segura Z, Kester ADM, Knottnerus AJ. Uncovering and responding to needs for sexual and reproductive health care among poor urban female adolescents in Nicaragua. Tropical Medicine and International Health 2006; [in press].

14. Senderowitz J. Health Facility Programs on Reproductive Health for Young Adults. Washington DC,USA: FOCUS on young adults; 1997.

15. Senderowitz J. Do Youth-Friendly Services Make a Difference? http://www fhi org/en/Youth/YouthNet/Publications/FOCUS/InFOCUS/YFSmakediff.htm Accessed 20 October 20001998

16. Bruce J. Fundamental elements of the quality of care: a simple framework. Stud Fam Plann 1990 Mar;21(2):61-91.

17. Koenig MA, Hossain MB, Whittaker M. The influence of quality of care upon contraceptive use in rural Bangladesh. Stud Fam Plann 1997 Dec;28(4):278-89.

18. Meuwissen LE, Gorter AC, Knottnerus JA. Perceived quality of reproductive care for girls in a competitive voucher programme. A quasi-experimental intervention study, Managua, Nicaragua. Int J Qual Health Care 2006 Feb;18(1):35-42.

19. Meuwissen LE, Gorter AC, Kester ADM, Knottnerus JA. Can a comprehensive voucher program prompt changes in doctors' knowledge, attitudes, and practices related to sexual and reproductive health care for adolescents? A case study from Latin Amerika. Tropical Medicine and International Health 2006;11(6):889-98.

20. Beullens J, Rethans JJ, Goedhuys J, Buntinx F. The use of standardized patients in research in general practice. Fam Pract 1997 Feb;14(1):58-62.

21. Rethans JJ, van Boven CP. Simulated patients in general practice: a different look at the consultation. Br Med J (Clin Res Ed) 1987 Mar 28;294(6575):809-12.

22. Rethans JJ. Needs assessment in continuing medical education through standardized patients. 1998;172-8.

23. Meuwissen LE, Gorter AC, Kester ADM, Knottnerus JA. Does a competitive voucher program for adolescents improve the quality of reproductive health care? A simulated patient study in Nicaragua. BMC Public Health 2006; [in press].

24. Meuwissen LE, Donaire T, Medina J, Segura Z, Gorter A. Nicaragua: Introducing a voucher scheme for disadvantaged adolescents' access to services in three districts. Sexual Health Exchange 2004;(3\&4):28-30. 


\section{Chapter 2}

The illusion of innocence

Why sexually active teenage girls in Nicaragua do not use contraceptives while not wanting to conceive?

A literature search 


\begin{abstract}
Objective

In Nicaragua, many teenagers suffer the consequences of unwanted pregnancy but very few make effective use of modern contraceptives. Current literature from Nicaragua and other Latin American countries has been searched to better understand this behaviour and to identify opportunities for interventions that could help to address the problem.
\end{abstract}

\title{
Results
}

Teenage behaviour, including sexual behaviour, is influenced by many social, cultural and economic factors. The general reluctance among adults in Latin America to talk about adolescents' sexuality at either individual or political levels reflects the socio-cultural background of machismo, the strong influence of the Catholic Church, and generalised disapproval of recreational sex for young people, especially for unmarried women. The failure to introduce sex-education in the school system in the last 25 years in Nicaragua illustrates the problem.

The vast majority of people engage in sexual relations during their teens, but many adolescents lack complete and accurate information on the risks involved and the possibilities for prevention. Furthermore, many sexual relations are characterised by marked power disparities, and an unknown percentage of teenage pregnancies is due to abusive sexual relations.

Girls who want to use contraceptives face obstacles relating to the availability, accessibility, quality and confidentiality of services. Girls who are not married and/or not yet mothers experience the greatest number of obstacles and also make least use of contraceptives. An important contributing factor appears to be that they do not want others to know that they are sexually active. Deficient knowledge on how contraceptives work and on side effects leads to high contraceptive discontinuation and failure rates.

\section{Conclusion}

Without accessible information and health care services it is impossible to determine to what extent the non-use of contraceptives by adolescents could be explained by social, cultural and religious norms and mechanisms, or as a consequence of the lack of access to reliable information and confidential health services. However, to change the existing situation, adolescents need access to information and services on sexual and reproductive health in order to be able to discuss, make and implement their choices. 


\subsection{Introduction}

In Central America, the number of girls aged 15 to 19 who give birth each year varies between 135 per 1000 adolescents in Nicaragua and 64 per 1000 in Mexico (1). In Nicaragua, eight percent of girls aged 15 year are pregnant or have already given birth. By age 19, the proportion has increased to 46 percent (2).

Many of these pregnancies are not planned, and adolescents are at high risk to experience adverse reproductive health outcomes, including unsafe abortion, maternal mortality and sexually transmitted infections (STIs), including HIV. These problems not only have serious consequences for the adolescent, but also for their families, society and national development (3). Most of these problems could be prevented by consistent use of contraceptives by sexually active teenagers. However, many adolescents do not use contraceptives effectively.

The purpose of the literature search is to provide an overview of what is known about female adolescents and their use of contraception in Latin America in general and in Nicaragua in particular. The aim is to better understand the non-use of contraceptives, the role of the health services, and to identify opportunities for interventions that could help to address the problem of unwanted adolescent pregnancies. Throughout this chapter, the terms adolescents and teenagers are used interchangeably to indicate young people aged between 10 to 19 . The results from demographic health surveys refer only to adolescents aged 15 years and over.

\subsection{Methodology}

A Medline search was undertaken covering the period January 1996 to September 2005, selecting literature on teenage pregnancy; unwanted teenage pregnancy; teenagers' access to family planning services and knowledge and use of contraceptives by teenagers. Relevant articles for the Nicaraguan and Central American context were selected. Other articles and reports were identified through additional references and library visits. English as well as Spanish documents have been used. Only those documents that contributed to the understanding of the phenomenon "Why sexually active teenage girls do not use contraception while they do not want to conceive?" have been cited. Results have been distinguished in the following categories: the extend of the problem; the socio-cultural context; the position of girls in partner relations; adolescents access to information; access and quality of health care services; and other factors related to contraceptive use.

The scope of this review is based on the following factors.

- First, young people have many common characteristics, but they are not the same. Individual and contextual factors need to be taken into consideration to understand their situation and behaviour and to interpret research results. Since 
Latin American countries have many historical, cultural and political factors in common that influence the position of adolescents, research from other Latin American countries is likely to contribute to our understanding of the situation of the Nicaraguan adolescents.

- Second, this chapter focuses on factors influencing the girls' behaviour because, in general, the regulation of fertility is a female issue in Latin America $(4 ; 5)$. Even if a man is not opposed to the use of contraception, he is still likely to regard it as 'her problem' $(5 ; 6)$ and girls are often the only ones facing the consequences of unprotected intercourse. In this chapter, men will only be considered with regard to their relationship to adolescent girls.

- Third, the chapter considers adolescents as a separate group because the transition from childhood to adulthood is one of the most crucial periods in an individual's life. Until age ten, most children in the developing world live at home, go to school and have not yet gone through puberty. By age 20 most have left school, have become sexually active, live with their partner and have children. The quality of their future lives depends largely on the extent to which adolescents can avoid potentially problematic outcomes of sexual relations, such as early dropout from school, unwanted pregnancy, or adverse health effects (7).

\subsection{Results}

The presentation of the results of the literature search follows the themes of subsequent chapters: public health aspects of teenage pregnancy and demographic trends; the socio-cultural context; the position of girls in partner relations; access to information; and access to sexual and reproductive health (SRH) care services; the quality of these services; and factors related to contraceptive use.

\subsubsection{Public health aspects of teenage pregnancy and demographic trends}

Public health problems related to high levels of teenage pregnancies are:

- High risks for mother and child: Adolescent pregnancy is associated with increased risk of maternal complications during pregnancy and delivery (8). Although these risks might be related more to socio-economic factors than to biological effects of age, the end result is that many young pregnant adolescents face high risks $(4 ; 9-11)$. Nicaragua is one of the countries where motherhood can be particularly devastating for young girls and their babies (12).

- Unwanted pregnancy: In Latin America, 20 per cent to 60 per cent of pregnant teenagers reported that their pregnancies were mistimed or unwanted (13). In a recent demographic health survey in Nicaragua, 45 per cent of pregnancies were reported to be either mistimed or unwanted: 32 per cent of mothers younger than 20 years who had given birth in the last 5 years reported the birth as mistimed and 13 per cent as unwanted (2). 
- $\quad$ Illegal abortion: Worldwide, an estimated 2.0 - 4.4 million adolescents resort yearly to abortion. In comparison with adults, adolescents are more likely to delay the abortion, to resort to unskilled persons to perform it, to use dangerous methods, and to present late when complications arise $(9 ; 14-16)$. In Nicaragua's Penal Code, abortion is defined as a crime unless the woman's life is endangered. However, even then abortion is only allowed in very rare cases, as illustrated by the low number of legal abortions and, in 2004 , by the national dispute on whether a nine year old girl who had been raped could receive a legal abortion $(17 ; 18)$. Many indications exist that backstreet abortion is very common, including among adolescents (19), but this is very difficult to investigate due to their illegality (20)

- Poverty: Adolescent motherhood is associated with adverse socio-economic conditions and poor earning opportunities. For poor mothers, early childbearing has marked economic effects, and appears to entrench their poverty (21-24).

- Risks for HIV: Unprotected sexual intercourse increases the risks for contracting sexually transmitted infections (STI). The likelihood of both acquiring and transmitting HIV considerably increases when someone is infected with an STI. Young people -15 to 24 years olds - account for nearly half of all new HIV infections worldwide (25). Although worldwide young women outnumber young men by a ratio of two to one, in Latin America more young men are infected with HIV (26). Adolescents are more vulnerable for STI/HIV because they lack knowledge (27); are ignorant or uncomfortable with safe sex practices; are easily influenced by peer pressure; and frequently fail to seek timely treatment $(9 ; 26 ; 28)$. Furthermore, the risk to become infected is highest among younger adolescents $(9 ; 28)$.

The use of contraceptives and condoms could largely prevent these problems. However, many adolescents in Latin America do not use them effectively. The percentages of sexually active single women aged 15-24 that are protected by contraception varies between $11 \%$ in Nicaragua and $49 \%$ in Colombia (29).

Throughout Latin America, an ongoing fertility decline has been noted resulting from the rapid and widespread adoption of contraception (7). However, this is not true for all age groups. The rate of fertility decline was slowest among those in the 15-19 age group, and some countries in the region even recorded slight increases in fertility rates in this age group (15). In many countries, including Nicaragua, the effect of these trends have been an increase in adolescents' share of total births (4). In Nicaragua, the average course of life has been stable for many years with a mean age of the first sexual intercourse is 18.2 years and a mean age of the first baby is 19.6, in all age cohorts of women (2). Conversely, there is a fertility decline due to limitation of the number of children per women (2).

Across the developing world, the age at menarche is declining (7), school attendance by girls is increasing $(7 ; 30)$, age of first intercourse remains 
approximately the same $(13 ; 15)$, age of marriage is increasing, and growing proportions of women are becoming sexually active before marriage $(9 ; 15 ; 29 ; 31 ; 32)$. In most countries in sub-Saharan Africa, current contraceptive use is higher among sexually active, unmarried teenagers than it is among married teenagers, whereas in Latin America and the Caribbean, current-use levels are lower among unmarried teenagers (33); Without successful interventions to increase consistent use of reliable contraceptives, the rate of unwanted teenage pregnancies is likely to increase, with all the negative consequences for the young mothers, their babies and society $(7 ; 15 ; 16 ; 33-36)$.

\subsubsection{Socio-Cultural Context}

Adolescents are affected by the norms and values of their society, their socialeconomic circumstances and the political and legislative framework of their countries. In many societies, adolescents, even if they are married and have children, are not considered autonomous individuals, but are subject to the authority of their parents, other family members, religious leaders and the educational system (37). In many societies, adults control over young peoples access to health education and services, including contraception, is seen as natural $(38 ; 39)$.

It is important to realise that 'adolescence' is a relatively new concept. In rural areas of Latin America, one could argue that young people go through puberty but not adolescence and that once puberty is attained, they acquire adult obligations. 'Adolescence'" is associated with modernization, industrialization and urbanization and is closely related to the years teenagers spend receiving education $(30 ; 40)$.

For many adults in Latin America, reproduction is still the only valid reason to initiate sexual activity (38). The Catholic Church teaches that sex is only justifiable if it is undertaken to become a parent, and provides an idealized picture of virginity and motherhood (41). Prohibitions on premarital sex are often far stronger and more energetically enforced on girls than on boys $(39 ; 42)$. In contrast, many boys perceive strong social encouragement and pressure to be sexually active $(42 ; 43)$. During the National Youth Health Survey in Nicaragua, 83\% of the boys versus. 26 $\%$ of the girls reported they had received encouragement to have sex from at least one person, and $22 \%$ of the boys were encouraged by their father (42).

The Latin American culture of machismo explains part of this. Dominant ideologies of masculinity encourage young men to seek sexual experience with a variety of partners at an early age $(38 ; 44 ; 45)$. Dominant versions of femininity promote ignorance, innocence and virginity. This ignorance on sexual matters is often viewed as a sign of purity (44). Women should be submissive and dependent on their partner, and motherhood is idealized. This link between maternity and feminine identity is reinforced in the media and by cultural ideas $(27 ; 41 ; 46)$. To prevent misunderstanding, the traditional ideal of femininity is not simple 'passivity', but rather an ideal of 'elevated motherhood' characterized by caring, nurturing, and self-sacrifice (47). 
Within this context, it is not surprising that up to $81 \%$ of teenage pregnancies are reported to be wanted (27). Motherhood is one of the few ways in which a young woman can affirm her value and identity to herself, her family and her community $(15 ; 23 ; 33 ; 46)$. Especially for poor girls, having children may be the only goal in life they feel they can realize through their own efforts $(23 ; 46)$. Pregnancy also exonerates girls to some extent from the shame of having engaged in premarital sexual relations (46). Many girls marry their boyfriends once pregnancy occurs. Some researchers have found that pregnancy frequently originates from the desire to achieve a stable relationship $(7 ; 29 ; 45 ; 48 ; 49)$. However, while the high percentage of marriages that follow out of wedlock conception could be cited as evidence of this, many of these marriages are forced by the family, on threat of exclusion $(42 ; 50)$.

Family characteristics are strongly associated with the sexual behaviour of teenage girls. Several studies found that having a mother who has herself given birth during her teens is significantly associated with teenage pregnancy $(23 ; 27)$. The absence of a father, parental separation and poor parental communication are associated with early sexual debut and/or teenage pregnancy $(1 ; 51-53)$. Girls who felt connected with or important to a family were less likely to have an early sexual debut $(54 ; 55)$, as were girls with a good relation with their mother (53), and girls with a high self-esteem (55).

\subsubsection{The position of girls in the partner relation}

In general, both male and female adolescents in Latin America are afraid to discuss sex and contraception with their partner. Young women perceive it as too risky for the ongoing relationship and males' attitudes reinforce these perceptions $(42 ; 48 ; 49 ; 56)$.'Good girls' are not well informed about sex (41). In Nicaragua, $25 \%$ of adolescent girls never discuss family planning with their partners (2) (The percentage in older women was even higher). In many Latin American couples, the male partner disapproves of the use of family planning, and/or is not aware of it $(5 ; 27 ; 38)$.

The socio-cultural context influences the partner relation considerably. This has led some researchers to refute, for example, the suggestion that the non-use of contraceptives can be attributed to adolescent irresponsibility. They argue that in many developing countries, the onset of puberty signals greater economic and family responsibility, and that the majority of adolescents are at least as responsible as their parents (44). Others conclude that Latino adult males continue to be as irresponsible as they were brought up to be (38).

Sexual relations often incorporate power disparities based on gender, age, class, and last but not least, economic dependency on men $(41 ; 57 ; 58)$. For example, the majority of the fathers of babies born to teenagers were past their teens $(27 ; 59)$. The younger the woman was at her first intercourse experience, the older her first partner was likely to be (41). These unequal power relations between women and 
men influence the capacity of young women to decide when, where and how sexual relations occur, and render young women vulnerable to coerced or unwanted sex $(9 ; 44 ; 60)$.

Sexual abuse is a serious public health problem in Latin America $(2 ; 35 ; 51 ; 61-63)$. In Nicaragua, $26 \%$ of women and $20 \%$ of men reported that they had experienced sexual abuse in their adolescence or childhood. Women had been victims of attempted or completed rape twice as often as men, 15\% compared to 7\% (61). Data from the Young Adults survey revealed that seven percent of girls interviewed and less than $1 \%$ of the men reported rape as the reasons for their first sexual experience (42).

Women who are physically or sexually abused have increased risks for unintended pregnancies (64). Teenage pregnancy and sexual abuse are related through various mechanisms. First of all, the pregnancy can be a direct effect of abuse. Second, adolescents who have been abused as a child are more likely to engage in risky sexual behaviour. Generally, victims of sexual abuse are incapable of developing the ability of self-protection, because the skills needed for safe sex have been atrophied by the sexual abuse. And, abuse can also result in low self-esteem, encouraging victims to look for acceptance through sexual contacts $(9 ; 65 ; 66)$. Possibly related to this is the finding that teenage mothers are at higher risk of being abused during their pregnancy than adult mothers $(2 ; 67-70)$.

\subsubsection{Access to information}

People need enough information about contraceptives to become interested in using them. The level of knowledge on contraceptives varies widely between Latin American countries and is influenced by factors as age, education, residence, parity and marital status $(27 ; 56)$. While the majority of girls can mention at least one modern method of contraception, in general adolescents' knowledge is very limited and many wrong perceptions prevail about the use of contraceptives and their side effects. For example, many believe that a girl cannot become pregnant the first time she has intercourse (27); or believe that the pill causes infertility (56). Lack of accurate knowledge is an important reason why adolescents choose not to use contraceptives $(33 ; 41 ; 48 ; 52 ; 57 ; 71-75)$.

Various studies report that open communication between mothers and teenage girls diminishes the risk of becoming pregnant $(48 ; 49 ; 51 ; 52 ; 76)$. However, in most Latin American countries, little or no communication exists between adolescents and parents about sexuality and family planning. For example, a survey in Nicaragua showed that $57 \%$ of boys and $50 \%$ of girls never communicated with their parents when they had doubts about or questions on sex (42). Many parents feel uneasy and embarrassed when discussing sexual issues with their children $(41 ; 44 ; 52 ; 57)$. Adolescents feel embarrassment, fear punishment or rejection, or perceive the parents' information as limited $(42 ; 48 ; 49 ; 51 ; 52 ; 76 ; 77)$ 
Sexual education at primary schools does not exist in Latin American countries. In these countries, programs about sexual and reproductive health are designed for secondary school students $(27 ; 38)$. Consequently, adolescents who do not attend secondary school are not reached and information comes late for those who still in school but who have already started sexual activity $(27 ; 38)$. Furthermore, school programs on sexual education are often very limited in the extent to which they discuss contraceptives, STIs and their prevention, and other issues related to sexuality. In the official curriculum in Nicaragua, none of these issues are dealt with and the focus is on abstinence, self-control and fidelity (27). Teachers play only a very limited role as source of information on sexuality $(42 ; 57)$.

The Catholic church's general condemnation of artificial contraceptives, together with their political influence, makes it difficult to promote contraceptive methods through the educational system $(27 ; 57 ; 78)$. In Nicaragua, the success of their opposition was again demonstrated in 2003. A new curriculum on integral sexeducation had been jointly developed by the Ministry of Education, the Ministry of Health and the UNFPA, and was ready to be launched. The document was leaked to the press and caused a political turmoil, implementation was cancelled and the existing (limited) curriculum maintained (79-82).

It is not only the quality of the sex education at school that influences behaviour. The number of years of education is a factor that has a significant impact on teenage fertility. Research demonstrates that girls who had completed at least five years of primary school had a much lower risk of early pregnancy, irrespective of socio-economic status $(4 ; 21 ; 78 ; 83 ; 84)$. Differences in teenage pregnancy rates between urban and rural dwellers disappear when controlled for education $(21 ; 27)$. Explanations given are that education increases the likelihood that women enter the labour market, are more aware of reproductive values outside their community, possess greater knowledge about contraceptive options, are more effective contraceptive users, and have a closer and more egalitarian relationship with their spouses $(7 ; 34 ; 84)$. Others add the influence of the higher socio-economic status obtained through education and a less fatalistic attitude towards reproduction (85). The direction of causality is less clear when teenage mothers are forced to leave school early upon having a child (83).

In Latin America, the contact frequency of young people with mass media is high. Adolescents are strongly influenced by popular personalities in entertainment and sports. Appropriate use of mass media can provide benefits regarding the improvement of adolescent reproductive behaviour $(38 ; 86)$. However, popular personalities do not always present as ideal role models and television can contribute to incomplete knowledge and false information (38).

Peers are often reported to be adolescents major source of information $(42 ; 77 ; 87 ; 88)$. Unfortunately, most peers share the lack of access to reliable information. 
In summary, those Latin American adolescents who are not lucky enough to have parents, teachers or peers who are well informed about sex, and are willing to talk about it, lack access to reliable information. Consequently, many Latin American adolescents are poorly informed about their sexuality, birth control methods and how to obtain them, safe sex and the risks of STIs/HIV (27;86). Independently from the quality of the sexual education at school, has school attendance a significant influence on teenage fertility.

\subsubsection{Access to reproductive health services}

Several studies suggest the existence of a positive relationship between the influence of family planning programs on the use of contraceptives. However, these studies used either population data or included only married women $(34 ; 57 ; 83 ; 89 ; 90)$. None considered adolescents as a specific group. The availability of services for adults does not necessarily imply that they are accessible to unmarried adolescents (35;91-94). Even if an adolescent is sufficiently well informed and decides to use family planning, there are still many obstacles to overcome. Access to health services ${ }^{1}$ is frequently found to be difficult, particularly for young, single and poor women and men $(15 ; 24 ; 33 ; 35 ; 71 ; 91 ; 95)$. What is the problem?

Firstly, the lower the adolescent's education and the deeper their level of poverty, the less likely they will know a distribution point $(27 ; 56 ; 73)$. Between $20 \%$ and $40 \%$ of the girls who can mention the name of a contraceptive method cannot mention a distribution point. Even among adolescents who already have children and who do not want to conceive at the moment of interview, between $6 \%$ and $35 \%$ can not mention a contraceptive distribution point (27).

Secondly, public-sector availability of contraceptive services and modern contraceptives $^{2}$ are highly constrained in many places $(56 ; 96 ; 97)$, due to shortage of health centres (38) or due to short supply of contraceptives in the health centres (96-99).

Thirdly, many practical obstacles exist. Generally, private and non-governmental clinics have high costs, may have inconvenient opening hours, are difficult to reach with public transport and/or provide services only by appointment $(52 ; 77 ; 99-102)$. Meanwhile, public services are renown for their long waiting times and limited hours of operation $(24 ; 91 ; 100 ; 103)$.

\footnotetext{
${ }^{1}$ Access is defined as the degree to which family planning services and supplies may be obtained at a level of effort and cost that is both acceptable to and within the means of a large majority of the population (106).

2 'Modern' contraceptives: These require clinical supplies or interventions such as contraceptive pills, injections, intrauterine devices, sterilization or diaphragms. The description 'Traditional' covers contraceptive techniques such as periodic abstinence (rhythm), coitus interruptus, douches and folk methods (4).
} 
Fourth, in some countries, adolescents' accessibility to health centres is limited by legal restrictions, such as minimum age requirements and the need for parental consent $(71 ; 101 ; 104)$. Various studies have found that providers are reluctant to serve clients younger than 16 years of age, which in most countries is the minimum legal age for consent $(35 ; 43 ; 71 ; 93 ; 99 ; 105)$. In Nicaragua, there are no rules that forbid access to public health care for adolescents and there is no need for consent of the parent for treatment (57).

\subsubsection{The quality of reproductive health services}

Access to and quality of care are closely connected, and the quality of care has an important influence on the acceptance of contraceptives and their continued use (106-109). In addition to potential problems shared by all contraceptive users, adolescents can face additional problems.

The first category of problems originates from the medical procedures. Medical procedures are sometimes unnecessarily long, tedious and even humiliating (38). Examples are the practice of performing a vaginal examination on first appointment; demanding laboratory tests before prescribing the pill; prescribing just one cycle of pills at a time $(97 ; 99 ; 106 ; 110)$ and requiring women to return on their first day of menstruation to obtain contraception (111-113). Other problems mentioned in the literature include: dissemination of incorrect information (99); non-prescription of certain methods such as the IUD and the morning after pill $(35 ; 35 ; 96 ; 106 ; 114-116)$ and the imposition of certain methods (38).

The most frequent reason given by adolescents for avoiding contact with clinics is that they feel uncomfortable with certain aspects of the procedures or the attitude of the staff. This perception can come from their own experience, from second hand information from friends or from the general reputation of the services $(94 ; 114)$. Unfortunately, these are not merely feelings $(56 ; 77 ; 92 ; 112)$. Providers often speak to adolescents in a language that they cannot identify with or understand. Frequently, provision of services is accompanied by a disciplinary talk or comments on the age of the adolescent, or even overtly punitive reactions $(38 ; 56 ; 77)$. In an investigation with simulated patients, several instances of unprofessional conduct by health centre staff were reported, such as aggression or efforts to seduce the patient (56).

Furthermore, many studies reveal that the privacy of patients is not respected $(56 ; 77 ; 97)$. Sometimes adolescents have to state out loud, in the waiting room, their reason for requesting a consultation, and frequently this is repeated, in a loud voice, by the person seeking the information (77). Instances are also reported of clinic personnel speaking to the adolescents' parents (38), of the door of the consulting room being left open, and of the consultation being performed in presence of other people (77;91). In addition, the widespread practice of using designated rooms in public health centres for family planning means that women cannot conceal the type of services they are seeking. This is a huge obstacle for 
young and unmarried women who are often ashamed of buying contraceptives because of the social disapproval associated with recreational sex for women $(27 ; 56 ; 78)$. Confidentiality is very important to adolescents. The use of health services is seen as admitting to being sexually active and tends to arouse fears of being punished by family and ridiculed by peers (56). Nicaraguan adolescents seek services that they can attend confidentially without the knowledge of adult and friends, and where they can consult with a competent professional, who is experienced in communicating with adolescents (77).

Various explanations are given for the problems encountered by adolescents in health centres. Both providers and clients have difficulty dealing with sexuality $(88 ; 97 ; 117)$. Providers, from receptionists to doctors, will share the same ideas and norms with other people of their community about sexuality, including disapproval of premarital sex for girls (38). In many countries, legal protection to assist younger adolescents is missing $(51 ; 94 ; 105)$. In addition, the predominant mindset is that the provider is the decision-maker. Medical doctors are trained to provide services and health education, which is often accompanied by an attitude of 'knowing better than others' $(38 ; 96 ; 112)$. This medical model may be appropriate in the context of treatment of complicated life-threatening illnesses, but is poorly adapted to providing information and access to safe and reliable family planning methods $(118 ; 119)$. During their medical education, most doctors in Latin America do not receive training in social and communication skills $(91 ; 92)$ and little or no teaching on family planning and sexual and reproductive health care $(97 ; 120)$.

Due to the obstacles to obtaining family planning methods through health services, many young people prefer the pharmacy as their supplier $(2 ; 56 ; 77)$. The first contact most adolescents have with sexual and reproductive health care is when they must deal with a pregnancy, an STI or for the management of complications arising from abortion $(88 ; 92 ; 121)$.

\subsubsection{Factors related to contraceptive use}

Despite all the obstacles to acquiring knowledge and obtaining contraceptives, a considerable number of women in Latin America have used a contraceptive method at least once. What can we learn from their experiences?

Adolescents are between two to three times more likely than older women to abandon contraceptives for reasons other than the desire to conceive $(33 ; 35 ; 122)$. A study in eight Latin American countries showed that the proportion of sexually active single women who discontinued contraceptive use for any reason within the first 12 months ranged from $51 \%$ for oral contraceptives to $69 \%$ for withdrawal (before ejaculation)(29). Dissatisfaction with the method (health concerns, sideeffects, and inconvenience constitutes the major reason for stopping (29). Another reason is contraceptive failure. Although failure rates may have been underreported because of omission of induced abortion, over $20 \%$ of young women reported an accidental pregnancy within the first 12 months of application of periodic 
abstinence or withdrawal $(29 ; 123)$. In all countries, failure rates for adolescents are higher than for adult women because many adolescents use unreliable methods or use reliable methods in an unreliable manner $(29 ; 33)$. Several studies showed that only half of young adults who reported current use of periodic abstinence can correctly identify the days of the menstrual cycle when a woman is at greatest risk of becoming pregnant $(6 ; 45 ; 48 ; 49)$. Adult women score only 5 to $10 \%$ better than adolescents (27).

Continued use of contraceptives and consequently contraceptive prevalence is linked to various aspects of quality and access $(7 ; 97 ; 98 ; 106 ; 107 ; 109)$. Within a year after starting to use a method, between 7 and 27 percent of women cease to practice contraception for reason related to the quality of the service environment (124). Analyses on the incidence of unwanted pregnancy in Peru suggested that it would be a more rewarding strategy to follow-up contraceptive users than to focus on women with unmet needs for contraceptives, because the absolute numbers of unwanted pregnancies in the first group by far exceeded those of the second group (125).

Method switching is probably the most common event among all changes in contraceptive status, and yet it has been one of the least studied topics relating to contraceptive use (126). Method switching may indicate that either a woman is actively taking advantage of a range of contraceptive choices, and selects different methods when her particular needs change, or that women have difficulty finding and continuing use of a preferred method (126). Expanding the variety of methods offered can lead to improved satisfaction, increased acceptance and increased prevalence of contraceptive use (127).

However, the range of available contraceptives, each with its advantages and disadvantages in terms of ease of use, side effects, costs and availability, does not make it easy for a first time user to make an informed choice $(73 ; 119 ; 122 ; 127)$. Education and individual counselling are needed $(122 ; 127)$. This means that improvement in the provision of services to adolescents is needed to increase consistent use of family planning methods and diminish demand for termination of unwanted pregnancies $(16 ; 29 ; 32 ; 33 ; 35 ; 122)$.

\subsection{Discussion}

Summarizing the main findings: In Latin America the socio-cultural background of machismo and the strong influence of the Catholic Church explain in large part the difficulties associated with openly discussing issues related to teenage sexuality at either individual or political levels. Furthermore, many sexual relations are characterised by marked power disparities. While a proportion of girls do not need contraceptives because they want to become pregnant, a considerable percentage of 
teenage pregnancies are to the result of abusive sexual relations, completely negating the idea of implementing ones' choices. Many adolescents do not have access to reliable information on contraceptives or other SRH issues. And the majority of adolescents - especially those who are not yet mothers - do not have access to health care services that can provide confidential access to contraceptives.

\subsubsection{Reliability of the data}

The majority of the information on young people's health has come from quantitative epidemiological and demographic studies collected through household surveys. If the subject matter of the interview is sensitive, young people are likely to avoid answering frankly, especially when they are not interviewed in private, as is common in developing countries (128). The limitation of the validity of data obtained through interviewing is illustrated by the implausibly low proportion of teenagers who reveal to the interviewer they have had sex (129); the much higher prevalence of sexual abuse in anonymous self reporting surveys than revealed through interviewing (61); and the underreporting of abortion in direct surveys (20). Similar difficulties arise when interviewing young women about contraception if socially accepted morality and feminine modesty prevents them from disclosing to a stranger what might be considered unsuitable knowledge or behaviour for a girl $(7 ; 13 ; 38 ; 130)$.

Statements like "the quantity of desired births of children by adolescents in Latin America exceeds $70 \%$ in the majority of countries with a high adolescent fertility" (27) are based on interviews with pregnant girls and teenage mothers. In addition to the above-mentioned problems, girls who have had an abortion are likely to deny ever having been pregnant, and those who have accepted an initially unwanted pregnancy are likely to deny initial rejection. Consequently, the desirability of the conception will seriously be overestimated, and the validity of this kind of statement should be questioned.

\subsubsection{The difficulty of the present situation}

Many researchers underscore that sex education and access to confidential health services are indispensable conditions in responding to the needs of adolescents. Yet, in many studies and reviews the absence of access to contraceptives is not considered as a potentially mayor factor in explaining youth behaviour and the non-use of contraceptives $(27 ; 52 ; 55 ; 83 ; 131 ; 132)$. As long as access to information and/or services is problematic, contraceptive use will never be integrated into adolescent culture, and adolescents might not even express a demand. Cultural, religious, gender, family and individual factors correlated to the non-use of contraceptives are consequently cited to explain adolescent behaviour. However, adolescents' attitudes and behaviours could just as well be the consequence of not having alternatives. It follows that only intervention programs that successfully provide adolescents with information and access to appropriate and confidential SRH care services will be able to evaluate the real influence of socio-cultural factors on the use and non-use of contraceptives by adolescents. 


\subsubsection{Information}

Sexuality occupies a dominant position in Latin American societies, and from birth onwards children are made aware of their specific gender roles. A clearly difficult situation is created for young women through a) gender roles that reinforce male control over sexual decision making, b) lack of reliable information about human sexuality and reproduction; and c) the social expectation for girls to maintain their virginity until marriage, while men are supposed to prove their manhood through sexual behaviour.

Nowadays, as a result of rapid social transformation and the difference between traditional and modern values, adolescents often find themselves faced with conflicting definitions of their rights, responsibilities and gender role. Overt access to reliable information on SRH for adolescents will, at least, provide girls with the opportunity to leave the pretended 'illusion of innocence' behind and be 'wise about sex' without being suspected of promiscuous behaviour. Furthermore, this will facilitate discussion with parents, teachers, health care providers, peers and partners, and it will considerably improve girls' negotiating power within a relationship. Along with access to SRH care services, girls will receive the basic tools needed to implement decisions that affect their own reproductive lives.

In Latin America, adolescents comprise up to $25 \%$ of the population. To reach such a large population in resource-constrained settings, cost effectiveness and sustainability are of paramount importance (88). Considering this setting and the general scarcity of even the most basic information on reproductive health, in Nicaragua and many other Latin American countries, possibilities of school education should be explored to the maximum. School programs have proven to be the easiest and cheapest way of providing the majority of the adolescents with basic knowledge about their bodily functions, pregnancy, contraceptives, and STIs and HIV/AIDS and prevention (133). Most teachers would be capable of teaching this information using the traditional teaching style, and ideally the teachings should start at the primary school, since many adolescents do not continue onto secondary education. As resources allow, skills-based sexual health education should be given, since these course have proven to be effective in supporting adolescents in implementing their choices (133).

The belief that sex education arouses interest in sex at an early age or that it stimulates promiscuity, has been refuted by researches in many countries $(3 ; 27 ; 134 ; 135)$. Hopefully, the threat of the HIV-pandemic and the fact that young people, and particularly young girls, are at highest risk, will force the religious and political leaders to allow sex education in schools in order to prevent deaths from ignorance (136).

\subsubsection{Services}

Teenagers will engage in sexual relations whether or not they have access to contraceptives (41). In view of all the preventable health care problems that 
adolescents face, they need access to confidential, individual-directed health advice and treatment, whether considered from the reproductive rights perspective or the public health perspective $(3 ; 26 ; 93 ; 122 ; 133)$.

The lack of access to information and care are important factors contributing to contraceptive failure and discontinuation of use. In view of the complexity of contraception, all women need individual, confidential counselling to be able to make rational choices that suit their situation. The pharmacy might be an appropriate supplier for an experienced and well-informed user, but for the young, poorly informed and shy adolescent, who is often hiding the use of contraceptives from her relatives and/or partner, it is not.

Legal protection of health care providers and inclusion of training on family planning and communication skills in the health care providers' curriculum are minimal requirements to improve reproductive health care delivery in a sustainable way.

\subsubsection{Conclusion}

The leading question of this literature overview is: Why do girls in Central America not use contraceptives while not wanting to conceive? A lot is known about how social, cultural and religious norms and traditions influence teenagers. However, it is not known to what extent these factors explain present behaviour or whether the behaviour is a consequence of the lack of access to reliable information and confidential health services. Without access to information and services it is difficult, if not impossible, to make effective use of contraceptives.

With the expectation of an increase of unwanted pregnancies among teenagers in the near future in Latin America and the threat of the HIV/AIDS epidemic, there is urgent need to:

1) Provide young people with reliable, concrete and practical information on their sexual and reproductive health, including contraception and STIs as well as how to access to health care services.

2) Provide access to reproductive health services of good quality for all young people, services in which providers show a fundamental preparedness to help young people in a confidential way to make appropriate decisions regarding their reproductive lives.

3) Research and publish the results of these interventions so that soon the question can be answered as to how Latin American adolescents can be best supported to consistently use contraceptives when they do not want to conceive, and programs can be implemented accordingly.

The illusion of innocence, as seen in the behaviour of teenage girls in Latin America, reflects the way society handles the sexual drive and activity of teenage girls. Despite high rates of teenage fertility, high levels of school-dropout, elevated maternal and infant morbidity and mortality, and high risks associated with illegal 
abortions, and the impact of all these factors on poverty, society pretends that 'it has nothing to do with it', and tends to blame the victims. The vast majority of people engage in sexual relations during their teens and access to information and confidential SRH care to decide what they want and to be able to engage in sexual relations safely.

\section{References}

1. UNFPA. The State of World Population 2004, The Cairo Consensus at Ten: Population, Reproductive Health and the Global Effort to End Poverty. New York, USA: UNFPA, United Nations Population Fund; 2004.

2. INEC Instituto National de Estadística Censos, Ministerio de Salud. Demographic Health Survey Nicaragua 2001 [in Spanish]. Managua, Nicaragua: Instituto nacional de Estadística and Censos y Ministerio de Salud, Calverton, MD USA; Marco International/DHS+ Program; 2001.

3. UNFPA. The State of World Population 2003. Investing in Adolescents' Health and Rights. New York, USA: UNFPA, United Nations Population Fund; 2003.

4. Gómez E, Gomez EG. Health and Women in Latin America and the Caribbean: Old issues and new approaches. Women and development Unit Economic commission for Latin America and the Caribbean; 1997. Report No.: 17.

5. Zelaya E, Pena R, Garcia J, Berglund S, Persson LA, Liljestrand J. Contraceptive patterns among women and men in Leon, Nicaragua. Contraception 1996 Dec;54(6):35965.

6. Morris L. Sexual experience and use of contraception among young adults in Latin America. MMWR CDC Surveill Summ. 41[4], 27-40. 28-8-1992. Ref Type: Abstract

7. Bongaarts J, Cohen B. Adolescent reproductive behavior in the developing world. Introduction and review. Stud Fam Plann 1998 Jun;29(2):99-105.

8. Conde-Agudelo A, Belizan JM, Lammers C. Maternal-perinatal morbidity and mortality associated with adolescent pregnancy in Latin America: Cross-sectional study. Am J Obstet Gynecol 2005 Feb;192(2):342-9.

9. Blum RW, Nelson-Mmari K. The health of young people in a global context. J Adolesc Health 2004 Nov;35(5):402-18.

10. Treffers PE, Olukoya AA, Ferguson BJ, Liljestrand J. Care for adolescent pregnancy and childbirth. Int J Gynaecol Obstet 2001 Nov;75(2):111-21.

11. Kurz K. Health Consequences of Adolescent Childbearing in Developing Countries. International Center for Research on Women; 1997. Report No.: 4.

12. Mayor S. Pregnancy and childbirth are leading causes of death in teenage girls in developing countries. BMJ 2004 May 15;328(7449):1152.

13. McCauley AP, Salter C, Kiragu K, Senderowitz J. Meeting the needs of young adults. Popul Rep J 1995 Oct;(41):1-43.

14. Olukoya AA, Kaya A, Ferguson BJ, AbouZahr C. Unsafe abortion in adolescents. Int J Gynaecol Obstet 2001 Nov;75(2):137-47.

15. Singh S. Adolescent childbearing in developing countries: a global review. Stud Fam Plann 1998 Jun;29(2):117-36.

16. Strickler J, Heimburger A, Rodriguez K. Clandestine Abortion in Latin America: A Clinic Profile. Int Fam Plan Perspect 2001;27(1):34-6. 
17. McNaughton HL, Mitchell EM, Blandon MM. Should doctors be the judges? Ambiguous policies on legal abortion in Nicaragua. Reprod Health Matters 2004 Nov;12(24 Suppl):18-26.

18. Adan Silva J. There was no delict in the abortion or Rosa [No hubo delito en aborto de "Rosa"]. La Prensa 2004 Mar 20.

19. McNaughton HL, Blandon MM, Altamirano L. Should therapeutic abortion be legal in Nicaragua: the response of Nicaraguan obstetrician-gynaecologists. Reprod Health Matters 2002 May;10(19):111-9.

20. Barreto TV, Campbell OMR, Davies JL. Investigating induced abortion in developing countries: methods and problems. Stud Fam Plann 1992;23(3):159-70.

21. Heaton TB, Forste R, Otterstrom SM. Family Transitions in Latin America: First Intercourse, First Union and First Birth. International journal of population geography 2002;8:1-15.

22. Buvinic M. The costs of adolescent childbearing: evidence from Chile, Barbados, Guatemala, and Mexico. Stud Fam Plann 1998 Jun;29(2):201-9.

23. Buvinic M. Cost of Adolescent Childbearing in Latin America and the Caribbean. International Center for Research on Women, National Research Council ; 1997.

24. Atkin LC, atorre-Rico J. Pregnant again? Psychosocial predictors of short-interval repeat pregnancy among adolescent mothers in Mexico City. J Adolesc Health 1992 Dec;13(8):700-6.

25. UNAIDS. Report on the global AIDS epidemic, Presented at the XV international AIDS conference Bangkok. 2004. UNAIDS: The Joint United Nations Programme on HIV/AIDS. Ref Type: Internet Communication

26. Kiragu KK. Youth and HIV/AIDS, Can we Avoid Catastrophe? Population Report Series F, The Johns Hopkins University USA, 2001;24(3):1-39.

27. Guzmán JM, Hakkert R, Contreras JM, et al. Diagnostic about Sexual and Reproductive Health of Adolescents in Latin America and the Carribean (in Spanish). UNFPA; 2001.

28. Mayaud P, Mabey D. Approaches to the control of sexually transmitted infections in developing countries: old problems and modern challenges. Sex Transm Infect 2004 Jun;80(3):174-82.

29. Ali MM, Cleland J. Sexual and reproductive behaviour among single women aged 1524 in eight Latin American countries: a comparative analysis. Soc Sci Med 2005 Mar;60(6):1175-85.

30. Henriques-Mueller MH, Ynes J. Adolescence: Misunderstandings and Hopes. Gender, Women and Health in the Americas. Pan American Health Organization; 1993. Report No.: 541.

31. Singh S, Wulf D. An overview of Clandestine Abortion in Latin America Issues. Brief Alan Gutmacher Institutions , 1-11. 1996. Ref Type: Internet Communication

32. Ali MM, Cleland J, Shah IH. Trends in reproductive behavior among young single women in Colombia and Peru: 1985-1999. Demography 2003 Nov;40(4):659-73.

33. Blanc AK, Way AA. Sexual behavior and contraceptive knowledge and use among adolescents in developing countries. Stud Fam Plann 1998 Jun;29(2):106-16.

34. Bongaarts J. Trends in unwanted childbearing in the developing world. Stud Fam Plann 1997 Dec;28(4):267-77.

35. Langer A. Unwanted pregnancy: impact on health and society in Latin America and the Caribbean [in Spanish]. Rev Panam Salud Publica 2002 Mar;11(3):192-204.

36. Cleland J, Ali MM. Reproductive consequences of contraceptive failure in 19 developing countries. Obstet Gynecol 2004 Aug;104(2):314-20. 
37. Venema A, Reerink I, Jenniskens F. Adolescent Reproductive Health, a review of program strategies . Draft report, Royal Tropical Institute, the Netherlands. 1999.

38. Pons JE. Contraceptive services for adolescents in Latin America: facts, problems and perspectives. Eur J Contracept Reprod Health Care 1999 Dec;4(4):246-54.

39. Rosen.J. Advocating for adolescent reproductive health: Addressing Cultural Sensitivities. Focus on Young Adults, Pathfinder International . 2000. Ref Type: Internet Communication

40. UNICEF / WHO. Picture of health: A review and annotated bibliography of the health of young people in developing countries. UNICEF / WHO; 1995.

41. Berglund S, Liljestrand J, Marin FM, Salgado N, Zelaya E. The background of adolescent pregnancies in Nicargua: A qualitative approach. Soc Sci Med 1997;44(1):1-12.

42. Rani M, Figueroa ME, Ainsle R. The psychosocial context of young adult sexual behavior in Nicaragua: looking through the gender lens. Int Fam Plan Perspect 2003 Dec;29(4):174-81.

43. Eggleston E, Hardee K, Jackson J. Sexual Attitudes and Behavior Among Young Adolescents in Jamaica. International Family Planning Perspectives 1999;25(2):78-84 \& 91.

44. Rivers K, Aggleton P. Adolescent sexuality, gender, and the HIV epidemic. BETA 2001;14(2):35-40.

45. Herold JM, Valenzuela MS, Morris L. Premarital sexual activity and contraceptive use in Santiago, Chile. Stud.Fam.Plann. 23[2], 128-136. 1992.

Ref Type: Abstract

46. UNFPA, INIM, Instituto Nicaragüense de la Mujer. What could I do else than getting a child?, Sociocultural background of teenage pregnancy in Nicaragua (in Spanish). Managua,Nicaragua: Fondo de población de las Naciones Unidas, and Instituto Nicaragüense de la Mujer; 1999. Report No.: RLA/94/P15.

47. Lancester RN. Life is hard: machismo, danger, and the intimacy of power in Nicaragua. University of California Press, Berkeley, Los Angeles, California, USA; 1992.

48. Berganza CE, Peyre CA, Aguilar G. Sexual attitudes and behavior of Guatemalan teenagers: considerations for prevention of adolescent pregnancy. Adolescence 24[94], 327337. 1989. Ref Type: Abstract

49. Pick De WS, Atkin LC, Gribble JN, ndrade-Palos P. Sex, contraception, and pregnancy among adolescent in Mexico City. Stud.Fam.Plann. 22[2], 74-82. 1991. Ref Type: Abstract

50. Zelaya E. Adolescent pregnancies in Nicaragua. The importance of education. Dissertation ed. University of Umea, Sweden: 1999.

51. Guijarro S, Naranjo J, Padilla M, Gutierez R, Lammers C, Blum RW. Family risk factors associated with adolescent pregnancy: study of a group of adolescent girls and their families in Ecuador. J Adolesc Health 1999 Aug;25(2):166-72.

52. Lipovsek V, Karim AM, Gutierrez EZ, Magnani RJ, Castro Gomez MC. Correlates of adolescent pregnancy in La Paz, Bolivia: findings from a quantitative-qualitative study. Adolescence 2002;37(146):335-52.

53. Murray NJ, Zabin LS, Toledo-Dreves V, Luengo-Charath X. Gender Differences in Factors Influencing First Intercourse Among Urban Students in Chile. International Family Planning Perspectives 1998;24(3):139-44\&152.

54. Blum RW, Halcon L, Beuhring T, Pate E, Campell-Forrester S, Venema A. Adolescent health in the Caribbean: risk and protective factors. Am J Public Health 2003 Mar;93(3):456-60.

55. Magnani RJ, Seiber EE, Gutierrez EZ, Vereau D. Correlates of sexual activity and 
condom use among secondary-school students in urban Peru. Stud Fam Plann 2001 Mar;32(1):53-66.

56. Belmonte LR, Gutierrez E, Magnani RJ, Lipovsek V. Barriers to Adolescents Use of Reproductive Health Services in Three Bolivian Cities. FOCUS on Young Adults/ Pathfinder -international.; 2000 Dec 6.

57. Braddock M, Grainger C, Morera F. Addressing the Reproductive Health Needs and Rights of Young People since ICPD, the contribution of UNFPA\&IPPF. Nicaragua; 2003.

58. Blanc AK. The effect of power in sexual relationships on sexual and reproductive health: an examination of the evidence. Stud Fam Plann 2001 Sep;32(3):189-213.

59. Taylor DJ, Chavez GF, Adams EJ, Chabra A, Shah RS. Demographic characteristics in adult paternity for first births to adolescents under 15 years of age. J Adolesc Health 1999 Apr;24(4):251-8.

60. Abma J, Driscoll A, Moore K. Young women's degree of control over first intercourse: an exploratory analysis. Fam Plann Perspect 1998 Jan;30(1):12-8.

61. Olsson A, Ellsberg M, Berglund S, Herrera A, Zelaya E, Pena R, et al. Sexual abuse during childhood and adolescence among Nicaraguan men and women: a population-based anonymous survey. Child Abuse Negl 2000 Dec;24(12):1579-89.

62. Heise LL, Raikes A, Watts CH, Zwi AB. Violence against women: a neglected public health issue in less developed countries. Soc Sci Med 1994 Nov;39(9):1165-79.

63. Asling-Monemi K, Pena R, Ellsberg MC, Persson LA. Violence against women increases the risk of infant and child mortality: a case-referent study in Nicaragua. Bull World Health Organ 2003;81(1):10-6.

64. Pallitto CC, O'Campo P. The Relationship Between Intimate Partner Violence and Unintended Pregnancy: Analysis of a National Sample From Colombia. International Family Planning Perspectives 2004;30(4):165-73.

65. Shanler S. Abuso Sexual y Salud Reproductiva del Adolescentes. FOCUS on Young Adults . 1998. Ref Type: Internet Communication

66. Jacoby M, Gorenflo D, Black E, Wunderlich C, Eyler AE. Rapid repeat pregnancy and experiences of interpersonal violence among low-income adolescents. Am J Prev Med 1999 May;16(4):318-21.

67. Campbell JC. Abuse during pregnancy: progress, policy, and potential. Am J Public Health $1998 \mathrm{Feb} ; 88(2): 185-7$.

68. Curry MA, Perrin N, Wall E. Effects of abuse on maternal complications and birth weight in adult and adolescent women. Obstet Gynecol 1998 Oct;92(4 Pt 1):530-4.

69. Elders MJ, Albert AE. Adolescent pregnancy and sexual abuse. JAMA 1998 Aug 19;280(7):648-9.

70. Peipert JF, Domagalski LR. Epidemiology of adolescent sexual assault. Obstet Gynecol 1994 Nov;84(5):867-71.

71. Frejka T, Atkin LC. [The role of induced abortion in changing fertility in Latin America]. Salud Publica Mex 1990 May;32(3):276-87. Ref Type: Abstract.

72. Garcia-Baltazar J, Figueroa-Perea JG. [Contraceptive practices among adolescents and youths of the metropolitan area of Mexico City]. Salud Publica Mex 1992 Jul;34(4):413-26. Ref Type: Abstract.

73. Barnett J. First Time users have different needs.Network study 19(4). FOCUS on Young Adults . 1999. Ref Type: Internet Communication

74. Morris L. Sexual behavior of young adults in Latin America. Adv Popul 1994;2:231-52. Ref Type: Abstract

75. Friedmann JJ, McFarlane C, Morris L. Jamaica Reproductive Health Survey 1997 
Young Adult report: Sexual Behaviour and Contraceptive Use among Young Adults. International Family Planning Perspectives 1999;25(4):21-8\&43.

76. Pick S, Palos PA. Impact of the family on the sex lives of adolescents. Adolescence 1995;30(119):667-75.

77. Braddock M, Hernández SJ, Muiruri Y. A cross cultural study of access of adolescents to education and reproductive health care services (in Spanish). Mary Stopes International; 1995.

78. Zelaya E, Marin FM, Garcia J, Berglund S, Liljestrand J, Persson LA. Gender and social differences in adolescent sexuality and reproduction in Nicaragua. J Adolesc Health 1997 Jul;21(1):39-46.

79. Calero A, Mcfields A. Critics on the manual on sex education continue [Siguen cr'iticas a manula de educacion sexual]. La Prensa 2003 Aug 13;9a.

80. Calero A. Church: The education is facing serious risks [La educaion enfretna graves peligros]. La Prensa 2003 Aug 14.

81. Calero A. The Manual of sex education under revision [Manual de Educacion Sexual a Revision]. La Prensa 2003 Aug 21.

82. Mcfields A, Calero A. Urge to protest against the ministry of education [incitan a protestar conta el MECD]. La Prensa 2003 Aug 5;5a.

83. Gupta N, da CL, I. Adolescent Fertility Behavior: Trends and Determinants in Northeastern Brazil. Int Fam Plan Perspect 1999;25(3):125-30.

84. Worldbank. Population and The world Bank, Adapting to change, revised edition. The Human Development Network, Washington: Worldbank; 2000.

85. Martin TC, Juarez F. The Impact of Women's Education on Fertility In Latin America: Searching for Explanations. Int Fam Plan Perspect 1995;21:52-7\&80.

86. Conroy C. Reaching young adolescents. Entre Amigas prepares young grils in Nicaragua for a healthy future. Directions in Global Health, Information on programs of PATH 2004;1(2):1-10\&12.

87. Schor N, Lopez F. [Adolescence and contraception: 1. A study knowledge and use among women hospitalized for childbirth or abortion]. Rev Saude Publica 1990 Dec;24(6):506-11.

88. Hughes J, McCauley AP. Improving the fit: adolescents' needs and future programs for sexual and reproductive health in developing countries. Stud Fam Plann 1998 Jun;29(2):233-45.

89. Bertrand JT, Seiber EE, Escudero G. Contraceptive Dynamics in Guatemala: 19781998. Int Fam Plan Perspect 2001;27(3):112-8\&136.

90. Nazar-Beutelspacher A, Molina-Rosales D, Salvatierra-Izaba B, Zapata-Martelo E, Halperin D. Education and Nonuse of Contraceptives Among Poor Women in Chiapas, Mexico. Int Fam Plan Perspect 1999;25(3):132-8.

91. Senderowitz J. Health Facility Programs on Reproductive Health for Young Adults. http://www futuresgroup com/abstract.cfm/43 Accessed 6 June 20011997 [cited 2001 Jun 6];1-51.

92. UNFPA. Thematic Evaluation of Adolescent Reproductive Health Programs. 1997. Report No.: 13.

93. Zabin LS, Kiragu K. The health consequences of adolescent sexual and fertility behavior in sub-Saharan Africa. Stud Fam Plann 1998 Jun;29(2):210-32.

94. Senderowitz J. Do Youth-Friendly Services Make a Difference? http://www.fhi org/en/Youth/YouthNet/Publications/FOCUS/InFOCUS/YFSmakediff.htm Accessed 20 October 20001998 
95. Senderowitz J. Reproductive Health Programs for Young Adults: Health Facility Programs. http://www.who.int/child-adolescent-health/New_Publications/ADH/IB_SRG pdf 1997

96. Diaz J, Diaz M. Quality of care in family planning in Latin America. Adv.Contracept. 9[2], 117-128. 1993. Ref Type: Abstract

97. Diaz M, Simmons R, Diaz J, Gonzalez C, Makuch MY, Bossemeyer D. Expanding contraceptive choice: findings from Brazil. Stud Fam Plann 1999 Mar;30(1):1-16.

98. Ross J, Hardee K, Mumford E, Eid S. Contraceptive Method Choice in Developing Countries. International Family Planning Perspectives 2002;28(1):32-9.

99. Velasco C, de la QC, Jove G, Torres LA, Bailey P. [Quality of contraception services in El Alto, Bolivia]. Rev Panam Salud Publica 1999 Jun;5(6):411-8.

100. Hanson K, Kumaranayake L, Thomas I. Ends versus means: the role of markets in expanding access to contraceptives. Health Policy Plan 2001 Jun;16(2):125-36.

101. Sedlock L. Reaching the youngest adolescents with reproductive health programs. FOCUS on Young adults. 2000. Ref Type: Internet Communication

102. Williams T, Schutt-Aine J, Cuca YP. Measuring Family Planning Service Quality Through Client Satisfaction Exit Interviews. Int Fam Plan Perspect 2005;26(2):79-83.

103. OPS PHA. Quality of sexual and reproductive health services (in Spanish). 2000. Panamerican Health Association.

104. Caceres CF, Rosasco AM, Mandel JS, Hearst N. Evaluating a school-based intervention for STD/AIDS prevention in Peru. J Adolesc Health 1994 Nov;15(7):582-91.

105. Carvalho PA, Kurita PG. Opinion of students in medicine and nursing on the autonomy of adolescents in health services [in Spanish]. American Journal of Public Health 1998;4(6):388-92.

106. Bertrand JT, Hardee K, Magnani RJ, Angle M. Access, Quality Of Care and Medical Barriers in Family Planning Programs. Int Fam Plan Perspect 1995;21:64-9\&74.

107. Koenig MA, Hossain MB, Whittaker M. The influence of quality of care upon contraceptive use in rural Bangladesh. Stud Fam Plann 1997 Dec;28(4):278-89.

108. Merino JM, Olavarria S, Isla X. [Neighborhood effects influencing reproductive health of Chilean women]. Rev Med Chil 2003 Sep;131(9):987-95.

109. RamaRao S, Lacuesta M, Costello M, Pangolibay B, Jones H. The link between quality of care and contraceptive use. Int Fam Plan Perspect 2003;29(2):76-83.

110. Hubacher D, Holtman M, Fuentes M, Perez-Palacios G, Janowitz B. Increasing Efficiency to Meet Future Demand: Family Planning Services Provided by the Mexican Ministry of Health. Int Fam Plan Perspect 1999;25(3):119-24\&138.

111. Hardee K, McDonald OP, McFarlane C, Johnson L. Quality of care in family planning clinics in Jamaica. Do clients and providers agree? West Indian Med J 2001 Dec;50(4):3227.

112. Shelton JD. The Provider Perspective: Human After All. International Family Planning Perspectives 2001;27(3).

113. Stanback J, Thompson A, Hardee K, Janowitz B. Menstruation requirements: a significant barrier to contraceptive access in developing countries. Stud Fam Plann 1997 Sep;28(3):245-50

114. Galvão L, Díaz J, Díaz M, Osis MJ, Clawson L, Ellertson C. Emergency Contraception: Knowledge, Attitudes and Practices Among Brazilian ObstetricianGynecologists. International Family Planning Perspectives 1999;25(4):168-71\&180.

115. Hardee K, Clyde M, McDonald OP, Bailey W, Villinski MT. Assessing family planning service-delivery practices: the case of private physicians in Jamaica. Stud Fam 
Plann 1995 Nov;26(6):338-49.

116. Katz K, Johnson L, Janowitz B, Carvalho ML. Reasons for the Low Level of IUD Use in El Salvador. Int Fam Plan Perspect 2002;28(1):26-33.

117. Becker J, Leitman E. Introducing Sexuality within Family Planning: The Experience of Three HIV/STD Prevention Projects from Latin America and the Caribbean. New York, N.Y.: The Population Council; 1997. Report No.: Number 8.

118. Shelton JD, Angle MA, Jacobstein RA. Medical barriers to access to family planning. Lancet 1992 Nov 28;340(8831):1334-5.

119. Upadhyay UD. Informed choice in family planning. Helping people decide. Popul Rep J 2001;(50):1-39.

120. Haslegrave M, Olatunbosun O. Incorporating sexual and reproductive health care in the medical curriculum in developing countries. Reprod Health Matters 2003 May;11(21):49-58.

121. WHO. The Second Decade: WHO Improving adolescent health and development. Geneva; 1998.

122. WHO Department of Child and Adolescent Health and Development, UNAIDS Inter Agency Task Team on Young People. Adolescent Friendly Health Services, an agenda for change. World Health Organisation. 2002 WHO/FCA/CHA/02.14.

123. Ranjit N, Bankole A, Darroch JE, Singh S. Contraceptive failure in the first two years of use: differences across socioeconomic subgroups. Fam Plann Perspect 2001 Jan;33(1):19-27.

124. Blanc AK, Curtis SL, Croft TN. Monitoring contraceptive continuation: links to fertility outcomes and quality of care. Stud Fam Plann 2002 Jun;33(2):127-40.

125. Anrudh J. Should Eliminating Unmet Need for Contraception Continue to Be a Program Priority? Int Fam Plan Perspect 1999;25:S39-S43\&S49.

126. Kost K. The dynamics of contraceptive use in Peru. Stud Fam Plann 1993 Mar;24(2):109-19.

127. WHO World Health Organisation. Improving access to quality care in family planning: medical eligibility criteria for initiating and continuing use of contraceptive methods. WHO Geneva; 2001.

128. WHO. A picture of Health. A Review and Annotated Bibliography of the Health of Young People in Developing Countries. Geneva: WHO; 1995. Report No.: WHO/FHE/ADA/95.14.

129. Westoff CF. Unmet needs at the End of the Century. Calverton, MD: ORC Macro; 2001.

130. Singh S, Wulf D, Samara R, Cuca YP. Gender Differences in the Timing of First Intercourse: Data from 14 Countries. Int Fam Plan Perspect 2000;26(1):25-8\&43.

131. WHO Department of Child and Adolescent Health and Development. Risk and Protective Factors Affecting Adolescent Reproductive Health in Developing Countries, a summary; An analysis fo the world's literature 1990-2004. Geneva, Switserland: World Health Organization; 2004.

132. Sanchez Lang RM. Diagnostic of the situation of adolescents in Nicaragua [in Spanish]. Managua: Pan American Health Association OPS/OMS Nicaragua; 1999.

133. WHO Department of Child and Adolescent Health and Development, UNAIDS Inter Agency Task Team on Young People. Steady ... Ready .... Go! http://www who int/childadolescent-health/New_Publications/ ADH/IB_SRG pdf, accessed 11 Oktober 2004.

134. Bennett SE, Assefi NP. School-based teenage pregnancy prevention programs: a systematic review of randomized controlled trials. J Adolesc Health 2005 Jan;36(1):72-81. 
135. Martiniuk AL, O'Connor KS, King WD. A cluster randomized trial of a sex education programme in Belize, Central America. Int J Epidemiol 2003 Feb;32(1):131-6.

136. Replogle J. Sex and the Catholic Church in Guatemala. Lancet 2005 Aug 20;366(9486):622-3. 


\section{Chapter 3}

Sexual and reproductive health care for adolescents

Overview of interventions in Latin America and description of health care in Nicaragua 


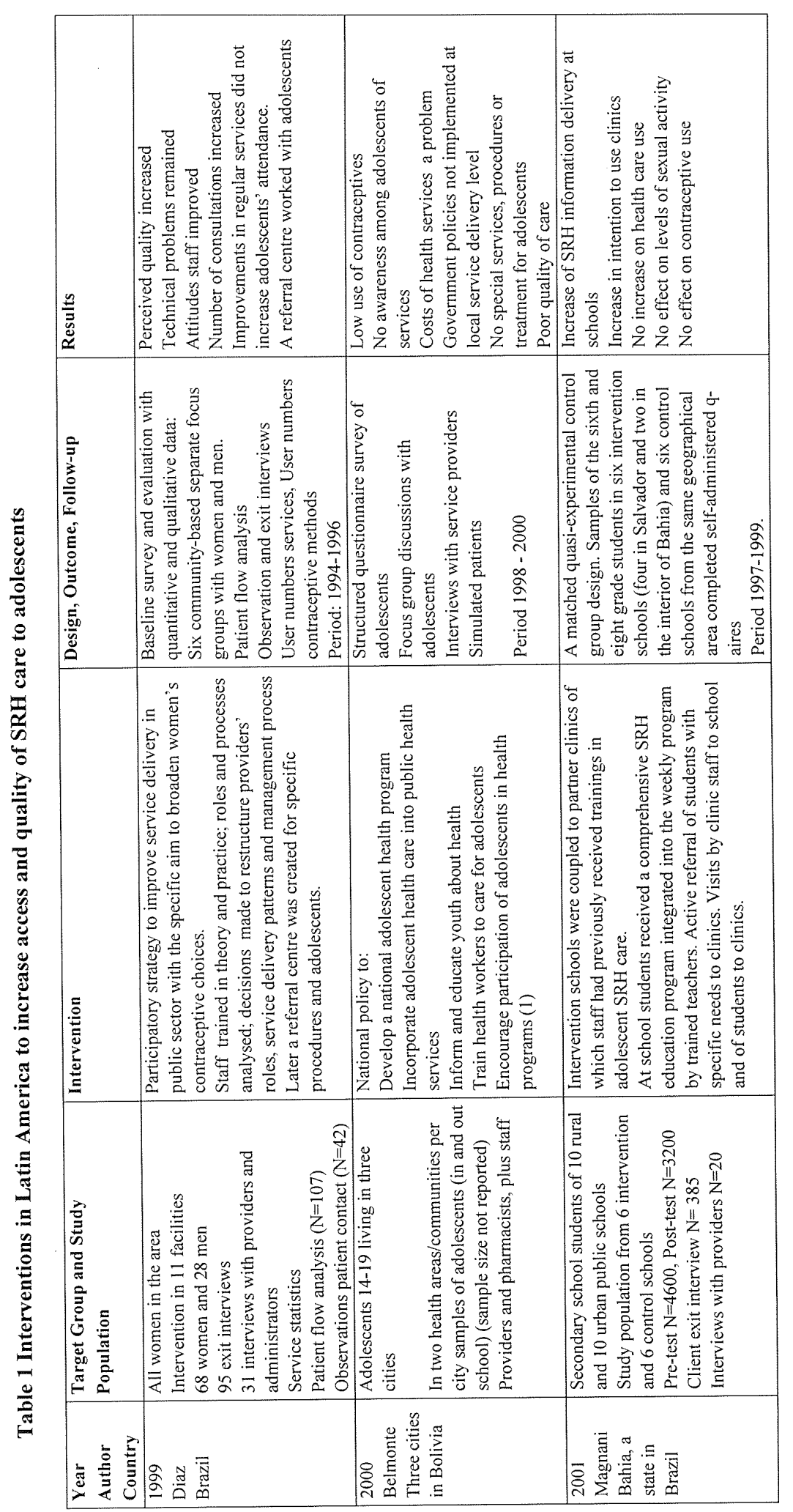




\subsection{Introduction}

While the causes of adolescent pregnancy and STIs are numerous and complex, one obvious barrier to decreasing STIs and unwanted or untimely teenage pregnancies is the lack of access to proper quality SRH care. Since the International Conference on Population and Development in Cairo in 1994, there has been an increasing effort to provide appropriate SRH care services to young people. These initiatives have been developed in response to emerging evidence that young people often feel unwelcome at traditional family planning or reproductive health clinics, combined with increased awareness of the special needs of young people in the area of SRH care and acknowledgment of their rights (2).

Most initiatives in developing countries have been organized on a small scale and few have been rigorously evaluated $(2 ; 3)$. In this chapter we will discuss the interventions in Latin America that have been evaluated and described, and the provision of health care to adolescents in Managua, Nicaragua.

\subsection{Evidence from adolescent SRH care interventions in Latin America}

The following three interventions were designed to improve adolescents' access to and the quality of public SRH care services.

In Southern Brazil, a participatory action research project was implemented to broaden women's contraceptive choices within the public health services. The process approach demonstrated the complexity of engendering changes in resource-constrained public services. The high turnover among doctors and their lack of motivation were especially problematic. Furthermore, this approach showed that improvements in regular services did not increase adolescents' attendance. A special adolescent referral centre was established to serve adolescents (4) (Table 1).

In Bolivia, national policies were developed to increase adolescents' access to SRH information and services through the public health services $(1 ; 5)$. To evaluate the implementation, quantitative and qualitative data were collected. The results indicated that the policies were not being put into action at service delivery level, and the use of clinic-based services by adolescents remained low (5) (Table 1). Despite the fact that the SRH care was evaluated as being not acceptable and appropriate to adolescents, recommendations focussed, in large part, on changing the attitudes and perceptions of youth and some of the values held by Bolivian parents as well as adults in general.

In another region of Brazil, a program was implemented in which sex education at 
schools was combined with referral by teachers of students with specified needs for sexual and reproductive health care to designated public health clinics. A matched control group design was used to evaluate the intervention. No effects on the use of public clinics or on sexual or contraceptive use behaviours were observed (6) (Table 1). Limitations in the design of this study include the researchers inability to control for school drop-out, which is often pregnancy related. A major limitation in the design of the intervention was the requirement for students to obtain a referral from their teacher in order to access care. In addition, some problems were reported in clinic organisation, as a result of which, at times, adolescents could not be served.

In summary, the described interventions, designed to improve service delivery through public facilities did not yield the desired results.

A different type of intervention promoted in the international context to address the health care needs of adolescents was the provision of health care through youth centres (7). The idea was to incorporate clinic services in multi purpose youth centres, to give all youth attending the centres easy access to medical consultation. Evaluation showed that this approach has not been able to reach new groups of adolescents $(3 ; 8 ; 9)$. Similar lessons were drawn in Managua, where an intervention was set up that provided, one day per week, easy and low-cost access to a psychologist and a doctor in 5 community centres that organised activities for young people. User numbers were low, and with very few seeking consultations for sexual or reproductive health issues, possibly because adolescents do not like to reveal use of SRH care services to their peers (10).

Another initiative developed in the international arena can be captured under the title of 'youth friendly services'. A variety of program models are being used to provide such services, based on evidence of the services sought by young people $(2 ; 11 ; 12)($ see Table 2$)$. 
Table 2 Characteristics that make health services youth friendly (2)

\begin{tabular}{|c|c|}
\hline $\begin{array}{ll} & \text { Service Provider } \\
\text { - } & \text { Specially trained staff } \\
\text { - } & \text { Respect for young people } \\
\text { - } & \text { Privacy and confidentiality honoured } \\
\text { - } & \text { Adequate time for client/provider } \\
\text { - } & \text { interaction } \\
\text { Peer counsellors available. }\end{array}$ & $\begin{array}{l}\text { Health facility } \\
\text { - } \quad \text { Separate space or special times set aside } \\
\text { - } \quad \text { Convenient hours and location } \\
\text { - } \quad \text { Adequate space } \\
\text { - } \quad \text { Comficient privacy } \\
\end{array}$ \\
\hline $\begin{array}{ll} & \text { Program design } \\
\text { - } & \text { Youth involvement in design, service } \\
\text { - } & \text { Dutreach and continuing feedback } \\
\text { - } & \text { Appointments arranged rapidly } \\
\text { - } & \text { No overcrowding } \\
\text { - } & \text { Short waiting times } \\
\text { - } & \text { Affordable fees } \\
\text { - } & \text { Publicity/recruitment that informs and } \\
\text { - } & \text { reassures youth } \\
\text { - } & \text { Woys/young men welcomed } \\
\text { - } & \text { Necessary referrals available }\end{array}$ & $\begin{array}{l}\text { Other possible characteristics } \\
\text { - } \quad \text { Educational material available on-site and to } \\
\text { take away } \\
\text { - Alternative, innovative ways to access } \\
\text { information, counselling and services } \\
\text { - Delay of pelvic examination and blood tests } \\
\text { possible } \\
\text { - Group discussions available }\end{array}$ \\
\hline
\end{tabular}

The models vary from region to region. A basic principle is that young people are both beneficiaries of the interventions as well as key resources in deciding what needs to be done. They should preferably be involved in all stages of the program, since they know best which elements will attract or sustain a specific target group (13). Other key aspects include: attention to the recruitment of clients; provision of services in a youth friendly environment, with emphasis on privacy and confidentiality; training of providers in effective youth counselling; access to appropriate contraception and informed choice; attention to STI/HIV prevention, diagnosis, treatment and counselling; and, last, but not least, provision of services that can be afforded by adolescents $(11 ; 14 ; 15)$. Organisations like UNFPA (United Nations Population Fund), WHO (World Health Organisation) and Family Health International strongly promote the implementation of programs embodying these concepts $(2 ; 15 ; 16)$. Many different countries now have experience with these programs and preliminary reports are positive $(8 ; 9)$. However, few youth friendly services have been rigorously evaluated $(2 ; 3 ; 8)$.

An example of a program in Latin America based on the concept of 'youth friendly' is an intervention in Ecuador. Clinic personnel provided education, counselling and clinical services to young people after being trained in adolescent health issues. To evaluate the intervention a pre/post test design was used in four intervention and four control clinics. While this program did not increase the 
number of new clients visiting intervention clinics, it did achieve a significant increase in number of adolescents who returned, thus improving continuity of care at intervention facilities (3).

Positive preliminary results on health care use and service satisfaction were also reported from an intervention intended to build the capacity of health professionals in the Andean region by training professionals who had close involvement with adolescents (17). Similar results were reported by an intervention to increase young peoples access to and use of SRH services at youth centres organised through non governmental organisations (NGOs) involved in health care in Brazil, Ecuador and Peru (18).

Because these interventions provide the only documented evidence of program outcomes, the most effective approach to increase the accessibility, acceptability and appropriateness of existing health services to young people in Nicaragua and other Latin American countries is still unknown. However, the concept of 'youth friendly services' appears promising and useful, although attracting adolescent clients remains a point of concern. There is a strong call to implement and evaluate youth friendly service initiatives in order to assemble the body of evidence of what works and what does not $(3 ; 14 ; 15)$.

\subsection{SRH care for adolescents in Managua}

In Nicaragua, there is a clear need for interventions that improve the access to and quality of SRH care for adolescents, as confirmed in policy documents from the Ministry of Health (19). Female adolescents in Managua normally start using sexual and reproductive health services only once they become pregnant, and male adolescents prefer to use the pharmacy if they have STI symptoms. In Managua, approximately $25 \%$ of the population is aged between 10 and 20 years (20). Despite representing such a large proportion of the population, very few resources are directly devoted to adolescents through existing health systems.

Primary health services in Managua consist of public health centres run by the Ministry of Health, municipal public health centres at the markets, private doctors, and clinics run by NGOs. A study carried out in 1995 to evaluate the quality of the public reproductive health services in Managua revealed serious deficiencies in the quality and the accessibility of care (21). Another serious constraint is that the public health services are only serving residents of their designated catchments area. Public health centres are understaffed, users have to line up from early morning, and the respect for privacy and confidentiality is generally poor. These are serious obstacles for everybody, but especially for adolescents seeking SRHcare who often prefer to hide their need for visiting a doctor, and prefer to go to places where the chance of meeting relatives/friends/acquaintances is low. 
Over the years, a number of initiatives have been introduced in Managua to improve access to and quality of SRH care for adolescents. For example, with the help of the UNFPA, a special clinic for adolescents was established in 1994 within the national referral hospital, Bertha Calderon ('La Casita Rosada'). In addition, the German development organisation GTZ started a program in 1998 to offer public health centres institutional support to improve health care delivery at public health centres to adolescents by setting up youth clubs. These clubs serve youth aged 10 to 19 years, and promote adolescent SRH through peer education, recreational and cultural activities, and through parent involvement. Their main geographic focus was the towns of Leon, Chinandega and Rivas, but they also included a few public health centres in Managua.

Furthermore, in Managua there are a number of clinics run by non-governmental women's health organisations, such as Si Mujer and Ixchen, Xochipilli, and Profamilia. In the late nineties, most of these organisations initiated special activities for adolescents. In the main, these activities had two components: medical attention, with special focus on adolescents, and adolescent clubs. In these clubs, adolescents can meet, get information and participate in delivering and receiving peer education. Social activities, including sports also form part of club activities. The NGO clinics are having a good reputation among the adolescents who have heard of them. However, the limited information and the fees create considerable obstacles to use.

Despite these initiatives, our baseline survey in the year 2000 and interviews with providers in 2001 indicated that adolescents in Managua continued to make little use of SRH care services. This is consistent with one of the findings of an assessment of youth reproductive health programs in Nicaragua undertaken by FHI (16). This assessment team concluded that in the existing health services: "institutional norms and individual service delivery practices in providing reproductive health services to adolescents are full of medical barriers and biases, and are not consistent with international norms. Incorrect or outdated information among providers reinforces cultural biases and misinformation among the population".

To reduce the rates of unwanted pregnancies and STIs among adolescents in Nicaragua, there was a clear need to improve access to and quality of SRH care services for adolescents. The need for SRH services that are acceptable, affordable, appropriate and accessible to adolescents, especially to poor adolescents, is pertinent in many countries (22). 


\section{References}

1. Rosen J. Formulating and Implementing National Youth Policy: Lessons from Bolivia and the Dominican Republic. Washington, USA: FOCUS on young adults; 2000.

2. UNFPA. The State of World Population 2003. Investing in Adolescents' Health and Rights. New York, USA: UNFPA, United Nations Population Fund; 2003.

3. Speizer IS, Magnani RJ, Colvin CE. The effectiveness of adolescent reproductive health interventions in developing countries: a review of the evidence. J Adolesc Health 2003 Nov;33(5):324-48.

4. Diaz M, Simmons R, Diaz J, Gonzalez C, Makuch MY, Bossemeyer D. Expanding contraceptive choice: findings from Brazil. Stud Fam Plann 1999 Mar;30(1):1-16.

5. Belmonte LR, Gutierrez E, Magnani RJ, Lipovsek V. Barriers to Adolescents Use of Reproductive Health Services in Three Bolivian Cities. FOCUS on Young Adults/ Pathfinder -international.; 2000 Dec 6.

6. Magnani RJ, Gaffikin L, de Aquino EM, Seiber EE, Almeida MC, Lipovsek V. Impact of an integrated adolescent reproductive health program in Brazil. Stud Fam Plann 2001 Sep;32(3):230-43.

7. Hughes J, McCauley AP. Improving the fit: adolescents' needs and future programs for sexual and reproductive health in developing countries. Stud Fam Plann 1998 Jun;29(2):233-45.

8. James-Traore T, Magnani RJ, Murray NJ, Senderowitz J, Speizer IS, Stewart L. Intervention Strategies that work for Youth. Summary of the FOCUS on Young Adults, End of Program Report. Family Health International, YouthNet Program; 2002.

9. UNAIDS Inter-Agency Task Team on Young People. Steady.... Ready.....Go. World Health Organisation, Department of Child and Adolescent Health and Development; 2004.

10. Cruz M. Experiences with health care supply through youth centres in Managua. 11-52000. Ref Type: Personal Communication

11. Senderowitz J. Reproductive Health Programs for Young Adults: Health Facility Programs.

/IB SRG pdf 1997.

12. WHO Department of Child and Adolescent Health and Development, UNAIDS Inter Agency Task Team on Young People. Adolescent Friendly Health Services, an agenda for change. World Health Organisation. WHO/FCH/CHA/02.14.

13. Senderowitz J. Health Facility Programs on Reproductive Health for Young Adults. http://www.futuresgroup com/abstract.cfm/43 Accessed 6 June 20011997 [cited 2001 Jun 6];1-51.

14. Senderowitz J. Do Youth-Friendly Services Make a Difference? http://www fhi org/en/Youth/YouthNet/Publications/FOCUS/InFOCUS/YFSmakediff.htm 1998 Accessed 20 October 2000.

15. WHO Department of Child and Adolescent Health and Development, UNAIDS Inter Agency Task Team on Young People. Steady ... Ready .... Go! http://www who int/childadolescent-health/New Publications/ADH/IB SRG pdf, accessed 11 Oktober 2004.

16. Scholl E, Burns A, Gutiérrez Z, Garache J. Assessment of youth reproductive health Programs in Nicaragua. Family Health International and USAID; 2003.

17. Quintana A, Hidalgo C, Cheetham N. YouthAccess: Bridging the Gap Between Health Providers and Youth.: 31st Annual Conference Youth \&Health: Generation on the Edge; Washington, USA: Global Health Council, 2004 p. A 57.

18. Finlay R. Expanding Access to Youth Friendly Services in Brazil, Ecuador and Peru. 
31st Annual Conference Youth \&Health: Generation on the Edge; Washington, USA: Global Health Council, 2004 p. A 77.

19. Direccion General de Servicios de Salud, Direccion de atencion integral, Programma de adolescentes. Technical and Administrative norms, First level of Attention. (in Spanish). Managua, Nicaragua; 1999.

20. Alcaldia de Managua. Managua a shared future (in Spanish) Plan General de Desarrollo Municipal. Alcaldia de Managua, Hermanamiento Amsterdam-Managua.; 2000.

21. Tinoco GY, Palacios N, Alvarez MC. Quality of public reproductive health services for women in Managua: A summary of the research (in spanish). 1995.

22. Bayley O. Improvement of sexual and reproductive health requires focusing on adolescents. Lancet 2003 Sep 6;362(9386):830-1. 


\section{Chapter 4}

Competitive voucher programs

Description of the voucher program for adolescents

and the design of the evaluation study 



\subsection{Introduction to use of vouchers in accessing health care}

In the first part of this chapter, the background and main concepts of competitive voucher programs are presented. In the second part, the implementation of the voucher program for adolescents will be described, with details of the institutional context and implementation, the contracting of the clinics, the distribution of the vouchers, the services provided and the costs of the intervention. In the final part of the chapter, the design of the evaluation will be discussed.

\subsubsection{Background to the voucher program}

In Managua, the Central American Health Institute (ICAS) had gained valuable experiences with another group of underserved people, sex workers (including transvestites and young male and female glue-sniffers), and other population groups vulnerable to HIV/AIDS, such as men who have sex with men and clients of sex workers. Sex workers carry high occupational risks for contracting STIs, including HIV. However, most sex workers shy away from the dedicated STI clinics established by the Ministry of Health: they are seen as stigmatising; they tend to treat their patients discourteously; and are perceived to have scant respect for the confidentiality of patient information. Instead, sex workers tend to visit general outpatient services, and choose not to reveal their occupational risks, given fear of discrimination and the illegality of prostitution in Nicaragua. As a consequence, the sex workers rarely receive adequate diagnosis or treatment for sexual health problems.

In 1996, ICAS set up a competitive voucher program for sex workers, providing free of charge access to STI/HIV diagnosis, treatment and counselling in between 10 and 15 clinics in Managua. In 1999, the program was expanded to include other vulnerable populations, and in 2002 the program extended its geographic coverage to three other departments in Nicaragua, contracting a further 10 clinics. Vouchers are distributed to sex workers, who then exchange the voucher for a medical consultation at the clinic of their choice. The voucher program succeeded in mobilising sex workers and other vulnerable population groups, to use the health services in which they received appropriate STI diagnosis and treatment and safe sex counselling, as well as voluntary counselling and testing for HIV.

Over the years since the ICAS program was established, many studies have confirmed that early treatment of STIs among high-risk groups is an important component of the strategy to reduce the spread of HIV in low prevalence countries (1). A number of economic evaluations of the ICAS program have demonstrated that, in Nicaragua, high efficacy STI treatment targeted to populations at highest risk can form a cost-effective approach to the prevention of HIV (2-4). 


\subsubsection{The main features of competitive voucher programs}

Health vouchers are designed to be exchanged, as full or part payment, for health services, diagnostic tests or drugs. Competitive voucher programs are one form of 'demand-side' financing, where purchasing power is given to the individual, with the value attached to the voucher in the hands of the consumer. The voucher program is competitive in the sense that it involves a number of different providers, with consumers able to choose between them. This encourages providers to compete to attract more voucher holders, since the level of funding received by each provider depends on the number of vouchers redeemed. By contrast, a 'supply side' subsidy covers some or all of the costs of required health service inputs (such as costs for staff, equipment, buildings and training) (5).

A typical competitive voucher scheme works as shown in figure I. The government or donor transfers funds to a voucher agency (1). Vouchers are then produced by the voucher agency and distributed to a target population, either by the agency itself (2a) or by third-party organisations (2b), which in turn distribute them to sections of the target population with whom they have close links (2c). Voucher recipients interested in the services offered take the vouchers to a health service provider of their choice (3) and exchange them for specified goods or services. The service providers return the vouchers to the voucher agency (4), along with required patient information. The agency then pays the provider a sum, agreed in advance, for each voucher returned (5). The voucher agency reports program outputs and outcomes to the government or donor providing the funds (6).

A voucher scheme works best for packages of services of largely fixed or predictable costs. A well planned scheme is relatively easy to administer, and once in place, scaling up to other populations or other geographic areas is relatively straightforward: it does not require the establishment of new procedures, but rather the incorporation of the additional scope within existing systems.

Competitive voucher programs have been implemented in a number of developing countries. Reported broad impacts include the following $(5 ; 6)$ :

- Poverty reduction and greater equity: voucher schemes can increase equity in access to specified health services, because they remove cost and quality barriers to service uptake, and because it is possible to target voucher distribution to disadvantaged groups, such as the poor and the vulnerable.

- Lower costs/higher technical efficiency: competitive voucher schemes increase consumer choice, encouraging providers to compete to attract and retain voucher holders. This has the potential to lead to both increases in service quality and increases in the efficiency of service delivery. It can also contribute to increasing the efficiency of resource use across the sector by increasing utilisation. In addition, payment is only made for services that are actually provided. A disadvantage however, is that vouchers cause additional transaction and administrative costs related to the costs of producing and 
distributing vouchers, contracting providers and monitoring their performance, reimbursing providers and establishing systems to avoid abuse of the voucher scheme.

Figure I: How does a voucher scheme work?

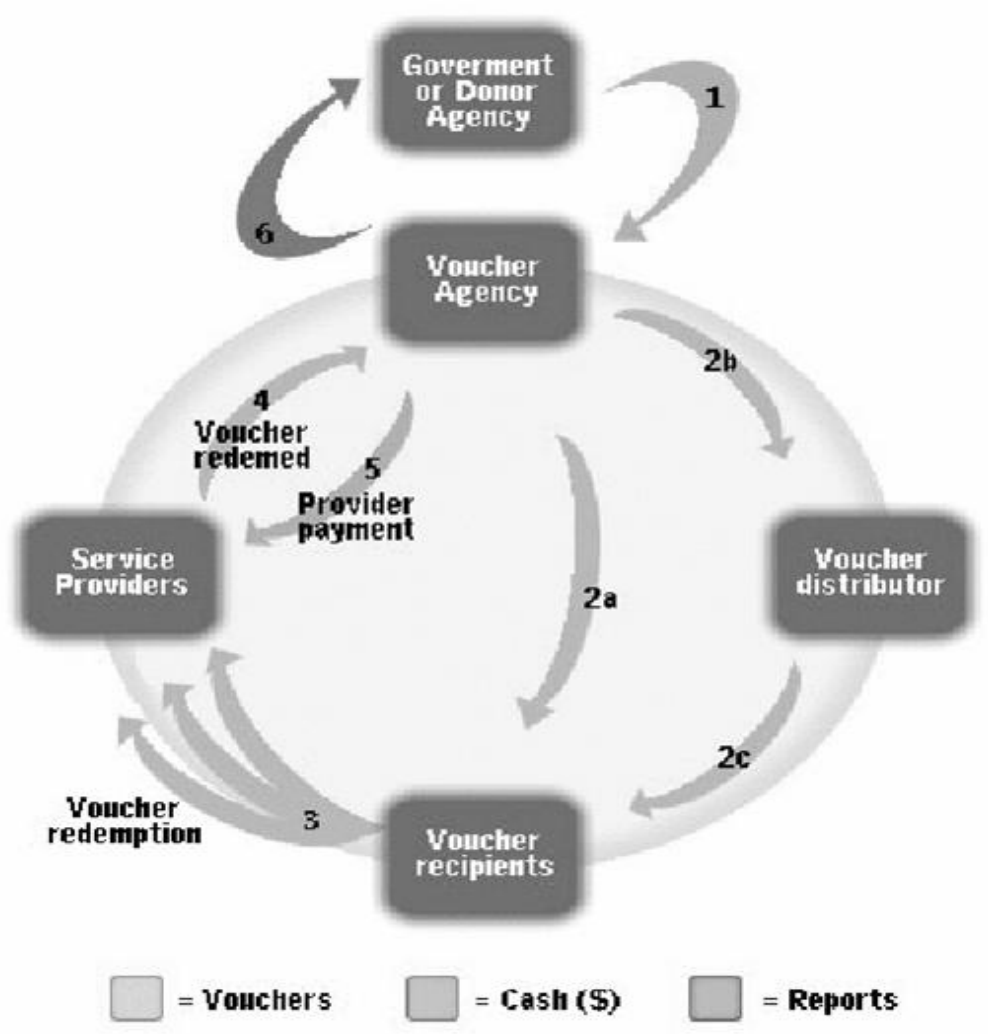

- Improved effectiveness/allocative efficiency: as mentioned above consumer choice has the potential to increase service quality. Furthermore, the contractual arrangements between the voucher agency and providers make it possible to employ evidence-based 'best practice' protocols and analysis of cost effectiveness in determining the package of services to be delivered. This package can also reflect beneficiaries' wishes about the type of services to be provided and where, when and how. As a result of the protocols introduced and monitored by the voucher agency, the voucher scheme also contributes to strengthening the existing health services (public, private and 
from non governmental organisations (NGOs). Effects on allocative efficiency depend on how the voucher system is designed and to whom the vouchers are targeted. Priority can be given to those services and individuals for which the greatest health gain will be obtained and by mobilising people to attend specific health interventions a voucher scheme can generate positive spillover effects to other members of a family or the society.

- Increased subjective quality /patient satisfaction: the competition between providers creates an incentive to use innovative approaches to attract voucher holders and to deliver services which are perceived by potential patients as being of high quality. Most voucher schemes provide targeted consumers with greater choice by including multiple providers and through the removal of cost barriers.

The next section details the implementation of the competitive voucher program for adolescents in Managua.

\subsection{The voucher program for adolescents}

\subsubsection{The clinics}

Inspired by the success of the voucher program for sex workers, it was hypothesised that similar mechanisms could work to improve the access to and the quality of sexual and reproductive care to poor and underserved adolescents. However, a key difference was that instead of tightly targeting a relatively small and specific group, the adolescent program would target a much larger proportion of the population: resource-constrained adolescents.

The program started in May 2000. In the first months, 200 adolescents were interviewed, using standardized questionnaires to collect general information on their knowledge and use of contraceptives and their knowledge and use of health services. Simultaneously, contacts were made with four NGO clinics to discuss their interest in participation in the project. Contracts were signed with the individual clinics, in which they committed to delivering a specified package of services to each voucher redeemer. In this contract, it was stipulated that ICAS would monitor the quality of services delivered. However, the methods to be employed were not specified for the pilot phase. Questionnaires for interviewing participating medical doctors and simulated patients were prepared, and all doctors were interviewed prior to the intervention beginning in the clinic in which they worked. Simulated patients were trained and started visiting the clinics before the intervention began.

Every three months, three or four new clinics were selected and prepared for inclusion in the program. Clinic selection was based on suitability (preferably experience with sexual and reproductive health care) and proximity to the low- 
income areas where vouchers were to be distributed. Identified clinics were invited to participate, and prices per consultation negotiated, based on their customary fees. The clinics received reimbursement for each voucher exchanged by an adolescent for a consultation. The average price negotiated per consultation and follow-up visit was US\$ 4.56. This was lower than the average normal consultation fee of US\$ 5.93 (7). Necessary laboratory tests for pregnant adolescents were reimbursed separately, and clinics were supplied with the necessary commodities and medications (see later).

The Minister of Health signed a Memorandum of Understanding with ICAS, in which the Ministry approved of the intervention.

\subsubsection{The distribution}

From September 2000 to July 2001, vouchers were distributed. The vouchers, dated and valid for three months, were distributed in 6 'rounds', on average, 2 months apart. On the reverse side of the voucher were printed the names of the clinics at which it could be redeemed. An example of the two sides of a voucher is shown in figure 2. The nature of the services to be delivered was not stated on the voucher to maintain the adolescent's privacy.

At each distribution 'round', new clinics could be included and non-performing clinics removed. The program started with 4 clinics; three months later another 7 joined; four months later another 3; 3 months later another 2; and 1 month later another 3 .

\section{Figure 2 Examples of vouchers distributed ${ }^{1}$}
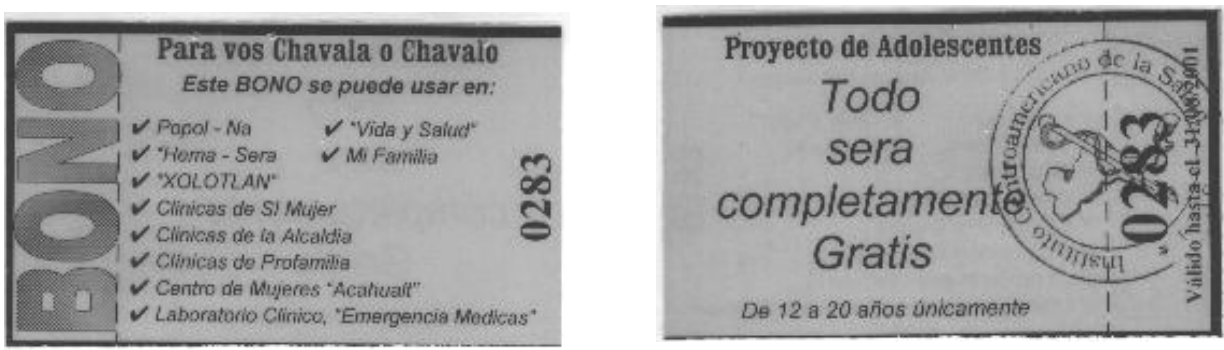

Most of the vouchers (75\%) were distributed by female adolescents contracted, trained and directly supervised by ICAS. They distributed vouchers on the streets

\footnotetext{
${ }^{1}$ The vouchers were $10 \times 6 \mathrm{~cm}$ and on the front was written: For you young ones; this voucher can be used in: names of the clinics. And on the back: Adolescent Project; everything will be completely free-of-charge; only for 12 to 20 year olds; Valid until days, months, year.
} 
and house to house in 221 disadvantaged neighbourhoods, at four markets and outside 19 public schools. The other vouchers were distributed through NGOs already in contact with the target group: $9 \%$ through five organisations linked to a specific clinic; $7 \%$ through ten community organisations; $9 \%$ through participating clinics. Clinics were given a stock of vouchers for additional consultations for voucher users in need of follow-up services, for partners of patients with STIs, and for friends of pregnant girls. During voucher distribution, registers were kept recording age, gender, level of school attainment, and the socio-economic status of the distribution site.

The vouchers distributed by ICAS were given to any adolescents aged between the 12 and 20 years present at the time of distribution. The voucher distributors visited an area in small teams, accompanied by an ICAS staff member. At markets and in neighbourhoods, girls were approached individually. At schools, vouchers were distributed outside the compounds in order to prevent compromising schools through direct association with a SRH care intervention given that official regulations forbid sex-education by health professionals in schools. Adolescents tend to leave school compounds in relatively large groups, and, as a result, the distribution of vouchers in these locations did not have the same 'one or two-at-atime' distribution possible at markets and in neighbourhoods.

During voucher distribution, adolescents were asked their age, and, if between 12 and 20 years, were given a voucher (see figure 2) and a leaflet. The leaflet contained information on the services that could be obtained, including a further explanation of the use of the voucher, the addresses of the clinics and the names of the participating doctors.

No negative reactions were reported from parents in neighbourhoods. On the contrary, when the program was explained to parents and they were asked if there was a teenager at home, they often requested vouchers for absent family members, giving, explanations such as "you know, I do not know how to talk about it, let them go to the doctor so that they can get proper explanations", or "my other child is already into these things, please leave a voucher for him/her".

In total, 28,711 vouchers were distributed to 16,850 female and 11,861 male adolescents aged 12 to 20 years, in disadvantaged areas of Managua. The selection of the areas was based on their low socio-economic status. In a later phase of the pilot, the relative poverty of the areas was classified based on an updated list obtained from the municipality indicating nature of housing, level of services (sewerage, electricity, drinking water) and quality of roads. Markets were classified on the relative price levels of goods sold. Schools were classified on the level of parental financial contributions and the socio-economic classification of the neighbourhood.

\subsubsection{Health care use}

The vouchers were not person-bound and were valid for three months. They 
entitled the holder to a free-of-charge consultation and a follow-up visit for advice/counselling, contraception, treatment of STIs or reproductive tract infections (RTIs), pregnancy testing and/or antenatal care in any of the four public, five private and ten NGO clinics contracted by ICAS.

Considerable efforts were made to include the public health centres in the neighbourhoods. One public health centre was incorporated in an early phase of the program, and some others were ready to join. The inclusion of governmental public health services was welcomed, especially of those in which adolescent clubs had been established and staff trained. However, due to a political decision, taken at the level of the Regional Health Authority of Managua (the SILAIS), collaboration was rejected. Because the organisation of health services in Nicaragua is decentralised, it was not possible for the responsible people at the national Department for Adolescent Health to overturn this decision.

All participating clinics were provided with the supplies to be used as part of this intervention: booklets on adolescent health; condoms, with information on their use; an assortment of contraceptives, and pre-packed medication for the syndromic treatment of STIs/RTIs. Syndromic treatment of STIs/RTIs is an approach to infection management in which diagnosis and treatment is based on the identification of syndromes (combinations of the symptoms the client reports and the signs the health care provider observes), while validation of risk helps to distinguish between an STI and an RTI. Syndromic treatment has been recommended by WHO for the control of STIs in developing countries. It has the important advantages that the costs of laboratory tests are avoided; treatment can be started immediately; and various types of health providers can be trained to prescribe it (8). It has proven to be a very effective approach to reduce the burden of STIs among adolescents in developing countries (9)

Of the 28,711 vouchers distributed 4,012 (14\%) were used: of 16,850 vouchers distributed to female adolescents $3,301(20 \%)$ were used and of 11,861 vouchers distributed to boys, 711 were used $(6 \%)$.

Doctors completed standardized clinical forms that guided them during each consultation. These forms were based on best practices and current guidelines, and were designed to ensure that every adolescent was asked about their sexual activity and their need for information and contraceptives. Voucher users received a booklet on adolescent health, two condoms with supportive information, and, if required, contraceptive methods, laboratory tests for antenatal control and syndromic treatment for STIs/RTIs. Doctors at participating clinics were obliged to attend an introductory meeting to learn about the program and its procedures. An information manual with background information and guidelines was also provided.

The mechanisms through which the voucher program further aimed to influence service quality were to mobilise users towards the health services and to support 
providers in meeting their needs through a short introductory training course, to learn about the program and its procedures, and continuous back-up. In other words, while the intervention focussed on users (the 'demand side'), it also addressed some aspects of the 'supply side'. In addition, as discussed above, the voucher program created an incentive for providers to increase the quality of care provided in order to attract more adolescent voucher recipients and hence to increase their incomes.

When we reviewed the reports from the first rounds of simulated patients, we discovered serious deficiencies in the personal and technical quality of care. It became clear that the doctors urgently needed more guidance in how to deal with adolescents and more information on the indications and contraindications for contraceptives. The staff of the Masters training program from the Department of Sexual and Reproductive Health at the University of Managua was asked to prepare a short course to train the doctors. A training course, over three mornings, was organised on 'youth friendly services', counselling, adolescence and sexuality, and contraceptives. All doctors were encouraged to attend, and, in the first course, nearly all doctors participated. They were very open in discussing the problems they had encountered in dealing with this new group of clients. The training course was repeated a number of times as the program incorporated new clinics and new doctors. In the later phase of the pilot, nurses and receptionists were also invited to join the training. In total, $70 \%$ of the doctors participated in at least one training session.

In September 2001, a meeting was organised to which all participating doctors were invited. In this meeting, the preliminary results of the intervention were presented, and discussions initiated in view of the possible continuation of the program beyond the pilot phase. At the conclusion of the pilot program in May 2002, all participants were invited to a formal meeting at which results were presented and official certificates of participation distributed.

After the pilot, the Royal Dutch Embassy in Managua agreed to fund the program for a further three years. During this period, the program was extended to the two departmental cities of Chinandega and Rivas.

\subsubsection{The costs of the pilot program}

The costs of the pilot program are shown in table 4.1. Of the 28,711 vouchers distributed, 4,160 were used. Therefore, one can cautiously estimate average costs to provide access to SRH care in the pilot phase as approximately US\$ 6.00 for each adolescent reached or US\$ 41.00 for each consultation, including follow-up consultation(s). These costs exclude the research costs of the London School for Hygiene and Tropical Medicine, but not those incurred by the local voucher agency ICAS. 
Table 4.1 Pilot programs costs 2000-2002

\begin{tabular}{|c|c|c|c|c|}
\hline Direct and indirect program costs & $\begin{array}{l}\text { Costs incurred in } \\
\text { Nicaragua } \\
\text { US\$ (2000) }\end{array}$ & $\begin{array}{l}\text { \% of costs } \\
\text { incurred in } \\
\text { Nicaragua }\end{array}$ & $\begin{array}{l}\text { Research } \\
\text { costs } \\
\text { US\$ }(2000) \\
\end{array}$ & $\begin{array}{l}\text { \% of total } \\
\text { costs }\end{array}$ \\
\hline Staff salaries (local staff) & 61,911 & $36 \%$ & & \\
\hline Consultations & 16,915 & $10 \%$ & & \\
\hline $\begin{array}{l}\text { Outreach work (transport, extra } \\
\text { daily labour and per diems) }\end{array}$ & 10,897 & $6 \%$ & & \\
\hline Medical supplies (medication) & 12,575 & $7 \%$ & & \\
\hline Laboratory & 5,163 & $3 \%$ & & \\
\hline $\begin{array}{l}\text { Health education material } \\
\text { (including condoms) }\end{array}$ & 3,491 & $2 \%$ & & \\
\hline Administrative overheads (ICAS) & 29,996 & $17 \%$ & & \\
\hline Direct and indirect costs & 172,414 & $100 \%$ & & $59 \%$ \\
\hline Research costs (LSHTM) & & & 119,917 & $41 \%$ \\
\hline Total pilot project costs & & & 292,331 & $100 \%$ \\
\hline
\end{tabular}

LSHTM = London School of Hygiene and Tropical Medicine)

For a number of reasons, these figures are likely to overestimate average unit costs incurred in providing ongoing SRH care to adolescents through a voucher scheme:

1. Establishing a voucher scheme requires a considerable level of skilled human resources - and therefore financial resources. Suitable clinics and partner organisations need to be identified, contracted and trained. Simultaneously, contact needs to be made with representatives of the target group and organisations currently working with them, and approaches developed and tested on how best to reach this group as well as definition of type of services to be offered. Many of these costs can be considered as once-only establishment expenses. Once the program is operational, resource requirements are reduced and focus on maintaining program quality, (for example, through evaluation of the performance in the clinics and the success of the distribution channels in reaching the target group); training new employees and contracting additional providers.

2. Monitoring and evaluation costs during a pilot phase can be elevated as a result of the intensive research activities required to evaluate all aspects of the intervention to guide planning of the main program. Once established, if the voucher program functioned purely as a health care delivery intervention, quality 
assessment costs would be lower, with quality assessment used only for quality control and to provide feedback to providers and clinics.

3. Distribution costs per voucher depend largely on the target group selected and the efforts required to reach the group. This, in turn, depends on the group's characteristics, such as geographic concentration and ease of identification. Another important factor influencing distribution costs per voucher will be the existence of suitable partners through whom distribution can be channelled. For example, one possible approach if the target group is broadly defined is to combine health education activities with voucher distribution. If the health education is organised by other partners, distribution costs can be reduced.

\subsection{The design of the evaluation study}

In the Introduction, the main research questions and related measures of impact were presented. In this chapter, the design of the evaluation study will be elaborated, detailing the choices made and the concepts used.

\subsubsection{The impact on use of health services and contraceptive knowledge and use}

To be able to evaluate the impact of the intervention on adolescents' knowledge and behaviour, we needed representative samples of our target group - adolescents from disadvantaged areas from Managua. We wanted a random sample of adolescents who all had had the same chance of receiving a voucher and who would feel free to share information on their SRH-care use, their perspectives on the quality of care and their knowledge and use of contraceptives and condoms.

We focussed the evaluation on girls. The practical reason was that the resources available for the evaluation were limited, and since boys made less use of the vouchers, we would have needed a much larger sample size to be able to measure any relevant differences. More importantly, the original focus of the intervention was to reduce unwanted pregnancies. Although boys play an undeniably important role in unwanted pregnancies, it was hypothesised that, as a result of the voucher program, girls would be empowered to take control of their fertility, without needing either the consent of parents or partner.

The survey took place 15 months after the first vouchers had been distributed and 3 months after the most recent distribution. Survey participants were identified in a similar way to the identification of voucher recipients. House to house, at markets and outside schools, at selected sites, each girl encountered was asked for her age. Selected sites were those where the largest numbers of vouchers had been distributed to increase the chance of encountering voucher receivers and voucher users. The sampling frame consisted of the 21 of the 244 sites.

Experiences with interviewing adolescents during demographic health surveys 
showed this method to be unreliable for issues related to sexuality (10-14). As a result, we developed a self-administered questionnaire in order to obtain more reliable answers on topics surrounded with taboos, such as sexual activity and contraceptive use. The wording of the questionnaires was developed in conjunction with adolescents from participating NGOs and extensively piloted.

At each site, convenience samples of adolescent girls were asked to complete the self-administered questionnaire. Each girl encountered at the site was asked to participate, the only criterion for selection was age. The survey was presented as a study seeking adolescents' opinions on health services, and was not linked to the voucher programme. Nearly all those approached agreed to participate. As an illustration of their enthusiasm, more than $20 \%$ noted additional observations on the questionnaire, having already completed 28 questions. The questionnaires were completed anonymously by the girls, with young people contracted by ICAS specifically for this survey standing nearby to guarantee privacy and to help with any questions. Of completed questionnaires, $18 \%$ were filled in by survey staff on behalf of girls who had difficulties reading or writing.

An estimated 3\% of girls refused to participate. The reasons provided included "in a hurry", "no permission from my boss" (at markets), while others believed the questionnaire was related to a political activity. A total of 3,130 questionnaires were completed of which 3,009 contained sufficient data for analysis. Within this sample 'voucher receivers' are considered as the intervention group, to be compared, at a group level, with the 'non-receivers', the control group, since it was by chance whether or not a respondent had received a voucher.

\subsubsection{The impact on the quality of care}

Researching quality of care and quality improvements is complex because quality of care has many aspects, not all of which are easily measurable. Therefore, we used various methods to assess quality and quality change. This makes it possible to look at a situation from different perspectives and helps in interpreting the findings. The methods we used were:

1. Self-administered questionnaires given to adolescents to compare satisfaction with services between users of SRH care with and without vouchers.

2. Interviews with medical doctors pre- and post intervention to assess and evaluate changes in their knowledge, attitudes and practices.

3. Simulated patients pre-, during- and post intervention to assess doctors' performance and to evaluate any changes due to the program

4. Review of patient medical files to evaluate the adherence by doctors to the treatment and 'social' protocols required by the intervention.

5. Focus group discussions to better understand the problems faced by adolescents and their perceptions of the health care services delivered by the voucher program in comparison with services delivered without a voucher. 


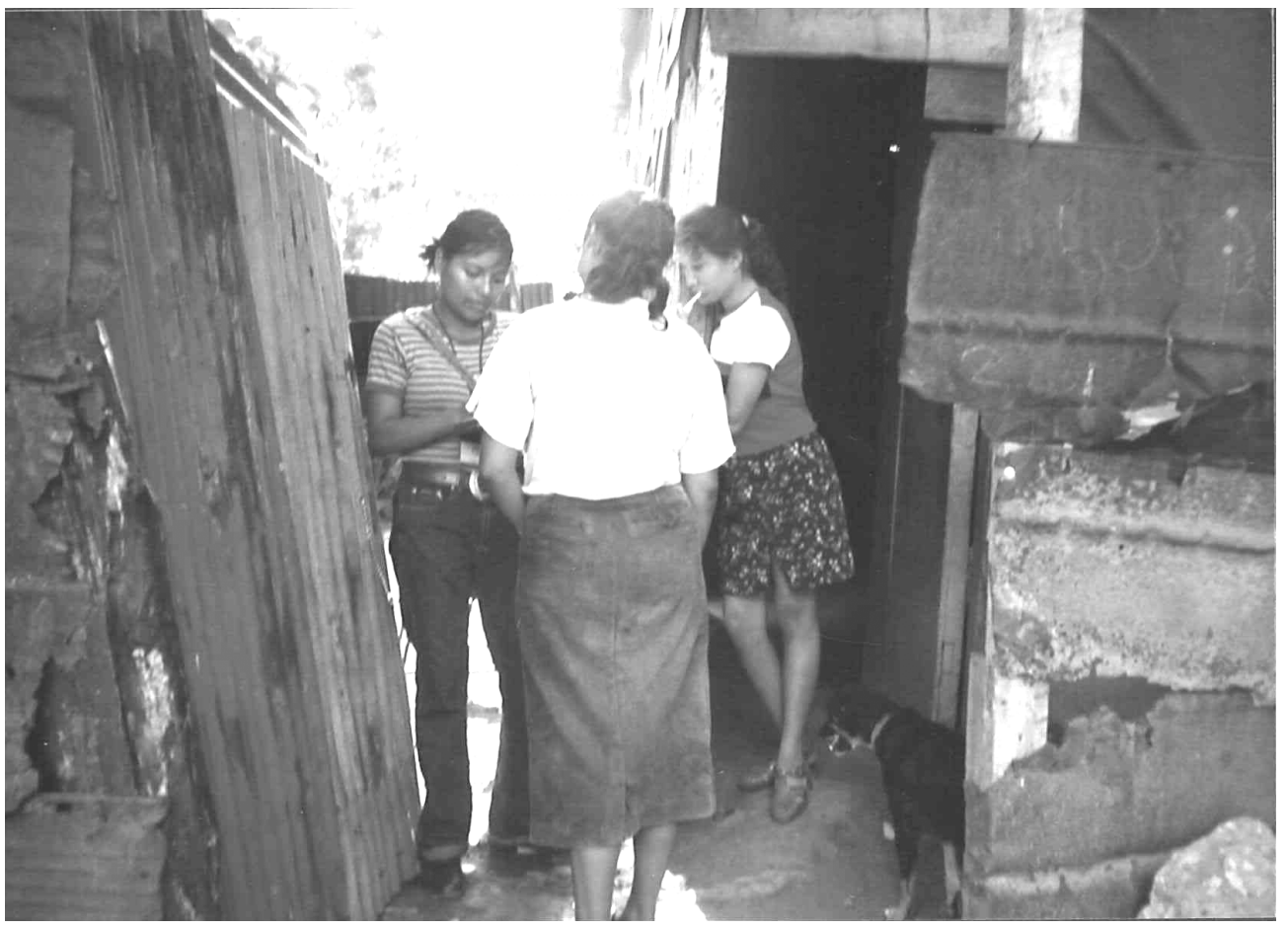

Explaining the survey to a girl and her mother

To integrate the information acquired through the different methods, we used the framework developed to evaluate the quality of family planning services $(15 ; 16)$. This framework defines the quality of care in terms of six dimensions (16):

- $\quad$ Choice of contraceptive methods - this refers to the number of methods and their variability;

- Information given to the clients - this refers to the information a patient needs to choose and employ contraception with satisfaction and technical competence;

- $\quad$ Technical competence - this refers to factors such as the clinical (technical) competence of providers. We included medical barriers under technical competence. Medical barriers refer to practices that use a medical rationale but result in an impediment to or denial of contraceptive use that cannot be scientifically justified (15).

- Interpersonal relations - this refers to the personal dimensions of the service;

- Follow-up mechanisms, including forward appointments;

- Appropriate constellation of services - this refers to situating the services so that they are convenient and acceptable to clients, and to the internal organisation within a clinic.

These six elements are not totally discrete, but can be used to describe the different aspects of the observed quality of care. The selection of specific issues relevant to 
adolescents to be used to evaluate these dimensions was based on the criteria for adolescent friendly services $(9 ; 17 ; 18)$.

The only method not covered in peer-reviewed articles is the focus group discussions. Seven discussion groups were organised: four with girls, one with boys and 2 mixed. A psychologist from the adolescent health team led the groups, and a secretary took notes. In total, 54 girls and 25 boys participated in these discussions. Four groups focused on determinants of health care use and knowledge and use of contraceptives; and three focussed on knowledge and use of contraceptives and the experiences with health care services with and without voucher. The findings from the focus groups were used to better understand adolescents' perceptions of health care services, contraceptives and the services delivered by the voucher program. Furthermore, two additional groups were organised to pilot and discuss the self-administered questionnaire to be used for the evaluation of the program.

\section{References}

1. Hogan DR, Baltussen R, Hayashi C, Lauer JA, Salomon JA. Cost effectiveness analysis of strategies to combat HIV/AIDS in developing countries. BMJ 2005; 331(7530):14311437.

2. Borghi J, Gorter A, Sandiford P, Segura Z. The cost-effectiveness of a competitive voucher scheme to reduce sexually transmitted infections in high-risk groups in Nicaragua. Health Policy Plan 2005; 20(4):222-231.

3. McKay J, Campbell D, Gorter AC. Lessons for Management of Sexually Transmitted Infection Treatment Programs as Part of HIV/AIDS Prevention Strategies. Am J Public Health 2006. May 2; [Epub ahead of print]

4. McKay JE, Campbell DJ. ¿Produce beneficios invertir en prevención del VIH/SIDA atendiendo a grupos con prácticas de alto riesgo?: Resultados de un estudio de costobeneficio en Managua. 2004. Spanish language summary of the thesis for the Masters in International Public Health at the University of Sydney, Australia.

5. Sandiford P, Gorter A, Rosas Z, Salvetto M. A guide to Competitive vouchers in health. Washington, DC, USA: The international Bank for Reconstruction and Development/The World Bank, 2004.

6. Gorter A, Sandiford P, Rojas Z, Salvetto M. Competitive Voucher Schemes for Health, Background Paper. Part of the Toolkit on Competitive voucher schemes in health. ICAS/Private Sector Advisory Unit of The World Bank Group, editor. 2003. Washington, DC, USA. Ref Type: Report

7. Gorter AC. Final project report: A voucher scheme for adolescents in Nicaragua to improve the uptake of reproductive health services Adolescent Project. 2002. London, United Kingdom, London School of Hygiene and Tropical Medicine/Department for International Development-UK. Ref Type: Report

8. WHO Regional Office for the Western Pacific Manila. Syndromic case management of Sexually Transmitted Diseases. A guide for decision makers Health care workds and communicators. 1-7. 1997. Ref Type: Report

9. UNAIDS Inter-Agency Task Team on Young People. Steady.... Ready.....Go. Bruce D, 
Ferguson J, editors. 1-8. 2004. World Health Organisation, Department of Child and Adolescent Health and Development. 11-10-2004. Ref Type: Report

10. Westoff CF. Unmet needs at the End of the Century. 2001. Calverton, MD: ORC Macro. DHS Comparative Report No.1. Ref Type: Report

11. Bongaarts J, Cohen B. Adolescent reproductive behavior in the developing world. Introduction and review. Stud Fam Plann 1998; 29(2):99-105.

12. McCauley AP, Salter C, Kiragu K, Senderowitz J. Meeting the needs of young adults. Popul Rep J 1995;(41):1-43.

13. Singh S, Darroch JE. Adolescent pregnancy and childbearing: levels and trends in developed countries. Fam Plann Perspect 2000; 32(1):14-23.

14. WHO. A picture of Health. A Review and Annotated Bibliography of the Health of Young People in Developing Countries. WHO/FHE/ADA/95.14. 1995. Geneva, WHO. Ref Type: Report

15. Bertrand JT, Hardee K, Magnani RJ, Angle M. Access, Quality Of Care and Medical Barriers in Family Planning Programs. Int Fam Plan Perspect 1995; 21:64-69\&74.

16. Bruce J. Fundamental elements of the quality of care: a simple framework. Stud Fam Plann 1990; 21(2):61-91.

17. Senderowitz J. Do Youth-Friendly Services Make a Difference? http://www.fhi.org/en/Youth/YouthNet/Publications/FOCUS/InFOCUS/YFSmakediff.htm Accessed 20 October 2000 . 1998. Ref Type: Electronic Citation

18. Senderowitz J, Hainsworth G, Solter C. A rapid assessment of youth friendly reproductive health services. 4, 1-12. 2003. Pathfinder International. Technical Guidance Series. Ref Type: Report 


\section{Chapter 5}

Impact of accessible sexual and reproductive health care on poor and underserved adolescents in Managua, Nicaragua

A quasi-experimental intervention study

Liesbeth E.Meuwissen, Anna C. Gorter and J.A. Knottnerus

Published in Journal of Adolescent Health 38 (2006) 56.e1-56.e9.

(C) 2006 Society for Adolescent Medicine. All rights reserved

Traduccion en espanol: http://www.icas.net/new-icasweb/docs/Traduccion\%20Impact\%20Adolescentes.pdf 


\begin{abstract}
Background

The objective of this study was to evaluate a competitive voucher program intended to make sexual and reproductive health (SRH) care accessible to adolescents from disadvantaged areas of Managua.
\end{abstract}

\title{
Methods
}

A quasi-experimental intervention study was performed in which 28,711 vouchers that gave free access to SRH care in 20 health centers ${ }^{1}$, were distributed to adolescents. To evaluate the impact, community sampling took place in markets, neighborhoods, and outside schools where self-administered questionnaires were distributed. The study comprised a random sample of 3,009 female adolescents, ages 12 to 20 years old, 904 voucher receivers and 2,105 nonreceivers. Their use of SRH care, and knowledge and use of contraceptives and condoms were measured.

\section{Results}

Voucher receivers had a significantly higher use of SRH care compared with nonreceivers, $34 \%$ versus $19 \%$ (adjusted odds ratio 3.1 ; 95\% confidence interval, 2.5-3.8). The highest influence was seen among respondents at schools, where use was $24 \%$ relative to $6 \%$ in nonreceivers (adjusted odds ratio $5.9 ; 95 \%$ confidence interval, 3.7-9.5). Voucher receivers answered significantly more questions correctly that were related to knowledge of contraceptives and sexually transmitted infections than nonreceivers. At schools, sexually active voucher receivers had a significantly higher use of modern contraceptives than nonreceivers, $48 \%$ versus $33 \%$ (adjusted odds ratio 2.3; 95\% confidence interval 1.2- 4.4); and in neighborhoods, condom use during last sexual contact was significantly greater among voucher receivers than nonreceivers (adjusted odds ratio 2.5; 95\% confidence interval 1.4-4.5).

\section{Conclusion}

he voucher program succeeded in increasing access to SRH care for poor and underserved girls. The needs of adolescents were met with a relatively simple intervention through existing health facilities. Many adolescents appeared willing to protect themselves against the risks of sexual intercourse. This suggest that access to SRH care can play an important role in changing youth behavior and increase the use of contraceptives and condoms.

\footnotetext{
${ }^{1}$ In this chapter 20 participating clinics are mentioned, while in the other chapters we only mention 19 . As described in chapter 4.2 .3 one public health centre had to be removed from the program for political reasons. The two doctors involved hired a room in a laboratory in front of the health centre, and continued consulting adolescents with vouchers. Initially we considered this a 'new' clinic. However, for the evaluation of the quality of care through interviews with doctor and the simulated patients, we did not consider it a new clinic, as the doctors were the same.
} 


\subsection{Introduction}

Nicaragua has the highest fertility rate in Latin America, with 119 births annually per 1,000 young women aged 15 to 19 years (1). Girls' mean age at first intercourse is reported to be 17.8 years, but at age 15 years, $8 \%$ of the girls already are mothers or pregnant, and by age 19 this has increased to

$45 \%$ (1). This is suggestive of the well-known underreporting of sexual activity in interview settings, and the real mean age at first intercourse may be lower than reported. Early sexual debut and high fertility rates are associated with low socioeconomic status and educational level. Adolescents experience high rates of unwanted pregnancy, illegal abortions, and high maternal mortality, and also are at high risk for contracting sexually transmitted infections (STIs), including human immunodeficiency virus/acquired immune deficiency syndrome.

Few adolescents use family planning methods and the latency period between first intercourse and the end of first pregnancy is an average of 21.5 months (2). Other Latin American countries face similar problems. Obstacles to accessing contraceptive services are believed to originate from different levels: adolescents and their sexual partners, health and education systems, and sociocultural factors $(3-6)$.

The obstacles to sexual and reproductive health services are as follows:

- $\quad$ Lack of access to information about sexual and reproductive health: there is no integrated sex education in schools, the media transmit ambivalent messages, and parents lack the necessary information and experience difficulties in discussing sex with their children.

- Lack of access to sexual and reproductive health (SRH) care services: existing centers lack confidentiality, privacy, and quality of service, all factors considered essential characteristics by adolescents. Centers with specialized services for adolescents are rare and/or relatively expensive, so poor adolescents cannot access them.

- Low quality of care: many doctors lack the knowledge and skills to provide adequate SRH care consultations to adolescents and treat them in a paternalistic way.

Various interventions in the region aimed at overcoming the obstacles faced by adolescents in accessing SRH care have not resulted in an increased uptake of services and/or use of contraceptives (7-9). This led various researchers to formulate the hypothesis that knowledge and availability of contraceptives are important but not sufficient to change adolescents' behavior. As a result, interventions are recommended that target not only adolescents and health service providers but also the social norms of parents and communities $(7,8,10-12)$. It is important to verify whether the formulated hypothesis is true. There is an urgent need to identify effective, low-cost interventions that assist adolescents in 
protecting themselves from unwanted or untimely pregnancies as well as STIs and human immuno-deficiency virus.

In Nicaragua, an innovative approach was piloted, focused on strengthening the demand of adolescents for SRH care through a competitive voucher scheme (13). Competition refers to the fact that in the described program there was competition between service providers, as opposed to programs in which the voucher is redeemable at a single service provider. Competition substantially increases the potential to produce efficiency and quality improvements in the health care delivered (13).

The impact of this intervention was evaluated through self-administered questionnaires completed by female adolescents in places where vouchers had been distributed, focusing on the use of SRH care and knowledge and use of contraceptives and condoms.

\subsection{Methods}

\subsubsection{The intervention}

Nicaragua is one of the poorest countries in Latin America, with an estimated population of 5.2 million inhabitants. Managua, the capital, had an estimated population of 1 million inhabitants in 2000, of whom $25 \%$ were aged between 10 and 20 years (14). From September 2000 to July 2001, a total of 28,771 vouchers were distributed to male and female adolescents in disadvantaged areas of Managua. The Central American Health Institute (ICAS) was the voucher agency. Vouchers were distributed through ICAS and nongovernmental organizations (NGOs) in 4 markets, outside 19 public schools, in clinics, and on streets and house to house in 221 poor neighborhoods. Vouchers were distributed in neighborhoods because pregnancy can be a reason to be expelled from school and attendance at secondary school among female adolescents in Managua is only $73 \%$ (1). Less than $.5 \%$ of adolescents refused a voucher. During distribution, registers were kept recording age, gender, level of school attainment, and the socioeconomic status of each distribution site.

Vouchers were not bound to the person who originally received them and could be passed to another adolescent with greater needs (voucher traveling). Of girls who redeemed a voucher, $27 \%$ reported that they had received it from someone not directly involved in the distribution.

Vouchers were valid for 3 months and could be used for 1 consultation and 1 follow-up visit for counseling, family planning, pregnancy testing, antenatal care, STI treatment, or a combination of these services. Four public clinics, 5 private clinics, and 11 NGO clinics participated. The selection of these clinics was based 
on suitability and proximity to the areas where the vouchers were distributed. All voucher redeemers received a booklet on adolescent health, 2 condoms with supportive information, as well as laboratory tests, drugs, and contraceptives, as required.

Clinic staff received a short introduction to the program followed by training sessions on counseling, adolescence and sexuality, and sexual abuse. Doctors filled in a standard medical form during each consultation. Based on the numbers of completed forms with the voucher attached, the clinics received reimbursement according to agreed fees (Figure 1).

Figure 1 Schematic presentation of the voucher scheme

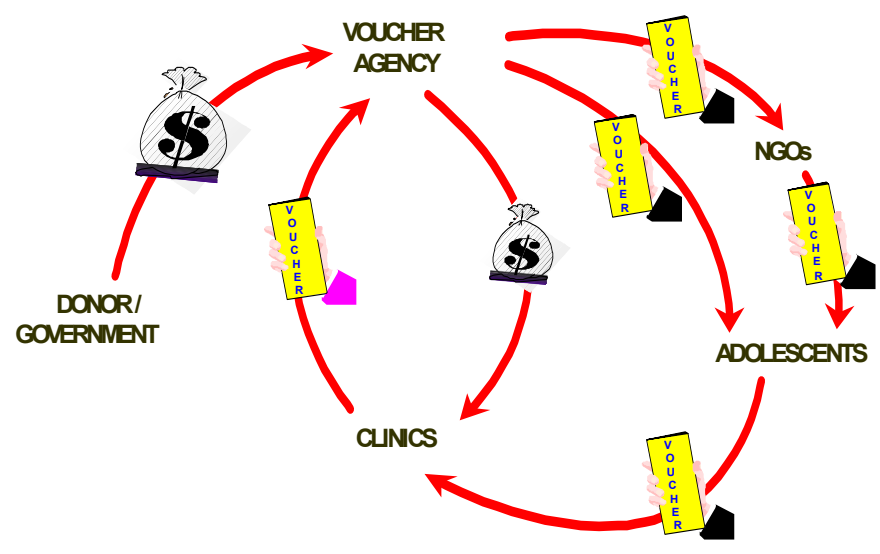

\subsubsection{Design and population}

The impact of this community-based quasi-experimental intervention study was assessed by comparing the use of SRH care, knowledge of contraceptives and STIs, and use of contraceptives and/or condoms from female voucher receivers compared with nonreceivers. Self-administered questionnaires were distributed randomly among female adolescents 3 to 15 months after the vouchers had been distributed in their area. The evaluation of the impact was limited to girls. To measure the impact of the intervention on male adolescents a much larger sample size would have been needed because only $6 \%$ of the male receivers used their voucher.

The sampling frame consisted of a selection of 21 of the 244 sites where a large number of vouchers had been distributed. At each site, convenience samples of adolescent girls were asked to complete a questionnaire. The only criterion for selection was age. At markets and in neighborhoods, girls were approached individually both during voucher distribution and the survey. During voucher distribution at schools, relatively large groups of adolescents were approached while leaving their school to prevent compromising schools with the SRH care intervention. During the survey, girls were approached on a more individual basis while still in or near the school compound. 


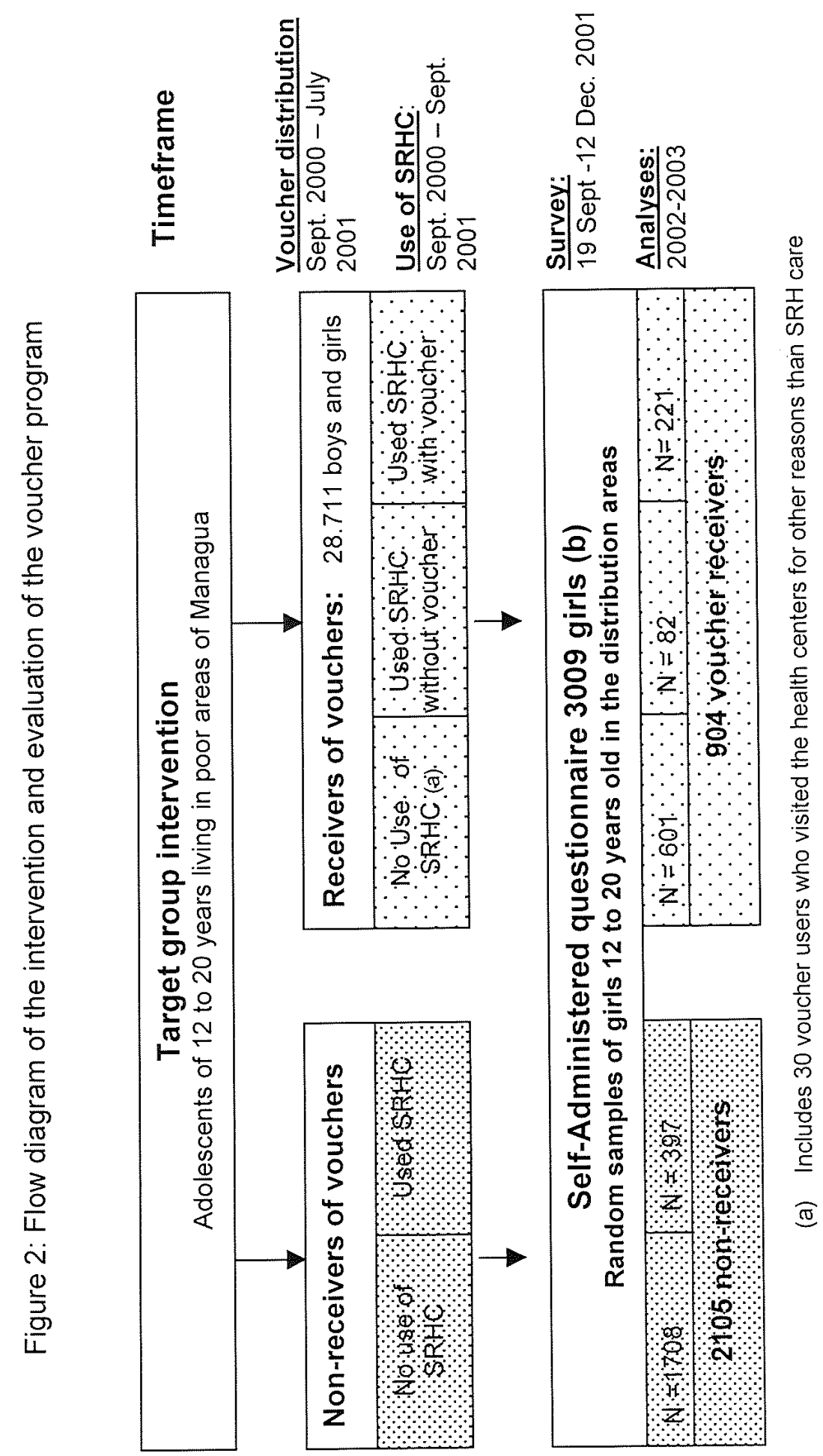


The survey was presented to girls as a study seeking adolescents' opinion on health services and was not linked to the program. The objective was to obtain a random sample of girls who had had the same chance of receiving a voucher. Within this sample, the voucher receivers were considered the intervention group to be compared at a group level with the control group, the nonreceivers, because it was by chance whether or not a respondent had received a voucher (Figure 2). The study was approved by the ethical review committees of the London School of Hygiene and Tropical Medicine and ICAS.

\subsubsection{Measurements}

A self-administered questionnaire was chosen to maximize honesty in responses given cultural taboos about premarital sex. The wording of the questions was developed in conjunction with adolescents from participating NGOs and was piloted extensively. The main challenge was to collect information on voucher receipt and use without overtly linking the questionnaire to the evaluation of the program. While the questionnaire was being completed, survey staff (female adolescents) stayed nearby to answer questions and to safeguard privacy. Of completed questionnaires, $18 \%$ had been filled in by survey staff on behalf of girls who had difficulties reading or writing.

The aim of the study was to assess whether the voucher program, through increased access to SRH care, would increase knowledge about STIs and contraceptive methods as well as increase contraceptive use. The selection of the variables was based on literature and previous studies in Nicaragua. The main outcome variables were as follows: (1) using SRH care within 15 months before the survey; (2) mentioning at least 2 modern contraceptives; (3) mentioning a health care facility as a place to obtain contraceptives; (4) mentioning 2 STIs; (5) mentioning condoms as a method to prevent transmission of STIs; (6) reported use of modern contraceptives; and (7) reported condom use during last sexual contact.

Open-ended questions were used to assess girls' knowledge. The use of SRH care was ascertained through the questions: "Did you consult a doctor for: information or advice, family planning methods, pregnancy test, control of pregnancy, a venereal disease, problems with your menstruation, or other?" (with a yes/no response). "How many months ago did you have this medical consultation?" With 2 exceptions, questions about sexual activity and the use of contraceptives and condoms were formulated with yes/no responses. Girls who used contraceptives were asked to fill out the name of the method and all girls were asked to provide the age at which they wanted to have their first or their next child.

The main exposure was voucher receipt. The variables of age, level of schooling, school attendance, socioeconomic (SE) indicators, childbearing experience, and survey site were considered potential confounders that might have been associated with receiving a voucher and independently influence outcome, or effect modifiers that might influence the effect of vouchers on outcome. 
SE indicators used to assess the level of relative poverty were the presence of a refrigerator, the number of people per bedroom, and SE classification of the survey site. The SE classification of neighborhoods was based on an updated list obtained from the municipality indicating the nature of housing, the level of services (sewerage, electricity, drinking water), and the quality of the roads. Markets were classified on the relative price levels of goods sold. Schools were classified on the level of parental financial contributions and the SE classification of the neighborhood. The very poor SE sites scored 2 points, followed by the poor sites with 1 point, with lower class/lower middle class sites with 0 points.

Pregnancy and motherhood increase the social acceptability of a girl seeking SRH care in Nicaragua. Therefore, the category of childbearing experience was classified into 3 groups. Group 1 comprised girls who had not started sexual relations. Group 2 comprised girls who had started sexual relations but had never been pregnant. Group 3 comprised pregnant girls and mothers. The distribution of childbearing experience by age was similar to the national distribution (1).

\subsubsection{Data collection and analysis}

An estimated 3\% of girls refused to participate. The reasons provided included "in a hurry" and "no permission from my boss" (at markets), whereas others believed the questionnaire was related to a political activity. A total of 3,130 questionnaires were completed, of which 3,009 (96\%) contained sufficient data for analysis. Data were entered twice in Epi-info by 2 different data processors. STATA 7.0 (Intercooled) software was used for further analysis.

The main characteristics describing study participants according to voucher receipt were calculated and tabulated (Tables 1 and 2). The crude odds ratio between voucher receipt and outcomes was assessed. The adjusted Mantel-Haenszel odds ratios for the different levels of possible confounders were calculated. Only statistically significant results $(\mathrm{p}<0.05)$ are reported. 
Table 1 Characteristics of voucher receivers and non-voucher receivers during the survey $(\mathrm{N}=3009)$

\begin{tabular}{|c|c|c|c|c|}
\hline Total & & $\begin{array}{l}\text { Non-receivers } \\
\mathrm{N}=\mathbf{2 1 0 5}(\%)\end{array}$ & $\begin{array}{l}\text { Receivers } \\
\mathrm{N}=904(\%)\end{array}$ & $\mathbf{P}$ \\
\hline \multirow[t]{3}{*}{ Age group } & $12-15$ years & $721(34.3)$ & $230(25.4)$ & \\
\hline & $16-17$ years & $558(26.5)$ & $286(31.6)$ & \\
\hline & $18-21$ years & $826(39.2)$ & 388 (42.9) & $<0.01$ \\
\hline Education & $0-6$ years & $389(18.5)$ & $123(13.7)$ & \\
\hline \multirow[t]{3}{*}{ Missing $=5$} & $7-9$ years & 987 (46.9) & $381(42.3)$ & \\
\hline & $10-11$ years & $528(25.1)$ & $207(23.0)$ & \\
\hline & $12-16$ years & $199(9.5)$ & $190(21.1)$ & $<0.01$ \\
\hline Attending school & No & $663(31.5)$ & $212(23.5)$ & \\
\hline Missing $=5$ & Yes & $1440(68.5)$ & $689(76.5)$ & $<0.01$ \\
\hline Fridge & No fridge & $1045(50.0)$ & $443(49.1)$ & \\
\hline Missing $=19$ & Fridge & $1043(50.0)$ & $459(50.9)$ & 0.64 \\
\hline Nr people/bedroom & $0-2$ & $1013(49.0)$ & $451(50.7)$ & \\
\hline \multirow[t]{2}{*}{ Missing $=50$} & more than $2-3$ & $579(28.0)$ & $263(29.6)$ & \\
\hline & more than 3 & $477(23.1)$ & $176(19.8)$ & 0.14 \\
\hline \multirow{3}{*}{$\begin{array}{l}\text { SE classification } \\
\text { survey site }\end{array}$} & lower/lower middle & $535(25.4)$ & $366(40.5)$ & \\
\hline & Poor & $1041(49.5)$ & $359(39.7)$ & \\
\hline & very poor & $529(25.1)$ & $179(19.8)$ & $<0.01$ \\
\hline \multirow[t]{3}{*}{ Place questionnaire } & Market & $507(24.1)$ & $184(20.4)$ & \\
\hline & Neighborhood & $961(45.7)$ & $319(35.3)$ & \\
\hline & outside school & $637(30.3)$ & $401(44.4)$ & $<0.01$ \\
\hline \multirow{3}{*}{$\begin{array}{l}\text { Sexual active } \\
\text { Missing }=55^{*}\end{array}$} & not started & $1366(66.1)$ & $563(63.4)$ & \\
\hline & $\begin{array}{l}\text { started no mother } \\
\text { mother and/or }\end{array}$ & $301(14.6)$ & $172(19.4)$ & \\
\hline & pregnant & $399(19.3)$ & $153(17.2)$ & 0.01 \\
\hline
\end{tabular}

*29 girls who did not complete the second page of the questionnaire, where was asked about sexual relations, pregnancy and children and 26 with missing data regarding the specific question. 
Multiple logistic regression analyses were used to adjust the association between voucher receipt and the outcome for group differences. The likelihood ratio test (LRT) was used to determine whether other variables individually had a significant effect on the outcome $(p<0.10)$. For each variable, it was assessed whether there was interaction with voucher receipt using the LRT. All categoric variables were tested for departure from the linear trend. Finally, the significance of each variable was tested with the LRT, by excluding them one by one from the model with all significant variables $(\mathrm{p}<0.05)$. Because the survey site (markets, neighborhoods, and schools) had considerable influence on the outcomes, multivariate analyses were performed for each site separately (Table 3 ). Only records with complete data for all significant variables were used in the multivariate analysis. Missing data were few and associated neither with the probability of voucher reception nor with any outcome.

\subsection{Results}

During the intervention, there were 3,067 girls who used a voucher for a total of 3,301 first consultations: $34 \%$ for family planning (for sexually active nonpregnant girls, $57 \%$ ), $31 \%$ for treatment of reproductive tract infections and STIs, $28 \%$ for antenatal care, $28 \%$ for counseling, $18 \%$ for pregnancy testing, and $15 \%$ for other reasons. Girls could attend for more than one reason. Based on the data collected during the voucher distribution, no relevant differences were found in the characteristics of the voucher receivers in sampled sites versus nonsampled sites. Furthermore, the characteristics of the respondents were similar to girls who had received a voucher during the intervention. As a result, it can be assumed that respondents are representative of the group who could have received a voucher.

Of the 3,009 girls who completed the questionnaire, 904 had received a voucher and 2,105 had not. Voucher receivers and nonreceivers differed significantly in some main characteristics (Table 1). These differences disappeared in markets and neighborhoods after stratification by survey site (Table 2). By constructing separate models per site, the impact of vouchers on subgroups of adolescents was shown (Table 3). Correcting for the $18 \%$ of questionnaires that were completed by survey staff did not change any outcome in the logistic regression model. 
Table 2 Differences in characteristics between voucher receivers and non-receivers per survey site

\begin{tabular}{|c|c|c|c|c|c|c|c|c|c|c|}
\hline Survey Sites & VR* & $\mathrm{Nb}(\%)$ & $\% \mathrm{VU} \dagger$ & $\begin{array}{l}\text { Mean } \\
\text { age }\end{array}$ & $\begin{array}{l}\text { Years } \\
\text { school }\end{array}$ & $\begin{array}{l}\% \text { At } \\
\text { school§ }\end{array}$ & $\begin{array}{l}\text { No } \\
\text { Fridge }\end{array}$ & $\begin{array}{l}\text { People/ } \\
\text { bedroom }\end{array}$ & $\begin{array}{l}\text { SE- } \\
\text { score// }\end{array}$ & $\begin{array}{l}\text { Started } \\
\text { व }\end{array}$ \\
\hline \multirow{5}{*}{$\begin{array}{l}\text { Markets } \\
(\mathrm{N}=691) \\
\text { Neighbour- } \\
\text { hoods } \\
(\mathrm{N}=1280)\end{array}$} & Yes & $184(27)$ & \multirow[t]{3}{*}{28.3} & 17.5 & 8.7 & 61 & \multirow{4}{*}{$\begin{array}{l}54 \\
49 \\
61\end{array}$} & 2.4 & 1.6 & 49 \\
\hline & No & $507(73)$ & & 17.6 & 8.6 & $49 * *$ & & 2.4 & 1.7 & 54 \\
\hline & & & & & & & & & & \\
\hline & Yes & $319(25)$ & \multirow[t]{2}{*}{35.7} & 16.5 & 7.5 & 58 & & 3.0 & 1.1 & 43 \\
\hline & No & $961(75)$ & & 16.3 & 7.5 & 63 & 58 & 2.9 & 1.0 & $35 * *$ \\
\hline \multirow{2}{*}{$\begin{array}{l}\text { At schools } \\
(\mathrm{N}=1038)\end{array}$} & Yes & $401(39)$ & 21.5 & 17.1 & 10.3 & 98 & \multirow{2}{*}{$\begin{array}{l}38 \\
39\end{array}$} & 2.3 & 0.2 & 26 \\
\hline & No & $637(61)$ & & $16.3 * * *$ & $9.3 * * *$ & $93 * * *$ & & 2.4 & $0.4 * * *$ & $15 * * *$ \\
\hline \multirow[t]{2}{*}{ All (N=3009) } & Yes & $904(30)$ & 27.9 & 17.0 & 9 & 76 & \multirow{2}{*}{$\begin{array}{l}49 \\
50\end{array}$} & 2.6 & 0.8 & 37 \\
\hline & No & $2105(70)$ & & $16.6^{* * *}$ & $8.3 * * *$ & $68 * * *$ & & 2.6 & $1.0 * * *$ & $34 * * *$ \\
\hline
\end{tabular}

(*) Voucher receipt Significance of difference between receivers and non-receivers:

$(\dagger) \%$ receivers who used voucher $\quad * * 0.05<\mathrm{p}<0.01$

(\$) Mean number of years been at school $* * * \mathrm{p}<0.01$

(§) \% presently at school

(//) Socio-economic score survey site

(q) $\%$ initiated sexual intercourse

\subsubsection{Use of SRH Care}

The overall use of SRH care during the 15 months since voucher distribution began was $700(23 \%): 303(33.5 \%)$ voucher receivers compared with $397(18.9 \%)$ nonreceivers (Fig. 2). Three groups profited most from voucher receipt. Of the girls completing questionnaires at school, $24 \%$ of the voucher receivers used SRH care compared with $6 \%$ of the girls who did not receive a voucher. Of the younger voucher receivers (age group, 12-15 y), 25\% used SRH care compared with 7\% of the nonreceivers. Of the voucher receivers who had completed less than 7 years at school, 56\% used SRH care compared with 26\% (Figure 3).

When controlling through logistic regression for all co-variables significantly correlated with the use of SRH care, voucher receipt was associated with a considerably higher use of SRH care. The strongest difference was seen in girls completing questionnaires at schools (Table 3 ).

\subsubsection{Knowledge and use of contraceptives}

Of all participants, 2,045 (68\%) mentioned at least 2 contraceptives: 667 (74\%) voucher receivers versus 1,378 (65\%) nonreceivers. In logistic regression analysis, voucher receipt was associated with a significantly greater capacity to mention at least 2 contraceptives. Per survey site, the influence of voucher receipt on knowledge of 2 types of contraception was absent in markets, but positive in neighborhoods and schools (Table 3). 
Figure 3 Illustrative Impact of Vouchers on Use of SRH care by sub-groups*

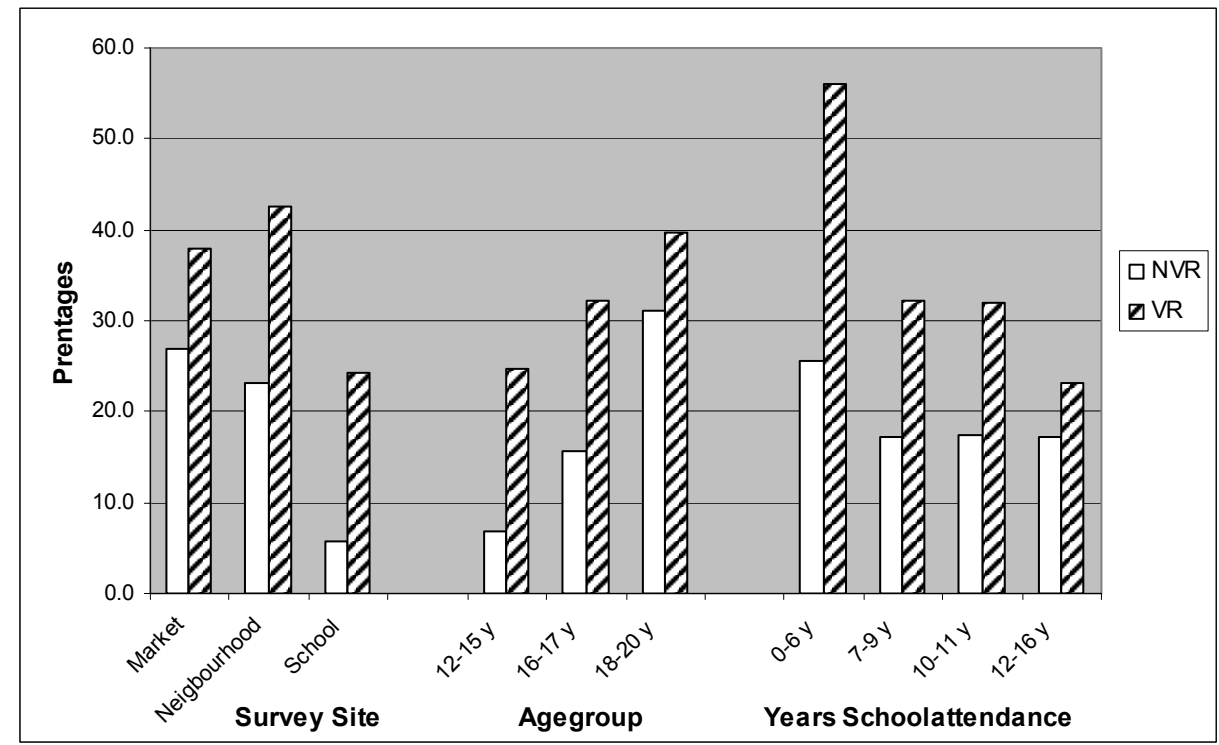

* Univariate Analyses $\quad \mathrm{NVR}=$ non voucher receiver $\mathrm{VR}=$ voucher receiver

Of all participants, $1,369(46 \%)$ mentioned a health care-related facility as a place to obtain contraceptives: 460 (51\%) voucher receivers versus 909 (43\%) nonreceivers. The difference between voucher receivers and nonreceivers was largest among girls with less education (56\% vs. 38\%). In multiple logistic regression analyses, voucher receipt was associated with a significantly greater capacity to mention a health facility. When analyzing the relationship by survey site, vouchers had a significant impact in neighborhoods and at schools (Table 3).

From the 1,025 girls who indicated that they had begun sexual intercourse, 11\% were pregnant and $2 \%$ said they wanted a baby within the coming year. For the use of modern contraceptives, only responses from the remaining 888 sexually active girls were considered. The difference between voucher receivers and nonreceivers was studied for the use of intrauterine device, sterilization, and oral or injectable contraceptives.

The overall use of modern contraceptives was 437 participants (50\%). No differences were noted between voucher receivers and nonreceivers. In multiple regression analyses, voucher receipt was associated with a nonsignificant higher use of modern contraceptives. The effect of the voucher was modified by the place of survey. At schools, voucher receipt was associated with a significantly greater use (Table 3). 


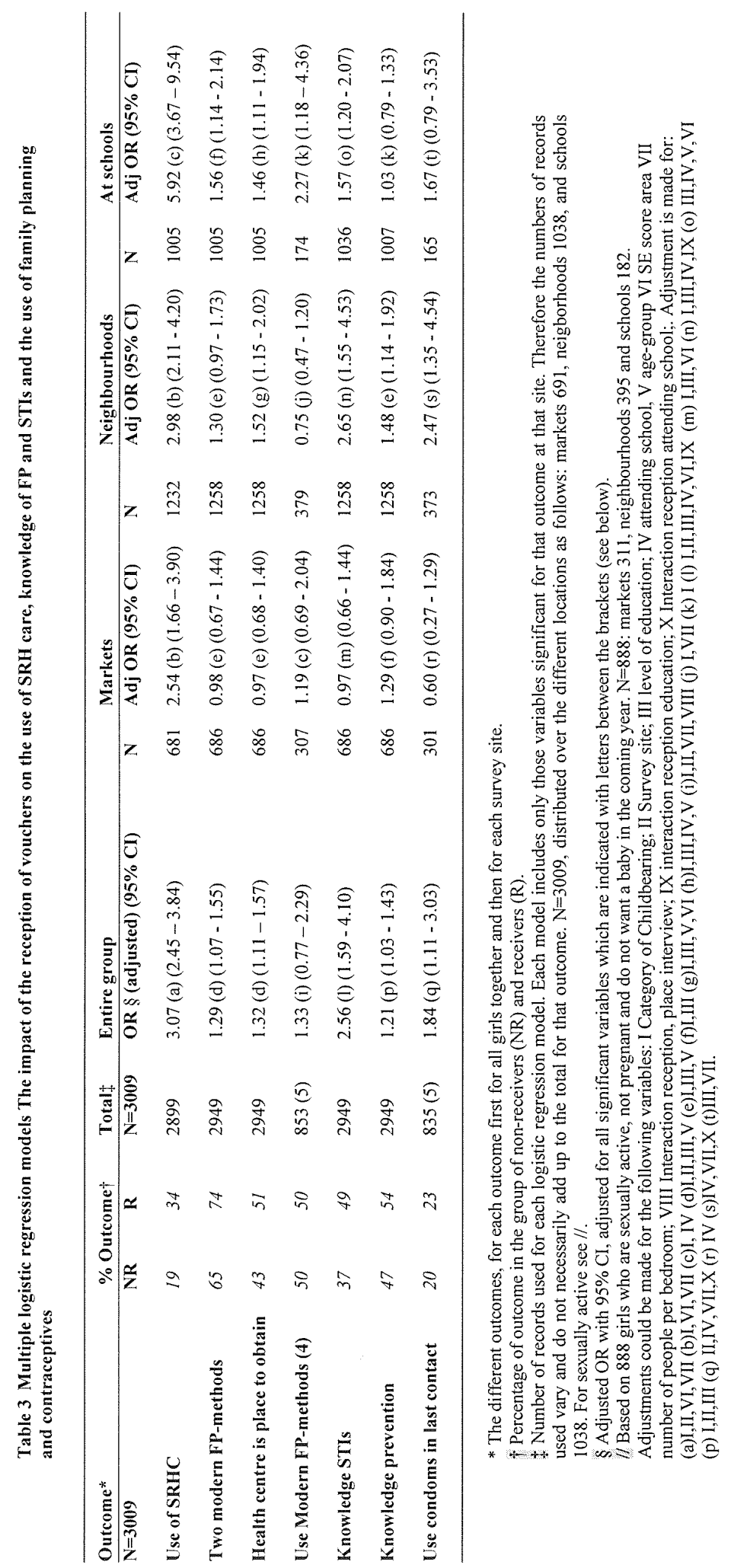




\subsubsection{Knowledge of STIS and their prevention and the use of condoms}

Of all participants, 1,220 (41\%) could mention 2 STIs: $441(49 \%)$ voucher receivers versus 779 (37\%) nonreceivers. Human immunodeficiency virus/acquired immune deficiency syndrome was mentioned by $74 \%$ of the girls independent of voucher receipt. Although the numbers of girls who mentioned 2 STIs increased with level of education, the difference between voucher receivers and nonreceivers was largest among girls with 0 to 6 years of education (33\% vs. $15 \%)$.

In logistic regression analysis, vouchers were associated with an increased capacity to mention STIs. The level of education modified the impact of vouchers because the lower the level of education, the stronger the influence of voucher receipt on knowledge of STIs. When analyzing by distribution site, voucher receipt was associated with significantly better STI knowledge among respondents in neighborhoods and at schools (Table 3).

Of all participants 1,480 (49\%) mentioned condom use as a method to prevent STIs, 487(54\%) of the voucher receivers versus 993 (47\%) of the nonreceivers. In logistic regression analysis, voucher receipt was associated with a significantly greater knowledge of STI prevention through condom use. This difference was largest among respondents in neighborhoods (Table 3).

The use of condoms in the last sexual encounter among sexually active girls was 179 (21\%): $64(23 \%)$ by voucher receivers versus $115(20 \%)$ by nonreceivers. Although condom use was highest among girls attending school, the difference between voucher receivers and nonreceivers was strongest in girls with little education ( $29 \%$ vs. $14 \%)$ and girls not attending school (24\% vs. $15 \%)$.

In multiple logistic regression analyses, vouchers were associated with a significant increase in condom use at last contact. The effect of the voucher was modified by school attendance because when analyzing all girls together, an increase in use was observed only among voucher receivers who were not attending school. When analyzing by survey site, condom use increased most among voucher receivers in neighborhoods (Table 3). 


\subsection{Discussion}

After adjustment for differences between groups, voucher receipt was associated with a significantly greater increase in the following: use of SRH care, knowledge of contraceptives, and knowledge of STIs and prevention through condom use. The impact of voucher receipt varied between subgroups. For respondents at markets only the use of SRH care increased. The use of contraceptives increased significantly among respondents at schools, and the increase in the use of condoms during last sexual encounter was strongest in neighborhoods.

In interpreting these findings, some methodologic comments should be considered. The main limitation of this study was the different characteristics of voucher receivers and nonreceivers among respondents at school. These differences can be explained by 2 mechanisms. The group approach during voucher distribution permitted a positive selection of girls with more unmet needs for SRH care (the sexually active and older girls) who were interested in receiving a voucher, whereas the more individual approach during the survey made such selection less likely. This process, together with voucher traveling, can explain the differences in age and sexual activity, controlled through logistic regression.

Because the questionnaire was completed anonymously, and in private, and was not overtly linked to the voucher program, nonrandom reporting bias is unlikely. The significant difference found between voucher recipients and non-recipients in the use of contraceptives and condoms is promising because these differences were found within a relatively small sample of sexually active girls who did not want to conceive within 1 year.

In conclusion, voucher receipt can be considered the main causal factor for improved use of services, knowledge, and use of contraceptives and condoms in this population. Considering the generalizability of the results, even adolescents from disadvantaged areas of Managua appear very diverse, benefiting differently from the voucher program. At markets, more girls were independent economically and had started adult life: through voucher receipt, these girls only increased their use of SRH care. In neighborhoods, more of the girls had left school mostly as a result of the SE situation of the family or pregnancy. These girls profited most from access to information and increased use of condoms. Girls at schools generally receive family support for further education and few are pregnant. In this group, knowledge increased and many used their voucher to obtain modern contraceptives. Because many adolescents in Nicaragua, as throughout Latin America, face obstacles accessing contraceptive information and services, a voucher program is likely to yield benefits for other groups of adolescents as well.

Twenty percent of the female voucher receivers used their voucher. This is a relatively high percentage considering the fact that the vouchers were valid for only 
3 months and were distributed without asking adolescents about their SRH care needs. Many female voucher receivers (63\%) were not yet sexually active, and thus had limited needs for SRH care services. Among the sexually active girls, 51\% used their voucher, whereas among girls who were not sexually active, voucher use was only $14 \%$.

Focus group discussions and interviews with adolescents during the intervention suggest that the factors that contributed to the success of the voucher program were the removal of practical obstacles (e.g., financial, the need to make an appointment, the lack of information on clinic location, and opening times) plus the guarantee of confidential access to a service provider of their choice. Many of these factors are known to be key features of youth-friendly services $(12,15)$.

It remains to be seen whether the impact will be sustained beyond the voucher program as financial obstacles for confidential care reappear and the financial incentives and guidance given to providers disappear. We hope that the training and experience obtained by the medical staff through the voucher scheme will prompt the provision of services based on the requirements of adolescents and an increase of the number of clinics providing quality SRH care to adolescents. Furthermore, the key finding of this intervention was that accessible health care of good quality can make an important contribution to helping a considerable proportion of girls use SRH care and to diminish the risks of sexual relations, even without their social context being changed.

This is very encouraging because other factors influencing sexual behavior, such as economic deprivation, cultural norms, low educational attainment, and sex inequality are complex issues that will take time to change at a societal level. It might well be that young people reached by the voucher program become the agents for such changes.

A possible reason why other researchers suggest that knowledge and access are not sufficient to change adolescent behavior could be an underestimation of the obstacles faced by adolescents in obtaining contraceptives. Research from other Latin American countries frequently fails to describe and/or investigate local financial and practical barriers to accessing SRH care, and the social and legal acceptability of providing adolescents with contraceptives without parental approval, making the interpretation of low contraceptive use difficult $(10,11,16-$ 18). Other intervention studies fall short of showing that obstacles to accessing confidential SRH care have been removed, leaving lack of effective access as an alternative explanation for low contraceptive use $(7,8)$.

Access is crucial for adoption and continued use of modern contraceptives, and it is known that adolescents, especially the youngest, and girls who have not started procreative life, face many obstacles to accessing SRH care in Latin America $(3,15,19,20)$. In our study population, younger girls and girls attending school had 
the lowest use of SRH care, and showed the strongest increase in use through voucher receipt, as shown in Fig. 3. Vouchers appear capable of removing many of the obstacles these girls face. Focusing on these groups is likely to increase the overall impact of a program on the use of contraceptives and condoms.

The increased contraceptive use found in this study is compatible with findings from studies in industrialized countries. Although sex education alone does not increase the use of contraceptives and/or prevent unintended pregnancies (21), several studies have documented an increased use of contraceptives when their provision was included in the program (22-25). This is supported by evidence from The Netherlands and other European countries where low-barrier family planning services for adolescents of all ages have been fundamental in decreasing unwanted teenage pregnancy and abortion $(20,26,27)$.

To conclude, this study emphasizes the diversity among adolescents and the need to classify adolescents correctly to be able to identify specific needs and measure program impact. The voucher program was capable of meeting the unmet needs of SRH care for many adolescent girls, and was especially successful in reaching out to younger girls, to girls attending school, and to those girls with lower levels of educational attainment. Their needs could be met with a relatively simple intervention, using existing health facilities, and despite a conservative political climate. The increased use of condoms and contraceptives in specific groups suggests many girls are motivated to protect themselves against the risks of sexual intercourse, once given access to reliable information and confidential health services. This finding underscores the crucial importance of accessible and affordable SRH care, not only for responding to the needs and rights of adolescents, but also for meeting public health objectives.

\section{Acknowledgements}

The authors thank all the adolescents who shared their views and experiences with us and therefore made this program and the evaluation possible. Without the hard and enthusiastic work of Zoyla Segura, Joel Medina, Patricia Gonzalez, Amelia Tijerino, Roger Torrentes, Alejandro Dormes, Gloria Medina, and Esteban Zuñiga, this intervention never could have become a success. The authors are very grateful to Erik van de Giessen and Julienne McKay for their continuing support during the preparation of this report. Last but not least, without financial support of DFID this interesting intervention would never have been possible. 


\section{References}

1. Instituto Nacional de Estadística y Censos y Ministerio de Salud. Demographic Health Survey Nicaragua2001(in Spanish), Managua, Nicaragua, Instituto Nacional de Estadística and Censos y Ministerio de Salud. Calverton, MD USA; Macro International/DHS Program. 2002.

2. Zelaya E, Marin FM, Garcia J, et al. Gender and social differences in adolescent sexuality and reproduction in Nicaragua. J Adolesc Health 1997;21:39-46.

3. Pons JE. Contraceptive services for adolescents in Latin America: facts, problems and perspectives. Eur J Contracept Reprod Health Care 1999;4:246 -54.

4. Berglund S, Liljestrand J, Marin FM, et al. The background of unwanted adolescent pregnancies in Nicaragua. A qualitative approach. Soc Sci Med 1997;44:1-12.

5. United Nations Population Fund. ¿Qué más podría hacer sino tener un hijo? Basis socioculturales del embarazo de las adolescentes en Nicaragua. (What Else Could I Do Than Getting a Child? Sociocultural Basis of Adolescent Pregnancy in Nicaragua.) Managua, Nicaragua: UNFPA, INIM, RLA/94/P15, 1999.

6. Braddock M, Hernández SJ, Muiruri Y. Un estudio transcultural de acceso de adolecentes a la educación y a servicios de salud reproductiva. (Transcultural Study of Access of Adolescents to Education and Reproductive Health Services). Mary Stopes International, In-forme final al Banco Mundial, 1995.

7. Magnani RJ, Gaffikin L, de Aquino EM, et al. Impact of an integrated adolescent reproductive health programme in Brazil. Stud Fam Plann 2001;32:230-43.

8. Belmonte LR, Gutierrez EZ, Magnani R, et al. Barriers to adolescents use of reproductive health services in three Bolivian cities. FOCUS on Young Adults/Pathfinder International. Available from: www. pathfind.org/focus.htm, 2000 (Accessed: December 6, 2000).

9. Diaz M, Simmons R, Diaz J, et al. Expanding contraceptive choice: findings from Brazil. Stud Fam Plann 1999;30:1-16.

10. Magnani R, Seiber E, Gutierrez EZ, et al. Correlates of early sexual activity and unprotected sex among urban secondary school students in Peru. Stud Fam Plann 2001;32:53- 66 .

11. Lipovsek V, Karim AM, Gutierrez EZ, et al. Correlates of adolescent pregnancy in La Paz, Bolivia: findings from a quantitative-qualitative study. Adolescence 2002;37:335-52.

12. Speizer IS, Magnani RJ, Colvin CE. The effectiveness of adolescent reproductive health interventions in developing countries: a review of the evidence. J Adolesc Health 2003;33:324-48.

13. Gorter A. Evidence of effectiveness of competitive voucher schemes on HIV prevention and care for young people. Background paper prepared for the WHO for the 'Global consultation on the health services response to the prevention and care of HIV/AIDS among young people' organized by WHO, UNICEF, UNFPA, UNAIDS, YouthNet. Geneva, Swiss: WHO, 2003.

14. Alcaldia de Managua. Managua a Shared Future (in Spanish) Plan General de Desarrollo Municipal, Alcaldia de Managua. Managua: Hermanamiento Amsterdam, 2000.

15. Senderowitz J. Making reproductive health services friendly for young people. FOCUS on Young Adults/Pathfinder International. Available from: http://www.pathfind.org/pf/pubs/focus/IN\%20FOCUS/ MakingYouthfriendly.html (Accessed September 5, 2000)

16. Pick de Weiss S, Atkin LC, et al. Sex, contraception, and pregnancy among adolescents 
in Mexico City. Stud Fam Plann 1991;22:74-82.

17. Martiniuk AL, O'Connor KS, King WD. A cluster randomized trial of a sex education programme in Belize, Central America. Int J Epidemiol 2003;32:131- 6 .

18. Gupta N, da Costa Leite I. Adolescent fertility behavior. Trends and determinants in Northeastern Brazil. Int Fam Plann Perspect 1999; 25:125-30.

19. Langer A. El embarazo no deseado: impacto sobre la salud y la sociedad en América Latina y el Caribe. (Unwanted pregnancy: impact on health and society in Latin America and the Caribbean). Rev Panam Salud Publica 2002;11:192-204.

20. Treffers PE. Tienerzwangerschapppen, een mondiaal probleem. (Teenage pregnancy, a worldwide problem). Ned Tijdschr Geneeskd 2003;147:2320 -5.

21. DiCenso A, Guyatt G, Willan A, et al. Interventions to reduce unintended pregnancies among adolescents: systematic review of randomised controlled trials. BMJ 2002;324:1426.

22. Kirby C, Waszak C, Ziegler J. Six school-based clinics: their reproductive health services and impact on sexual behavior. Fam Plann Perspect 1991;23:6 -16.

23. Tiezzi L, Lipshutz J, Wrobleski N, et al. Pregnancy prevention among urban adolescents younger than 15: results of the 'In Your Face' program. Fam Plann Perspect 1997;29:173-6, 197.

24. Lou CH, Wang B, Shen Y, Gao ES. Effects of a community-based sex education and reproductive health service program on contraceptive use of unmarried youths in Shanghai. J Adolesc Health 2004;34: 433- 40.

25. Frost JJ, Forrest JD. Understanding the impact of effective teenage pregnancy prevention programs. Fam Plann Perspect 1995;27:188- 95.

26. Ketting E, Visser AP. Contraception in The Netherlands: the low abortion rate explained. Patient Educ Couns 1994;3:161-71.

27. Furstenberg FF. When will teenage childbearing become a problem? The implications of western experience for developing countries. Stud Fam Plann 1998;29:246 -53. 


\section{Chapter 6}

Uncovering and responding to needs for sexual and reproductive health care among poor urban female adolescents in Nicaragua

Meuwissen LE, Gorter AC, Segura Z, Kester ADM, Knottnerus JA 


\begin{abstract}
Background

To meet the needs of female adolescents from low-income urban areas for sexual and reproductive health (SRH)-care, vouchers providing free-of-charge access to SRH-care at 19 primary care clinics were distributed in Managua, Nicaragua. These vouchers substantially increased use of services among voucher receivers, demonstrating that many adolescents are willing to use such services if readily accessible. The voucher redemption made it possible to identify the nature of existing, but largely unmet needs for SRH-care.
\end{abstract}

\title{
Method
}

The medical files from 3301 consultations with female adolescents were analysed using descriptive statistical methods and multiple logistic regression.

\section{Results}

Female adolescents presented SRH-problems that merited medical attention. The mean number of problems presented was 1.5 per consultation. One third of the vouchers were used for contraceptives (34\%), nearly one third $(31 \%)$ for complaints related to sexually transmitted infection (STI) or reproductive tract infection (RTI), $28 \%$ for counselling/advice, $28 \%$ for antenatal check-up, and $18 \%$ for pregnancy testing. A new category of health care users emerged: sexually active girls who were neither pregnant nor mothers, who sought contraceptives or STI/RTI treatment. Contraceptive use doubled among the sexually active nonpregnant voucher redeemers. Consultation with a female doctor younger than 36 years was associated with a higher chance of having contraceptives prescribed.

\section{Conclusion}

Accessible and appropriate SRH-care has the potential to make an important contribution to increased contraceptive use, decreased risk of unwanted teenage pregnancies and decreased prevalence of STIs/RTIs among underserved adolescents. Once adolescents access the services, providers have a crucial role in ensuring current and continuing needs are met. 


\subsection{Introduction}

Nicaragua has one of the highest adolescent fertility rates in Latin America, with 119 births annually per 1000 young women aged 15-19. High fertility rates are associated with low socio-economic status and low educational attainment(1). In addition, adolescents experience high rates of unwanted pregnancy, illegal abortions and maternal mortality, and are at high risk of contracting sexually transmitted infections (STIs), including HIV. While use of contraceptives and condoms could diminish these risks, only $7 \%$ of sexually active female adolescents uses a condom and $47 \%$ another modern method of contraception (1).

An important reason for the low use of contraceptives is that adolescents have limited access to contraceptives and counselling in Nicaragua (2-4). Although wide agreement exists that health care services should respond to these needs - as explicitly outlined in Ministry of Health guidelines (5) - there are numerous obstacles to accessing appropriate care. To address this situation, the Central American Health Institute (ICAS) piloted a competitive ${ }^{1}$ voucher program aimed at increasing both the accessibility and quality of sexual and reproductive health (SRH) care for poor adolescents (6-9). The pilot program was implemented in collaboration with the London School of Hygiene and Tropical Medicine, and financed by the British Department for International Development (DFID).

Conventional estimates of unmet needs for health care or contraceptives are based on interviews with women. However, a disadvantage of this approach is that the extent to which unmet needs could be met by increased access to appropriate health care services remains unknown. The intervention described here succeeded in mobilising adolescents from disadvantaged areas from Managua to attend health services. Evaluation showed that the use of SRH-care among female adolescents increased considerably (adjusted odds ratio 3.1, 95\% confidence interval $2.5-3.9$ ) (9). As such, the intervention provides unique data to answer the question: What are the health care problems for which female adolescents consult a doctor if he/she is available, accessible and affordable? The information collected allows this question to be explored, taking into account the different characteristics of the girls (demographic, socio-economic, knowledge and experience with contraceptives) and of the providers, as well as the factors associated with demand for contraceptives in sexually active teenagers. These results provide valuable input to the discussion of the public health relevance of interventions that aim to increase access and quality of SRH-care for underserved adolescents - a phenomenon common to many developing countries.

\footnotetext{
${ }^{1}$ The 'competitive' element is that the voucher is redeemable at multiple providers and that the user is free to make his/her choice $(28 ; 29)$.
} 


\subsection{Methods}

\subsubsection{Design and population}

The intervention took place in Managua, the capital of Nicaragua, one of the poorest countries of Latin America. Managua had an estimated population of about one million inhabitants in the year 2000, of whom $25 \%$ were aged between 10 and 20 years (10). Primary health care services in Managua consist of public health centres run by the Ministry of Health, municipal public health centres, private doctors, and clinics run by non-governmental organizations (NGOs).

From September 2000 to July 2001, vouchers were distributed to 16,850 female and 11,861 male adolescents from 12 to 20 years old in disadvantaged areas of Managua. The vouchers were distributed through ICAS, NGOs and participating clinics, at four markets, in clinics ${ }^{2}$, outside 19 public schools and in 221 disadvantaged neighbourhoods (door-to-door) to each adolescent present at the time of distribution. Most of the vouchers $(75 \%)$ were distributed by female adolescents contracted and trained by ICAS. The voucher distributors worked in small teams, accompanied by an ICAS staff member. At markets and in neighbourhoods, girls were approached individually. At schools, vouchers were distributed outside the compounds to groups of adolescents leaving the school to prevent compromising schools through direct association with a SRH care intervention (given that official regulations forbid sex education by health professionals in schools). The vouchers were given to any adolescents present at the time of distribution. The voucher receivers were a representative sample of the target group of the intervention (9).

Vouchers were not person-bound and were valid for three months. They entitled the holder to a free-of-charge consultation and a follow-up visit for advice/counselling, contraception, treatment of STIs or reproductive tract infections (RTIs), pregnancy testing and/or antenatal care in any of the four public, five private and ten NGO clinics, contracted by ICAS. Clinic selection was based on suitability (preferably with some experiences in sexual and reproductive health care) and proximity to areas where vouchers were distributed. Identified clinics were invited to participate, and prices per consultation were negotiated based on their customary fees. The average price negotiated per consultation and follow-up visit was U\$ 4.56. (The average normal consultation fee is US \$ 5.93)

The clinics received reimbursement for each adolescent consultation. Doctors at participating clinics were obliged to attend an introductory meeting describing the program and its procedures. An information manual with background information and guidelines was also provided. Furthermore, clinic staff were encouraged to attend a training course on SRH-care for adolescents. During each consultation,

\footnotetext{
${ }^{2}$ The clinics had a stock of vouchers for additional consultations for voucher users in need of follow-up; for partners of patients with STIs; and for friends of pregnant girls.
} 
doctors completed standardized clinical forms. Voucher redeemers received a booklet on adolescent health, two condoms with supportive information, and, if required, contraceptive methods, laboratory tests and syndromic treatment for STIs.

In total, $3301(20 \%)$ of the vouchers distributed to girls were redeemed. This is a relatively high redemption rate, considering the limited time period over which the vouchers were valid and that they were distributed without asking adolescents about their SRH-care needs. Earlier evaluation showed that among girls, who had had intercourse, $51 \%$ used their voucher, while among girls who had never had intercourse use was only $14 \%$. We also found that the increases in SRH-care use were much more pronounced among younger girls, girls still at school and girls with lowest level of education, when voucher receivers were compared to girls who had not received a voucher (9).

\subsubsection{Data collection and analysis}

The clinical forms, completed for each adolescent redeeming a voucher, were composed of a general section comprising: reason for consultation; age; educational level; daily activity; socio-economic background; former use of health care services; knowledge of family planning methods; preferred method; and gynaeco-obstetric history including former and present use of contraceptives, sexual activity and need for contraception. After the general section, only those parts corresponding with the reason for the consultation were completed. Collecting information in a medical setting has the important advantage that many intimate questions, e.g. age at first intercourse, are considered routine. However, this was not true for all questions. Doctors appeared reluctant to ask whether the girl intended to become pregnant during the next six months, a question introduced later in the program to better assess the need for contraception.

Once a week all clinics were visited, completed forms copied and the original forms were returned to the clinic. Two medical doctors from the project codified all copied information. Data were entered twice by different data-clerks using Epi-info 6.04d (CDC, Atlanta, GA, USA). Stata 7.0 software (Stata Corporation, College Station, TX, USA) was used for further analysis.

First, characteristics of the girls and their use of SRH-care in the last year were tabulated. All girls were asked about their former use of SRH-care because we wanted to assess which underserved groups of adolescents were reached through vouchers. A logistic regression model was constructed to analyse the influence of various independent variables on former health care use, corrected for the influence of other variables.

Previous research has suggested that adolescents have different needs depending on whether they had had intercourse and if they have experienced any negative consequences, such as unwanted pregnancies or STIs (11). As a result, we explored the reason for consultation with a voucher according to girls' sexual activity and 
category of childbearing. In addition, answers referring to knowledge of contraceptives, past and present contraceptive use, and method of preference were tabulated according to the girls' experience.

Table 1 Characteristics of the girls on their first visit with voucher and characteristics of the services visited

\begin{tabular}{|c|c|c|c|c|c|}
\hline \multirow[b]{2}{*}{ Variables } & \multirow[b]{2}{*}{ Categories } & \multicolumn{4}{|c|}{ Use of SRHC ${ }^{1}$ last year } \\
\hline & & All & $\%$ used & Adj OR $(95 \%$ CI $)$ & $\mathbf{L R T}^{3}$ \\
\hline & & N (\%) & $\%$ & $\mathrm{~N}=\mathbf{2 5 5 1}$ & $\mathbf{P}$ \\
\hline \multirow[t]{3}{*}{ Age group } & $11-15$ years & $501(16.5)$ & 12.4 & 1.0 & \\
\hline & $16-17$ years & $968(31.8)$ & 25.8 & $1.1(0.8-1.6)$ & \\
\hline & $18-20$ years & $1576(51.8)$ & 36.6 & $1.2(0.9-1.8)$ & \\
\hline Level of school attainment & $0-6$ years & $922(30.3)$ & 31.5 & 1.0 & \\
\hline \multirow[t]{2}{*}{$\mathrm{M}=1$} & $7-9$ years & $1310(43.0)$ & 29.7 & $1.0(0.8-1.3)$ & \\
\hline & $>10$ years & $812(26.7)$ & 25.6 & $0.8(0.6-1.0)$ & \\
\hline \multirow[t]{4}{*}{ Daily activity } & Studying & $1138(37.4)$ & 20.3 & 1.0 & \\
\hline & Working & $446(14.7)$ & 37.5 & $0.9 \quad(0.6-1.2)$ & \\
\hline & Working and studying & $186(6.1)$ & 34.2 & $1.4(0.9-2.1)$ & \\
\hline & At home & $1275(41.9)$ & 33.9 & $0.7(0.6-1.0)$ & 0.02 \\
\hline \multirow[t]{3}{*}{ Status of relationship } & Single & $1185(38.9)$ & 14.7 & 1.0 & \\
\hline & Engaged & $1425(46.8)$ & 37.6 & $1.7(1.4-2.2)$ & \\
\hline & Married & $435(14.3)$ & 40.5 & $1.9(1.4-2.7)$ & $<0.001$ \\
\hline \multirow[t]{5}{*}{ Category of Childbearing } & Not yet had intercourse & $431(14.2)$ & 1.4 & 1.0 & \\
\hline & $\begin{array}{l}\text { Sexually active (not } \\
\text { pregnant/mother) }\end{array}$ & $923(30.3)$ & 25.0 & $17.7(7.1-44.5)$ & \\
\hline & First time pregnant & $626(20.6)$ & 15.3 & $9.2(3.6-23.8)$ & \\
\hline & Mother and pregnant & $232(7.6)$ & 40.6 & $32.1(12.1-85.2)$ & \\
\hline & Mother not pregnant & $833(27.4)$ & 56.6 & $62.1(24.2-159.3)$ & $<0.001$ \\
\hline Refrigerator & Not present & $1759(58.0)$ & 30.3 & 1.0 & \\
\hline $\mathrm{M}=13$ & Present & $1273(42.0)$ & 27.5 & $1.0(0.8-1.2)$ & \\
\hline Nr of people/bedroom & $0-2$ & $1376(45.6)$ & 28.7 & 1.0 & \\
\hline \multirow[t]{2}{*}{$M=26$} & $>2-3$ & $958(31.7)$ & 30.2 & $1.0(0.8-1.2)$ & \\
\hline & $>3+$ & $685(22.7)$ & 28.4 & $1.0 \quad(0.8-1.3)$ & \\
\hline Total & & $3045(100)$ & 29.1 & & \\
\hline
\end{tabular}

LRT: Likelihood Ratio Test M: missing value

${ }^{1}$ Reported use of sexual and reproductive health care in the last 12 months. $\mathrm{N}=2551$, since there are 467 missing values for this outcome, and a further 10 for refrigerator and 17 for $\mathrm{nr}$. of people/bedroom.

${ }^{2}$ Results of logistic regression analysis with all tabled variables included and exclusion of girls older than 20 years

${ }^{3}$ Results of the LRT, only values with $\mathrm{p}<0.05$ are reported 
We then constructed a logistic regression model to identify factors that were associated with the use or planned use of contraceptives among sexually active non-pregnant adolescents at the end of the consultation. Because characteristics of the provider could play an important role in the communication on contraceptive needs, a multilevel analysis was performed, accounting for dependence of the results within providers by robust estimation of the model variance clustered on provider. The Wald test $(\mathrm{p}<0.05)$ was used to evaluate the strength of the association between the independent variables and the outcome. Only the variables significantly associated were retained in the model.

\subsection{Results}

In total, 3067 girls used 3301 vouchers, $(190$ girls $(6 \%)$ used more than one voucher for various episodes of 'illness'). Forty percent of the girls came back for a follow-up visit. Most vouchers were redeemed in NGO clinics $(2063,62.5 \%)$, against $733(22 \%)$ in private clinics and $505(15 \%)$ in public clinics. Most girls $(59 \%)$ were having a consultation with a young female doctor (aged less than 36 ). Twenty-two girls were more than 20 years old and were excluded from further analysis.

Records were generally well kept and most questions completed. Common medical questions had few missing values, while e.g. questions about former health care use or provider of contraceptives had not been answered on about $15 \%$ of forms.

\subsubsection{Who uses the services?}

In Table 1, an overview is given of the main characteristics of the girls who used their voucher. Nearly half of the girls who used the services were younger than 18 years. Only $21 \%$ of the girls were earning an income, $43.5 \%$ were studying and $42 \%$ stayed at home. Nearly all (86\%) were sexually active and $28 \%$ were pregnant. Thirty-five percent of the girls were already mothers $(78 \%$ with one child, $19 \%$ with two and $3 \%$ three or more, not shown in table 1). Seven girls had given birth to twins and 63 girls reported that a child had passed away (not shown in table 1).

The percentages using SRH-care in the year before the voucher visit are shown in column 2 of Table 1. Less than $30 \%$ of the girls reported use of SRH services in the last year. When all factors were considered simultaneously through logistic regression analysis, single girls and girls staying at home had made significantly less use of health services, whereas girls who were already mothers had made most frequent use. The profile of girls using the vouchers was different. The vouchers succeeded in attracting different types of users to the clinics: $45 \%$ were neither pregnant nor mothers and 39\% were single (Table 1). 


\subsubsection{What are the reasons for consulting a doctor?}

In total, 5069 reasons for consultation were registered, on average, 1.5 reasons per consultation. One third of the vouchers were used for contraceptives $(34 \%)$, nearly one third (31\%) for complaints related to an STI or RTI, $28 \%$ for counselling/advice, $28 \%$ for antenatal check-ups, and $18 \%$ for pregnancy testing. In $10 \%$ of the consultations vouchers were used exclusively for advice/counselling. In $50 \%$ of the consultations provided to sexually active girls who were neither pregnant nor mother, contraceptives were requested and 39\% of these girls presented with complaints of symptoms of either an STI or RTI. Many had additional requests for advice or counselling (Table 2).

Table 2 Reasons for using a voucher, for all medical consultations provided to girls and distributed over each childbearing category

\begin{tabular}{|c|c|c|c|c|c|c|}
\hline \multirow[b]{2}{*}{ Problems identified } & \multirow{2}{*}{$\begin{array}{l}\text { ALL } \\
\begin{array}{l}\mathrm{N}=3301 \\
(100 \%)\end{array}\end{array}$} & \multicolumn{5}{|c|}{ Reason for consultation in \% per childbearing category ${ }^{1}$} \\
\hline & & $\begin{array}{r}\text { Not started }^{2} \\
441(100 \%)\end{array}$ & $\begin{array}{r}\text { Started }^{2} \\
1001(100 \%)\end{array}$ & $\begin{array}{r}\text { First } \\
\text { pregnancy } \\
673(100 \%)\end{array}$ & $\begin{array}{r}\text { Pregnant \& } \\
\text { mother } \\
249(100 \%)\end{array}$ & $\begin{array}{r}\text { Mother not } \\
\text { pregnant } \\
937(100 \%)\end{array}$ \\
\hline Advice/counselling & $923(28.0)$ & 73.2 & 28.7 & 11.7 & 10.4 & 22.2 \\
\hline Contraceptives & $1137(34.4)$ & 4.3 & 50.3 & 0.4 & 0.8 & 65.0 \\
\hline Pregnancy test & $581(17.6)$ & 0.0 & 25.4 & 22.9 & 24.9 & 11.8 \\
\hline Antenatal care & $922(27.9)$ & 0.0 & 0.0 & 100 & 100 & 0.0 \\
\hline STI/RTI & $1023(31.0)$ & 10.2 & 38.9 & 20.1 & 29.3 & 40.7 \\
\hline $\begin{array}{l}\text { Other reproductive } \\
\text { health issues }\end{array}$ & 347 (10.5) & 22.7 & 11.5 & 3.6 & 1.6 & 11.1 \\
\hline $\begin{array}{l}\text { Other health issues } \\
\text { (gastritis, dermatitis } \\
\text { etc) }\end{array}$ & $136(4.1)$ & 14.7 & 3.6 & 0.4 & 0.8 & 3.2 \\
\hline $\begin{array}{l}\text { Total reasons for } \\
\text { consultations }\end{array}$ & 5069 & 552 & 1585 & 1071 & 418 & 1443 \\
\hline $\begin{array}{l}\text { Mean number of } \\
\text { reasons per } \\
\text { consultation }\end{array}$ & 1.5 & 1.3 & 1.6 & 1.6 & 1.7 & 1.5 \\
\hline
\end{tabular}

STI/RTI: Sexually Transmitted Infections, Reproductive Tract Infection

${ }^{1}$ The percentages are calculated per childbearing category and girls could come for more than one reason

${ }^{2}$ Not started $=$ not yet had intercourse, started $=$ sexually active neither pregnant nor mother

Of the 1137 consultations for contraceptives only $39 \%$ were used exclusively for this reason; in $27 \%$ also advice/counselling was provided; $13 \%$ a pregnancy test (of which some were positive); $28 \%$ STI/RTI treatment; and $8 \%$ advice on other complaints (not shown). 
Some girls discussed problems related to sexual abuse with the doctor, and others referred to previous abuse when asked for the age at first intercourse. Forty-two (2\%) girls had had intercourse before their first menstruation, some as young as 8 years, and $146(6 \%)$ in the year of their first menstruation.

\subsubsection{What is their knowledge of, experience with and demand for contra- ceptives?}

In Table 3 details are tabulated on voucher users' knowledge of, experience with and demand for contraceptive methods according to category of childbearing experience. Some interesting findings surface:

- Nearly half of the sexually active girls who were neither pregnant nor mothers had never used contraceptives. Of the girls who were pregnant for the first time only $32 \%$ reported having ever used contraceptives.

- The current use of contraceptives among sexually active girls who were neither pregnant nor mothers was only $24 \%$. This percentage was strongly influenced by their civil state. The lowest use was seen among the singles $(20 \%)$ and the highest among the married (34\%). Among the girls who were already mothers, the use of contraceptives was higher (47\%) and their civil state had no influence on their use (data not shown).

- The health services were the most common supplier of contraceptives among girls who were already mothers $(75.5 \%)$, while the pharmacy was more common among sexually active girls not yet mothers $(63 \%)$.

- $\quad$ Fifty seven percent of the sexually active girls who were neither pregnant nor mothers and $82 \%$ of the non-pregnant mothers were using or requested a modern contraceptive method. Of those already using a modern method, $8 \%$ and $17 \%$ consulted for another reason, respectively.

- Twenty-three percent of the mothers who requested modern contraceptives never had used them before.

- $\quad$ Four percent of the girls who had not yet started sexual activity visited the doctor to request contraceptives to be protected at their sexual debut.

- An overall result was that the intended use of contraceptives doubled among the sexually active non-pregnant voucher redeemers (from $24 \%$ to $57 \%$ among the girls not yet mothers and from $47 \%$ to $82 \%$ among the mothers, table 3). Sixty-nine percent of the sexually active girls left with a contraceptive method. 
Table 3 Knowledge, past and present use of contraceptives, for all girls and for each childbearing category

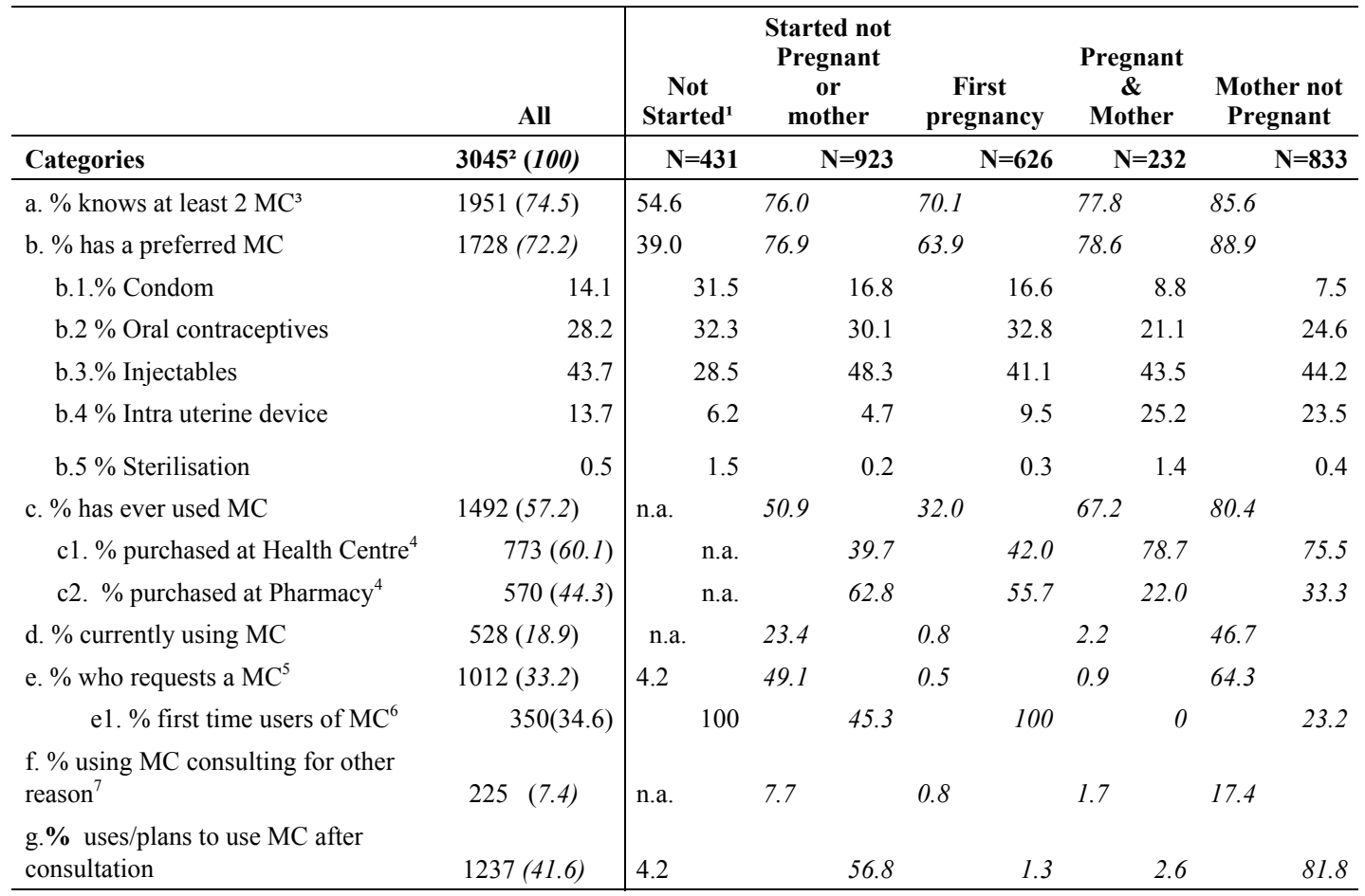

Missing values (mv) were for a. $m v=427$; b. $m v=652$; c. $m v=5$; d. $m v=251$; c1. mv=206; c2. m=206, e. $\mathrm{mv}=0 ; \mathrm{f} . \mathrm{mv}=0, \mathrm{~g} . \mathrm{mv}=2$

MC: modern contraceptives (hormonal contraceptives, oral or injectables, intra-uterine device, condoms, male or female sterilisation $)^{3}$

${ }^{1}$ Not started $=$ not started having sexual relations.

${ }^{2}$ Based on the 3045 first visits of girls younger than 21 years.

${ }^{3}$ Only modern contraceptives (MC) are accounted for. Natural methods require discipline and teamwork within the couple and have a much higher failure rate. If one seriously wants to help adolescent's girls to avert unwanted pregnancies, modern contraceptive methods are the only methods that should be recommended by the health services for girls in this phase of life (12-14).

${ }^{4}$ Denominator is the number of girls ( $\mathrm{N}$ for entire group is 1492) with experience in using modern methods (girls under c).

${ }^{5}$ Includes current and new users requesting MC. It also includes 5 girls who requested contraceptives but had a positive pregnancy test

${ }^{6}$ The denominator is the number of girls using or wanting to use a MC (girls under e).

74 of these girls were using permanent methods like IUD or sterilisation. Nine girls reported using modern contraceptives but were nevertheless pregnant

Due to the late introduction of the question and the many missing values, only 510 sexually active non-pregnant girls were asked if they intended to become pregnant in the next 12 months. Of these girls, $468(92 \%)$ answered no, but, in fact, 77 $(16.5 \%)$ were already pregnant.

The type of contraceptive method (oral, injectables, IUD, condoms) prescribed was 
in half the cases similar to the method indicated by the girls as their preferred type of method. The contraceptive methods most frequently prescribed were monthly injectables (mesigyna $\left.{ }^{\circledR}{ }^{3}\right)(39 \%)$ and oral contraceptives $(38.5 \%)$. Condoms were used by $8 \%$. Of the 528 girls who reported using contraceptives prior to redeeming their voucher, $141(27 \%)$ used the consultation to change the type of method (not taking into account changes in kind of hormonal methods).

Five-and-half percent of the girls who requested contraceptives left the clinic with no contraceptive method. This percentage ranged from $0 \%$ to $11 \%$ across the different doctors, with younger female doctors ( $<36$ years) and older male doctors ( $>35$ years) having lowest percentages (not shown). Some of the girls were instructed to come back on the first day of their menstruation. In other cases no remarks were written down which could explain the reason.

\subsubsection{Who wants contraceptives?}

Sixty-two percent of the sexually active non-pregnant girls were presently using or requested contraceptives (Table 4). This percentage ranged from $43 \%$ to $96 \%$ according to which of the doctors was consulted (not shown). A multi-level logistic regression model was constructed to analyse which factors were associated with the actual or planned contraceptive use. Studying and having children were associated with a significantly higher use, and knowing two methods was associated with a nearly significant higher use. Girls assisted by young female doctors more frequently had contraceptives prescribed than those who were attended by female doctors older than 35 years or by male doctors younger than 35 years of age. Girls' age group, status of relationship and having a preferred method were only significantly associated with the outcome in bivariate analysis (Table 4).

\footnotetext{
${ }^{3}$ Mesigyna is a monthly injectable hormonal contraceptive available in Latin America. This type of method has several advantages for adolescents: it does not require continuous application; its coitus-independent; it is highly effective and reversible; and it does not require the user to keep supplies, and therefore its use can be concealed (30)
} 
Table 4 Girl and provider related factors related to the use or planned use of contraceptives among sexually active girls who are not pregnant

\begin{tabular}{|c|c|c|c|c|}
\hline $\begin{array}{l}\text { Variables } \\
\text { All } \\
\end{array}$ & Category & $\begin{array}{l}N^{1} \\
1456 \\
\end{array}$ & $\begin{array}{c}\text { \% uses } \mathrm{MC}^{2} \\
906(62.2) \\
\end{array}$ & $\begin{array}{l}\text { Adjusted Odds Ratio } \\
\text { AOR (95\% CI) }\end{array}$ \\
\hline \multirow[t]{2}{*}{ Knows 2 MC methods } & No & 281 & 52.0 & 1.00 \\
\hline & Yes & 1175 & 64.7 & $1.40(0.97-2.01)$ \\
\hline \multirow[t]{4}{*}{ Daily activity } & Studying & 507 & 60.2 & 1.00 \\
\hline & Working & 237 & 60.3 & $0.65(0.49-0.86)$ \\
\hline & Working and studying & 109 & 55.0 & $0.85(0.55-1.32)$ \\
\hline & At home & 603 & 66.0 & $0.80(0.57-1.14)$ \\
\hline \multirow[t]{3}{*}{ Nr of children } & 0 & 778 & 51.0 & 1.00 \\
\hline & 1 & 526 & 73.8 & $2.94(2.18-3.95)$ \\
\hline & 2 or more & 152 & 79.6 & $4.24(2.83-6.38)$ \\
\hline \multirow[t]{4}{*}{ Gender/age of the doctor } & + doctors $\leq 35 \mathrm{Y}$ & 821 & 67.4 & 1.00 \\
\hline & $q$ doctors $>35 \mathrm{Y}$ & 271 & 52.0 & $0.51(0.30-0.88)$ \\
\hline & $\delta$ doctors $\leq 35 \mathrm{Y}$ & 73 & 56.2 & $0.62(0.44-0.89)$ \\
\hline & $\delta$ doctors $>35 \mathrm{Y}$ & 291 & 58.8 & $0.73(0.42-1.28)$ \\
\hline
\end{tabular}

MC: modern contraceptives (hormonal contraceptives, oral or injectables, intra-uterine devise, condoms, sterilisation)

${ }^{1} \mathrm{~N}=1456$ : missing values (MV) = 300: For 'Knows two modern methods" $\mathrm{MV}=258$; for 'Nr of children' $\mathrm{MV}=14$; for 'Gender/age doctor' $\mathrm{MV}=28$ (because some girls were seen by a nurse or a counsellor and not a doctor and therefore excluded from the analysis). There were significantly more missing values on "knowing two methods" among girls who did not use or request modern contraceptives. However, the direction of the associations was similar among these records.

$2 \%$ uses MC is percentage of sexually active girls who are not pregnant and who were already using modern contraceptives together with the girls who requested modern contraceptives during their consultation

3 Results of reduced logistic regression analysis with clustering per doctor. Only factors significantly associated with the outcome are included in the model. Other factors tested for, but which were not significantly associated with the outcome were: educational attainments; age group; status of relationship; the socio-economic indicators: number of people per bedroom and presence of a refrigerator; type of clinic (public, private, NGO); having a preferred method; When the 225 girls who reported using contraceptives but did not use their voucher for that reason, were excluded from the analysis, the association of daily activity, $\mathrm{Nr}$ of children, and of the age-gender group of the doctor with the use of contraceptives remained the same (not shown).

\subsection{Discussion}

Female adolescents presented SRH problems that merited medical attention. The mean number of problems presented was 1.5 per consultation. One third of the vouchers were used to obtain contraceptives and nearly one-third for STI/RTI treatment. A new category of health care users emerged: girls who were sexually active and not yet mothers or pregnant, who consulted for contraceptives or STI/RTIs. Consultation with a female doctor younger than 36 years was associated with a higher chance of having contraceptives prescribed. 


\subsubsection{Which girls were served?}

The most pertinent methodological question is: who are the girls using the vouchers and can similar results be achieved in other populations? By using different voucher distribution strategies in low-income areas of Managua, a serious effort was made to reach major subgroups of poor adolescents. Earlier evaluation of the program showed that representative samples were reached from the population that was targeted by the various distribution strategies (9). A previous finding that girls who were neither pregnant nor mothers profited most from the increased access to care provided by the program (9) is confirmed by the present study. These girls have also been identified as the group facing the greatest obstacles to SRH-care in other Latin American countries (15-17). It is likely that the needs for SRH-care, as identified in this study, are similar to those in other Latin American countries.

\subsubsection{Relevance}

Before the start of the program sceptical observers expressed concerns that the health care services would be deluged by unnecessary demands. However, reviewing the reasons for attending shows the contrary. The group that used the voucher presented problems that merited medical attention. While girls who have not yet started sexual intercourse may seem the least important group to mobilise to the health services, health care services could well be the only place where Nicaraguan adolescents can obtain reliable information on SRH-issues. In addition, access to contraceptive advice and methods for this group of adolescents is crucial to break the pattern of mostly unprotected sexual debut $(2 ; 4 ; 18)$.

Based on data from the evaluation study where SRH-care use by voucher receivers was compared with use by girls who had not received a voucher, we can estimate the frequency of consultation in the absence of the voucher program. Of the girls who had not yet had intercourse only one third would have attended and of the girls who were sexually active but neither pregnant nor mothers only half. However, of the girls who were pregnant or mothers three-quarters would have sought SRHcare. Previous research suggests that the confidential and free-of-charge access offered by the voucher program played a central role in mobilising the first two groups of girls to SRH-care (8).

Strategies to increase contraceptive prevalence among adolescents often focus on reaching out to new users. However, responding to dissatisfaction with the current contraceptive method might be a strategy of equal importance. More than half (57\%) of girls had experience with using contraceptives while only $19 \%$ were current users. This is a strong illustration of the high discontinuity in contraceptive use among adolescents $(12 ; 19)$. Furthermore, at least one quarter of current users appeared dissatisfied with the current method and wanted to change. These findings reinforce the need for interventions focussing on achieving continuity in contraceptive use in parallel to the interventions to reach out to new users. 
One third of the girls came for STI/RTI treatment. Correct treatment is important, not only because of the direct consequences of inappropriate or no treatment, such as infertility, but also because STIs enhance the transmission of HIV by increasing the infectiousness of HIV-positive individuals and/or the susceptibility of HIVnegative persons (20-22). Adolescents are a widely recognised group at risk of HIV infection and syndromic treatment of STIs and condom promotion through health facilities have proven to be effective strategies to diminish risks among adolescents (23). The main problem policy makers face is how to reach these groups. The high percentage of female voucher receivers that consulted for STIs/RTIs suggests that vouchers for reproductive health were very effective in mobilising adolescents for STI treatment for themselves and their partners. A similar success was reached among male voucher receivers (24).

One third of the girls came for antenatal control. Adolescent pregnancy in Nicaragua is widespread and is associated with elevated maternal morbidity and mortality $(25 ; 26)$. Adolescents often obtain antenatal control only very late in their pregnancy and $15 \%$ receive no antenatal control at all (1). Early detection of pregnancies at risk is an important strategy for reducing these risks.

\subsubsection{Adequate care}

The results of this study reinforce that doctors need many skills to adequately address the SRH-care needs of adolescents. In Nicaragua, dealing with adolescents involves a group who are generally very poorly informed about their own bodies and about issues related to sexual health and prevention of pregnancy. It also involves dealing with wanted as well as unwanted pregnancies; with wanted and unwanted sexual intercourse; with safe and unsafe sexual practices; and with substantial social pressure in a society with marked gender imbalances, particularly surrounding sexuality and contraceptive use.

If unmet needs for contraception among sexually active teenagers are to be addressed, access to 'adolescent friendly' SRH-care seems crucial. Isolation of family planning from SRH-care - by over-the-counter selling of contraceptives or community distribution of contraceptives - does not seem appropriate in view of the high prevalence of STIs/RTIs, the need for information and the seriousness of the other problems in this age group.

Furthermore, the results of this study do not support the idea that it would be appropriate to differentiate levels of care according to criteria such as 'having/not having had intercourse' and 'having/not having experienced problems' (11). These selection criteria seem impractical because of their intimate and delicate character, and are questionable because of the seriousness of the problems faced by adolescents. Our experiences rather underscore the importance of establishing easy, quick and free-of-charge referral links to higher levels of psychological or medical care, to support the primary health care providers. 
Dealing with adolescents is not the same as dealing with adults, and requires a high level of sensitivity. The indicator 'percentage sexually active, not pregnant adolescents who request contraceptives' can provide a quick estimation of doctors' alertness in using a consultation to support adolescents in protecting themselves from unwanted/untimely pregnancy. The results revealed considerable differences between providers with the outcome 'use or planned use of contraceptives' varying between $43 \%$ and $96 \%$. The crucial role of the provider is further demonstrated by differences in the percentages of adolescents who leave the doctor with a method after requesting a contraceptive. The result that younger female doctors were most supportive in these aspects confirms the findings of previous studies (27). The most likely explanation for this phenomenon is that it is easier for a young female doctor to ask for the risks a young woman carries, and easier for a young women to admit the risks and to ask for contraceptives when communicating with a young female doctor.

In conclusion, the results of this study give an important input into the debate about the relevance of free-of-charge, easy and confidential access to primary health care to meet the needs for SRH-care among poor adolescents. The groups most left out by current practices are younger adolescents, those who are single and those who are not yet mothers. These girls are at high risk of serious health threats such as STIs and HIV, and unwanted or untimely teenage pregnancies that could to a large extent - be prevented, and for which they appear willing to seek medical care. Policies that promote and enable the accessibility and availability of appropriate health service have the potential to make an important contribution to reduce these sexual and reproductive health risks among underserved adolescents.

\section{References}

1. INEC Instituto National de Estadística Censos, Ministerio de Salud. Demographic Health Survey Nicaragua 2001 [in spanish]. Managua, Nicaragua: Instituto nacional de Estadística and Censos y Ministerio de Salud, Calverton, MD USA; Marco International/DHS+ Program; 2001.

2. Berglund S, Liljestrand J, Marin FM, Salgado N, Zelaya E. The background of adolescent pregnancies in Nicargua: A qualitative approach. Soc Sci Med 1997;44(1):1-12.

3. Braddock M, Hernández SJ, Muiruri Y. A cross cultural study of access of adolescents to education and reproductive health care services (in spanish). Mary Stopes International; 1995.

4. Zelaya E, Pena R, Garcia J, Berglund S, Persson LA, Liljestrand J. Contraceptive patterns among women and men in Leon, Nicaragua. Contraception 1996 Dec;54(6):35965.

5. Direccion General de Servicios de Salud, Direccion de atencion integral, Programma de adolescentes. Technical and Administrative norms, First level of Attention. (in Spanish). Managua, Nicaragua; 1999.

6. Meuwissen LE, Gorter AC, Kester ADM, Knottnerus JA. Can a comprehensive voucher 
program prompt changes in doctors' knowledge, attitudes, and practices related to sexual and reproductive health care for adolescents? A case study from Nicaragua. Tropical Medicine and International Health 2006;11(6):889-98.

7. Meuwissen LE, Gorter AC, Kester ADM, Knottnerus JA. Does a competitive voucher program for adolescents improve the quality of reproductive health care? A simulated patient study in Nicaragua. BMC Public Health 2006; [in press].

8. Meuwissen LE, Gorter AC, Knottnerus JA. Perceived quality of reproductive care for girls in a competitive voucher programme. A quasi-experimental intervention study, Managua, Nicaragua. Int J Qual Health Care 2006 Feb;18(1):35-42.

9. Meuwissen LE, Gorter AC, Knottnerus AJ. Impact of accessible sexual and reproductive health care on poor and underserved adolescents in Managua, Nicaragua: a quasiexperimental intervention study. J Adolesc Health 2006 Jan;38(1):56.

10. Alcaldia de Managua. Managua a shared future (in Spanish) Plan General de Desarrollo Municipal. Alcaldia de Managua, Hermanamiento Amsterdam-Managua.; 2000.

11. Hughes J, McCauley AP. Improving the fit: adolescents' needs and future programs for sexual and reproductive health in developing countries. Stud Fam Plann 1998 Jun;29(2):233-45.

12. Ali MM, Cleland J. Sexual and reproductive behaviour among single women aged 1524 in eight Latin American countries: a comparative analysis. Soc Sci Med 2005 Mar;60(6):1175-85.

13. Che Y, Cleland JG, Ali MM. Periodic abstinence in developing countries: an assessment of failure rates and consequences. Contraception 2004 Jan;69(1):15-21.

14. Ranjit N, Bankole A, Darroch JE, Singh S. Contraceptive failure in the first two years of use: differences across socioeconomic subgroups. Fam Plann Perspect 2001 Jan;33(1):19-27.

15. Langer A. Unwanted pregnancy: impact on health and society in Latin America and the Caribbean [in spanish]. Rev Panam Salud Publica 2002 Mar;11(3):192-204.

16. Pons JE. Contraceptive services for adolescents in Latin America: facts, problems and perspectives. Eur J Contracept Reprod Health Care 1999 Dec;4(4):246-54.

17. Senderowitz J. Health Facility Programs on Reproductive Health for Young Adults. http://www futuresgroup com/abstract cfm/43 Accessed 6 June 20011997 [cited 2001 Jun $6] ; 1-51$.

18. Rani M, Figueroa ME, Ainsle R. The psychosocial context of young adult sexual behavior in Nicaragua: looking through the gender lens. Int Fam Plan Perspect 2003 Dec;29(4):174-81.

19. Blanc AK, Way AA. Sexual behavior and contraceptive knowledge and use among adolescents in developing countries. Stud Fam Plann 1998 Jun;29(2):106-16.

20. Baeten JM, Overbaugh J. Measuring the infectiousness of persons with HIV-1: opportunities for preventing sexual HIV-1 transmission. Curr HIV Res 2003 Jan;1(1):6986.

21. Sexton J, Garnett G, Rottingen JA. Metaanalysis and metaregression in interpreting study variability in the impact of sexually transmitted diseases on susceptibility to HIV infection. Sex Transm Dis 2005 Jun;32(6):351-7.

22. Buchacz K, Patel P, Taylor M, Kerndt PR, Byers RH, Holmberg SD, et al. Syphilis increases HIV viral load and decreases CD4 cell counts in HIV-infected patients with new syphilis infections. AIDS 2004 Oct 21;18(15):2075-9.

23. UNAIDS Inter-Agency Task Team on Young People. Steady.... Ready.....Go. World Health Organisation, Department of Child and Adolescent Health and Development; 2004. 
24. Gorter AC. Final project report: A voucher scheme for adolescents in Nicaragua to improve the uptake of reproductive health services Adolescent Project. London, United Kingdom: London School of Hygiene and Tropical Medicine/Department for International Development-UK; 2002.

25. Conde-Agudelo A, Belizan JM, Lammers C. Maternal-perinatal morbidity and mortality associated with adolescent pregnancy in Latin America: Cross-sectional study. Am J Obstet Gynecol 2005 Feb;192(2):342-9.

26. Mayor S. Pregnancy and childbirth are leading causes of death in teenage girls in developing countries. BMJ 2004 May 15;328(7449):1152.

27. Hippisley-Cox J, Allen J, Pringle M, Ebdon D, McPhearson M, Churchill D, et al. Association between teenage pregnancy rates and the age and sex of general practitioners: cross sectional survey in Trent 1994-7. BMJ 2000 Mar 25;320(7238):842-5.

28. Gorter A, Sandiford P, Rojas Z, Salvetto M. Competitive Voucher Schemes for Health, Background Paper. Part of the Toolkit on Competitive voucher schemes in health. Washington, DC, USA; 2003.

29. Sandiford P, Gorter A, Rosas Z, Salvetto M. A guide to Competitive vouchers in health. Washington, DC, USA: The international Bank for Reconstruction and Development/The World Bank; 2004.

30. Singh S. Adolescent knowledge and use of injectable contraceptives in developing countries. J Adolesc Health 1995 May;16(5):396-404. 


\section{Chapter 7}

Perceived quality of reproductive care for girls in a competitive voucher program, A quasi-experimental intervention study, Managua, Nicaragua

Liesbeth E. Meuwissen, Anna C. Gorter, and J. A. Knottnerus.

Published in International Journal for Quality in Health Care 2006; Volume 18, Number 1: pp. 35-42 @ The Author 2006. Published by Oxford University Press on behalf of International Society for Quality in Health Care; all rights reserved

Traduccion en espanol: http://www.icas.net/newicasweb/docs/Traduccion\%20Perceived\%20Quality.pdf 


\section{Abstract}

\section{Objective}

To determine whether female adolescents from low-income areas in Managua were satisfied with the sexual and reproductive healthcare provided through a competitive voucher programme and to analyse the determinants of their satisfaction.

\section{Design}

A community based quasi-experimental intervention study from 2000 to 2002 .

\section{Setting}

Low-income areas of Managua.

\section{Intervention}

Distribution of 28,711 vouchers giving adolescents free-access to sexual and reproductive healthcare in 19 clinics; training and support for health care providers.

\section{Study Participants}

A random sample of 3009 girls from 12 to 20 years completed self-administered questionnaires: 700 respondents had used this care in the last 15 months, 221 with voucher (users-with-voucher) and 479 without voucher (users-without-voucher).

\section{Main Outcome Measures}

User satisfaction; Satisfaction with clinic reception; Clarity of doctors' explanations.

\section{Results}

User satisfaction was significantly higher in users-with-voucher compared with users-without-voucher (Adjusted OR 2.2; 95\% CI: 1.2-4.0). Voucher use was associated with more frequent satisfaction with clinic reception, especially among sexually active girls not yet pregnant or mother (Adjusted OR 6.9; 95\% CI: 1.5 31.8). The clarity of doctors' explanations was not perceived differently (Adjusted OR 1.4; 95\%CI: 0.9-2.2).

User satisfaction was highly correlated to satisfaction with clinic reception and clarity of doctors' explanations $(\mathrm{p}<0.001)$. Longer consultation times, shorter waiting times, older age, and having a female doctor positively influenced user satisfaction.

\section{Conclusion}

Voucher use by teenage girls was associated with a better-perceived sexual and reproductive health care. This is an important result, given the crucial role user satisfaction plays in adoption and continued use of healthcare and contraceptives. Though more research is needed, confidential and guaranteed access appear key factors to voucher success. 


\subsection{Introduction}

Nicaragua has the highest adolescent fertility rates of Latin America, with 119 births annually per 1000 women aged 15 to 19 years. High fertility rates are associated with low economic status and low educational attainment (1). In addition, adolescents experience high rates of unwanted pregnancy, illegal abortions, high maternal mortality rates, and carry high risk of contracting sexually transmitted infections, including $\operatorname{HIV}(2,3)$. These risks are largely due to low use of contraceptive methods among sexually active adolescents: $7 \%$ use a condom and $47 \%$ another modern method (1).

Other Latin American countries face similar problems. Obstacles to accessing contraceptive services are believed to originate from different levels: adolescents and their sexual partners, health and education systems and socio-cultural factors $(3,4,5,6)$. Health system obstacles are caused by lack of access to information about sexual and reproductive health (SRH) and to SRH care and by low quality of care. Quality is a problem because most services are not designed for adolescents, many providers lack knowledge and skills, and, when introduced, SRHprogrammes for adolescents often meet with resistance from providers as they challenge cultural ideas about sexuality, parenting and gender $(5,6,7,8,9,10)$.

In Nicaragua, an innovative approach was piloted, intended to increase accessibility and quality of SRH care to poor and underserved adolescents through a competitive voucher programme. Evaluation of the impact of the intervention among female adolescents showed that voucher receipt increased use of SRH care among all groups (Adjusted OR 3.1,95\%CI: 2.5-3.9) and of contraceptives and condoms in specific groups (11). Since quality affects the decision to use contraceptives, to continue using services $(12,13,14,15)$ and to recommend the services to others, various methods were used to evaluate the impact on quality.

Poor and underserved adolescents rarely use SRH care and very little is known of their perception of these services. This intervention provided the opportunity for this group to experience SRH care services and to obtain their opinions. A better understanding of their perspectives can contribute to improve the effectiveness of public health interventions aimed at increasing use and acceptability of SRH care and contraceptives by adolescents.

This paper reports on the quality of SRH care as perceived by female adolescents from low-income areas of Managua, using self-administered questionnaires. It addresses two questions: Were girls who consulted SRH care with vouchers more satisfied with the different aspects of quality of care than girls who consulted without a voucher? What were the key determinants of adolescents' satisfaction with SRH care? 


\subsection{Methods}

\subsubsection{The intervention}

The intervention took place in Managua, the capital of Nicaragua, one of the poorest countries of Latin America. Primary health services in Managua consist of public health centres run by the Ministry of Health, municipal public health centres, private clinics, and clinics run by non-governmental organisations.

Over 2000 and 2001, 28,711 vouchers were distributed at four markets, outside 19 public schools and in 221 poor neighbourhoods to adolescents aged between 12 and $20,16,850$ to girls and 11,861 to boys. The vouchers gave free-of-charge access to SRH care in any of the four public, five private and 10 clinics from nongovernmental organizations, contracted by the Central American Health Institute. Clinic selection was based on suitability and proximity to areas where vouchers were distributed. Identified clinics were invited to participate, and the price per consultation negotiated based on their customary fees. The clinics received reimbursement for each adolescent attended. The vouchers were valid for three months and were distributed in rounds. Every new distribution round new clinics could join and non-functioning clinics could be removed. The programme started with four clinics and new clinics were added periodically.

In total $3301(20 \%)$ vouchers were redeemed by girls: $34 \%$ for contraceptives, $30 \%$ for sexually transmitted infections, $28 \%$ for counselling, $27 \%$ for antenatal care, $17 \%$ for pregnancy testing, and/or 15\% gave other reasons (adolescents could attend for more than one reason). Voucher redeemers received a booklet on adolescent health, two condoms with supportive information, as well as access to laboratory tests, treatment specific to diagnosis, and contraceptives, as required.

The voucher programme addressed various aspects of quality of care. Doctors completed standardized clinical forms based on 'best practice' protocols that guided them during each consultation and ensured that all adolescents were asked about their sexual activity and their need for information and supply of contraceptives. Contraceptives (condoms, ovrette $\AA$, microgynon ${ }^{\circledR}$, mesigyna ${ }^{\circledR}$ and copper-T) were made available and ensured method choice. Doctors at participating clinics were obliged to attend an introductory meeting to learn about the program and its procedures. An information manual with background information and guidelines was also provided. All doctors were encouraged to attend a training course of three mornings on adolescent friendliness (9), counselling, adolescence and sexuality, contraceptives, and sexual abuse. The course was organised by the department of sexual and reproductive health of the University of Nicaragua. Seventy percent of the doctors participated in at least one training sessions. Also the receptionists received training on adolescent friendliness. Furthermore, it was assumed that the competitive nature of the voucher programme would prompt providers to improve the quality of services to 
attract more voucher bearers (16). Quality was monitored by review of medical forms, focus group discussions, and interviews with doctors and simulated patients before, during, and after the programme.

\subsubsection{Evaluation}

\section{Design and population}

The impact of this community based quasi-experimental intervention on the perceived quality of care was assessed by comparing experiences with SRH care between adolescent girls who consulted a doctor with and without a voucher. Selfadministered questionnaires were distributed randomly among female adolescents 3 to 15 months after the vouchers had been distributed in their area. The evaluation was limited to girls. To measure the impact of the intervention on male adolescents a much larger sample size would have been needed because only $6 \%$ of the male receivers used their voucher.

The sampling frame consisted of a selection of 21 of the 244 sites. Those sites were selected where the largest numbers of vouchers had been distributed, to increase the chance of encountering voucher receivers and voucher users. At each site, convenience samples of adolescent girls were asked to complete a questionnaire. Each girl present at the site during the visit of the survey staff (composed of female adolescents) and with the appropriate age was asked to participate. The survey was presented as a study seeking adolescents' opinions on health services, and was not linked to the voucher programme. The objective was to obtain a random sample of girls who all had had the same chance of receiving a voucher and who would feel free to share information on their SRH care use and their perspectives on the quality of care. Within this sample a sub-sample of "users" was analysed: "userswith-voucher" were compared with "users-without-voucher" to evaluate whether vouchers made a difference to perceptions of service quality (Figure 1). The study was approved by the ethical review committees of the London School of Hygiene and Tropical Medicine and the Central American Health Institute.

\section{Measurements}

A self-administered questionnaire was chosen to maximise 'honesty' in responses given taboos about sexuality. The selection of the variables was based on literature and information derived from focus group discussions with adolescents. The wording of the questions was developed in conjunction with adolescents from participating organisations and was extensively piloted.

SRH care use was ascertained through the questions: "Have you consulted a doctor for: information or advice, contraceptive methods, pregnancy test, control of pregnancy, a venereal disease, problems with menstruation or other reasons?" and "How many months ago did you have this medical consultation?" Only girls who reported health care use completed questions on quality, waiting and consultation time, gender of the doctor and type of clinic. 

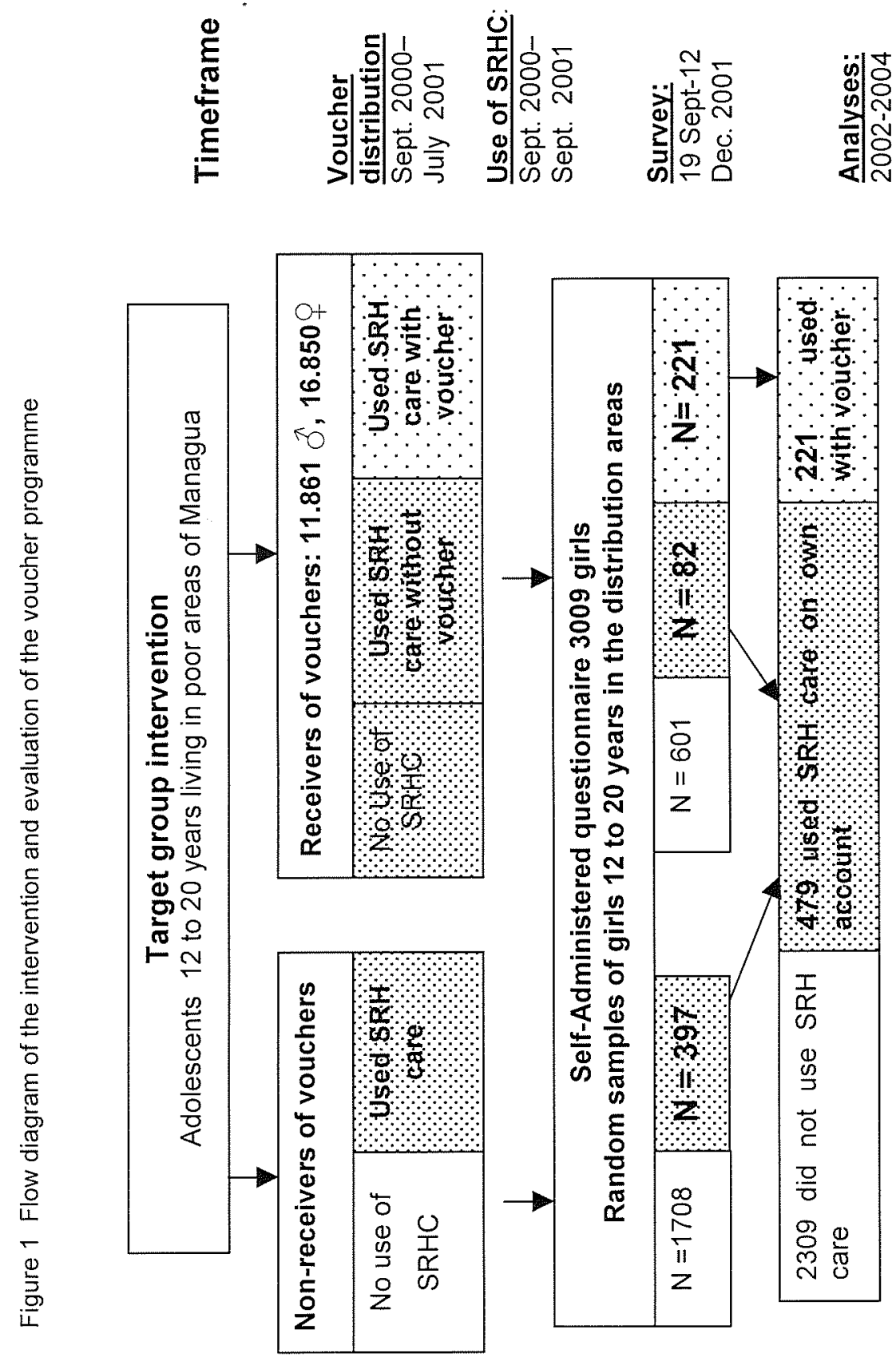
Answers to three questions were used to assess quality:

A) "Would you like to consult the same doctor again?" (Yes or no), was used as summary indicator of the quality of the entire consultation, since a discontent person would be unlikely to want to return (17).

B) "How was the attention in the clinic before you were attended to?" indicated how the girls perceived the way they were received before the consultation. The pre-coded answers 'bad' and 'regular' were classified as poor (in Nicaragua the term 'regular' means that something is not quite right), and 'good' and 'excellent' were classified as good.

C) The clarity of the explanations provided was assessed by asking: "How was the explanation of the doctor?" The pre-coded answers 'did not understand' and 'did not understand well' were classified as poor; 'did understand' and 'did understand very well' were classified as clear.

Information was collected on the characteristics of the adolescents (age; years of schooling; currently attending school; socio-economic indicators; and childbearing experience); on the survey site (market, neighbourhood, school); and on whether the questionnaire was self-administered or completed by an interviewer.

Since pregnancy and motherhood strongly influence the social position of girls and the social acceptability of seeking SRH care, childbearing experience was classified into three groups: girls who had not started sexual relations; girls who had started but had never been pregnant; and pregnant girls/mothers. The socioeconomic-indicators to assess relative poverty were presence of a refrigerator in the house, number of people per bedroom and socio-economic classification of the survey site ${ }^{1}$.

\section{Data Collection and Analysis}

While the questionnaire was being completed, survey staff (female adolescents) stayed nearby to answer questions and to safeguard privacy. Survey staff completed $18 \%$ of the questionnaires on behalf of girls who had difficulties reading or writing.

An estimated 3\% of girls refused to participate: reasons included "in a hurry", "no permission from my boss" (at markets), while others believed the questionnaire was related to a political activity. Of the 3,130 questionnaires completed, 3009 (96\%) contained sufficient data for analysis. Data were entered twice in Epi-info by two different data processors. STATA 7.0 software was used for further analysis.

\footnotetext{
1 The socio-economic classification of neighbourhoods was based on an updated list from the municipality indicating nature of housing, level of services (sewerage, electricity, drinking water) and quality of roads. Markets were classified on the relative price levels of goods sold. Schools were classified on the level of parental financial contributions and the socio-economic-classification of the neighbourhood. The very poor sites scored 2 points, poor sites 1 point, and lower class/lower middle class sites 0 points.
} 
Table 1 Girls' Characteristics: all respondents and female users of SRH care: userswith-voucher versus users-without-voucher

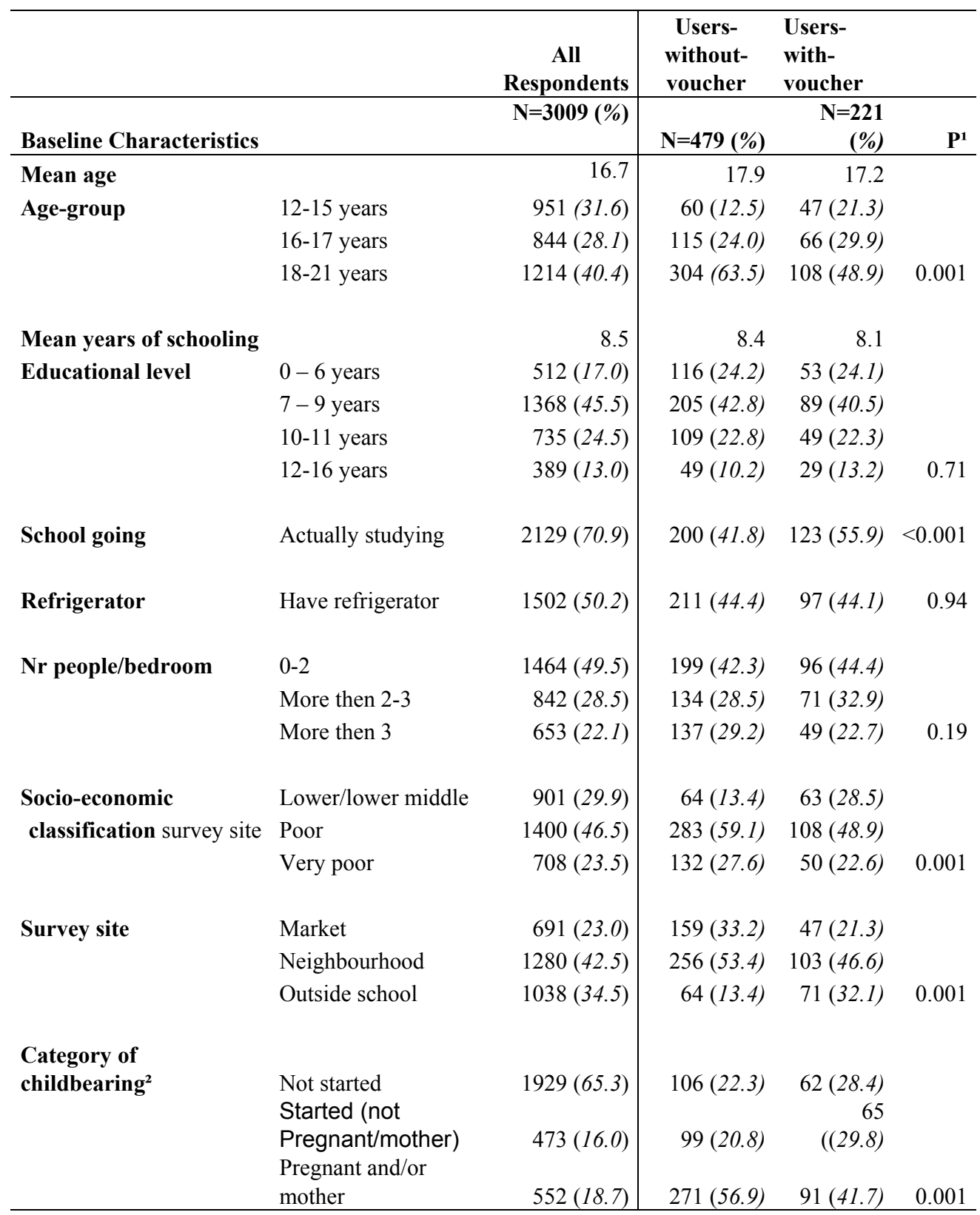

${ }^{1}$ Results of the chi-square test comparing the SRH care users-with-voucher with users-without-voucher for the various variables

${ }^{2}$ Girls who are first time pregnant and visited a doctor more than 6 months ago, are considered as started with sexual relations but not pregnant, because in Nicaragua it is most unlikely these girls did visit a doctor for an antenatal control in their first 3 months of pregnancy. 
Main characteristics describing study participants were calculated and tabulated (Table I). The chi-square test was used to compare the characteristics of the userswith-voucher with the users-without-voucher.

For analysis of the influence of voucher use on the quality indicators, voucher use was the main exposure in multiple logistic regression analysis. Adolescent and survey characteristics were considered potential confounders that might be associated with voucher use and could independently influence perceptions of quality, or effect modifiers that might influence the effect of voucher use on the perceived quality. The likelihood ratio test (LRT) was used to determine whether variables were significantly associated with the outcome $(p<0.05)$. For each variable, it was assessed whether there was interaction with the exposure using the LRT. All ordinal variables were tested for departure from the linear trend (Table 2). Only records with complete data were used in the multivariate analysis.

To analyse the determinants of user satisfaction, logistic regression models were constructed that included variables related to the SRH care and adolescent and survey site characteristics. Since many girls could not remember the name of the clinic they had visited, it was impossible to include clinic type (public, private, or non-government) in the analysis. The LRT was used as described above to assess the influence of the different variables (Table 3 ).

\subsection{Results}

No relevant differences were found in characteristics of voucher receivers in sampled sites versus non-sampled sites. Furthermore, characteristics of respondents were similar to girls who had received a voucher during the intervention. Therefore, it is likely that respondents are representative of girls who could have received a voucher, the target group of the intervention. Of the 3009 adolescent girls who completed the questionnaire, 700 adolescents reported use of SRH care within the last 15 months, 221 'users-with-voucher', and 479 'users-withoutvoucher'. Older and sexually active girls, especially mothers and pregnant girls, made more frequent use of SRH care. Users-with-voucher, compared to userswithout-vouchers, were younger, more frequently still at school, less likely to be pregnant or mothers, and more frequently contacted outside school (Table 1).

\subsubsection{The influence of voucher use on quality}

Of all SRH care-users, $593(87 \%)$ were satisfied with the care received, 91\% of users-with-voucher and $85 \%$ of users-without-voucher. In multiple logistic regression analysis, voucher use was significantly associated with more frequent user satisfaction (Table 2). 
Table 2 The impact of voucher use on user satisfaction, satisfaction with the reception and the clarity of the explanations

\begin{tabular}{|c|c|c|c|c|c|}
\hline Outcomes & $\begin{array}{c}\text { Without } \\
\text { Voucher } \\
\mathrm{N}=\mathbf{4 7 9}(100 \%) \\
\end{array}$ & 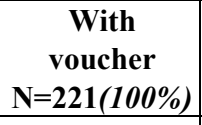 & $\mathbf{N}^{1}$ & $\begin{array}{c}\text { Unadjusted OR } \\
(95 \% \mathrm{CI}) \\
\end{array}$ & $\begin{array}{c}\text { Adjusted OR } \\
(95 \% \mathrm{CI})^{2}\end{array}$ \\
\hline $\begin{array}{l}\text { Overall satisfaction } \\
\text { Missing data }=19\end{array}$ & $394(85)$ & $199(91)$ & $\mathrm{N}=660$ & $1.99(1.13-3.48)$ & $2.23^{4}(1.24-4.02)$ \\
\hline $\begin{array}{l}\text { Satisfied with the Reception } \\
\text { Missing data }=17 \\
\text { Voucher use/not started } \\
\text { Voucher use/started(not pregn } \\
\text { or mother) } \\
\text { Voucher use/pregnant or mother }\end{array}$ & $374(80)$ & $190(88)$ & $\mathrm{N}=664$ & $1.99(1.22-3.26)$ & $\begin{array}{l}2.22(0.87-5.63) \\
6.93(1.51-31.84) \\
1.13(0.58-2.20)\end{array}$ \\
\hline $\begin{array}{l}\text { Doctors' explanations were } \\
\text { clear } \\
\text { Missing data }=21 \\
\end{array}$ & $370(80)$ & $181(83)$ & $\mathrm{N}=660$ & $1.34(0.87-2.08)$ & $1.37^{5}(0.87-2.17)$ \\
\hline $\begin{array}{l}{ }^{1} \mathrm{~N} \text { is the number of reco } \\
{ }^{2} \text { Result of multiple log } \\
\text { childbearing experience; } \\
\text { house; number of peopl } \\
\text { or completed by an intery } \\
{ }^{4} \text { The variable childbearir } \\
{ }^{5} \text { The variable level of } \\
\text { confounder. }\end{array}$ & $\begin{array}{l}\text { rds included in the } \\
\text { gistic regression a } \\
\text { age group; schoo } \\
\text { e/bedroom; socio- } \\
\text { viewer. } \\
\text { g experience was } \\
\text { educational attai }\end{array}$ & $\begin{array}{l}\text { logistic regression } \\
\text { halysis. The varia } \\
\text { attendance; level } \\
\text { conomic classifica } \\
\text { ignificantly associ } \\
\text { ament was signifi }\end{array}$ & $\begin{array}{l}\text { analysis } \\
\text { bles inclu } \\
\text { of educa } \\
\text { tion of th } \\
\text { lated with } \\
\text { cantly as }\end{array}$ & $\begin{array}{l}\text { uded in the model a } \\
\text { tional attainment; re } \\
\text { e survey site; surves } \\
\text { the outcome, but no } \\
\text { sociated with the o }\end{array}$ & $\begin{array}{l}\text { are: category of } \\
\text { frigerator in the } \\
\text { y site; self-filled } \\
\text { confounder. } \\
\text { utcome, but no }\end{array}$ \\
\hline
\end{tabular}

Of all users, $564(83 \%)$ were satisfied with attention at the reception of the clinic, $88 \%$ of users-with-voucher and $80 \%$ of users-without-voucher. In multiple logistic regression analysis, interaction existed between voucher use and childbearing experience. The positive influence of a voucher on perceptions of the quality of reception was very strong in sexually active girls who were neither mothers nor pregnant, strong in girls who were not yet sexually active, but absent in girls who were mothers or pregnant (Table 2).

Of all users, $551(81 \%)$ reported that the explanation by the medical doctor was clear, $83 \%$ of users-with-voucher and $80 \%$ of users-without-voucher. In multiple logistic regression analysis, voucher use was not significantly associated with the clarity of explanation (Table 2).

No statistically significant differences were found for any of the quality indicators or with voucher use when comparing records with missing values with complete records.

\subsubsection{Determinants of user satisfaction}

The quality of reception and clarity of explanations were strongly correlated with overall satisfaction $(\mathrm{p}<0.001 ; \mathrm{p}<0.001)$ and therefore not included in the multiple 
logistic regression analysis. Voucher users were significantly more frequently satisfied. Girls were more satisfied with a female than a male doctor; voucher use made this effect much stronger (Table 3 ).

Longer consultation times progressively increased satisfaction; longer waiting times progressively diminished satisfaction; older girls were more frequently satisfied as were girls who were pregnant or mother. Educational level, schoolattendance, socio-economic background, and survey characteristics were not significantly associated with satisfaction.

Table 3 Factors influencing female adolescent user satisfaction

\begin{tabular}{|c|c|c|}
\hline Variables $\quad \mathrm{N}=\mathbf{5 8 4}$ & Categories & Adjusted OR (95\% CI) $)^{1}$ \\
\hline \multirow[t]{2}{*}{ Voucher use ${ }^{2}$} & No & Reference Category \\
\hline & Yes & $3.32(1.27-8.69)$ \\
\hline \multirow[t]{3}{*}{ Doctors Gender ${ }^{2}$} & Female doctor & Reference Category \\
\hline & Male doctor & $0.38(0.19-0.75)$ \\
\hline & Interaction male doctor voucher use & $0.21(0.05-0.81)$ \\
\hline Consultation Time $^{2}$ & $0-10 \mathrm{~min} ; 10-20 \mathrm{~min} ; 21-30 \mathrm{~min} ;>30 \mathrm{~min}$ & $2.61(1.89-3.60)^{3}$ \\
\hline Waiting Time $^{2}$ & $0-30 \mathrm{~min} ; 31-60 \mathrm{~min} ; 60-120 \mathrm{~min} ;>120 \mathrm{~min}$ & $0.45(0.34-0.60)^{3}$ \\
\hline Age group ${ }^{2}$ & $12-15 y ; 16-17 y ; 18-21 y$ & $1.62(1.02-2.57)^{3}$ \\
\hline \multirow[t]{3}{*}{ Childbearing experience $^{2}$} & Not started & Reference Category \\
\hline & Started (not pregnant/mother) & $0.60(0.27-1.33)$ \\
\hline & Pregnant and/or mother & $1.53(0.66-3.55)$ \\
\hline Educational Level & $0-6 y ; 7-9 y ; 10-11 y ; 12-16 y$ & $0.70(0.47-1.06)^{3}$ \\
\hline School going & Actually studying & $0.94(0.44-2.13)$ \\
\hline $\mathrm{Nr}$ of people per bedroom & $0-2 ; 2-3 ;>3$ & $0.96(0.66-1.38)^{3}$ \\
\hline Refrigerator & No refrigerator in the house & $1.36(0.74-2.50)$ \\
\hline Socio-economic classification survey site & Lower/lower middle; poor; very Poor & $0.84(0.47-1.49)^{3}$ \\
\hline Filling of questionnaire & Survey staff filled questionnaire & $1.06(0.53-2.13)$ \\
\hline \multirow[t]{3}{*}{ Survey site } & Market & Reference Category \\
\hline & Neighbourhood & $1.40(0.65-3.05)$ \\
\hline & School & $0.79(0.28-2.28)$ \\
\hline
\end{tabular}

${ }^{1}$ Results of the multiple logistic regression analysis.

${ }^{2}$ The variables marked with ${ }^{2}$ were statistically significant associated with user satisfaction in the multiple logistic regression analysis.

${ }^{3}$ The reference category is the first category mentioned (e.g. for waiting time this is $0-30$ minutes, for consultation time 0-10 minutes, for age group 12-15 years etc). 


\subsection{Discussion}

Voucher use was associated with a more frequent satisfaction with the consult and the reception in the clinic, compared to use-without-voucher. No association was found with the clarity of doctors' explanations. User satisfaction was associated with voucher use, consultation with a female doctor, longer consultation times, shorter waiting times, older age and being pregnant or mother.

In interpreting our findings, strengths and limitations of the study design should be considered. The high response rate and the random sampling were strong aspects of this study. A representative sample of the target group of the intervention was obtained. However, while we have adjusted for all significant variables, we cannot exclude that girls who already had access to SRH care and girls accessing care through vouchers are different for aspects we were not able to control for through logistic regression. If this would be the case, it would most likely reinforce the success of the intervention in increasing acceptability of SRH care, since underserved adolescents mobilised through vouchers are not an easy group to reach and satisfy.

Sexual activity as reported through the self-administered questionnaires was higher than reported in interview-based surveys in Nicaragua. This illustrates known underreporting of sexual activity in face-to-face interviews and suggests a high degree of frankness when completing the questionnaire. The time between service use and the survey probably influenced the assessment of SRH care, but cannot explain the impact of voucher use, since there were no important differences in time elapsed comparing users-with-voucher with users-without-voucher. Furthermore, non-random reporting biases are unlikely because the survey was not overtly linked to the voucher programme, specific clinics or doctors.

Given these factors we consider it likely that the associations found can be attributed to the intervention. But how can we understand the success of vouchers on quality?

Part of the higher satisfaction associated with voucher use might be explained by differences in quality between types of clinics. Vouchers gave access to private and non-governmental clinics that are not accessible by poor adolescents, a factor we were unable to analyse.

The finding that voucher users who were sexually active but not yet pregnant or mothers were most satisfied with clinic reception and that the quality of reception was strongly associated with user satisfaction suggests that confidentiality is a central factor for voucher-success. Confidentiality is very important to adolescents because they fear that attending SRH care is a public declaration of being sexually active and/or that their parents will find out $(3,7,9,18,19)$. This was confirmed 
during focus-group discussions. The vouchers enhanced confidentiality in a number of ways. They removed the need to ask family and friends for funds or information because services were free-of-charge and clinics nominated. Adolescents could select a clinic of their choice with a good reputation, nearby, or where the chance of meeting acquaintances was minimal. And adolescents could attend a clinic without fear of rejection, without prior appointment and without the need to inform the trained receptionist about the reason for the visit.

The quality was probably also influenced by other mechanisms. Clinic staff was trained in receiving adolescents and respecting their privacy. Also, providers felt supported by the program serving young unaccompanied adolescents. Although there are no age restrictions in Nicaragua, providers affirmed during interviews moral reservations towards serving adolescents aged under 16. Furthermore, the voucher provided financial incentives to provide good quality care in order to attract more adolescents.

The finding that $82 \%$ of the adolescents were satisfied confirms findings from other studies that patients report satisfaction with $80-90 \%$ of the care given regardless of its actual quality (20). Our survey data permit analysis of the relative importance of the different determinants of perceived quality. The results confirm evidence $(9,21,22,23)$ underlining the importance of the entire circuit in a health centre, including waiting and consultation times, the quality of the reception and the clarity of doctors' explanation.

Intriguingly, differences in education, school-attendance, and socio-economic background did not influence girls' assessment of quality. While respect for diversity is key to success in many adolescent programmes, for health care quality this aspect seems of less importance. The main inter-girl variable that made a difference was that girls who had not started reproductive live felt less well attended than mothers and pregnant girls. This suggests there remains room for improvements in addressing the needs of these girls.

Survey participants demonstrated a preference for consulting female doctors. Voucher use made this preference even stronger. Culturally it is easier for girls to discuss issues related to sexuality with women. In addition, gender influences the communication styles of doctors (24) and the doctors' gender is an important factor in this type of intervention $(24,25)$. In general, the female doctors reacted more enthusiastic towards the programme than their male colleagues who also seemed less motivated to spend time on health education and to comply with programme protocols and instructions. Further research is planned to understand the underlying mechanisms.

In conclusion, adolescents in Nicaragua face many health threats related to their sexuality. Health care providers should provide information and services that adolescents need to make choices in their sexual and reproductive life, but 
commonly fail to do so. The voucher program mobilised adolescents towards the services (11), supported the providers to attend to them, and users were more satisfied with the services, than those who consulted without voucher. This is an important achievement given the crucial role user satisfaction plays in the adoption and continued use of SRH care and contraceptives. It is encouraging that a relatively simple and cheap intervention has potential to contribute to addressing a serious and persistent public health problem. Although further research is needed to prove causality and understand the exact mechanisms, confidential and guaranteed free access appear key factors behind increased user satisfaction through vouchers. While the question of sustainability also needs further attention, vouchers are likely to be a powerful tool in reaching out to adolescents in need, and almost certainly have potential beyond the Nicaraguan borders.

\section{Acknowledgements}

Without the hard and enthusiastic work of Zoyla Segura, Joel Medina, Patricia Gonzalez, Amelia Tijerino, Roger Torrentes, Alejandro Dormes, Gloria Medina and Esteban Zuñiga, this intervention could never have become a success. We are very grateful to Erik van de Giessen and Julienne McKay for their continuing support during the preparation of this report. Last but not least, without the financial support of DFID this interesting intervention would never have been possible.

\section{References}

1. Instituto Nacional de Estadística y Censos and Ministerio de Salud. Demographic Health Survey Nicaragua 2001 (in Spanish), Managua, Nicaragua, Instituto Nacional de Estadística and Censos y Ministerio de Salud. Calverton, MD USA; Macro International/DHS+ Program. 2002.

2. Zelaya E Marin FM Garcia J Berglund S Liljestrand J Persson LA. Gender and social differences in adolescent sexuality and reproduction in Nicaragua J Adolesc Health 1997; 21: 39-46.

3. Braddock M Grainger C Morera F. Addressing the Reproductive Health Needs and Rights of Young People since ICPD, the contribution of UNFPA \& IPPF. Nicaragua, Country Evaluation Report Nicaragua, 2003.

4. UNFPA and Instituto Nicaragüense de la Mujer. What can I do else than getting a child? Socio-cultural background of adolescent pregnancy in Nicaragua (in Spanish). Fondo de población de las Naciones Unidas, and Instituto Nicaragüense de la Mujer. RLA/94/P15, 1999.

5. Pons JE, Contraceptive services for adolescents in Latin America: facts, problems and perspectives. Review. Eur J Contracept Reprod Health Care 1999; 4(4): 246-54.

6. Berglund S, Liljestrand J, Marin FM, et al. The background of unwanted adolescent pregnancies in Nicaragua. A qualitative approach. Soc Sci Med 1997; 44(1): 1-12.

7. Eggleston E Jackson J Hardee K. Sexual Attitudes and Behavior Among Young 
Adolescents in Jamaica. Int Fam Plan Perspect 1999; 25 (2) 78-91.

8. Langer A. Unwanted pregnancy: impact on health and society in Latin America and the Caribbean (in Spanish). Pan American Journal Public Health 2002;11(3) 192-204.

9. Senderowitz J, Health Facility programs on Reproductive Health for Young Adults. http://www.pathfind.org /RPPS-Papers/Heatlh\%20Facility.html. 1997, assessed 6 June 2001.

10. Sedlock L, Reaching the youngest adolescents with reproductive health programs . FOCUS on Young adults. www.pathfind.org \focus.htm, 2000.

11 Meuwissen LE, Gorter AC, Knottnerus JA. Impact of accessible sexual and reproductive health care on poor and underserved adolescents in Managua, Nicaragua: A quasiexperimental intervention study. J Adolesc Health.2006; 38(1):56.

12. RamaRao S, Lacuesta M, Costello M, Pangolibay B, Jones H. The link between quality of care and contraceptive use. Int Fam Plan Perspect 2003; 29(2):76-83.

13. Bertrand JG Hardee K Magnani RJ Angle MA , Access, quality of care, and medical barriers in family planning programs, Int Fam Plan Perspect, 1995; 21(2) 64-69+74.

14. Blanc AK Curtis SL Croft TN. Monitoring contraceptive continuation: Links to fertility outcomes and quality of care. Stud Fam Plann. 2002; 33(2): 127-140.

15. Koenig MA Hossain MB Whittaker M. The influence of quality of care upon contraceptive use in rural Bangladesh. Stud Fam Plann. 1997; 28(4): 278-289.

16. Gorter A Sandiford P Rojas Z Salvetto M. Competitive Voucher Schemes for Health, Background Paper. Part of the Toolkit on Competitive voucher schemes for health. August 2003. World Bank.

17. Baron-Epel O Dushenat M Friedman N Evaluation of the consumer model: relationship between patient expectations, perceptions and satisfaction with care. Int J Qual Health Care 2001; 13(4):317-23.

18. Belmonte LR Gutierrez EZ Magnani R Lipovsek. Barriers to Adolescents Use of Reproductive Health Services in Three Bolivian Cities. FOCUS on Young Adults/ Pathfinder -international. Available at: www.pathfind.org/focus.htm, 2000. Accessed [December 6, 2000].

19. Walker ZAK Townsend J. the role of general practice in promoting teenage health: a review of the literature. Fam Pract. 1999; 164-172.

20. Rethans JJ Westin S Hays R, Methods for quality assessment in general practice. Fam Pract. 1996; 13(5) 468-476.

21. Lynam PF Smith T Dwyer J Client flow analysis: a practical management technique for outpatient clinic settings. Int J Qual Health Care 1994;6(2):179-86.

22. Williams T Schutt-Ainé J Cuca Y. Measuring Family Planning Service Quality Through Client Satisfaction Exit Interviews. Int Fam Plan Perspect 2000; 26(2): 63-71.

23. Cromer BA McCarthy M. Family Planning Services in Adolescent pregnancy prevention: The views of Key Informants in four countries. Fam Plann Perspect 1999;31(6) 287-293.

24. Hippisley-Cox J Allen J Pringle M Ebdon D McPhearson M Churchill D Bradley S. Association between teenage pregnancy rates and the age and sex of general practitioners: cross sectional survey in Trent 1994-7. BMJ 2000;320: 842-845.

25. Van Ness CJ Daryl Lunch A. Male adolescents and physician sex preference. Arch Pediatr Adolesc Med 2000; 154:49-53. 


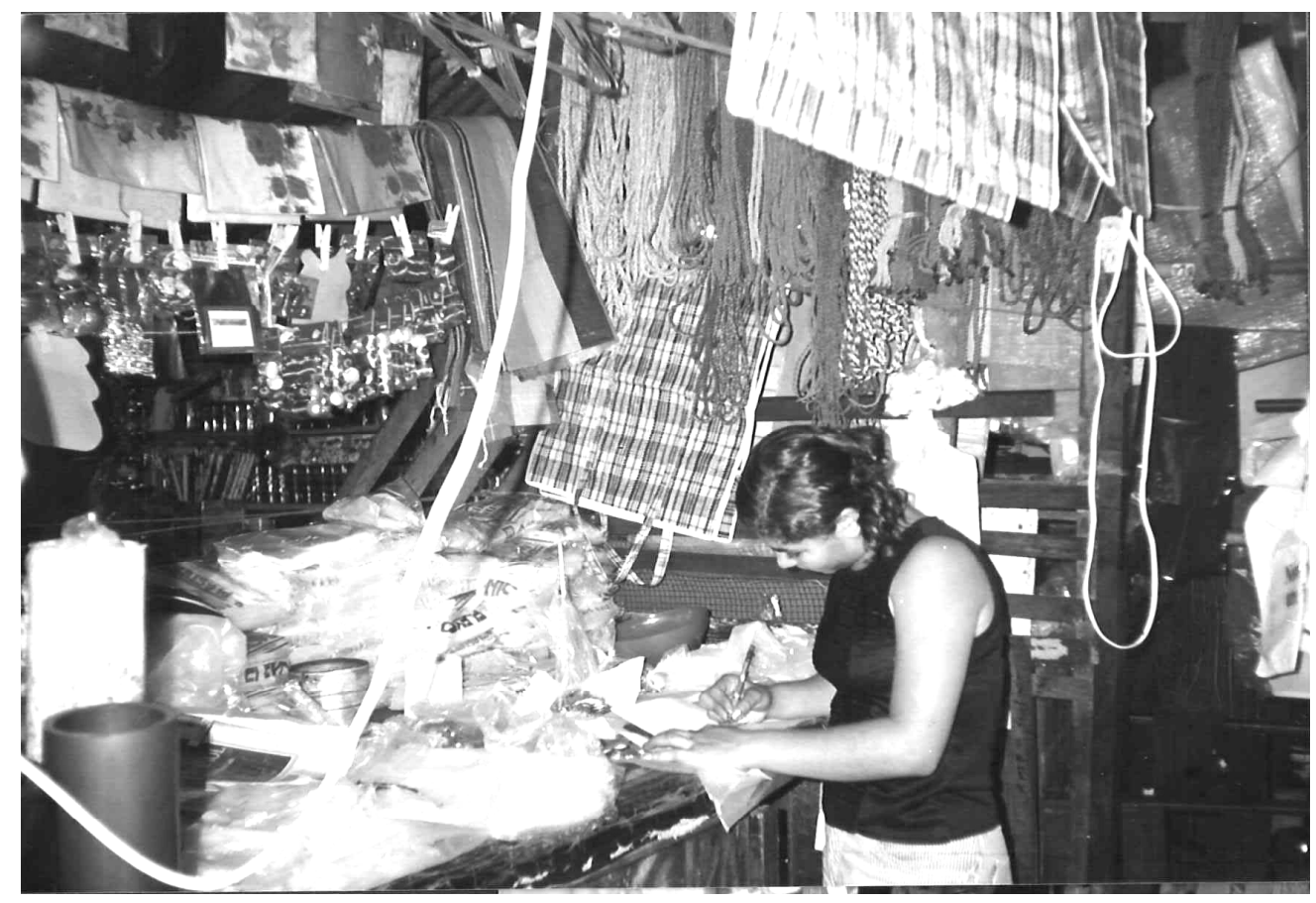

Girl completing a questionnaire at central market 


\section{Chapter 8}

Can a comprehensive voucher program prompt changes in doctors' knowledge, attitudes, and practices related to sexual and reproductive health care for adolescents?

A case study from Latin America

Liesbeth E. Meuwissen, A.C. Gorter, Arnold DM Kester, J.A. Knottnerus 


\begin{abstract}

\section{Objects}

To evaluate whether participation in a competitive voucher program designed to improve access and quality of adolescents' access to sexual and reproductive health care (SRH-care), prompted changes in doctors' knowledge, attitudes and practices.
\end{abstract}

\title{
Methods
}

The voucher program provided free access to SRH-care for adolescents. Doctors received training and guidelines on how to deal with adolescents, a treatment protocol, and financial incentives for each adolescent attended. To evaluate the impact of the intervention on doctors, nearly all participating doctors $(\mathrm{N}=37)$ were interviewed before the intervention, and 23 were interviewed after the intervention. Answers were grouped in sub-themes, and scores compared using non-parametric methods.

\section{Results}

The initial interviews disclosed deficiencies in doctors' knowledge, attitudes and practices relating to adolescent SRH-issues. Gender and age of the doctor were not associated with the initial scores. Comparing scores from before and after the intervention revealed significant increases in doctors' knowledge of contraceptives $(\mathrm{p}=0.003)$ and sexually transmitted infections $(\mathrm{p}<0.001)$; barriers to contraceptive use significantly diminished $(\mathrm{p}<0.001 \& \mathrm{p}=0.003)$; and some attitudinal changes were observed $(0=0.046 \& p=0.11)$. Doctors became more aware of the need to improve their communication skills and were positive about the program.

\section{Conclusions}

This study confirmed provider related barriers that adolescents in Nicaragua may face and reinforces the importance of focusing on the quality of care and strengthening doctors' training. Participation in the voucher program resulted in increased knowledge, improved practices, and to a lesser extent changed attitudes. A competitive voucher program with technical support for the participating doctors can be a promising strategy to prompt change. 


\subsection{Introduction}

Nicaragua has one of the highest adolescent fertility rates of Latin America, with 119 births annually per 1000 young women aged 15-19. High fertility rates are associated with low socio-economic status and low educational attainment (1). In addition, adolescents experience high rates of unwanted pregnancy, illegal abortions, high maternal mortality rates, and are at high risk of contracting sexually transmitted infections (STIs), including HIV. These risks are closely connected with the low use of contraceptive methods among sexually active adolescents: only $7 \%$ use a condom and $47 \%$ another modern method (1).

Lack of access to information about sexual and reproductive health, lack of access to sexual and reproductive health care (SRH-care) and a low quality of care are the principal reasons for the low use of contraceptive methods among adolescents. Whilst there is no need to further assess the extent to which knowledge, attitudes, and practices of medical doctors can be an obstacle to appropriate care for adolescents, there is an urgent need to better understand how to motivate and support doctors to change (2-11).

Evidence of interventions that have succeeded in improving the quality of SRHcare for adolescents in existing health centres in developing countries is scarce. A competitive ${ }^{1}$ voucher program for sex-workers in Managua, Nicaragua, proved to be a cost-effective intervention with potential to encourage quality care practices (13). Although indications existed that competitive voucher programs in health have strong potential to improve quality (12) this had never been the subject of explicit research. Therefore, when the Central American Health Institute (ICAS) piloted, between 2000 and 2002, a voucher program designed to increase access to and quality of SRH-care for poor and underserved adolescents, various aspects of the quality of care provided were closely monitored and evaluated. Methods used were interviews with adolescents, focus group discussions, revision of medical files, simulated patients and interviews with doctors.

Evaluation of the impact of the intervention among female adolescents showed that voucher receipt increased use of SRH care among all groups (adjusted odds ratio $3.1,95 \%$ confidence interval $2.5-3.9$ ) and of contraceptives and condoms in specific groups (14). Furthermore, girls were more satisfied with the quality of SRH-care delivered through the voucher program, compared to care delivered without voucher (15).

\footnotetext{
${ }^{1}$ Competition refers to the fact that in the described program there is competition between service providers, as opposed to programs were the voucher is redeemable at a single service provider. Competitive voucher schemes are one form of demand side financing where purchasing power is given to the consumer and money follows the patient (12)
} 
The fact that vouchers offered SRH-care free-of-charge can explain part of the increase in satisfaction. However, the voucher program was also seeking to induce improvements in technical and communication skills in relation to SRH-care in the participating health facilities. This was to be achieved through specific training and support providers would receive as well as the experience gained through participation in the program. To evaluate whether the program influenced knowledge, attitudes and practices, doctors were interviewed before and after the intervention. This paper reports our findings.

\subsection{Methods}

\subsubsection{The Intervention}

The intervention took place in Managua, the capital of Nicaragua, one of the poorest countries of Latin America. Primary health services in Managua consist of public health centres run by the Ministry of Health, municipal public health centres, private doctors, and clinics run by non-governmental organizations (NGOs). Most clinics are staffed by two doctors, and, in general, in the larger clinics two doctors were allocated to receive adolescents.

Over fifteen months, 28,711 vouchers were distributed to poor adolescents at markets, outside schools and door-to-door in disadvantaged neighbourhoods. The vouchers gave free access to SRH-care in any of the four public, five private or 10 NGO clinics contracted by ICAS. The selection of clinics was based on suitability and proximity to the areas in which vouchers were distributed. Identified clinics invited to participate were required to sign a contract, while prices per consultation were negotiated based on customary fees. The clinics received reimbursement for each adolescent consultation. The program started with four clinics and new clinics were added periodically.

Vouchers were valid for three months and $20 \%$ of the vouchers were redeemed by girls. This is a relatively high redemption rate, considering the short life of the vouchers ( 3 months) and that they were distributed without asking adolescents about their SRH-care needs. Among sexually active girls, 51\% used their voucher, while among girls who were not yet sexually active use was only $14 \%$. Adolescents could seek more than one service during their consultation, so the sum of percentages exceeds 100\%: $34 \%$ sought contraceptives, 30\% sought treatment for an STI or reproductive tract infection (RTI), 28\% counselling, 27\% antenatal care, $17 \%$ pregnancy testing, and $15 \%$ gave other reasons.

Doctors completed standardized clinical forms that guided them during each consultation. This protocol was designed to ensure that every adolescent was asked about their sexual activity, their need for information, their need for contraceptives and was given a package with two condoms plus health education material on adolescence and STIs. Doctors at participating clinics were obliged to attend an 
introductory meeting to learn about the program and its procedures. An information manual with background information and guidelines was also provided. Furthermore, all doctors were encouraged to attend a training course, conducted over three mornings on 'youth friendly services' (16) counselling, adolescence and sexuality, contraceptives, and sexual abuse. The course was organized by the Department of Sexual and Reproductive Health at the University of Nicaragua. Seventy percent of the doctors participated in at least one training session.

\subsubsection{The evaluation}

\section{Design and population}

Thirty-seven of the 40 participating doctors were interviewed before the program started in their clinic. The 3 missed were doctors newly employed in the participating clinics after the program had started and had already started seeing adolescents, using program protocols.

Two doctors from the research team interviewed the participating doctors. They made appointments and interviewed the doctors in the privacy of their consultation rooms. A structured questionnaire with 28 open-ended questions was used. The interviewers were instructed to record answers and not to provide feedback. One month after the intervention ended, doctors were contacted for a second interview, with the same basic questionnaire, with additional questions on their experience. The study was approved by the ethical review committee of ICAS.

Measurement of knowledge, attitudes, and practices

The selection of questions was based on program objectives and literature review, and was refined by a team of medical doctors with experience of SRH-care in Nicaragua.

Measurement of knowledge was straightforward, focusing on a) family planning and b) STIs. The doctors were asked for example: According to your criteria, what type of family planning is most suitable for girls aged 12 to 14 ? What type for girls aged 15 to 17? And for girls who have had a baby? Please explain your understanding of the relationship between STIs and HIV/AIDS? Describe the syndromic treatment for STIs? Why is the syndromic treatment used in STI programs?

Attitudes were assessed through questions related to barriers to SRH-care and to understanding how access to care can be facilitated. The focus was a) on service delivery and b) on family planning. Examples of questions include: What do you think are the different reasons why adolescents experience difficulties in consulting a doctor for sexual and reproductive health issues? If an adolescent aged 14 consults you and asks for oral contraceptives, do you prescribe them?

Practices were assessed by evaluating the medical barriers mentioned when doctors described how they dealt with contraception among adolescents. Medical barriers 
are practices that use a medical rationale but result in an impediment to or denial of contraceptive use that cannot be scientifically justified (17). The focus was a) on barriers due to erroneous knowledge (e.g. When you prescribe mesigyna $\AA^{2}$, when can it be started?); b) on barriers due to socio-cultural assumptions and values (e.g. In what type of cases do you propose the use of emergency contraceptives?); and c) facilitation of correct used (e.g. included instruction on what to do when a girl forgets to take the pill as essential information to be shared with an adolescent who starts using oral contraceptives). The full questionnaire is available on request.

The criteria for evaluation were based on program objectives, defined before the data were analyzed, and approved by the research team. Each aspect was divided in two sub-themes as indicated above. By providing the correct responses to all 4 or 5 criteria of one sub-theme, a maximum score of 10 points could be attained. For an overview of all criteria used see Table 2 to 4 . The internal reliability of the multiple subscale scores is good (Cronbachs' alpha $=0.75$ )

\section{Data collection and analysis}

All completed questionnaires were codified in a random order (before and after mixed) by one doctor after disconnection from the personal identifiers. Data were entered twice using Epi Info (6.0). Stata 7.0 software was used for further analysis.

A general description of the participating doctors is given, reflecting basic characteristics and experience. The total number of positive answers for each criterion, and the mean score per sub-theme, are calculated and tabulated for all 37 doctors interviewed at the beginning of the program. The relation between different characteristics of these 37 doctors (gender, age group and type of clinic) and their initial score was assessed. The Mann-Whitney rank sum test was used to analyze the influence of gender and age group on the scores in each sub-theme and the Kruskal-Wallis test for the influence of the type of clinic (public, private, NGO).

Of the 23 doctors interviewed twice, the numbers of correct answers before and after the intervention are tabulated, and the total score per sub-theme calculated. The scores before and after the intervention are compared using the Wilcoxon signed rank test (paired design).

\footnotetext{
2 Mesigyna is a monthly injectable hormonal contraceptive available in Latin America. This type of method has several advantages for adolescents: it does not require continuous application; its coitus-independent; it is highly effective and reversible; and it does not require the user to keep supplies, and therefore its use can be concealed (18). Mesigyna is very popular among adolescents in Nicaragua but rather expensive in its use.
} 
Table 1 Baseline characteristics and experience of the doctors

\begin{tabular}{|c|c|c|c|c|}
\hline & $\begin{array}{r}\text { All doctors before } \\
\mathbf{N}=\mathbf{3 7}(\mathbf{1 0 0 \%})\end{array}$ & $\begin{array}{l}\text { MD Followed* } \\
\text { N=23 (100\%) }\end{array}$ & $\begin{array}{r}\text { MD lost } \dagger \\
\mathrm{N}=14(100 \%)\end{array}$ & $\begin{array}{l}\chi^{2} \\
\mathbf{p}\end{array}$ \\
\hline \multicolumn{5}{|l|}{ Sex doctor } \\
\hline Female & $22(59.5)$ & $15(65.2)$ & $7(50.0)$ & \multirow[b]{2}{*}{0.36} \\
\hline Male & $15(40.5)$ & $8(34.8)$ & $7(50.0)$ & \\
\hline \multicolumn{5}{|l|}{ Age Doctor } \\
\hline 30-34 years & $11(29.7)$ & $7(30.4)$ & $4(28.6)$ & \multirow[b]{3}{*}{0.20} \\
\hline 35-39 years & $16(43.2)$ & $12(52.2)$ & $4(28.6)$ & \\
\hline $40+$ years & $10(27.0)$ & $4(17.4)$ & $6(42.9)$ & \\
\hline \multicolumn{5}{|l|}{ Type of clinic } \\
\hline Public & 7 (18.9) & $4(17.4)$ & $3(21.4)$ & \multirow[b]{3}{*}{0.81} \\
\hline Private & $9(24.3)$ & $5(21.7)$ & $4(28.6)$ & \\
\hline NGO & $21(56.8)$ & $14(60.9)$ & $7(50.0)$ & \\
\hline \multicolumn{5}{|c|}{ Reported experience at first interviews } \\
\hline Little experience & $5(13.5)$ & $1(4.4)$ & $4(28.6)$ & \multirow[b]{2}{*}{0.04} \\
\hline Lot of experience & $32(86.5)$ & $22(95.6)$ & $10(71.4)$ & \\
\hline \multicolumn{5}{|c|}{ Prescribes pill to 14 years old girls } \\
\hline Has serious reservations & $16(43.2)$ & $7(30.4)$ & $9(64.3)$ & \multirow[b]{2}{*}{0.08} \\
\hline Yes & $21(56.8)$ & $16(69.6)$ & $5(35.7)$ & \\
\hline \multicolumn{5}{|c|}{ Experience with prescribing the morning after pill } \\
\hline No & $23(62.2)$ & $13(56.5)$ & $10(71.4)$ & \multirow[b]{3}{*}{0.66} \\
\hline $1-2$ times /year & $7(18.9)$ & $5(21.7)$ & $2(14.3)$ & \\
\hline$>2$ times/regular & $7(18.9)$ & $5(21.7)$ & $2(14.3)$ & \\
\hline \multicolumn{5}{|c|}{ Reported experience in this year with girls suffering from sexual abuse $\$$} \\
\hline None & $17(60.7)$ & $10(55.6)$ & $7(70.0)$ & \multirow{4}{*}{0.68} \\
\hline 1-2 times /year & $6(21.4)$ & $4(22.2)$ & $2(20.0)$ & \\
\hline 3 times or more/year & $5(17.9)$ & $4(22.2)$ & $1(10.0)$ & \\
\hline Missing & 9 & 5 & 4 & \\
\hline
\end{tabular}

* Doctors with complete follow-up

$\dagger$ Doctors lost to follow-up

\$ This question was not asked for in the first 9 interviews

\subsection{Results}

Twenty-three of the 37 medical doctors were interviewed twice (62\%). Reasons for failure to follow-up were that the doctor had stopped working in the participating clinics (5 doctors); exclusion of the clinic from the program due to administrative reasons (4); absence during interview period (2); refusal due to moral rejection of the program (2); removal from the program because of complaints from adolescents (1). The sample of 23 doctors (that is, those who participated in the follow-up) did not differ significantly in terms of their main characteristics from the 14 doctors lost to follow-up (Table 1). 
As a result of the stepwise introduction of the program, the period over which 'the 23 doctors' had participated before the second interview varied between 4.5 months and 15.2 months: $44 \%$ had participated more than 9 months. 'The 23 doctors' were aged between 28 and 53. Most were younger than 40, and worked in NGO clinics. More female than male doctors participated, similar to the gender profile among general practitioners in Nicaragua.

\subsubsection{Before the intervention}

Answers from the 37 initial interviews are shown in the second column of Table 2 to 4. In summary, the main findings were: not all doctors knew of current contraceptives appropriate for adolescents and knowledge of STIs and syndromic treatment was limited (Table 2). Few doctors appreciated that provider related obstacles contribute to non-use of health care services by adolescents and many were reluctant to prescribe contraceptives to younger adolescents (Table 3). Many doctors imposed medical barriers to the use of modern contraceptives and most doctors clearly had a favourite contraceptive that they prescribed for specific age groups (Table 4). For example, a condom is their favourite method for girls aged 12 to 15 , while only $2 / 37(5 \%)$ include condoms as the recommended method for girls who have already had a baby. Ten of the 37 doctors (27\%) gave information on the negative aspects of condom use to teenagers who wanted to start using them: for example "not the best method to prevent STIs"; "can give irritations"; "can give allergic reactions"; "psychological disadvantages"; "condoms break easily"; "can have disadvantages"; "90\% effective"; "not good as a contraceptive".

\subsubsection{Differences between doctors}

When comparing the initial scores of male and female doctors and doctors aged less than 35 with older doctors, no statistically significant differences were found in any sub-theme. However, the initial scores of doctors working in public clinics were statistically significantly lower in attitudes towards accessibility (sub-theme 3) and medical barriers due to erroneous knowledge (sub-theme 5) (not shown). The group followed up was too small to permit analysis of whether different groups of doctors responded differently to the program.

\subsubsection{Pre- and post-intervention}

The scores of the initial interviews with 'the 23 doctors' are comparable to the scores of the complete group of 37 (Table 2 to 4, column 'All Initial' and column 'Initial').

When comparing the results of the initial interview with the interview after the intervention, a significant increase in knowledge of contraceptives was noted $(\mathrm{p}=0.003$, Table 2$)$. A higher percentage knew that mesigyna ${ }^{\circledR}$ can be started from day 1 up to day 5 of the menstrual cycle, and more were able to mention at least one emergency contraceptive. 
Table 2 The knowledge of the medical doctors before and after the intervention

\begin{tabular}{|c|c|c|c|c|}
\hline Knowledge & All Initial* & Initial $\uparrow$ & After $\dagger$ & $\mathbf{P}+$ \\
\hline I On contraceptives and their use & $\mathbf{N}=\mathbf{3 7}(\%)$ & $\mathbf{N}=\mathbf{2 3}$ & $\mathbf{N}=\mathbf{2 3}$ & \\
\hline $\begin{array}{l}\text { 1.1 Did not mention natural methods among } \\
\text { appropriate for adolescents }\end{array}$ & $32(86.5)$ & 20 & 21 & \\
\hline 1.2 Prescribes ovrette ${ }^{\circledR}$ only to lactating mothers & $20(54.1)$ & 15 & 19 & \\
\hline $\begin{array}{l}1.3 \text { Knows girls can start mesigyna }{ }^{\circledR} \text { on day } 1 \text { to } 5 \text { of } \\
\text { their menstrual cycle }\end{array}$ & $15(40.5)$ & 10 & 16 & \\
\hline $\begin{array}{l}\text { 1.4 Can mention at least one method for emergency } \\
\text { contraception correctly }\end{array}$ & $26(70.3)$ & 19 & 23 & \\
\hline $\begin{array}{l}\text { 1.5 Can mention the dose of at least one method or } \\
\text { emergency contraception correctly }\end{array}$ & $13(35.1)$ & 10 & 13 & \\
\hline Mean Score $\S$ & $5.7 \mathrm{sd} 2.0$ & $6.4 \mathrm{sd} 1.7$ & 8.0 sd 1.7 & $\mathbf{0 . 0 0 3}$ \\
\hline \multicolumn{5}{|l|}{ II On STIs, their prevention and treatment } \\
\hline $\begin{array}{l}2.1 \text { Mentions risk assessment, as a crucial part of STI } \\
\text { treatment }\end{array}$ & $3(8.1)$ & 2 & 4 & \\
\hline $\begin{array}{l}2.2 \text { Knows what syndromic treatment is and can give } \\
\text { at least one correct } \\
\text { reason for its use }\end{array}$ & $7(18.9)$ & 4 & 15 & \\
\hline $\begin{array}{l}2.3 \text { Mentions that STIs increase the transmission-rates } \\
\text { of HIV }\end{array}$ & $10(27.0)$ & 7 & 14 & \\
\hline $\begin{array}{l}2.4 \text { Knows the correct treatment for urethral discharge } \\
\text { in male adolescents }\end{array}$ & $15(40.5)$ & 12 & 13 & \\
\hline Mean Score $\S$ & $3.6 \mathrm{sd} 2.8$ & $2.7 \mathrm{sd} 2.4$ & $5.2 \mathrm{sd} 2.6$ & $<0.001$ \\
\hline
\end{tabular}

* Number of doctors and percentage of total that responded correctly to the criteria

$\dagger$ These columns reflect the absolute number of doctors who gave the correct answers in the interviews before and after the intervention

\$ The $p$ calculated from the Wilcoxon Signed Rank Test comparing the scores before and after the intervention for every sub-theme

$\S$ Scores are the mean scores per sub-theme and can range between 0 and 10 points.

Knowledge of STIS also increased significantly $(\mathrm{p}<0.001$, Table 2$)$. Higher proportions, but far from all, understood what syndromic treatment is and why it is used, and/or could mention that STIs facilitate the transmission of HIV.

A significant improvement was observed in attitudes towards accessibility of SRHcare. More doctors recognized obstacles faced by adolescents to accessing SRHcare ( $\mathrm{p}=0.046$, Table 3$)$. Many more mentioned accessibility to health services and contraceptives as crucial elements of SRH programs, while in the first interview, their focus had been more on health education.

Attitudes by doctors towards contraceptive use by adolescents did not change significantly. Many doctors remained reluctant to prescribe hormonal contraceptives in the hypothesized case were requested by a 14-year-old girl. With regard to instructions given to adolescents wanting to start using condoms, only a few doctors stressed the advantage of condoms for dual protection against pregnancy and STIs. 
Table 3 The attitudes of the medical doctors before and after the intervention

\begin{tabular}{|c|c|c|c|c|}
\hline Attitudes & All Initial* & Initial $\uparrow$ & After $\dagger$ & p: \\
\hline III Towards accessibility SRH-care for adolescents & $\mathrm{N}=37(\%)$ & $\mathrm{N}=23$ & $\mathrm{~N}=23$ & \\
\hline $\begin{array}{l}\text { 3.1 Mentions at least one clinic related obstacle as reason } \\
\text { for no-use of SRH-care }\end{array}$ & $14(37.8)$ & 9 & 9 & \\
\hline $\begin{array}{l}\text { 3.2 Does not mention negative factors attributed to } \\
\text { adolescents such as they do not care/do not have } \\
\text { time/ignorance as reason for non-use of SRH care like they } \\
\text { do not care/do not have time/ignorance as reason for no-use } \\
\text { of SRH care }\end{array}$ & $30(81.1)$ & 20 & 20 & \\
\hline $\begin{array}{l}\text { 3.3 Mentions the importance of health care services in SRH } \\
\text { programs }\end{array}$ & $13(35.1)$ & 8 & 15 & \\
\hline $\begin{array}{l}\text { 3.4 Mentions the importance of contraceptives in SRH } \\
\text { programs }\end{array}$ & $21(56.8)$ & 13 & 22 & \\
\hline Mean Score $\S$ & $6.0 \mathrm{sd} 2.6$ & $5.4 \mathrm{sd} 2.3$ & $7.2 \mathrm{sd} 2.2$ & 0.046 \\
\hline
\end{tabular}

IV Towards contraceptive use by adolescents

4.1 Includes a modern contraceptive that can be controlled by girls

$17(46.0) \quad 11 \quad 14$

amongst methods suitable for girls of 12 to 14 years

4.2 Suggests more then one modern method for girls of 15

to 17 years

$10(27.0) \quad 5 \quad 11$

4.3 Prescribes oral contraceptives if an adolescent of 14 years ask for that.

4.4 Indicates what a girl should do when forgetting to take the pill, as essential information when prescribing oral contraceptives.

4.5 Explains that the condom has double usage, preventing STIs and pregnancy

Mean Score $\S$

* Number of doctors and percentage of total that responded correctly to the criteria

$\uparrow$ These columns reflect the absolute number of doctors who gave the correct answers in the interviews before and after the intervention

\$ The p calculated from the Wilcoxon Signed Rank Test comparing the scores before and after the intervention for every sub-theme

$\S$ Scores are the mean scores per sub-theme and can range between 0 and 10 points.

Significantly less medical barriers due to erroneous knowledge were observed $(\mathrm{p}<0.001$, Table 4). However, most doctors remained very reluctant to prescribe IUDs to adolescents who had not yet given birth. The promotion of condoms for protection against STIs increased, but remained low.

Also significantly less medical barriers due to the doctors' socio-cultural assumptions and values were recorded $(\mathrm{p}=0.003$, Table 4$)$. More doctors suggested to younger girls contraceptive methods which girls could themselves control; indicated unprotected intercourse as reason to prescribe emergency contraception and not only in cases of rape; and less frequently provided negative information on condoms. 
Table 4 The medical barriers before and after the intervention

\begin{tabular}{|c|c|c|c|}
\hline Medical Barriers & All Initial* & Initial $\uparrow$ & After \\
\hline V Due to erroneous knowledge & $\mathrm{N}=37(\%)$ & $\mathrm{N}=23$ & $\mathrm{~N}=23$ \\
\hline $\begin{array}{l}5.1 \text { Knows the current contraceptive methods for } \\
\text { adolescents mesigyna }{ }^{\circledR} \text { and ovrette } \AA\end{array}$ & $30(81.1)$ & 20 & 23 \\
\hline $\begin{array}{l}\text { 5.2 Does not mention out-dated contra-indications for IUD } \\
\text { use }\end{array}$ & $11(29.7)$ & 6 & 9 \\
\hline $\begin{array}{l}5.3 \text { Knows girls can start mesigyna }{ }^{\circledR} \text { on day } 1 \text { to } 5 \text { of their } \\
\text { menstrual cycle }\end{array}$ & $15(40.5)$ & 10 & 16 \\
\hline $\begin{array}{l}5.4 \text { Knows that emergency contraception can be prescribed } \\
\text { until } 72 \text { hours after unprotected intercourse }\end{array}$ & $17(46.0)$ & 14 & 19 \\
\hline 5.5 Explains that condoms protect against STIs. & $10(27.0)$ & 6 & 12 \\
\hline Mean Score $\S$ & $5.4 \mathrm{sd} 2.5$ & 4.9 sd 1.9 & 6.9 sd $2.4<\mathbf{0 . 0 0 1}$ \\
\hline
\end{tabular}

VI Due to socio-cultural assumptions and values

6.1 Includes a modern contraceptive that can be controlled

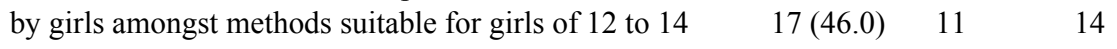

years

6.2 Includes condoms in the methods preference in girls

who have already a baby

6.3 Prescribes oral contraceptives if an adolescent of 14 years ask for that.

$2(5.4) \quad 2 \quad 6$

6.4 Considers unprotected intercourse an indication for emergency contraception

$20(54.1) \quad 15 \quad 16$

6.5 Does not give exclusive practical and negative attributions when girls start using condoms

$23(62.2) \quad 17 \quad 23$

$28(75.7) \quad 18 \quad 21$

Mean Score §

$5.7 \mathrm{sd} 2.2 \quad 5.5 \mathrm{sd} 1.9 \quad 7.0 \mathrm{sd} 1.8 \quad \mathbf{0 . 0 0 3}$

* Number of doctors and percentage of total who responded correctly to the criteria

+ These columns reflect the absolute number of doctors who gave the correct answers in the interviews before and after the intervention

\# The $\mathrm{p}$ calculated from the Wilcoxon Signed Rank Test comparing the scores before and after the intervention for every sub-theme

$\S$ Scores are the mean scores per sub-theme and can range between 0 and 10 points.

\subsubsection{Doctors' evaluation of the program}

All doctors were asked on which topics they would like to be better informed. In the initial interview 13/23 asked for information on contraception, 14/23 on STIs and $2 / 23$ on topics related to communication (on sexuality, counselling, or dealing with violence). When asked in the second interview, the results on contraception and STIs were the same, but the number of doctors asking for training in relation to communication had increased to $11 / 23$.

When asked about their experience with the program, all but one was positive: $17 / 23$ reported to have improved their knowledge, 15/23 reported to have improved their communication skills, and 15/23 to have gained experience. None complained about the increased workload. Most had enjoyed this new experience, although $12 / 23$ found it difficult to work with adolescents. Some explained that it was difficult to gain their confidence; that it was hard to identify their real reason for con- 
sulting; that some were very timid; and that adolescents lack a lot of information.

\subsection{Discussion}

The responses of the doctors clearly illustrate the obstacles that adolescents may face when they consult a doctor for sexual or reproductive health care. Erroneous knowledge, outdated practices and non-supportive attitudes appeared rather common. Significant improvements were observed among the participating doctors, especially with regard to doctors' knowledge and practices.

\subsubsection{Method}

There was nearly full participation of available doctors. Only one doctor refused to participate in the second interview. The most important reason for doctors being not available was frequent doctors' rotation, not only in the public but also in the private and nongovernmental sector, complicating the intervention as well as the survey. The interviews were taken in a relaxed and non-judgmental way and the doctors appeared to put effort in answering the questions. While a potential bias of this type of survey is that study participants report what they think the interviewer wants to hear, rather than what they actually do (19) the strength of the design was that no feedback was given to the doctors. Their answers give the impression that they were not seeking to provide answers consistent with the objectives of the intervention. The degree of correspondence between their answers and their daily practice cannot be assessed by interviews alone, but it is unlikely that they perform better than their self-assessment $(20 ; 21)$.

Although no control group was available, the observed changes are likely to be attributed to the voucher program since no other interventions on SRH-care took place in these clinics in the same timeframe. Furthermore, all but one doctor confirmed the contribution the intervention had made in improving their knowledge of SRH-care, and their experience and communication with adolescents.

The main objective of this survey was to evaluate whether participation in a voucher program could improve doctors' knowledge, attitudes, and practices. As a result, the representativeness of the sample for all Nicaraguan doctors was for this exploratory study of less importance. However, the fact that only few differences were observed between different groups of doctors (male-female, younger-older, public-private-NGO), suggests that similar results might be found among other doctors in Nicaragua. More research is needed to assess the potential of a competitive voucher program in other populations of adolescents and doctors; to evaluate whether specific groups of doctors are more responsive to this kind of intervention; which elements of the program are especially effective; and how the length of the implementation period influences the results. 


\subsubsection{The implications}

The study illustrates the many opportunities that are missed by health care providers to reach out to adolescents who want to protect themselves against the risks of sexual intercourse. Provider attitudes persist as a major obstacle towards good quality SRH-care. In Nicaragua, doctors know that sexual activity among young teenagers is a reality, with $8 \%$ of 15 year-old girls and $45 \%$ of 19 -year old girls pregnant or already mothers (1)and they are familiar with the high levels of unwanted pregnancies and forced sexual activity $(1 ; 22)$. The reluctance to prescribe the contraceptive pill to a 14-year old girl, despite the risks of a pregnancy and the lack of alternative contraception, is more typically characteristic of a parent than a medical doctor. Also, the negative attitudes towards condom use that some doctors exhibit do not reflect current public health insights that promote the use of condoms among sexually active teenagers for their dual protection (prevention of STIs and prevention of unwanted pregnancy).

It should be noted that these phenomena are not unique to Nicaragua $(2 ; 3 ; 19)$. The results underscore the need to develop and evaluate effective approaches to improve the quality of the care delivered by the doctors. Strengthening the demand side by supporting adolescents to claim their rights is very important but might not be enough.

Individual doctors cannot be blamed. During their training in medical school, SRHcare is scarcely addressed, communication training is not given, neither are medical ethics and attitudes discussed. Most doctors participated enthusiastically in the voucher program and training sessions, and attempted to provide this new group of clients with high quality care. The fact that payment was linked to the number of adolescents a doctor succeeded in attracting to her/his clinic may have been an important incentive. An interesting result of the program was that doctors discovered their own deficiencies in communicating with adolescents. Improving client-provider interactions shows great promise in increasing positive outcomes in terms of clients' satisfaction, increased knowledge, and more effective and longer use of contraceptives (23). Consulting with adolescents in relation to SRH is not easy, as has been concluded in many places in the world (24;25). More substantial changes in how the participants deal with adolescents might be achieved by intensification of the training in communication and extension of the intervention period.

The interviews with doctors proved an effective instrument to identify problems and assess advances in knowledge, attitudes, and practices related to adolescent friendly health care. Although the doctors showed improvement, particularly in the more practical aspects of their work, in terms of attitude change, the program was less successful. The risk is that doctors remained unaware of erroneous understandings and of how their attitudes make their professional behaviour less effective. Personalized feedback has proven to be an important strategy in motivating doctors to change $(8 ; 9 ; 26 ; 27)$, and procedures should be developed to 
provide feedback to doctors. Small group interactive education with active participation is another strategy that showed positive effects (28)) and could be used to strengthen programs' impact.

In conclusion, this study reveals that serious deficiencies exist in the knowledge, attitudes and practices of doctors with regard to the quality of SRH-care provided to adolescents; that doctors were willing to improve; that a competitive voucher program with technical support for the participating doctors can be a promising strategy to prompt change among practicing doctors; and that the voucher program can be developed further to increase its' impact. The success of the intervention could be explained by the combination of training, support, and experience with adolescents, as well as financial incentives. These results are of special interest in view of the key role that doctors can play in decreasing the vulnerability of youth to HIV infection through correct treatment of sexually transmitted infections, and in reducing the risks of unwanted teenage pregnancies by providing ready access to reliable contraceptives.

\section{Acknowledgement}

We thank all doctors for their enthusiastic participation in the intervention and the evaluation. Special words of thanks go to Patricia Gonzalez, Amelia Tijerino, Roger Torrentes, Alejandro Dormes, Zoyla Seguro, Joel Medina, and Tomás Donaire. We are very grateful to Julienne McKay for her encouraging and continued support during the preparation of this report. Last but not least, without the financial support of DFID this program would never have been possible.

\section{References}

1. INEC Instituto National de Estadística Censos, Ministerio de Salud. Demographic Health Survey Nicaragua 2001 [in spanish]. Managua, Nicaragua: Instituto nacional de Estadística and Censos y Ministerio de Salud, Calverton, MD USA; Marco International/DHS+ Program, 2001.

2. Langer A. Unwanted pregnancy: impact on health and society in Latin America and the Caribbean [in spanish]. Rev Panam Salud Publica 2002; 11(3):192-204.

3. Pons JE. Contraceptive services for adolescents in Latin America: facts, problems and perspectives. Eur J Contracept Reprod Health Care 1999; 4(4):246-254.

4. Senderowitz J. Health Facility Programs on Reproductive Health for Young Adults. http://www.futuresgroup.com/abstract.cfm/43 Accessed 6 June $2001,1-51.1997$. Washington DC,USA, FOCUS on young adults. Research Series. 6-6-2001.

Ref Type: Electronic Citation

5. Shelton JD. The Provider Perspective: Human After All. International Family Planning Perspectives 2001; 27(3).

6. Speizer IS, Hotchkiss DR, Magis C, Hubbard B, Nelson K. Do Service Providers in 
Tanzania Unnecessarily Restrict Clients' Access to Contraceptive Methods? International Family Planning Perspectives 2000; 26(1):13-20\&42.

7. Stanback J, Thompson A, Hardee K, Janowitz B. Menstruation requirements: a significant barrier to contraceptive access in developing countries. Stud Fam Plann 1997; 28(3):245-250.

8. Lande RE. Performance Improvement. Population Report Series J, 2002; 52.

9. Rudy S, tabutt-henry J, Schaefer BSN, McQuide P. Improving client provider interaction. Population Reports Series Q 2003; 1.

10. Stanback J, Twum-Baah KA. Why do Family planning providers restrict access to services? An examination in Ghana. Int Fam Plan Perspect 2001; 27(1):37-41.

11. Eggleston E, Hardee K, Jackson J. Sexual Attitudes and Behavior Among Young Adolescents in Jamaica. International Family Planning Perspectives 1999; 25(2):78-84 \& 91.

12. Gorter A, Sandiford P, Rojas Z, Salvetto M. Competitive Voucher Schemes for Health, Background Paper. Part of the Toolkit on Competitive voucher schemes in health. ICAS/Private Sector Advisory Unit of The World Bank Group, editor. 2003. Washington, DC, USA. Ref Type: Report

13. Borghi J, Gorter A, Sandiford P, Segura Z. The cost-effectiveness of a competitive voucher scheme to reduce sexually transmitted infections in high-risk groups in Nicaragua. Health Policy Plan 2005; 20(4):222-231.

14. Meuwissen LE, Gorter AC, Knottnerus AJ. Impact of accessible sexual and reproductive health care on poor and underserved adolescents in Managua, Nicaragua: a quasi-experimental intervention study. J Adolesc Health 2006; 38(1):56.

15. Meuwissen LE, Gorter AC, Knottnerus JA. Perceived quality of reproductive care for girls in a competitive voucher programme. A quasi-experimental intervention study, Managua, Nicaragua. Int J Qual Health Care 2006; 18(1):35-42.

16. Senderowitz J. Do Youth-Friendly Services Make a Difference?

http://www.fhi.org/en/Youth/YouthNet/Publications/FOCUS/InFOCUS/YFSmakediff.htm Accessed 20 October 2000 . 1998.

Ref Type: Electronic Citation

17. Bertrand JT, Hardee K, Magnani RJ, Angle M. Access, Quality Of Care and Medical Barriers in Family Planning Programs. Int Fam Plan Perspect 1995; 21:64-69\&74.

18. Singh S. Adolescent knowledge and use of injectable contraceptives in developing countries. J Adolesc Health 1995; 16(5):396-404.

19. Hardee K, McDonald OP, McFarlane C, Johnson L. Quality of care in family planning clinics in Jamaica. Do clients and providers agree? West Indian Med J 2001; 50(4):322327.

20. Hardee K, Clyde M, McDonald OP, Bailey W, Villinski MT. Assessing family planning service-delivery practices: the case of private physicians in Jamaica. Stud Fam Plann 1995; 26(6):338-349.

21. Hardee K, Janowitz B, Stanback J, Villinski MT. What Have We Learned from Studying Changes in Service Guidelines and Practices? Int Fam Plan Perspect 1998; 24(2):84-90.

22. Olsson A, Ellsberg M, Berglund S, Herrera A, Zelaya E, Pena R et al. Sexual abuse during childhood and adolescence among Nicaraguan men and women: a population-based anonymous survey. Child Abuse Negl 2000; 24(12):1579-1589.

23. RamaRao S, Mohanam R. The quality of family planning programs: concepts, measurements, interventions, and effects. Stud Fam Plann 2003; 34(4):227-248. 
24. Macfarlane A, McPherson A. Primary health care and adolescence. BMJ 1995; 311(7009):825-826.

25. Hassan EA, Creatsas GC. Adolescent sexuality: a developmental milestone or risktaking behavior? The role of health care in the prevention of sexually transmitted diseases. J Pediatr Adolesc Gynecol 2000; 13(3):119-124.

26. Hays RB, Jolly BC, Caldon LJ, McCrorie P, McAvoy PA, McManus IC et al. Is insight important? measuring capacity to change performance. Med Educ 2002; 36(10):965-971. 27. Wensing M, Grol R. Single and combined strategies for implementing changes in primary care: a literature review. Int J Qual Health Care 1994; 6(2):115-132.

28. Grol R, Grimshaw J. From best evidence to best practice: effective implementation of change in patients' care. Lancet 2003; 362(9391):1225-1230. 


\section{Chapter 9}

Does a competitive voucher program for adolescents improve the quality of reproductive health care?

A simulated patient study in Nicaragua

By Liesbeth E. Meuwissen, Anna C. Gorter, Arnold D.M. Kester and

J.A. Knottnerus 


\begin{abstract}
Background

Evaluate the impact and sustainability of a competitive voucher program on the quality of sexual and reproductive health care for poor and underserved adolescents and the usefulness of the simulated patient (SP) method for such evaluation.
\end{abstract}

\title{
Methods
}

28,711 vouchers were distributed to adolescents in disadvantaged areas of Managua that gave free-of-charge access to sexual and reproductive health care in 4 public, 10 non-governmental and 5 private clinics. Providers received training and guidelines, treatment protocols, and financial incentives for each adolescent attended. All clinics were visited by female adolescent SPs requesting contraception. SPs were sent one week before, during (with voucher) and one month after the intervention. After each consultation they were interviewed with a standardized questionnaire. Twenty-one criteria were scored and grouped into four categories: choice of contraceptive method; continuity in contraceptive use; sexually transmitted infection prevention; and organisation of services. Clinics' scores were compared using non-parametric statistical methods (paired design: before-during and before-after). Also the influence of doctors' characteristics was tested using non-parametric statistical methods.

\section{Results}

Some aspects of service quality improved during the voucher program. Before the program started 8 of the 16 SPs returned 'empty handed', although all were eligible contraceptive users. During the program 16/17 left with a contraceptive method $(\mathrm{p}=0.01)$. Furthermore, more SPs were involved in the contraceptive method choice $(13 / 17$ vs.5/16, $p=0.02)$. Shared decision-making on contraceptive method as well as condom promotion had significantly increased after the program ended.

Female doctors had best scores before- during and after the intervention. The improvements were more pronounced among male doctors and doctors older than 40 , though these improvements did not sustain after the program ended.

\section{Conclusions}

This study illustrates provider-related obstacles adolescents often face when requesting contraception. The care provided during the voucher program improved for some important outcomes. The improvements were more pronounced among providers with the weakest initial performance. Shared decision-making and condom promotion were improvements that sustained after the program ended. The SP method is suitable and relatively easy to apply in monitoring clinics' performance, yielding important and relevant information. Objective assessment of change through the SP method is much more complex and expensive. 


\subsection{Background}

Nicaragua has one of the highest adolescent fertility rates of Latin America, with 119 births annually per 1000 young women aged $15-19$. By the age of $19,45 \%$ of the girls are either pregnant or have already given birth. High fertility rates are associated with low socio-economic status and low educational attainment (1). In addition, adolescents experience high rates of unwanted pregnancy, illegal abortions; high maternal mortality rates, and are at high risk of contracting sexually transmitted infections (STIs), including HIV. These risks are closely connected with the low use of contraceptive methods among sexually active adolescents. Although $98 \%$ of the $15-19$ year olds could name at least one contraceptive method, only $46 \%$ of the sexually active girls in this age group used such a method (1).

Major reasons for the low use of contraceptive methods among adolescents are lack of access to information and services on sexual and reproductive health (SRH) and a low quality of care. While obstacles to appropriate care have been documented extensively (2-5), there is an urgent need to better understand how to change the existing situation $(6 ; 7)$.

Evidence of interventions that have succeeded in improving the quality of SRH care for adolescents in existing health centres in Latin America is scarce. Indications existed that the competitive ${ }^{1}$ voucher program for sex-workers in Managua, Nicaragua, succeeded in improving the quality of care for these women $(8 ; 9)$, however this was never subject of specific research. Therefore, when the Central American Health Institute (ICAS) implemented a pilot voucher program between 2000 and 2002, designed to increase access to and quality of SRH care for poor and underserved adolescents, various aspects of the quality of care provided were closely monitored and evaluated. Though the program had impact on boys and girls, we focussed the evaluation on girls due to resource constraints and because we wanted to assess if girls could be supported to take control of their fertility, without requiring the consent of parents or partner.

The evaluation showed that voucher receipt increased use of SRH care among

\footnotetext{
${ }^{1}$ Competition refers to the fact that in the described program there is competition between service providers, as opposed to programs were the voucher is redeemable at a single service provider. Competitive voucher schemes are one form of demand side financing where purchasing power is given to the consumer and money follows the patient (8).
} 
female adolescents (adjusted odds ratio 3.1, 95\% confidence interval 2.5 - 3.9) and of contraceptives and condoms in specific groups (10). Furthermore, girls were more satisfied with the quality of SRH care delivered through the voucher program, compared to care delivered without voucher (11). Quality as perceived by the patients is an important aspect of quality, but not the only one the program aimed at influencing.

The objective of the simulated patient (SP) study reported here was to assess whether the technical quality, the content of the communication and the general treatment were improved by the voucher program, and whether any change was sustained after the intervention ended. The second aim of this exploratory study was to evaluate the usefulness of the SP method to evaluate such changes. SPs were sent to the participating clinics, before, during and after the intervention to request a contraceptive method. This paper reports on their experiences with the health care and our experiences with the SP method.

\subsection{Methods}

\section{The intervention}

The intervention took place in Managua, the capital of Nicaragua, one of the poorest countries of Latin America. Primary health services in Managua consist of public health centres run by the Ministry of Health, municipal public health centres, private clinics, and clinics run by non-governmental organisations (NGOs). Most participating clinics are staffed by two doctors, and in most larger clinics two doctors were allocated to receive adolescents.

Over fifteen months, 28,711 vouchers were distributed to adolescents aged between 12 and 20, at markets, outside schools and door-to-door in disadvantaged neighbourhoods. The only selection criterion was age. The vouchers gave free of charge access to SRH care in any of the four public, five private or ten NGO clinics contracted by ICAS, for one consult and a follow-up visit. The selection of clinics was based on suitability and proximity to the areas where vouchers were distributed. Identified clinics were invited to participate, and the price per consultation was negotiated based on their customary fees. The average price negotiated per consultation and follow-up visit was US\$ 4.56. Adolescents were free to redeem their voucher in a clinic of their choice, and the clinics received reimbursement for each adolescent consultation with a voucher. The voucher program started with four clinics and new clinics were added periodically. 
Vouchers were valid for three months and $20 \%$ of the vouchers distributed to girls were redeemed (boys 6\%). This is a relatively high redemption rate considering the limited period over which the vouchers were valid and that a large percentage of the receivers was not yet sexually active. Among sexually active girls, 51\% used their voucher, while among girls who were not yet sexually active, use was only $14 \%(10)$.

The voucher program addressed various aspects of quality of care. Doctors had to complete a standardized clinical form based on 'best practice' protocols, which guided them during each consultation. The form was designed to ensure that every adolescent was asked about their sexual activity; their need for information; their need for contraceptives; and was given a package with two condoms plus health education material on adolescence and STIs. Contraceptives, drugs for syndromic treatment of STIs and laboratory tests for pregnant girls were made available through the program. It was assumed that the competitive nature of the voucher program would prompt providers to improve the quality of services to attract more voucher users (8). Doctors at participating clinics received an information manual and were obliged to attend an introductory meeting to learn about the program and its procedures. Furthermore, they were encouraged to attend a training course conducted over three mornings on 'adolescent friendliness' (12), counselling, adolescence and sexuality, contraceptives, and sexual abuse organized by the University of Nicaragua. Seventy percent of the doctors participated in at least one training session. In addition, clinic receptionists received training on 'adolescent friendliness'

\section{The design}

In the SP method patients are 'standardized' making it possible to compare the performances of different doctors or of one doctor at different moments. The use of the SP method in developed countries has proven to be reliable, valid, feasible and acceptable (13-15). The reported experiences in developing countries are promising (16-20). To assess the individual performance of a doctor one has to use at least 8 to $10 \mathrm{SPs}$, but for the assessment of a group performance for one medical problem, one SP probably suffices $(15 ; 21)$. To evaluate the intervention we measured the performance pre- during and post intervention. We selected the clinics as unit of analysis, because the intervention envisaged to improve the quality of care provided by the participating clinics.

All 19 participating clinics signed a contract of agreement that included information that the quality of care would be evaluated on a regular basis. They were not informed specifically on the methods to be used. The week before the 
intervention started in a certain clinic, a SP without a voucher was sent. During the course of the program, SPs were sent with a voucher to monitor the quality of care provided under the program. One to two months after the program ended, SPs without a voucher visited each clinic again.

The SPs were female adolescents active in NGOs involved in the voucher distribution, and university students participating in social work activities. They were contracted on a day-to-day basis and were paid a days' wage and enough money to pay for the consultation fees, if needed, and transportation costs. In total, 17 SPs took part in the survey. Their mean age was 18.7 years (range 16-22 years) and seven had secondary school education and 10 studied at the university. The mean number of doctors visited was 3.5 (range $1-12$ ).

All SPs received a short training on the task to be performed. The objective of the study was explained and the girls were instructed to present a story that over the past three months they had formed a relationship with a boyfriend and were presently using withdrawal or periodic abstinence, but did not want to risk pregnancy. Furthermore, they had to ask for information on HIV/AIDS. All were told that they were free to accept or reject any information or services offered to them. If necessary, they were advised to decline vaginal examination by saying that they were currently menstruating.

The SPs were not accompanied to the clinic. If needed, the SP would make an appointment. After the consultation, the SPs were immediately interviewed by one of the two doctors of the research team at the ICAS office, using a standardized questionnaire. The answers were recorded by the interviewer on the questionnaire. The study was approved by the ethical review committee of ICAS.

\section{Measurement}

The questionnaire contained 35 open-ended questions and included commonly used elements for evaluating quality of family planning services: choice of contraceptive methods, information given to users, technical competence, interpersonal relations, mechanisms to encourage continuity and appropriate organisation of services (22). Questions included: Did the doctor explain a contraceptive-method? Which methods were explained to you? Which method was decided upon? Did the doctor orientate you about the method or did you feel he/she imposed the method? What did he/she tell you about the advantages and disadvantages of the method? Where you satisfied with the explanations given by the doctor? (The questionnaire is available on request). 
The 21 criteria for evaluation are based on the program objectives, and were extensively discussed by the research team and defined before the analysis was performed. They are grouped into four categories. Two categories relate to contraception: A. method choice and B. continuity in use; category C. relates to prevention of STIs; and D. to the organisation of the services. The last category is composed of a selection of criteria that have been found to influence patients' perception of the quality of care, but do not relate directly to the doctors performance. A maximum score of 10 points could be attained if there was a positive response for all criteria in one category. The addition of the scores of the first three categories serves as an indicator of the quality of the consultation. For more details on the components of each category see Tables 1 and 2. The internal consistency for category $\mathrm{A}$ to $\mathrm{C}$ is high. Cronbachs alpha is respectively $0.67,0.60$ and 0.72 . For category $\mathrm{D}$ the alpha is 0.26 , which is not a surprise in view of the independency of the underlying criteria (e.g. waiting time, cleanliness and privacy are not necessarily associated, though all important).

\section{Data handling and analysis}

Information on date of interview, clinic, and doctor visited was disconnected from the file, and records were put in a random order. Codification was done by one person, and checked by another. All data were entered twice in Epi-info 6.04 by two different data processors. Stata 7.0 (StataCorp, College Station, TX, USA) was used for further analysis.

The response to each criterion is tabulated in table 1 and 2. To guarantee equal representation of all clinics, mean scores per criterion were calculated for clinics visited more than once during a particular round. The Wilcoxon signed ranks test (paired design) was used to look for differences in performance before and during the intervention, and before and after the intervention. Because the sample size is small, associations with borderline significance $(0.5<\mathrm{p}<0.10)$ are also reported.

To get an indication as to whether doctors' characteristics influence their performance while counselling for contraception and STI/HIV, the sum scores of the three categories reflecting the quality of the consultation are calculated, at the three relevant time-points. Because the doctors are not necessarily the same at the different time-points, only comparisons per time-point are made. Per time-point, the non-parametric Mann Whitney test is used to assess the influence of doctors' gender and the Kruskal-Wallis test to assess the influence of the age group and the type of clinic on their responses.

Since doctors had to complete a medical form for all patients with a voucher, this 
included the SPs. These forms were used to evaluate the SPs' performance and doctors' registration.

\subsection{Results}

All clinics received SPs. In total 65 visits were made to 16 clinics before, 17 during and 15 after the intervention. Seventeen SPs visited 16 of the 19 participating clinics before the intervention. In one clinic, the SP was received by the counsellor instead of the doctor, one was sent too late and treated according to the voucher protocol, and one is missing for unknown reasons. During the intervention, 17 clinics were visited by $30 \mathrm{SPs}$ with a voucher. One of the clinics was excluded due to administrative problems and one resigned from further participation. After the pilot, one clinic was temporarily closed and another permanently closed. Eighteen SPs visited the remaining 15 clinics.

Thirty-three of the 40 doctors who participated in the voucher program received at least one SP. Their characteristics are similar to the entire group of participating doctors. Six (18\%) of the doctors worked in a public facility; $19(58 \%)$ in an NGO clinic and $8(24 \%)$ in a private clinic. Sixty-one percent are female and 39\% younger than 35 years, broadly conforming to the gender and age profile of primary health care doctors in Nicaragua.

The choice of the method (Table 1, part A).

Few SPs said they received counselling on all contraceptive methods. During the voucher program the number of methods presented was more frequently less than three than before the program (A2, 12/16 vs. 11/17 vs. $\mathrm{p}=0.09$ ). However, the number of barriers to use diminished. Barriers related to unnecessary diagnostic tests disappeared during the voucher program $(\mathrm{A} 3,12 / 16$ vs. $17 / 17, \mathrm{p}=0.08)$, but returned after the program.

There was considerable variation in the methods recommended by the doctors. Some doctors promoted the condom for its safety or dual protection, where other doctors advised that condoms were unsafe, boyfriends would resist using them, or warned about possible allergic reactions. The same variation was seen in methods such as the intra-uterine device and monthly injectables. Before and after the program, some doctors recommended natural methods like periodic abstinence as best method for adolescents. The quality of the explanations given improved during the voucher program and remained better after the program ended (A5, $\mathrm{p}=0.08$ ). 


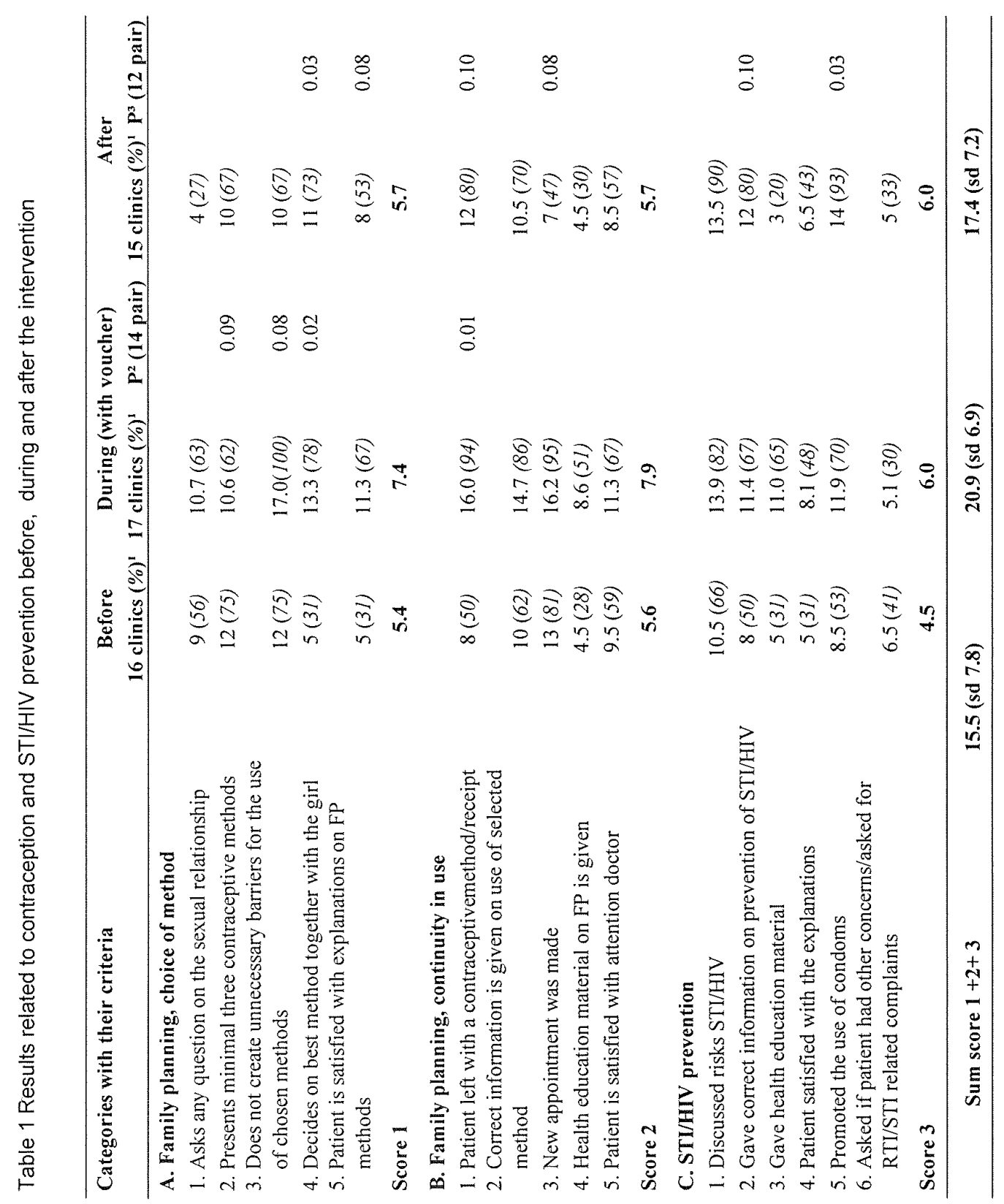


See Table 1:

FP Family Planning STI Sexually Transmitted Disease

${ }^{1}$ Column before: the information is based on 17 observations. Column during: the information is based on 30 observations. Column after: the information is based on 18 observations. When a clinic was visited more than once, the mean values of that clinic were calculated and considered

${ }^{2}$ the $\mathrm{p}$ value that is the result of the Wilcoxon Signed Ranks test (Paired design), comparing the scores of the clinics before and during the program, only p-values $\leq 0.10$ are reflected.

${ }^{3}$ the $\mathrm{p}$ value that is the result of the Wilcoxon Signed Ranks test (Paired design), comparing the scores of the clinics before and after the program, only p-values $\leq 0.10$ are reflected.

Before the intervention started, most SPs indicated that it was the doctor who decided on the type of contraceptives to be used. Patients with a voucher reported more frequently that they made the choice jointly with the doctor (A4, 13/17 vs. $5 / 16, \mathrm{p}=0.02)$. The percentage of SPs reporting shared decision-making remained relatively high after the intervention $(\mathrm{p}=0.03)$.

Continuity in use (Table 1. part B)

Although all SPs were eligible contraceptive users, before the program eight of the 16 SPs left the consultation room without a contraceptive method or prescription. Six of these eight SPs were told to come back on the first day of their next menstrual cycle. One doctor preferred to wait for the results of unnecessary laboratory tests (e.g. liver function tests, urine sediments) and one advised periodic abstinence (the 'rhythm method').

During the voucher program, $94 \%$ of the girls left the clinic with a contraceptive method $(\mathrm{B} 1, \mathrm{p}=0.01)$. This improved practice continued after the program ended $(p=0.10)$, but the frequency of follow-up appointments decreased $(B 3, p=0.08)$.

Information on STIs/HIV (Table 1, part C)

Although the percentage of doctors discussing STI/HIV-risks during a consultation increased, a considerable number of patients did not receive the desired information. More than $10 \%$ of the SPs in each round felt the doctor was in a hurry to end the consult. Some felt pressured to the extent that they did not ask their question on STIs.

Although in less than half of the consultations before, during and after the intervention SPs were satisfied with the explanations provided, patients seen after the intervention more frequently received correct information than before $(\mathrm{C} 2$, $\mathrm{p}=0.10)$ and condom promotion increased from $53 \%$ to $93 \%(\mathrm{C} 5, \mathrm{p}=0.03)$.

There was considerable variation in the content of the information on prevention on STIs/HIV. Some doctors gave good and reliable information where others confined 
themselves to observations like: "One has to know the person with whom one is with"; "The only way to prevent AIDS is not to sleep with someone who has AIDS"; "One should not use clothes from other persons"; or "If someone's partner is sweating and having weight loss he might have AIDS".

Table 2 Results related to the organisation of the clinic before during and after the intervention

\begin{tabular}{|c|c|c|c|c|c|}
\hline D. Organisation of the clinic & $\begin{array}{l}\text { Before } \\
16 \text { clinics } \\
(\%)^{1}\end{array}$ & $\begin{array}{l}\text { During } \\
17 \text { clinics } \\
\text { (\%) }{ }^{1}\end{array}$ & $\begin{array}{l}P^{2} \\
(14 \\
\text { pair })\end{array}$ & $\begin{array}{c}\text { After } \\
15 \text { clinics } \\
(\%)^{1}\end{array}$ & $\begin{array}{c}\mathrm{P}^{3} \\
\text { (12pair) }\end{array}$ \\
\hline 1. Clean and appropriate & $14(88)$ & $14.3(84)$ & & $10.5(70)$ & \\
\hline 2. Waiting time not more than 1 hour & $14(88)$ & $13.9(82)$ & & $13.5(90)$ & \\
\hline 3. Privacy maintained during consultation & $11(69)$ & $12.5(74)$ & & $15(100)$ & 0.08 \\
\hline 4. No interruptions during consultation & $12(13)$ & $13.3(78)$ & & $13(87)$ & \\
\hline 5. Consultation time of at least a quarter of an hour & $12(15)$ & $14.8(87)$ & & $10.5(70)$ & \\
\hline Score 4 & 7.9 & 8.1 & & 8.3 & \\
\hline
\end{tabular}

\footnotetext{
${ }^{1}$ Column before: the information is based on 17 observations. Column during: the information is based on 30 observations. Column after: the information is based on 18 observations. When a clinic was visited more than once, the mean values of that clinic were calculated and considered

${ }^{2}$ the $p$ value that is the result of the Wilcoxon Signed Ranks test (Paired design), comparing the scores of the clinics before and during the program, only $\mathrm{p}$-values $\leq 0.10$ are reflected.

${ }^{3}$ the $\mathrm{p}$ value that is the result of the Wilcoxon Signed Ranks test (Paired design), comparing the scores of the clinics before and after the program, only $\mathrm{p}$-values $\leq 0.10$ are reflected.
}

\section{Organisation of the clinic (Table 2)}

No clear differences in the organisational aspects of the clinic could be established, except that privacy during consultation appeared better respected after than before and during the intervention $(\mathrm{p}=0.08)$.

\section{Handling of voucher users}

Patients with a voucher were not always treated according to the contractual agreements. SPs reported that receptionists sometimes completed considerable parts of the medical forms and that other patients were favoured in the waiting room.

Experiences of the SPs with vouchers suggest that some private clinics tried to make as much money as possible out of the program by erroneous declarations, and by selling or withholding the materials provided by the program. 
Table 3 Influence of doctors and clinics characteristics on their performances before during and after the intervention.

\begin{tabular}{|c|c|c|c|c|c|c|c|c|}
\hline \multirow{2}{*}{$\frac{\text { Scores }^{1}}{\text { Gender }^{2}}$} & \multicolumn{3}{|c|}{ Before } & \multicolumn{3}{|c|}{ During (with voucher) } & \multicolumn{2}{|r|}{ After } \\
\hline & $\mathbf{N}=\mathbf{1 7}$ & Mean & $\mathbf{p}^{3}$ & $\mathrm{~N}=\mathbf{2 4}$ & Mean & $\mathbf{p}^{3}$ & $\mathbf{N}=\mathbf{1 7}$ & Mean \\
\hline Women & 9 & $19.7(\mathrm{sd} 8.0)$ & & 16 & $22.8(\operatorname{sd} 6.5)$ & & 11 & $20.5(\operatorname{sd} 5.6)$ \\
\hline Male & 8 & $9.7(\mathrm{sd} 2.9)$ & 0.01 & 8 & $16.4(\operatorname{sd} 7.1)$ & 0.05 & 6 & $12.6(\mathrm{sd} 5.6) 0.03$ \\
\hline Age group $^{2}$ & & & $\mathbf{p}^{4}$ & & & $\mathbf{P}^{4}$ & & $\mathbf{p}^{4}$ \\
\hline $30-34$ & 6 & $14.8(\mathrm{sd} 8.9)$ & & 7 & $24.2(\operatorname{sd} 5.3)$ & & 6 & $18.7(\operatorname{sd} 6.1)$ \\
\hline $35-39$ & 7 & $17.6(\operatorname{sd~8.7)}$ & & 12 & $19.8(\operatorname{sd} 7.3)$ & & 7 & $21.2(\mathrm{sd} 4.6)$ \\
\hline $40+$ & 4 & $10.8(\mathrm{sd} 3.1)$ & & 5 & $17.7(\operatorname{sd} 8.6)$ & & 4 & $10.1(\operatorname{sd} 4.7) 0.04$ \\
\hline Type of clinic ${ }^{5}$ & $N=16$ & & $\mathbf{P}^{4}$ & $\mathbf{N}=17$ & & $\mathbf{P}^{4}$ & $\mathrm{~N}=15$ & $\mathbf{P}^{4}$ \\
\hline Public & 4 & $12.5(\mathrm{sd} 8.0)$ & & 3 & $22.2(\mathrm{sd} 10.3)$ & & 2 & $14.8(\operatorname{sd} 2.9)$ \\
\hline NGO & 8 & $18.4(\mathrm{sd} 8.6)$ & & 10 & $20.6(\operatorname{sd} 4.9)$ & & 9 & $20.7(\operatorname{sd} 6.2)$ \\
\hline Private & 4 & $12.9(\operatorname{sd~5.1)}$ & & 4 & $22.1(\operatorname{sd} 6.3)$ & & 4 & $11.3(\mathrm{sd} 7.2)$ \\
\hline
\end{tabular}

${ }^{1}$ Mean sum score of categories I to III reflecting the consultation

${ }^{2}$ During the voucher programme some doctors were visited more than once by SPs, but for this analysis only the first visits were considered. After the intervention 1 SP was seen by a Nurse.

${ }^{3}$ Outcome of the Mann Whitney test (comparing the mean sum score of men and women) only p-values $<$ 0.10 are reflected.

${ }^{4}$ Outcomes of the Kruskall Wallis test, only p-values $\leq 0.10$ are reflected.

${ }^{5}$ For each clinic the mean score is considered. Column 'before' is based on 17 observations, column 'during' on 30 observations and 'after' on 18 observations, only p-values $\leq 0.10$ are reflected.

Other factors influencing the results (Table 3)

The gender of the doctor was strongly associated with the results. Female doctors scored better than male doctors before, during and after the intervention. Male doctors improved by a greater degree during the voucher program. However, these changes were not sustained except for the category on STI/HIV prevention (not shown). Elderly doctors had the lowest initial scores, which improved during the program, but still remained the lowest. Doctors younger than 35 improved most during the voucher program. In contrast to the analyses mentioned above, individual doctors are here the unit of analysis (results are reflected in first part of table 3).

Comparing the public, NGO and private clinics, the NGO clinics performed best before the intervention. During the intervention, the improvements observed were more pronounced among the public and private clinics, that is, the clinics with weakest initial performance. The performances became of a comparable quality during the intervention, but the improvements were not sustained after the intervention ceased (Second part of table 3). 


\subsection{Discussion}

Experiences of the SPs without vouchers illustrate the obstacles faced by adolescents in obtaining contraceptives through health services. Although all were eligible contraceptive users, a considerable number returned 'empty-handed'. For some important aspects the quality of care improved during the voucher program: more girls were involved in the method choice and more girls received a method. The improvements were more pronounced among providers and within clinics with the weakest initial performance. Shared decision-making and condom promotion were improvements that sustained after the program ended.

\section{Methodological considerations}

No mention was made by any SP or doctor that a patient was "detected" as SP, meaning that the method was valid (face validity). Judged from the medical records of patients who went with a voucher to the clinic, the SPs performed their role correctly.

SP studies designed to measure differences usually limit themselves to record doctors' actions because inter-observer variability for criteria related to doctorpatient interaction is much higher $(13 ; 14 ; 21 ; 23)$. Nevertheless, we incorporated the patients' perception in the criteria, because their subjective evaluation is probably the most important factor determining patient satisfaction (24), and decisive for future use of services. Our SPs were well instructed, relatively well educated, from a relatively homogeneous group, and were interviewed immediately after the consultation. As a result, we consider the differences found as indicative of real differences in performance.

We cannot exclude that the simulated patients were treated differently because of their somewhat higher level of education and higher age than the average voucher redeemer. However, accessing sexual and reproductive health care is difficult for many adolescents in Nicaragua, even for those who attended secondary school. Because the same group of girls participated in the pre- during and post assessment, the changes observed do not relate to their background.

Significant changes were foremost observed in criteria directly influenced by the program, such as how a decision on type of contraceptive method was taken and the improved delivery of methods. This may indicate that these criteria were the only ones influenced by the program. Because we compared clinics and not individual providers and the sample size was modest, it is also possible that less pronounced effects, or effects with lower inter-observer and/or inter-provider 
agreement, may not have been detected.

\section{The voucher program}

The voucher program had a substantial impact on the number of women that left the clinic with a contraceptive method. This is in accordance with the programs instruction to give any women who requested a contraceptive method, a one month supply of that method with clear instructions on when to start (first day of the next menstruation) and to use condoms before. Patients were asked to return during the month following their menstruation and to relate their experiences. In this return visit, still covered by the voucher, patients could then receive a three months supply.

Clinics and doctors with weakest initial scores showed biggest improvements, suggesting they made serious efforts to comply with the program requirements. Unfortunately, most changes did not sustain beyond the program. Furthermore, even during the program there is room for further improvement. A longer intervention period and specific strategies to enhance quality improvements might realize more substantial and more sustainable changes. The voucher program carries this possibility. On one hand, the participating doctors were enthusiastic about the program, appreciated the experience, and were interested to improve their communication and other skills (25). On the other hand, the approach can easily be strengthened by strategies such as interactive education in small groups (26) or supervision and self-assessment (27), which have proven to be effective in prompting sustained changes in daily practice.

Another strategy that could be combined with the voucher program is explicit use of the criteria for 'adolescent friendliness' (7). Recently, a tool has been developed for assessing and improving reproductive health services for youth (12). This assessment is best done by a small group of stakeholders, including adolescents, and can be used to grant clinics a label as 'adolescent friendly' or to develop an action plan for clinics to become adolescent friendly. Public display of such label signals to adolescents before entering the clinic that the staff will be receptive to their needs. A voucher program can limit inclusion to clinics and doctors that agree to conform to the standards required to be labelled 'adolescent friendly'. An additional and important advantage of such an approach would be that all adolescent patients are likely to benefit (and not only voucher bearers).

\section{The simulated patient method}

Preparing and sending SPs, and recording their experience is the simplest part of the SP method. Their experiences provide valuable information about the actual 
performance of health services. The SP method, when openly employed, can furthermore be a useful support for regular feedback and identification of further training needs. It becomes more complicated when the experiences of SPs are to be converted into indicators to assess and evaluate changes in quality of care in a scientifically correct manner. This methodological challenge is insufficiently emphasized in the literature. Although the SP method is particularly recommended for evaluating programs with a focus on the interaction between patients and doctors, difficulties and solutions related to standardized assessment of the inherently subjective patient's opinion are not reported. This is an interesting field for future research in view of the importance of patients' perception in health care use.

Assessing quality improvements -including through the SP method- is complicated and requires highly trained human resources, time and financial resources. Although many health care interventions in developing countries aim to achieve quality improvements, programs are seldom supplied with sufficient funds to make such valuable and important evaluations possible.

\section{Conclusion}

The adolescent voucher program seemed to have succeeded in increasing the accessibility of contraceptives through health services, and had the greatest impact on the quality of care in clinics with lowest initial quality levels. This is an important achievement, because if unwanted and untimely pregnancies are to be prevented, adolescents who engage in sexual relations need access to information and contraceptive methods.

Although in Nicaragua wide agreement exists that health care services should respond to these needs -as is explicitly outlined in norms and guidelines of the Ministry of Health (28)- implementation in daily practice lags well behind. The voucher program appears to be a relatively simple intervention able to improve important aspects of the quality of care delivered to adolescents. During the program adolescents received health care that better responded to their needs. Not all changes sustained after the program ceased. It is likely that implementation of the intervention over a longer period of time, with continued support to the providers, would be able to prompt a more sustained improvement in the quality of SRH care provided to adolescents.

The SP method proved to be a valuable and feasible method for program monitoring in a developing country. The results of this pilot study suggest that scaling up of the voucher program could be an effective strategy to make SRH care accessible, acceptable and appropriate for underserved teenagers. 


\section{Acknowledgement}

We thank all simulated patients for their enthusiastic participation in the evaluation. Special words of thanks go to Patricia Gonzalez, Amelia Tijerino, Roger Torrentes, Alejandro Dormes, Zoyla Seguro, Joel Medina, Gloria Medina and Tomás Donaire. We are very grateful to Julienne McKay for her encouraging and continued support during the preparation of this report. Last but not least, without the financial support of DFID this program would never have been possible.

\section{References}

1. INEC Instituto National de Estadística Censos, Ministerio de Salud. Demographic Health Survey Nicaragua 2001 [in spanish]. Managua, Nicaragua: Instituto nacional de Estadística and Censos y Ministerio de Salud, Calverton, MD USA; Marco International/DHS+ Program, 2001.

2. Eggleston E, Hardee K, Jackson J. Sexual Attitudes and Behavior Among Young Adolescents in Jamaica. International Family Planning Perspectives 1999; 25(2):78-84 \& 91.

3. Pons JE. Contraceptive services for adolescents in Latin America: facts, problems and perspectives. Eur J Contracept Reprod Health Care 1999; 4(4):246-254.

4. Shelton JD. The Provider Perspective: Human After All. International Family Planning Perspectives 2001; 27(3).

5. Stanback J, Thompson A, Hardee K, Janowitz B. Menstruation requirements: a significant barrier to contraceptive access in developing countries. Stud Fam Plann 1997; 28(3):245-250

6. Hughes J, McCauley AP. Improving the fit: adolescents' needs and future programs for sexual and reproductive health in developing countries. Stud Fam Plann 1998; 29(2):233245.

7. Senderowitz J. Health Facility Programs on Reproductive Health for Young Adults. http://www.futuresgroup.com/abstract.cfm/43 Accessed 6 June 2001 , 1-51. 1997. Washington DC,USA, FOCUS on young adults. Research Series. Ref Type: Electronic Citation

8. Gorter A. Evidence of effectiveness of competitive voucher schemes on HIV prevention and care for young people. Background paper 'Global consultation on the health services response to the prevention and care of HIV/AIDS among young people'. 2003. Montreux, Swiss, WHO, UNFPA, UNAIDS and YouthNet. Ref Type: Report

9. Sandiford P, Gorter A, Salvetto M. Vouchers for Health, Using Voucher Schemes for Output-Based Aid. Public Policy for the Private Sector, Viewpoint. 243, 1-4. 2002. The World Bank Group. Ref Type: Report

10. Meuwissen LE, Gorter AC, Knottnerus AJ. Impact of accessible sexual and 
reproductive health care on poor and underserved adolescents in Managua, Nicaragua: a quasi-experimental intervention study. J Adolesc Health 2006; 38(1):56.

11. Meuwissen LE, Gorter AC, Knottnerus JA. Perceived quality of reproductive care for girls in a competitive voucher programme. A quasi-experimental intervention study, Managua, Nicaragua. Int J Qual Health Care 2006; 18(1):35-42.

12. Senderowitz J, Hainsworth G, Solter C. A rapid assessment of youth friendly reproductive health services. 4, 1-12. 2003. Pathfinder International. Technical Guidance Series. Ref Type: Report

13. Beullens J, Rethans JJ, Goedhuys J, Buntinx F. The use of standardized patients in research in general practice. Fam Pract 1997; 14(1):58-62.

14. Rethans JJ, van Boven CP. Simulated patients in general practice: a different look at the consultation. Br Med J (Clin Res Ed) 1987; 294(6575):809-812.

15. Rethans JJ. Needs assessment in continuing medical education through standardized patients. 1998;172-178.

16. Hardee K, McDonald OP, McFarlane C, Johnson L. Quality of care in family planning clinics in Jamaica. Do clients and providers agree? West Indian Med J 2001; 50(4):322327.

17. Huntington D, Schuler SR. The simulated client method: evaluating client-provider interactions in family planning clinics. Stud Fam Plann 1993; 24(3):187-193.

18. Madden JM, Quick JD, Ross-Degnan D, Kafle KK. Undercover careseekers: simulated clients in the study of health provider behavior in developing countries. Soc Sci Med 1997; 45(10): 1465-1482.

19. Schuler SR, McIntosh EN, Goldstein MC, Pande BR. Barriers to effective family planning in Nepal. Stud Fam Plann 1985; 16(5):260-270.

20. Tatum C, Garcia SG, Goldman L, Becker D. Valuable safeguard or unnecessary burden? Characterization of physician consultations for oral contraceptive use in Mexico City. Contraception 2005; 71(3):208-213.

21. Rethans JJ, Saebu L. Do general practitioners act consistently in real practice when they meet the same patient twice? Examination of intradoctor variation using standardised (simulated) patients. BMJ 1997; 314(7088):1170-1173.

22. Bruce J. Fundamental elements of the quality of care: a simple framework. Stud Fam Plann 1990; 21(2):61-91.

23. Rethans JJ, Sturmans F, Drop R, van d, V, Hobus P. Does competence of general practitioners predict their performance? Comparison between examination setting and actual practice. BMJ 1991; 303(6814):1377-1380.

24. Zoppi K, Epstein RM. Is communication a skill? Communication behaviors and being in relation. Fam Med 2002; 34(5):319-324.

25. Meuwissen LE, Gorter AC, Kester ADM, Knottnerus JA. Can a comprehensive voucher program prompt changes in doctors' knowledge, attitudes, and practices related to sexual and reproductive health care for adolescents? A case study from Latin Amerika. Tropical Medicine and International Health 2006; 11(6):889-898.

26. Grol R, Grimshaw J. From best evidence to best practice: effective implementation of change in patients' care. Lancet 2003; 362(9391):1225-1230.

27. Kim YM, Figueroa ME, Martin A, Silva R, Acosta SF, Hurtado M et al. Impact of 
supervision and self-assessment on doctor-patient communication in rural Mexico. Int $\mathrm{J}$ Qual Health Care 2002; 14(5):359-367.

28. Direccion General de Servicios de Salud, Direccion de atencion integral, Programma de adolescentes. Technical and Administrative norms, First level of Attention. (in Spanish). Ministry of Health, editor. 1-37. 1999. Managua, Nicaragua. Ref Type: Report. 


\section{Chapter 10}

General discussion 



\subsection{Overview of the main findings}

\subsubsection{Situation before the intervention}

The results of this study confirm that female adolescents in Nicaragua lack important information on modern contraceptive methods and how to obtain them and on STIs and condoms. They made little use of SRH care, especially when they were neither pregnant nor a mother $(\mathrm{Ch} 5,6)$. The study reveals considerable problems with the quality of care (Ch 7 - 9). Erroneous knowledge, outdated practices and non-supportive attitudes appeared common among health care providers (Ch 8). Doctors provided very little health education (Ch 9). The requirement that a woman must be menstruating to receive contraceptives resulted in many clients leaving clinics empty-handed (Ch 9).

\subsubsection{The influence of the voucher program on adolescents' use of SRH care, contraceptive knowledge and contraceptive use.}

a. Contraceptive knowledge: Voucher receivers had a significant better knowledge of contraceptives and condoms than non-receivers. The impact of receiving a voucher was strongest among girls interviewed at schools and in disadvantaged neighbourhoods. Nevertheless, the level of knowledge remained relatively low, even among voucher receivers (Ch 5).

b. Contraceptive use: Voucher receivers used a condom in the last sexual encounter significantly more frequently than non-receivers (Adj. OR 1.8; 95\% CI $1.1-3.0$ ). There were significant differences between respondents in markets, at schools and in disadvantaged neighbourhoods. Among respondents in the neighbourhoods, voucher receivers had the strongest increase in condom use compared to nonreceivers (Adj. OR 2.5; 95\%CI 1.4 - 4.5). Among respondents at schools, voucher receivers had a significantly higher use of modern contraceptives than nonreceivers (Adj.OR 2.3; 95\% CI 1.2 - 4.4) (Ch 5).

c. Use of SRH care: Voucher receivers showed a statistically significant higher use of SRH care compared to non-receivers (Adj. OR 3.1, 95\%CI $2.5-3.9$ ). The increase in use was highest among respondents at schools (Adj. OR 5.9; 95\% CI 3.7-9.5) compared to respondents at markets and in neighbourhoods (Ch 5).

Female adolescents presented many SRH-problems that merited medical attention. Thirty-four percent of the vouchers were used for contraceptives, $31 \%$ for complaints related to STIs/RTIs, $28 \%$ for counselling/advice, $28 \%$ for antenatal check-up, and $18 \%$ for pregnancy testing (Note: girls could consult for more than one reason). A new category of health care users emerged through the voucher 
program, namely sexually active girls who were neither pregnant nor mothers, who sought contraceptives or STI/RTI treatment (Ch 6). The emergence of this group largely explains the increased use of contraceptives and condoms by girls interviewed in the neighbourhoods and at schools.

\subsubsection{The influence of the voucher program on the quality of SRH care}

a. User satisfaction: Users of SRH care with a voucher were significantly more often satisfied with the quality of care than users without a voucher (Adj. OR 2.2; $95 \%$ CI 1.2- 4.0). User satisfaction was highly correlated with satisfaction with the reception in the clinic and the clarity of doctors' explanations $(\mathrm{p}<0.001)$. While the clarity of doctors explanations was not associated with voucher use (Adj OR 1.4; $95 \%$ CI $0.9-2.2$ ), satisfaction with the reception in the clinic was significantly greater among voucher users, especially among girls who where neither pregnant nor mother. The adjusted odds ratio in this group was 6.9 (95\% CI 1.5-31.8).

b. Quality of care: The results of the different surveys were collated using the six aspects of quality of care that have been presented in chapter 4.3.

The choice of contraceptive method: Method choice was ensured by free-of-charge provision of an assortment of contraceptive methods and health education material. Furthermore, pre-packed supplies of drugs for STIs/RTIs were available. Although the number of contraceptive methods explained to the simulated patients did not increase over the course of the pilot program, a higher proportion of voucher users than non-users felt that the chosen method was the result of joint decision-making (Ch 9).

Information given to the client: Voucher users and girls who used SRH care without a voucher did not differ in their appreciation of the clarity of doctors' explanations (Ch 7). However, the responses of the doctors in the post-intervention interview showed that their knowledge of the reproductive health of adolescents had increased (Ch 8). The simulated patients confirmed this: they were more satisfied with the explanations given on contraceptive methods and STIs during and after the intervention than before (Ch 9).

Technical competence and medical barriers: The post-intervention interviews with the doctors showed that their knowledge on indications and contra-indications for contraceptives had improved. The providers also reported presenting a variety of contraceptive methods to adolescents in each age group, instead of one preferred method. This implies that medical barriers to contraceptives had decreased and that access had improved (Ch 8).

During the program nearly all simulated patients received a contraceptive method, compared to half of the patients before intervention (Ch 9). Of the girls who used a voucher and requested contraceptives, $6 \%$ still left without method. This occurred 
despite the doctor registering the girl's wish to start using contraception (Ch 6). Although there has been an improvement, this outcome does illustrate the difficulties associated with bringing about change in service delivery.

Interpersonal relations: The voucher program positively influenced the interpersonal relations between providers and their adolescent clients. Providers felt that they had learned a lot about interaction with adolescents. They evaluated the experience positively and were interested to learn more (Ch 8). As mentioned earlier, voucher users were more often satisfied with the quality of care than girls who used SRH care without a voucher (Ch 7). This is an important achievement, although it is important to acknowledge that 'satisfaction with quality of care' is influenced by a combination of many factors.

Doctors' gender played an important role. The indicators, scored by the simulated patient method, showed that female doctors performed better with female adolescents than male doctors before, during and after the intervention (Ch 9). Sexually active girls who consulted a female doctor younger than 36 had a significantly higher chance of having contraceptives prescribed (Ch 6). Girls were much more frequently satisfied with consultations with female doctors than with male doctors. Among girls who used a voucher, this preference was even stronger (Ch 7).

Follow-up mechanism: During the program, more girls left a consultation with an appointment for a follow-up visit than prior to its introduction. However, after the intervention this effect disappeared (Ch 9). Furthermore, very few providers (pre and post intervention) indicated that they would give a new user of a contraceptive method instructions on possible side effects or other problems; when to consult a doctor; or what to do if they forgot to take the pill ( $\mathrm{Ch} 8)$. This was confirmed by the simulated patients ( $\mathrm{Ch}$ 9).

Proper set-up of services: Based on the experiences of the simulated patients, no differences were observed in the set-up of SRH care services as a result of the program (Ch 9). Important aspects of the internal organisation of the clinic were waiting time and duration of the consultation, for voucher users and non-users alike (Ch 7). It should be noted, however, that the reception in the clinic was not included in the scores used in the simulated patient survey. Overall, patient satisfaction appeared strongly related to the way in which they were received in the health centre, which, in turn, was strongly influenced by the voucher program.

c. Sustainability of changes: After the program ended, some improved practices persisted, such as shared decision-making and increased education on condom use (Ch 9). In addition, since health care providers do not intentionally ill-treat their patients, they are likely to continue to apply their new knowledge and experience. However, the long-term effect of the intervention is uncertain, as guidance and 
practical support from the program is no longer being provided, and the providers' technical knowledge and skills were still far from perfect when the pilot concluded. The quality of care will further be influenced by the return of other obstacles. For example, the attitudes and practices of staff responsible for the reception in the clinics; the costs of consultations and medications; and the absence of health education material tailored to the needs of adolescents.

\subsection{Methodological considerations}

\subsubsection{The community based survey}

The study used a quasi-experimental design to assess the impact of the intervention on the knowledge and use of contraceptives, use of SRH care and perceived quality of care. This was the only feasible approach to obtaining random samples of voucher receivers (including voucher users and non-users) and non-receivers. Participants were obtained from a representative sample of the intervention areas, using a similar selection approach to that used during the voucher distribution. Respondents were blinded for the research question. Furthermore, during the distribution of both vouchers and questionnaires, by far the majority of adolescents were interested in participating. As a result, the risks of selection biases based on voucher receipt or voucher use were low.

Measuring change in teenage pregnancy rate, the most concrete indicator of program achievement, proved impractical. In Nicaragua, as in many other developing countries, a considerable but unknown percentage of teenage pregnancies end in illegal abortion. In addition, many births are not registered. As a consequence, the reported use of contraception and condoms was used as a proxy for pregnancy prevention.

To estimate the effects of the intervention on the various outcomes, multiple logistic regression analysis was used, adjusting for the observed differences in the composition of the intervention and control groups. Analysing the impact on use of SRH care, knowledge and use of contraceptives and condoms, the differences in the composition of the intervention and control group appeared to be associated with the place at which the survey questionnaires were distributed (market, school, or neighbourhood). Because these places were associated with subgroups of adolescents, separate analyses were also performed by subgroup (Ch 5). Receipt of a voucher was the central difference between the intervention and control group, and remaining differences were corrected for through multiple logistic regression analysis. Therefore, it can be assumed that the results were caused by voucher receipt. 
Considerable differences were found in the way different subgroups of female adolescents profited from the voucher program. Because our sample size was relatively large, we were able to draw significant results from subgroups of adolescents. This underlines the importance of collecting sufficient data on adolescents' characteristics, because it is not known in advance which variables will discriminate between subgroups. For example, we were surprised to find that the place at which the adolescent was contacted had such a significant influence on the outcomes. Furthermore, we had expected that the socio-economic indicators would have had a much stronger influence, because in Nicaragua socio-economic background is found to be strongly associated with knowledge and use of contraceptives and condoms (1). However, the indicators we used to evaluate socio-economic background (relative poverty of the neighbourhood, number of people per bedroom and presence of a refrigerator in the house) contributed very little to the explanation of the various outcomes. There may be a number of reasons for this: the socio-economic indicators were not appropriate for differentiating among the adolescents; the group targeted by the program was too homogeneous to detect differences; or the socio-economic differences coincided with other characteristics (e.g. level of education, category of child bearing) that proved to be significantly associated to the outcomes.

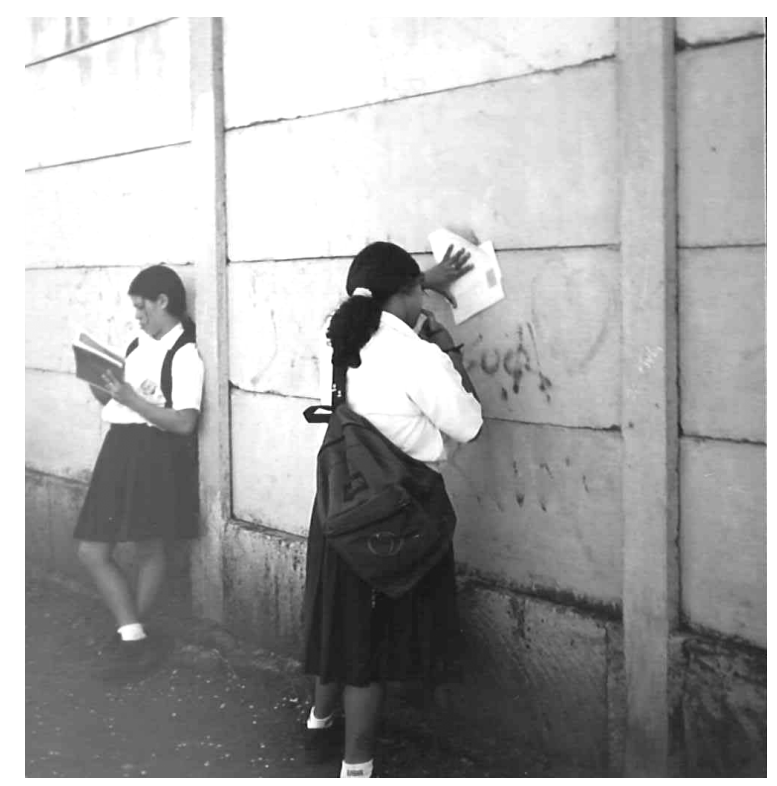

Girl completing a questionnaire outside school 


\subsubsection{Evaluation of the quality of care}

The possible biases related to the evaluation of the quality of care have been extensively discussed in previous chapters. Strong aspects of the evaluation include the blind codifying of the questionnaires used to interview doctors and simulated patients, and the definition and classification of the criteria prior to analysis. Another strength is the use of different perspectives and methods to evaluate the intervention, allowing findings to be triangulated. This allowed confirmation and deeper understanding of certain findings. For example, simulated patients who unsuccessfully sought a contraceptive method did not perform their role poorly. They had, in fact, experienced a common practice among doctors, as appeared in the medical records, and as was confirmed during the interviews with the doctors. Another example is that the strong preference to consult with female doctors revealed in the self-administered questionnaires was not only based on girls' feelings, but also on tangible differences in the performance of female and male doctors participating in this intervention. This was observed by the simulated patients, by us during the interviews with the doctors, and in the doctors' prescription habits as recorded in the clinical files.

The major limitations of the different surveys were the small sample size of clinics and doctors, the unequal period of the intervention among participating providers, and the high turnover among doctors. A practical limitation was that, before the intervention began, we did not know doctors' knowledge and practices. Consequently, the questionnaires used for interviewing doctors and simulated patients had a rather explorative character, which also might have influenced the ability to obtain statistically significant results.

Since there were no other interventions in the clinics during the intervention period, the changes observed in the perceived and technical quality of care are likely to have been caused by the intervention.

\subsubsection{The external validity}

When the same program was extended to other departmental cities in Nicaragua, even higher voucher redemption rates were achieved, and similar observations were made on the quality of care (Annex I). Adolescents from all over the developing world face strikingly similar obstacles to SRH care: they lack information on contraceptives and on health care services; they lack financial means to access the available services; and they fear disclosure of their sexual activities and the hostile attitudes of the staff (2-7). At the same time, the obstacles to effectively responding to their needs are strikingly similar. Providers often hold conservative attitudes towards sexual activities among unmarried adolescents, and 
are not trained for nor experienced in serving non-pregnant adolescents $(3 ; 4 ; 8-10)$. The voucher program creates an interesting dynamic, in which adolescents are mobilised to attend the health services and health care providers are supported, and paid, to attend to them according to best practice protocols. It is to be expected that, in other settings, adolescents facing similar situations will profit equally from such an intervention, and doctors working in similar situations, facing comparable problems, will also profit from a similar intervention.

\subsection{How do the results relate to other studies?}

The voucher program increased the use of health services, among all adolescents, and especially among those who could be characterised as 'the most shy': that is, the youngest adolescents and those sexually active adolescents who were not yet pregnant. No other intervention in Latin America has yielded similar results. The only other intervention found that also reported an increase in use of services and contraceptives among very young adolescents took place in New York, United States. Here, a school-based health education program, with individual and group sessions, was combined with free-of-charge access to care in designated clinics (11).

The voucher program increased both the knowledge of contraceptives and STIs, as well as the use of contraceptives and condoms. Among specific groups these increases were significant. No other reported interventions in Latin America have succeeded in increasing contraceptive and condom use among adolescents (see $\mathrm{Ch}$ 3.2). The researchers involved with these interventions explain this with the argument that broader social, cultural, political and environmental factors were so dominant that adolescents did not protect themselves against the risks of sexual encounters (12-14). These researchers conclude that, as a consequence, programs that focus only on the 'proximate' antecedents of adolescent behaviour (such as knowledge, attitudes and access to contraceptives and health services) are not likely to be effective (12-14). Although indications exist that these interventions did not succeed in making the health services more easily accessible and appropriate to adolescents, the researchers do not consider this as the main reason for the interventions lack of impact. Instead, they focus on factors beyond the influence and responsibility of the program, such as opinion leaders and parents. By doing so, they implicitly judge young people as incapable or incompetent in making individual choices about their sexuality. Furthermore, this focus on broad factors that are difficult to influence diverts attention away from the difficulty of reducing the risks associated with sexual activity without access to information and services. 
This blind spot is not only found among these researchers. The WHO recently performed a review of the risks and protective factors affecting adolescents' reproductive health in developing countries, based on studies dating from 1990 (15). Access to health care and contraceptives were not considered as contributing factors or as possible solutions, nor as areas for further research. The conclusions and recommendations of the review focussed on school enrolment, programs targeting peer norms and the need for further research on the impacts of school, peers, family and community. As such, it seems that even an international organisation, which leads developments in the field of health care, sometimes, misses the chance to focus attention on the absence of information and services that could enable adolescents to behave differently.

Recent evidence from interventions in developing countries in other parts of the world indicates that improved access to information and care can induce behaviour change. An intervention in Zimbabwe combined an educational campaign with the training of providers, and yielded similar results: increased health care use and increased knowledge and use of contraceptives by adolescents (16). A multifaceted intervention program that provided information and skills, as well as counselling and other services, led to a strong and significant increase in contraceptive practices and condom use among unmarried young females and males in suburban Shanghai (3). In Tanzania, an intervention designed to make public sector facilities adolescent friendly succeeded in attracting many more users (17). Key factors contributing to the success of these interventions appear to be the combination of outreach activities and easy access to adolescent friendly health services.

There is similarity with the evidence from developed countries. While sex education alone does not appear to increase the use of contraceptives and/or prevent unintended pregnancies in the USA (18), several studies have documented increased use of contraceptives when provision is included as part of a program $(11 ; 19-21)$. In the same way, high teenage pregnancy rates in the USA can not be explained by differences in sexual activity, but by differences in contraceptive use (22). This is in agreement with evidence from the Netherlands and other European countries, where low barrier family planning services for adolescents of all ages have been fundamental in decreasing unwanted teenage pregnancy and abortion (23-26).

Another important outcome of the program was that the health care providers were, in general, enthusiastic about the intervention and interested in the continuation of the program. This is an important outcome because in Nicaragua, as in many developing countries, most health personnel are underpaid, work in difficult conditions, and, as a result, lack motivation $(27 ; 28)$. Consequently, negative 
attitudes among providers are an obstacle that emerges from many studies aimed at improving health care delivery. Adequate training and support have been documented as being able to remove an important part of the resistance (4;29). An important contribution of the voucher program is that greater effort by providers is rewarded through financial incentives. The combination of support and incentives makes the voucher program a promising strategy for prompting providers to deliver higher quality health care to underserved groups. It is such a strong formula, that the same mechanism probably has the potential to improve health care delivery at the public health services as well.

\subsection{Program impact in a broader perspective}

In this paragraph, we review the results of the program with respect to the expected impact discussed in chapter 4.3. In terms of contributing to poverty reduction and promoting greater equity, it is clear that the intervention succeeded in increasing access to and use of SRH care services among underserved adolescents. Furthermore, it increased their ability to choose a health care provider and contraceptive method.

Whether the voucher program succeeded in delivering services at lower costs needs to be evaluated in relation to the costs and reach of other interventions. While the clinical services were delivered at a slightly lower cost than the regular consultation fees, there were additional costs specific to the program. These costs can be substantial and concern costs associated with voucher production and distribution, contracting providers and monitoring performance, distributing pharmaceuticals and educational material, and reimbursing providers. However, the benefits can be substantial, particularly if the private and social savings associated with the prevention of unwanted pregnancies, illegal abortions, infant and maternal mortality, STIs and school drop-out, are taken into account (30). For example, it has been estimated that preventing unintended pregnancies through access to family planning could avert from $20 \%$ to $35 \%$ of maternal deaths (31), a high proportion of which are adolescent deaths.

As discussed in chapter 4.3, the effects on allocative efficiency depend on how the voucher system is designed and to whom the vouchers are targeted. Among the voucher receivers, $40 \%$ of girls aged 18 to 20 used their voucher, compared to $25 \%$ among girls aged 12 to 15 . This suggests a greater need among the older girls. However, among girls who had never received a voucher, $31 \%$ of those aged 18 to 20 consulted for SRH care, against only 7\% among girls aged 12 to 15 . This indicates that the unmet needs for SRH care met by the voucher program are much higher among the younger adolescents. As a consequence, focussing on the 
younger girls will increase the costs per voucher distributed, but is likely to contribute more to the public health gains. Voucher redemption rates are therefore not a very reliable guide in evaluating the impact of such an intervention. Evaluation should be based on the difference that receipt of a voucher makes, for example, to health care use among the target groups.

With respect to the quality of SRH care available to adolescents in Nicaragua, demand side financing and contractual agreements alone will not be sufficient to increase the competence of the providers. If the voucher program aims to improve both the technical and communication skills of providers in a sustainable way, then additional strategies are needed, such as specific training and support and feedback systems.

The quality of care, as perceived by the adolescents, clearly improved while the voucher program was in operation (Ch 7). However, the results of the evaluation suggest that this was not caused primarily by changes in providers' performance, but by a combination of factors. These factors included: the ability to choose between providers; the absence of fear of rejection; attendance without prior appointment; not needing to inform the receptionist about the reason for the visit; the use of 'best practice' clinical protocols; the interest of the providers in serving this group; the range of contraceptive methods and medications available; and last but not least the absence of financial constraints.

\subsection{Main Findings and Policy Implications}

\subsubsection{On the demand side}

A key finding of this intervention is that access to SRH care is an important determinant of adolescent sexual and reproductive behaviour, even without their social context being changed. In the localities in which the intervention operated, parents, neighbours and other adults supported the program.

Adolescents have substantial unmet needs for SRH information and SRH care that warrant professional attention. Adolescents that face the highest proportion of unmet needs are those who are sexually active but not yet pregnant or a mother. Addressing their needs can contribute to reducing serious public health problems related to teenage pregnancy, unwanted pregnancy, illegal abortion and STIs. The incidence of these problems is expected to increase with socio-economic development, since the numbers of years that people are sexually active outside marriage tends to increase as development progresses (32-35). A significant 
increase in the use of contraceptives and condoms is needed to slow this trend (3539).

\subsubsection{On the supply side}

Another key finding of this intervention is that, relatively quickly and without huge investment, existing health services can be made accessible, appropriate and acceptable to adolescents.

The mobilisation of adolescents to attend health services was an important step in making doctors aware of their deficiencies, in motivating them to attend the training sessions; and providing opportunities to practice new skills. A voucher program proved to be an effective strategy for both involving and improving the capacity of existing health services (public, private and NGO) to service populations such as (unmarried) adolescents, who are currently underserved and often poorly treated.

Doctors generally appeared well intentioned but were often poorly prepared to service adolescents. Patients' rights include the right to be well cared for by health services. Therefore, providers need to be well prepared for their task. The findings of our study strongly reinforce the importance of strengthening medical education, especially in relation to the skills required to communicate effectively with adolescents (40).

The medical form that guaranteed that a minimum number of questions were asked and guided the doctor through the consultations appeared an important tool. The effect of the intervention on the quality and organisation of care could be further improved by specific trainings and by monitoring providers' performance and providing feedback. Both individual feedback and group discussions could be used.

The close involvement of adolescents in the development and implementation of the voucher program proved to be very important. Feedback indicated that the adolescents enjoyed being involved in the program and its evaluation. In addition, their contribution was beneficial to the operation of the program during and beyond the pilot phase. Importantly, their priorities and views were sometimes distinct from those of the providers and program staff. This indicates that incorporation of the adolescents' perspective is crucial to being able to adapt the intervention to their needs.

\subsubsection{On the program side}

Although distribution of vouchers is relatively simple in a mechanical sense, the 
design of a voucher program to target a 'new' population may require an intensive preliminary process in order to build contact with all stakeholders. In the case of a program targeting adolescents, this process should include: 1) assessing existing health care services; 2) contacting community organisations working with adolescents; 3) getting to know the target group, the problems faced in accessing services and their needs for SRH care services; and 4) analysing previous experiences to improve health care delivery to them.

Although a voucher program works best for a defined package of health care services (41), it is important to include provision for incidental additional services, for example, through 'referral' vouchers.

If the quality of the medical training is low, focus on enhancing providers' capacity to deal with adolescents is essential if a voucher program is to increase adolescents' use of services in a sustainable way. This extra attention to improving the quality of SRH care is necessary because it is providers who determine whether current and continuing needs are met during consultation. Furthermore, adolescents are not likely to continue using services if they are not treated in privacy, confidentially and with respect. This indicates that a 'comprehensive' voucher program, that is, a voucher program that is both competitive and pays explicit attention to improving and supporting providers, is likely to be a more sustainable strategy.

To expand the coverage of the intervention to adolescents without a voucher, (during the program and after the program has ended) a system could be developed to assess the 'adolescent friendliness' of existing services. Clinics assessed as treating adolescents 'well' could be classified as 'adolescent friendly', and this status could be displayed outside the clinic. Such a label would reassure adolescents (with and without vouchers) that they will be accepted and treated with respect, recognising their rights to privacy and confidentiality. At present, interventions categorising and labelling clinics are being piloted in South Africa and various other developing countries $(2 ; 42)$

A voucher program can prompt changes at the individual level, within families and among adolescents. There is a need for parallel interventions to address the additional obstacles that can prevent sexually active adolescents avoiding pregnancy and STIs. Direct examples include legal restrictions to providing confidential care to minors and obstacles related to safe abortion. Less direct obstacles include gender inequity, intra-familiar violence and drug use, and society's reactions to these factors. 


\subsection{Sustainability and future perspectives}

Sustainability is a key issue in development work, where the ultimate objective is to achieve improvements that last long after the interventions has ended. The most effective delivery of SRH care to adolescents - who comprise approximately $25 \%$ of the population in most developing countries - is likely to occur when public, private and NGO services see it as their role to assist adolescents - whether they are married or not - with confidential health care services. However, in many developing countries, there is still a long way to go before this will be realised.

The results of our study showed that a voucher program represents an effective strategy for addressing the immediate needs for SRH care among adolescents. However, it is clear that without external financial support the intervention could not be maintained. This is true for all programs designed to provide services to populations who have very limited personal resources. However, as said before, unintended pregnancies and STIs among adolescents pose considerable problems and incur substantial opportunity costs - for the adolescents, their children and the community in general. In this context, it is highly likely that the benefits from prevention will substantially outweigh costs.

The sustainability of a voucher program lies in its potential to prompt ongoing change in the way adolescents use health care services. A voucher program can achieve this in a number of ways. First, by facilitating access to appropriate health care services and enabling adolescents to become accustomed to using such services. Second, by prompting change in the way in which health care providers attend to young people. The expectation is that these changes will influence both adolescents' attitudes and behaviours towards sexual risk taking, and the attitudes and behaviours of providers towards meeting the needs of adolescents. While consolidation of these changes will take longer than one year, an intervention based on a voucher program would not require an indefinite commitment from donors. Indeed, over time, the need for such an intervention may disappear if these above mentioned changes have been realised.

It is hoped that international donors will support and fund this type of intervention, despite the present orientation towards 'sector wide approaches' (SWAps) in financing health care in developing countries. Under SWAps, the Ministry of Health allocates funds to health care interventions perceived as carrying the greatest priority. Although SWAps have many advantages, and are in themselves compatible with voucher programs, the risk is that innovative interventions, focussed on sensitive issues will never be implemented because of their political 
sensibilities. Given the current dominance of a conservative view of sexuality, not only in Nicaragua, but also in the international context, even when innovative interventions have delivered unprecedented results, finding donors can still be very difficult.

\subsection{Recommendations}

This dissertation ends with one overriding recommendation: "Start implementing voucher schemes for adolescents now." Research should concentrate on the assessment of the difference that accessible, affordable, appropriate and confidential SRH care can make to the quality of life of different groups of adolescents in developing countries and to their life time opportunities. If adolescents are to be able to take prime responsibility for their own health, then society needs to provide non-judgemental information and education as well as easy access to SRH care services $(28 ; 43)$.

There seems no urgency to further study the relative importance of the various background variables in relation to SRH problems among teenagers. However, the need to invest in solutions is urgent. A voucher program provides a tool that utilises and supports existing health infrastructure and resources to fill the immediate need. At the same time, it empowers adolescents and allows them to influence their own futures. Therefore, large-scale implementation will probably influence adolescent culture and, over time, help to change societal attitudes towards adolescents and their sexuality.

The huge information gap that still exists among adolescents cannot be filled by medical doctors during one or two consultations: safer sexual practices among young people require increased access to sexual and reproductive health information. To reach many adolescents, sex education should be implemented in schools, and additional interventions need to be developed to reach out-of-school youth and adults.

To increase the likelihood that interventions will succeed, they should be designed in collaboration with the targeted beneficiaries, the adolescents. They also should be evaluated in a methodologically sound manner to facilitate learning from experience and to assess the potential to influence current situations. Research questions warranting attention in relation to voucher programs include:

1. How does a voucher program affect health care use, STI treatment, partner treatment, sexual risk behaviour and condom use among male adolescents? 
2. Does a voucher program influence the gender relations within the couple?

3. Is a voucher program capable of improving the quality of health services and service use in governmental health services?

4. Can adolescents living in rural areas be reached through voucher programs?

5. Can the effect of a voucher program be enhanced by the simultaneous implementation of 'adolescent friendly service' labels?

\section{References}

1. INEC Instituto National de Estadística Censos, Ministerio de Salud. Demographic Health Survey Nicaragua 2001 [in spanish]. Managua, Nicaragua: Instituto nacional de Estadística and Censos y Ministerio de Salud, Calverton, MD USA; Marco International/DHS+ Program, 2001.

2. Dickson-Tetteh K, Pettifor A, Moleko W. Working with public sector clinics to provide adolescent-friendly services in South Africa. Reprod Health Matters 2001; 9(17):160-169.

3. Lou CH, Wang B, Shen Y, Gao ES. Effects of a community-based sex education and reproductive health service program on contraceptive use of unmarried youths in Shanghai. J Adolesc Health 2004; 34(5):433-440.

4. Mmari KN, Magnani RJ. Does making clinic-based reproductive health services more youth-friendly increase service use by adolescents? Evidence from Lusaka, Zambia. J Adolesc Health 2003; 33(4):259-270.

5. Flaherty A, Kipp W, Mehangye I. 'We want someone with a face of welcome': Ugandan adolescents articulate their family planning needs and priorities. Trop Doct 2005; 35(1):4-7. 6. Champion JD, Kelly P, Shain RN, Piper JM. Rural Mexican-American adolescent sexual risk behavior. J.Rural.Health 20[3], 279-285. 2004. Ref Type: Abstract

7. Ozumba BC, Obi SN, Ijioma NN. Knowledge, attitude and practice of modern contraception among single women in a rural and urban community in southeast Nigeria. J.Obstet.Gynaecol. 25[3], 292-295. 2005. Ref Type: Abstract

8. Pons JE. Contraceptive services for adolescents in Latin America: facts, problems and perspectives. Eur J Contracept Reprod Health Care 1999; 4(4):246-254.

9. Senderowitz J. Health Facility Programs on Reproductive Health for Young Adults. http://www.futuresgroup.com/abstract.cfm/43 Accessed 6 June $2001,1-51.1997$. Washington DC,USA, FOCUS on young adults. Research Series. Ref Type: Electronic Citation

10. Kiapi-Iwa L, Hart GJ. The sexual and reproductive health of young people in Adjumani district, Uganda: qualitative study of the role of formal, informal and traditional health providers. AIDS Care 2004; 16(3):339-347.

11. Tiezzi L, Lipshutz J, Wrobleski N, Vaughan RD, McCarthy JF. Pregnancy prevention among urban adolescents younger than 15: results of the 'In Your Face' program. Fam Plann Perspect 1997; 29(4):173-6, 197.

12. Magnani RJ, Gaffikin L, de Aquino EM, Seiber EE, Almeida MC, Lipovsek V. Impact 
of an integrated adolescent reproductive health program in Brazil. Stud Fam Plann 2001; 32(3):230-243.

13. Lipovsek V, Karim AM, Gutierrez EZ, Magnani RJ, Castro Gomez MC. Correlates of adolescent pregnancy in La Paz, Bolivia: findings from a quantitative-qualitative study. Adolescence 2002; 37(146):335-352.

14. Belmonte LR, Gutierrez E, Magnani RJ, Lipovsek V. Barriers to Adolescents Use of Reproductive Health Services in Three Bolivian Cities. 6-12-2000. FOCUS on Young Adults/ Pathfinder -international. Ref Type: Report

15. WHO Department of Child and Adolescent Health and Development. Risk and Protective Factors Affecting Adolescent Reproductive Health in Developing Countries, a summary; An analysis fo the world's literature 1990-2004. 1-13. 2004. Geneva, Switserland, World Health Organization. Ref Type: Report

16. Kim YM, Kols A, Nyakauru R, Marangwanda C, Chibatamoto P. Promoting Sexual Responsibility Among Young People in Zimbabwe. Int Fam Plan Perspect 2006; 27(1):1119.

17. Making Public Sector Facilities youth-friendly: Tanzania's Case Study. Washington, USA: Global Health Council, 2004.

18. DiCenso A, Guyatt G, Willan A, Griffith L. Interventions to reduce unintended pregnancies among adolescents: systematic review of randomised controlled trials. BMJ 2002; 324(7351):1426.

19. Frost JJ, Forrest JD. Understanding the impact of effective teenage pregnancy prevention programs. Fam Plann Perspect 1995; 27(5):188-195.

20. Kirby D, Waszak C, Ziegler J. Six school-based clinics: their reproductive health services and impact on sexual behavior. Fam Plann Perspect 1991; 23(1):6-16.

21. DeLamater J, Wagstaff DA, Havens KK. The impact of a culturally appropriate STD/AIDS education intervention on black male adolescents' sexual and condom use behavior. Health Educ Behav 2000; 27(4):454-470.

22. Darroch JE, Singh S, Frost JJ. Differences in teenage pregnancy rates among five developed countries: the roles of sexual activity and contraceptive use. Fam Plann Perspect 2001; 33(6):244-50, 281.

23. Visser AP, Ketting E. Sexual health: education and counseling perspectives on contraceptive use, HIV and sexuality. Patient Educ Couns 1994; 23(3):141-145.

24. Treffers PE. [Teenage pregnancy, a worldwide problem]. Ned Tijdschr Geneeskd 2003; 147(47):2320-2325.

25. Ketting E, Visser AP. Contraception in The Netherlands: the low abortion rate explained. Patient Educ Couns 1994; 23(3):161-171.

26. Furstenberg FF, Jr. When will teenage childbearing become a problem? The implications of western experience for developing countries. Stud Fam Plann 1998; 29(2):246-253.

27. Van LW, Conceicao C, Van DW, Ferrinho P. When staff is underpaid: dealing with the individual coping strategies of health personnel. Bull World Health Organ 2002; 80(7):581584.

28. Bayley O. Improvement of sexual and reproductive health requires focusing on adolescents. Lancet 2003; 362(9386):830-831. 
29. Becker J, Leitman E. Introducing Sexuality within Family Planning: The Experience of Three HIV/STD Prevention Projects from Latin America and the Caribbean. Number 8. 1997. New York, N.Y., The Population Council. Quality/Calidad/Qualité. Ref Type: Report 30. Singh S, Darroch JE, Vlassoff M, Nadeau J. Adding it up. The benefits of investing in Sexual and Reproductive Health Care. 1-33. 2006. Washington, USA, Alan Guttmacher Institute and UNFPA. Ref Type: Report

31. UNFPA. The State of World Population 2005. 2005. New York, USA, UNFPA, United Nations Population Fund. Ref Type: Report

32. Singh S. Adolescent childbearing in developing countries: a global review. Stud Fam Plann 1998; 29(2):117-136.

33. McCauley AP, Salter C, Kiragu K, Senderowitz J. Meeting the needs of young adults. Popul Rep J 1995;(41):1-43.

34. Henriques-Mueller MH, Ynes J. Adolescence: Misunderstandings and Hopes. Gender, Women and Health in the Americas. 541, 43-61. 1993. Pan American Health Organization. Scientific Publication. Ref Type: Report

35. Bongaarts J, Cohen B. Adolescent reproductive behavior in the developing world. Introduction and review. Stud Fam Plann 1998; 29(2):99-105.

36. Ali MM, Cleland J. Sexual and reproductive behaviour among single women aged 1524 in eight Latin American countries: a comparative analysis. Soc Sci Med 2005; 60(6):1175-1185.

37. Blanc AK, Way AA. Sexual behavior and contraceptive knowledge and use among adolescents in developing countries. Stud Fam Plann 1998; 29(2):106-116.

38. Cleland J, Ali MM. Reproductive consequences of contraceptive failure in 19 developing countries. Obstet Gynecol 2004; 104(2):314-320.

39. Ali MM, Cleland J, Shah IH. Trends in reproductive behavior among young single women in Colombia and Peru: 1985-1999. Demography 2003; 40(4):659-673.

40. Haslegrave M, Olatunbosun O. Incorporating sexual and reproductive health care in the medical curriculum in developing countries. Reprod Health Matters 2003; 11(21):49-58.

41. Sandiford P, Gorter A, Rosas Z, Salvetto M. A guide to Competitive vouchers in health. Washington, DC, USA: The international Bank for Reconstruction and Development/The World Bank, 2004.

42. Senderowitz J, Hainsworth G, Solter C. A rapid assessment of youth friendly reproductive health services. 4, 1-12. 2003. Pathfinder International. Technical Guidance Series. Ref Type: Report

43. Editorial. Who is responsible for adolescent health? Lancet 2004; 363(9426):2009. 


\section{Annex}

Nicaragua: Introducing a voucher scheme for disadvantaged adolescents' access to services in three districts

Liesbeth Meuwissen, Tomás Donaire, Joel Medina, Zoyla Segura \& Anna Gorter

Published in Sexual Health Exchange 2004-3\&4,28-30

Traduccion en espanol:http://www.icas.net/new-icasweb/docs/ Traduccion\%20Revista\%20Sexual\%20Health\%20Exchange.doc 



\section{Introduction}

Nicaragua has the highest fertility rate of Latin America, with 119 births annually per 1000 young women aged $15-19$, and $46 \%$ of adolescent girls pregnant or mothers by the age of 19 (1). High fertility rates are associated with low socioeconomic status and educational level. In addition, adolescents experience high rates of unwanted pregnancy, illegal abortions, high maternal mortality rates, and are also at high risk of contracting STIs, including HIV. These risks are due to the low use of contraceptive methods among sexually active adolescents: according to the Ministry of Health only $7 \%$ used a condom and $47 \%$ another modern method in 2001. In response to these high rates of unwanted pregnancies and STIs, the Central American Health Institute (ICAS) initiated an innovative voucher scheme for poor adolescents in the capital Managua and various other cities.

The principal reasons for the low use of contraceptive methods among adolescents are:

- Lack of access to information about sexual and reproductive health - There is no integrated sex education in schools; the media transmit ambivalent messages; and parents lack the necessary information and experience difficulties in discussing sex with their children.

- Lack of access to sexual and reproductive health services - Existing centres lack confidentiality, privacy and quality of service, all considered essential characteristics by adolescents. Centres with specialized services for young people are rare and/or relatively expensive, so poor adolescents cannot access them.

- Low quality of care - Many doctors lack the knowledge and skills to provide adequate sexual and reproductive health services consultations to adolescents and treat them in a paternalistic way.

\section{The adolescent voucher programme}

Inspired by the success of a voucher programme for sex workers in Managua in improving access to treatment and reducing the incidence of STIs, ICAS piloted a voucher programme for poor adolescents in Managua. Aiming at the reduction of the incidence of unwanted pregnancies and HIV/STIs among poor adolescents in Managua, the specific objectives were defined as: 1) to facilitate access to and improve the quality of sexual and reproductive health services; 2) to increase adolescents' use of services; and 3) to increase their knowledge and use of contraceptives. 
A Memorandum of Understanding was signed with the Ministry of Health and the scheme was first piloted in Managua from 2000-2002, with DFID support. In 2002, with funding from the Dutch Government, the programme was extended to cities in the districts of Rivas and Chinandega and recently, to Matagalpa and Leon, where it will operate until 2007. Under the programme, vouchers are distributed to poor adolescents, aged 12 to 20 years, at markets, outside schools and door-to-door in disadvantaged neighbourhoods. Distribution is done by ICAS adolescent fieldworkers, NGOs, clinics (for example, for friends of pregnant girls or partners of STI patients), and adolescent clubs associated with clinics.

The vouchers are not person-bound and are regularly transferred to others in greater need. They are valid for three months and entitle the bearer to a free consultation and follow-up visit at any of the four public, eight private, or thirteen NGO clinics contracted. The service package consists of counselling, family planning, pregnancy testing, antenatal care and syndromic STI treatment. All clients receive a booklet on adolescent health; two condoms with supportive information; as well as access to laboratory tests (for pregnant girls), drug treatment for STIs and contraceptives, as required. The selection of clinics by ICAS is based on suitability and proximity to the areas where vouchers are distributed. Doctors complete standard medical forms during each consultation. Participating clinics receive reimbursement based on the number of completed forms with voucher attached, according to agreed fees, between 2.5 and 5 US \$ for the first consultation.

\section{Schematic presentation of the voucher scheme}

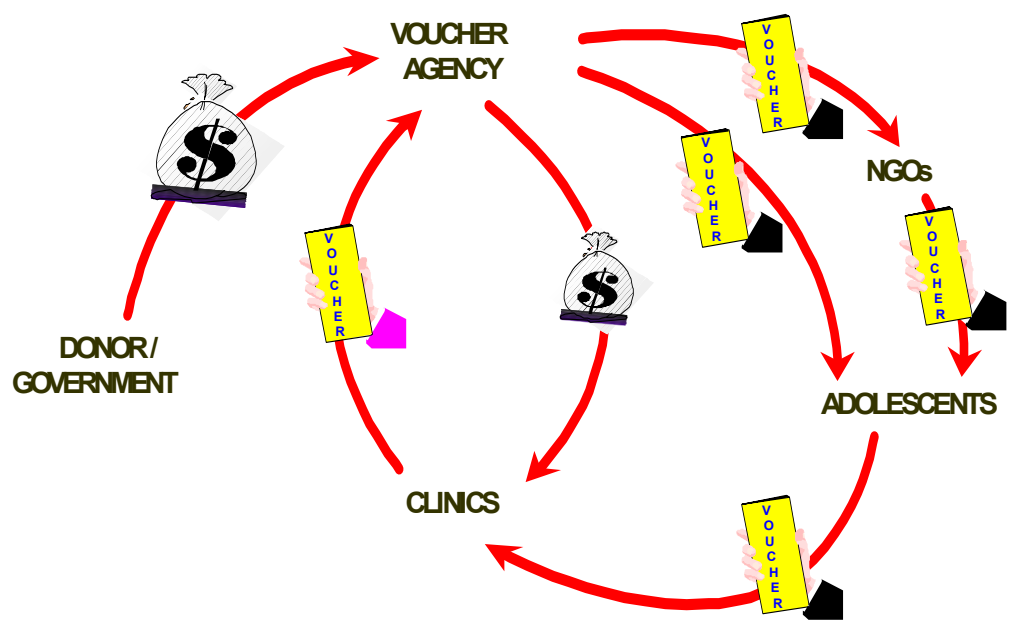


Capacity building for staff of participating clinics includes a short introduction to the programme, followed by training sessions on counselling, adolescence and sexuality, contraceptives, syndromic STI treatment and sexual abuse. Monitoring and evaluation of the programme takes place through different strategies, including information on distribution and use of the vouchers; medical forms; interviews with doctors and simulated patients before, during and after the programme; and focus group discussions with adolescents.

\section{Results so far}

The reception of the programme by parents and teenagers has been very positive. Nearly all adolescents accept a voucher when offered, and during distribution in neighbourhoods parents often request additional vouchers for other teenage children. The programme demonstrates a high level of unmet need for sexual and reproductive health services among poor adolescents. The most important reasons for girls to consult the services in 2003 were contraceptives, STI treatment, general information/counselling and antenatal control (in order of importance); for boys the main reasons were contraceptives, general information/counselling and STIs. To date, over 11,000 consultations have been provided. In 2003/2004, $23 \%$ of the 22,786 female and $15 \%$ of the 17,314 male adolescents who received a voucher used it. These are relatively high percentages, considering the fact that the vouchers are distributed without asking adolescents about their sexual and reproductive health needs. Many adolescents $-63 \%$ of the girls who received a voucher in the pilot - are not yet sexually active, and thus have limited needs for related services. Among sexually active adolescents, experience so far shows that many use their vouchers: during the pilot; half of the sexually active girls who had received a voucher used it. Boys normally do not use these services, because they have less sexual and reproductive health needs and they usually go to a pharmacy for STI treatment (where they receive neither counselling nor partner treatment). Vouchers succeeded in mobilizing young men towards the clinics: for each 100 male voucher receivers, fifteen vouchers were used and of these two consulted the doctor for an STI. Although reliable prevalence data on STIs in this age group is missing, it is not likely to be much higher than $2 \%$. Summarizing, the programme is a promising strategy to improve adolescents' access to, and use of sexual and reproductive health services, as was confirmed by a recent evaluation (1).

The programme also has a positive impact on quality of care. It succeeded in strengthening and updating the technical knowledge of many participating doctors on subjects such as contraceptives and syndromic STI treatment. However, it is 
more difficult to change attitudes, social skills and the existing curative focus. The high turnover of doctors in all types of clinics has been a limitation.

The voucher programme is a strategy that works through organizations that are already in contact with the target group and uses existing infrastructure and staff. All health-care providers approached were very interested to participate. In most districts, except in Managua, public health services were integrated successfully into the programme, and scaling up to other geographic areas proved to be relatively easy.

\section{Lessons learned and challenges for the future}

The voucher programme has shown that poor adolescents have large unmet needs for sexual and reproductive health services, which can be met with a relatively simple intervention that removes barriers to confidential care. However, a number of important challenges remain:

- A voucher programme will never be able to achieve nationwide coverage for sexual and reproductive health services for $25 \%$ of a population. The only sustainable way to organize such essential care requires that public, private and NGO services see it as their task to help adolescents - whether they are married or not - with confidential health care. This is presently not the case. The sustainability sought by the programme is that young people familiarize themselves with the use of sexual and reproductive health services; that clinics learn to provide adequate services in a confidential way; that clinics become interested in attracting this new group of clients; and that the young boys and girls reached by the voucher programme become the agents for change in the way teenagers and society handle teenage sexuality.

- While quality control is important, training and feedback for medical doctors and clinics have proven insufficient to increase the quality to the level required. In order to improve the ability of doctors and other medical staff to provide adolescent-friendly sexual and reproductive health services, it is necessary to change their attitudes and curative focus, by adapting medical training at universities.

- The huge available information gap that still exists among young people cannot be met by medical doctors during one consultation: safer sexual practices among young people require increased access to sexual and reproductive health information. However, this is difficult in a context where government and some donors fail to accept adolescent sexuality, and reject 
open discussion on sexuality and effective sex education in schools.

- It is a particular challenge to provide continued support to adolescents under 15 years - of whom $10 \%$ of girls is already pregnant or a mother, and who have the highest unmet needs - when a number of important donors prefer to exclude them from voucher programmes.

\section{Reference}

1. Meuwissen, L.E., Gorter, A.C., Knottnerus, J.A. Impact of accessible sexual and reproductive health care on poor and underserved adolescents in Managua, Nicaragua: a quasi-experimental intervention study. J Adolesc Health. 2006 Jan;38(1):56.

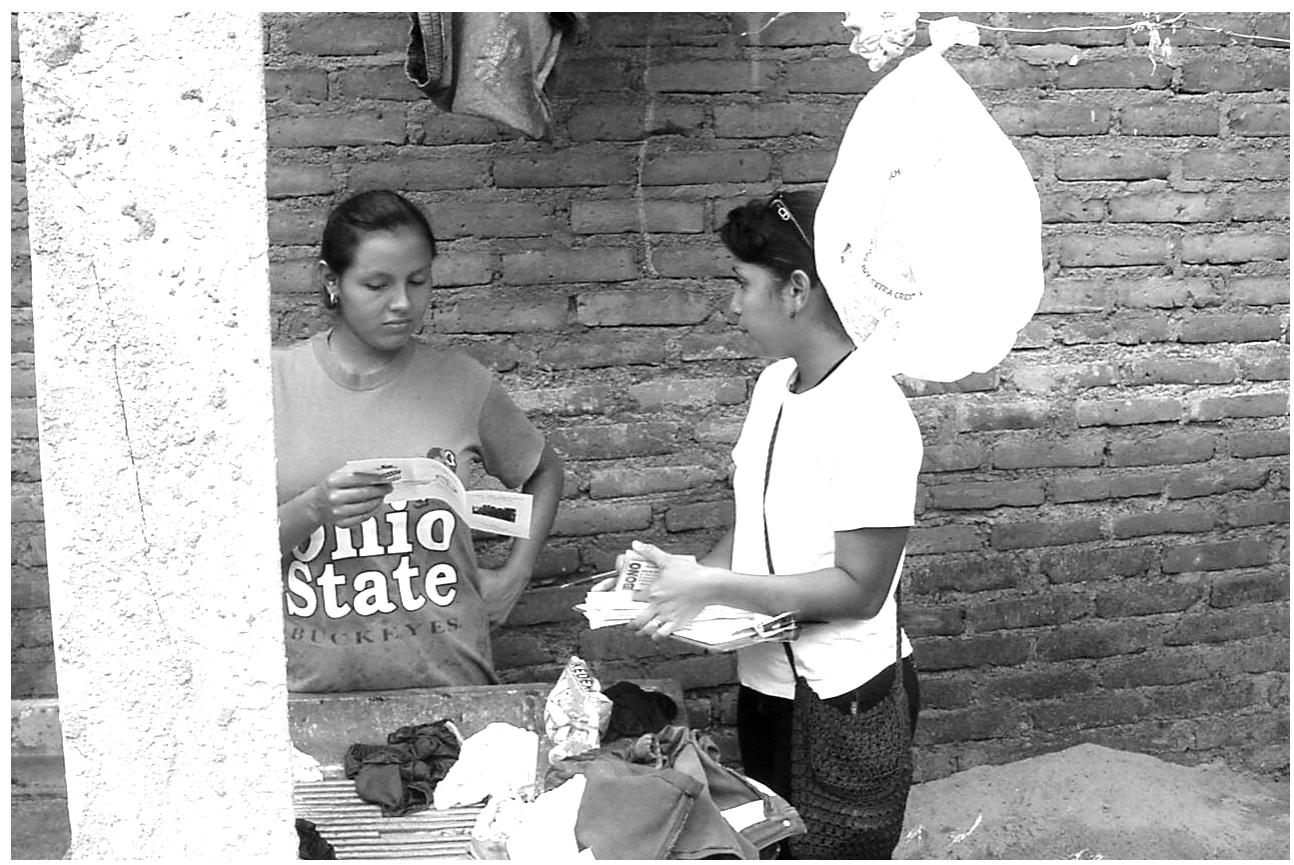

Handing out vouchers to peers 
Summaries 



\section{Summary}

Teenage pregnancy is very common in Nicaragua and adolescents make little use of modern contraceptives. Each year, 119 per 1000 girls between 15 and 19 years old give birth. By the age of $19,45 \%$ of girls are either pregnant or have already given birth. This thesis describes the evaluation of a competitive voucher program for adolescents in Managua, the capital of Nicaragua, aimed at increasing access to and quality of sexual and reproductive health (SRH) care for adolescents. The ultimate objective of the intervention was to reduce the rate of unwanted pregnancies and the risks of contracting sexually transmitted infections (STIs), including HIV. The intervention involved the distribution of vouchers to adolescents aged between 12 and 20, living in disadvantaged areas of Managua. Vouchers could be exchanged for a free-of-charge consultation relating to SRH care in one of 19 participating clinics. The context of the intervention, the research questions and the structure of the thesis are discussed in chapter 1.

To better understand the factors behind adolescents' current low use of contraceptives and to identify opportunities for effective interventions, literature from Nicaragua and Latin America was reviewed and is discussed in chapter 2. The main findings were that the vast majority of people engage in sexual relations during their teens, but many adolescents lack complete and accurate information on the risks involved and the possibilities for protecting themselves against these risks. Furthermore, many sexual relations are characterised by marked power disparities, and an unknown percentage of teenage pregnancies are due to abusive sexual relations. There is a general reluctance among adults in Latin America to talk about adolescents' sexuality at all levels - from the individual to the political. This reluctance reflects a number of factors: the socio-cultural background of machismo; the strong influence of the Catholic Church; and the generalised disapproval of recreational sex for young people, especially for girls. Female adolescents who want to use contraceptives face obstacles related to the availability, accessibility, quality and confidentiality of services. Without easy access to information and health care services it is impossible to determine to what extent the non-use of contraceptives by adolescents should be explained by social, cultural and religious norms and mechanisms, or as a consequence of the lack of access to reliable information and confidential health services.

The first part of chapter 3 provides a description of available literature on interventions in Latin America that aimed at improving adolescents' access to health care and contraceptives. Until now, few of such interventions have been rigorously evaluated and documented. None of these evaluations provided evidence 
of success in increasing adolescents' uptake of SRH care services or contraceptives. Recently, the concept of 'adolescent friendly services' has been developed. This offers a comprehensive framework that facilitates the design of interventions that comprise all of the organisational, technical and communicative elements important for health care delivery to adolescents. Presently, interventions based on this concept are being implemented and evaluated in many places in the developing world.

In chapter 3.3, the provision of health care services to adolescents in Managua is detailed. Despite representing approximately $25 \%$ of the population, very few resources are directly devoted to adolescents through the existing health system. Institutional norms and practices in providing SRH care to adolescents were characterised by the existence of medical barriers and biases and were inconsistent with international 'best practice'. In Managua, female adolescents normally only start using SRH care services once they are pregnant, while male adolescents prefer to use a pharmacy if they have STI symptoms. In other words, there is a clear need for interventions that improve access to and the quality of SRH care for adolescents.

In 1996, the Central American Health Institute (Instituto CentroAmericano de la Salud, ICAS) had implemented a competitive voucher program in Managua to improve access to STI treatment among sex workers as a means of contributing to reducing HIV prevalence among this underserved group. 'Competitive' refers to the fact that a number of different providers are involved in the program, with consumers able to choose between them. This encourages the providers to compete to attract and retain voucher holders. The concept of competitive voucher programs, and experiences with their implementation, are presented in chapter 4.1. Inspired by the success of this intervention, ICAS developed, in collaboration with the London School of Hygiene and Tropical Medicine, a pilot program to increase the access to and quality of SRH care for underserved adolescents using a similar mechanism. The British Department for International Development (DFID) provided the funding, and ICAS was the voucher agency. A memorandum of understanding was signed with the Ministry of Health, and the program was piloted in Managua from 2000-2002. It is this pilot program that is the subject of the studies underlying this thesis.

The specific objectives of the intervention were to: 1) facilitate access to and improve the quality of SRH care services for adolescents; 2) increase adolescents' use of SRH care services; and 3) increase adolescents' knowledge and use of contraceptives. Under the program, vouchers were distributed to poor adolescents, 
aged 12 to 20, at markets, outside schools and door-to-door in disadvantaged neighbourhoods. Distribution was done by ICAS adolescent fieldworkers, nongovernmental organisations (NGOs), clinics (for example, to friends of pregnant girls or partners of adolescent STI patients), and adolescent clubs associated with clinics. The vouchers were not person-bound and were valid for three months. They entitled the bearer to a free consultation and follow-up visit at any of the four public, five private and ten NGO clinics contracted by ICAS. The SRH care service package consisted of counselling, family planning, pregnancy testing, antenatal care and syndromic STI treatment. All voucher users received a booklet on adolescent health; two condoms with supportive information; as well as access to laboratory tests (for pregnant girls), drug treatment for STIs, and contraceptives, as required. The selection of clinics was based on suitability and proximity to the areas where vouchers were distributed. During each consultation, doctors completed standard medical forms based on 'best practices'. Participating clinics were reimbursed based on the number of completed forms returned with a voucher attached and previously agreed fees. Capacity building for staff from participating clinics involved a short introduction to the program, followed by training sessions on counselling, adolescence and sexuality, contraceptives, syndromic STI treatment and sexual abuse. All doctors received an information manual with background information and guidelines. The details of the intervention are described in chapter 4.3 .

Monitoring and evaluation of the program was undertaken using a number of different instruments: self-administered questionnaires; medical forms; interviews with doctors and simulated patients before, during and after the program; and focus group discussions with adolescents. The design of the evaluation study is discussed in chapter 4.4 .

A quasi-experimental design was used to examine the impact of the intervention on the use of SRH care and the knowledge and use of contraceptives and condoms. The results of this study are presented in chapter 5. Community sampling took place in markets, neighbourhoods and outside schools, in a representative sample of the low-income areas of Managua where the intervention had taken place. Selfadministered questionnaires were distributed to female adolescents aged 12 to 20 . The questionnaires were introduced as a study seeking their opinions on health care delivery to adolescents, and were not linked to the voucher program. The study comprised a random sample of 3,009 female adolescents, of whom 904 were voucher receivers and 2,105 had never received a voucher. Voucher receivers had a significantly higher use of SRH care compared with non-receivers. Voucher receivers had greater knowledge of contraceptives and STIs than non-receivers. At 
schools, sexually active voucher receivers had a significantly higher use of modern contraceptives than non-receivers. In neighbourhoods, condom use during last sexual contact was significantly greater among voucher receivers than nonreceivers.

In chapter 6, the analyses of the medical files from the 3,301 consultations with female voucher users is described. Adolescents who used a voucher presented SRH problems that warranted medical attention. The mean number of problems presented was 1.5 per consultation. One third of the vouchers were used for contraceptives, nearly one third for complaints related to STIs or reproductive tract infection (RTI), $28 \%$ for counselling/advice, $28 \%$ for antenatal check-up, and $18 \%$ for pregnancy testing. A new category of health care users emerged: sexually active girls who were neither pregnant nor mothers, who sought contraceptives or STI/RTI treatment. Contraceptive use doubled among the sexually active nonpregnant voucher redeemers. Consultation with a female doctor younger than 36 years was associated with a higher chance of having contraceptives prescribed. This illustrates the influence providers have on the response to girls' needs.

In chapter 7, the results are presented of the survey undertaken to determine how the quality of SRH care delivered through the voucher program was perceived in comparison to the care normally received. The self-administered questionnaire comprised questions designed to explore girls' feelings about the care received. Seven hundred of the 3,009 respondents had sought SRH care in the last 15 months, 221 with a voucher (users-with-voucher) and 479 without a voucher (users-without-voucher). Their anonymously completed questionnaires were used to analyse the determinants of their satisfaction. Clear associations were found between the perceived quality of care and voucher use. The satisfaction of the users-with-voucher was significantly higher compared with users-without-voucher. Voucher use was also associated with more frequent satisfaction with the reception in the clinic, especially among sexually active girls not yet pregnant or mothers. However, the clarity of doctors' explanations was not perceived differently between the two groups. Overall, the satisfaction of users of SRH care services was highly correlated to satisfaction with clinic reception and clarity of doctors' explanations. Voucher use, longer consultation times, shorter waiting times, older age, and having a female doctor positively influenced user satisfaction.

Since the provider plays a crucial role in service provision, a survey was conducted to assess if participation in the program prompted changes in doctors' knowledge, attitudes and practices. This study is described in chapter 8 . Nearly all participating doctors $(\mathrm{N}=37)$ were interviewed before the intervention, and 23 were interviewed 
after the intervention, by one of the doctors on the research team. Their answers confirmed the existence of provider related barriers that adolescents in Nicaragua may face. The initial interviews disclosed serious deficiencies in doctors' knowledge, attitudes and practices relating to adolescent SRH-issues. Gender and age of the doctor were not associated with the initial scores, which measured the correct answers. Comparing scores from before and after the intervention revealed significant increases in doctors' knowledge of contraceptives and STIs; barriers to contraceptive use significantly diminished; and some attitudinal changes were observed. Furthermore, doctors became more aware of the need to improve their communication skills and were positive about the program.

All participating clinics were visited before, during and after the intervention, by simulated patients (SPs) (female adolescents) requesting contraception. After each consultation, they were interviewed, using a standardized questionnaire, by one of the doctors on the research team. The objective of this survey was to assess whether the doctors' performance improved as a result of participation in the voucher program. Chapter 9 presents their experiences. The SP survey yielded important and relevant information on providers' performance. SPs experiences were illustrative of the difficulties that adolescents may encounter when requesting contraceptives. A considerable number of SPs returned 'empty-handed', although none had contraindications for using contraceptives. The care provided during the voucher program improved in relation to some important outcomes: more SPs were involved in the choice of contraceptive method and more received a contraceptive method. The improvements were more pronounced among providers with the weakest initial performance. Shared decision-making and condom promotion remained at a significantly higher level after the pilot program had ended.

In chapter 10, the main findings are discussed. The SRH care needs of many adolescents were met with a relatively simple intervention utilizing existing health facilities. While no other studies in Latin America have reported similar results they have been recorded elsewhere. Outreach activities, combined with easy access to adolescent friendly health services, appear key factors to success.

Teenage girls were more frequently satisfied with the health services when they had used a voucher. Confidential and guaranteed access appeared important contributing factors. Most providers were not well prepared for the task of consulting adolescents, neither in terms of their technical knowledge nor their communication skills. This reinforces the need to strengthen medical training in this area. Furthermore, it explains why a voucher program aiming at improving SRH care for adolescents needs to comprise training of providers and development 
of systems for providing feedback and support. Extra attention to improving the quality of SRH care is important because it is providers who determine whether current and continuing needs are met. This is due to two factors. First, to the crucial role that providers play in identifying and responding to girls' needs, and second to the crucial role that user satisfaction has in the acceptance of the advice given and in intention to return.

On the basis of the empirical studies on which this thesis is based, we have been able to draw a number of policy relevant conclusions. First, responding to adolescents' needs for confidential SRH care can significantly contribute to the prevention of serious public health problems related to early teenage pregnancy, unwanted pregnancy, and STIs. Second, reaching sexually active adolescents who are not yet pregnant probably yields the highest public health impact. Third, existing health services can be made accessible, appropriate and acceptable to adolescents, relatively quickly and without huge investment, through a voucher program. Fourth, incorporation of the views of adolescents is crucial if the intervention is to effectively meet their specific needs. Fifth, a 'comprehensive' voucher program, that is, a competitive voucher program that pays explicit attention to improving and supporting providers, is likely to generate a more sustainable improvement in the quality of care than a program based principally on competition between providers. Sixth, a valuable area for further research would be to determine if the coverage of the intervention could be expanded to other groups of adolescents by developing a system to assess the 'adolescent friendliness' of existing clinics, and prominently displaying this accreditation outside clinics. Last but not least, the sustainability of a voucher program lies in its potential to prompt ongoing change in the way adolescents use health care services and in the way the health services attend to adolescents. In view of the substantial direct costs saved at both the individual and societal level when rates of unwanted pregnancies and STIs decrease, the intervention is likely to be highly cost effective.

The program proved to be an effective approach to meeting needs of many adolescents in Managua and later in other Nicaraguan cities, and it is probable that it would prove effective elsewhere. Responding to adolescents' needs for SRH care enables them to reduce the risks of sexual behaviour and to assume responsibility for their own well-being and that of their partners. Therefore, the overriding recommendation drawn from our research is to start now implementing voucher programs for adolescents, and to incorporate evaluation strategies in the design of these interventions so that the difference that accessible, affordable, appropriate and confidential SRH care can make to the quality of life and life time opportunities of adolescents in developing countries can be tracked and measured. 


\section{Samenvatting}

Tienerzwangerschap is heel gewoon in Nicaragua en adolescenten maken weinig gebruik van moderne anticonceptiva. Elk jaar krijgen 119 van de 1000 meisjes tussen 15 en 19 jaar een baby. Op hun $19 \mathrm{e}$ is $45 \%$ van de meisjes zwanger of al moeder. Dit proefschrift beschrijft de evaluatie van een competitief voucherprogramma voor adolescenten in Managua, de hoofdstad van Nicaragua. Dit programma was gericht op het verhogen van de toegang en kwaliteit van de seksuele en reproductieve gezondheidszorg (SRG) voor adolescenten. Het uiteindelijke doel van de interventie was het verminderen van ongewenste zwangerschappen en van de risico's op seksueel overdraagbare aandoeningen (SOA's), inclusief HIV. De interventie bestond onder andere uit het uitdelen van vouchers aan adolescenten van tussen de 12 en 20, woonachtig in achterstandswijken van Managua. Een voucher is een bon waarmee voor een bepaalde dienst kan worden betaald. In dit programma konden vouchers worden gebruikt voor een gratis consult seksuele en reproductieve gezondheidszorg in een van de 19 deelnemende klinieken. De context van de interventie, de onderzoeksvragen en de opbouw van het proefschrift worden behandeld in hoofdstuk 1 .

Om de factoren die bijdragen tot het huidige lage niveau van gebruik van anticonceptiemiddelen beter te begrijpen, en de mogelijkheden voor effectieve interventies te identificeren, werd literatuur uit Nicaragua en andere LatijnsAmerikaanse landen bestudeerd. Deze wordt behandeld in hoofdstuk 2. De belangrijkste bevindingen waren dat de overgrote meerderheid van mensen seksuele verhoudingen aangaan in hun tienerjaren, maar dat het veel adolescenten ontbreekt aan complete en accurate informatie over de hieraan verbonden risico's en de mogelijkheden zich te beschermen tegen deze risico's. Bovendien worden veel seksuele relaties gekenmerkt door een duidelijke machtsongelijkheid, en een onbekend percentage van tienerzwangerschappen is het gevolg van seksueel misbruik. Er bestaat een algemene weerzin onder volwassenen in Latijns Amerika van individueel tot politiek niveau - om op een constructieve manier over seksualiteit te praten. Deze weerzin komt voort uit een aantal factoren: de sociaalculturele achtergrond van het machismo; de sterke invloed van de Katholieke Kerk; en de algemene afkeuring van recreatieve seks voor jonge mensen, speciaal voor meisjes. Vrouwelijke adolescenten die anticonceptiemiddelen willen gebruiken komen obstakels tegen die te maken hebben met de beschikbaarheid, toegankelijkheid, kwaliteit en vertrouwelijkheid van de dienstverlening. Zonder eenvoudige toegang tot informatie en gezondheidszorg is het onmogelijk te bepalen in welke mate het niet-gebruiken van anticonceptiemiddelen door adolescenten 
moet worden verklaard uit sociale, culturele en religieuze normen en mechanismen, of als voortvloeisel van het gebrek aan toegang tot betrouwbare informatie en vertrouwelijke gezondheidszorg.

Hoofdstuk 3.2 geeft een overzicht van de beschikbare literatuur over interventies in Latijns Amerika die tot doel hadden de toegang tot gezondheidszorg en anticonceptiemiddelen voor adolescenten te verbeteren. Tot nu toe zijn er weinig van zulke interventies grondig geëvalueerd en gedocumenteerd, en geen enkele evaluatie toonde succes aan in het verhogen van het gebruik van SRG of anticonceptiemiddelen door adolescenten. Recentelijk is het concept van 'adolescentvriendelijke dienstverlening' ontwikkeld. Dit biedt een veelomvattend kader voor het ontwerpen van interventies die alle organisatorische, technische en communicatieve elementen bevatten die belangrijk zijn voor het verlenen van gezondheidszorg aan adolescenten. Op dit moment worden er op veel plaatsen in ontwikkelingslanden interventies uitgevoerd die gebaseerd zijn op dit concept.

In hoofdstuk 3.3 wordt de gezondheidszorg aan adolescenten in Managua nader beschreven. Ondanks dat zij ongeveer $25 \%$ van de bevolking uitmaken worden er zeer weinig middelen direct besteed aan adolescenten in het bestaande gezondheidszorgsysteem. Institutionele normen en de dagelijkse praktijk van SRG aan adolescenten worden gekenmerkt door medische obstakels en onjuiste gebruiken, en zijn niet consistent met internationaal aanvaarde normen. In Managua maken vrouwelijke adolescenten normaliter pas gebruik van de gezondheidszorg als zij al zwanger zijn, terwijl mannelijke adolescenten de voorkeur geven aan de apotheek als zij symptomen hebben van een SOA. Kortom, er bestaat een duidelijke noodzaak voor interventies die de toegang en kwaliteit van SRG voor adolescenten verbeteren.

In 1996 heeft het Centraal Amerikaans Gezondheid Instituut (Instituto Centro Americano de la Salud, ICAS) een competitief voucherprogramma in Managua uitgevoerd om te toegang tot behandeling van SOA's onder sekswerkers te verbeteren, en op die manier bij te dragen aan het reduceren van de HIVprevalentie in deze groep mensen die verstoten zijn van gezondheidszorg. Competitief verwijst naar het feit dat er verschillende zorgverleners betrokken zijn bij het programma, waarbij de patiënten vrij tussen hun kunnen kiezen. Dit moedigt zorgverleners aan om met elkaar te concurreren om voucher bezitters aan te trekken en te behouden als klant. Het concept van competitieve voucherprogramma's, en ervaringen met hun uitvoering, worden beschreven in hoofdstuk 4.1. Geïnspireerd door het succes van deze interventie ontwikkelde het ICAS, in samenwerking met de London School of Hygiene and Tropical Medicine, een pilot 
programma om de toegang en kwaliteit van de SRG zorg voor kansarme adolescenten te verbeteren, gebruik makend van een gelijksoortig mechanisme. Het British Department for International Development (DFID) stelde de fondsen beschikbaar en het ICAS was de uitgever van de vouchers. Er werd een memorandum of understanding getekend met het Ministerie van Gezondheid, en het pilot programma werd uitgevoerd in Managua van 2000 tot 2002. Het was dit voucherprogramma dat het onderwerp van studie is van dit proefschrift.

De specifieke doelstelling van de interventie waren om: 1) de toegang en kwaliteit van de SRG zorg voor adolescenten te verbeteren; 2) het gebruik van de SRG zorg door adolescenten te verhogen; 3) de kennis en het gebruik van anticonceptiemiddelen onder adolescenten te verhogen. Als onderdeel van het programma werden vouchers uitgedeeld aan arme adolescenten van 12 tot 20 jaar, op markten, buiten schoolterreinen en van deur tot deur in achterstandswijken. De distributie werd uitgevoerd door adolescenten die ingehuurd waren als veldwerkers door ICAS, door niet-gouvernementele organisaties (NGO's), door klinieken (bijvoorbeeld voor vriend(inn)en van zwangere meisjes of partners van voucher gebruikers met een SOA), en door adolescenten uit z.g. adolescentenclubs die verbonden zijn aan klinieken. De vouchers waren niet persoonsgebonden en drie maanden geldig. Ze gaven de eigenaar recht op een gratis consult en een vervolg visite in een van de vier publieke, vijf privé- of tien NGO-klinieken die waren gecontracteerd. Het SRG dienstenpakket bestond uit voorlichting/advies, anticonceptie, een zwangerschapstest, zwangerschapscontrole en syndromatische SOA behandeling. Alle vouchergebruikers ontvingen een boekje over de puberteit, twee condooms met een informatieve folder, en daarnaast - afhankelijk van de behoefte - laboratoriumtesten (voor zwangere meisjes), medicijnen voor de SOAs en anticonceptiemiddelen. De selectie van de klinieken was gebaseerd op geschiktheid en nabijheid ten opzichte van de gebieden waar de vouchers werden uitgedeeld. Gedurende ieder consult vulden de artsen medische formulieren in die gebaseerd waren op 'best practices'. De participerende klinieken werden betaald op basis van het aantal ingevulde formulieren met een ingesloten voucher, volgens tevoren overeengekomen tarieven. De kundigheid van het personeel van de betrokken klinieken werd versterkt door een bijeenkomst waarin het programma werd uitgelegd, gevolgd door een serie van vier trainingssessies over counseling, adolescentie en seksualiteit, anticonceptiemiddelen, geslachtsziektebehandeling en seksueel misbruik. Alle artsen ontvingen een handleiding met achtergrond informatie en richtlijnen. De details van de interventie worden beschreven in hoofdstuk 4.3.

Voor de monitoring en evaluatie van het programma werden een aantal 
verschillende instrumenten gebruikt: zelfingevulde vragenlijsten, medische formulieren, interviews met artsen en met simulatiepatiënten vóór, tijdens en na het programma en focusgroepdiscussies met adolescenten. Het ontwerp van de evaluatiestudie wordt beschreven in hoofdstuk 4.4.

Om de impact van de interventie op het gebruik van de SRG zorg en de kennis over anticonceptiemiddelen en condooms te onderzoeken werd een quasi-experimentele onderzoeksopzet gebruikt. De resultaten van deze studie worden gepresenteerd in hoofdstuk 5. Steekproeven werden genomen van vrouwelijke adolescenten in een representatieve selectie van de plaatsen waar vouchers waren uitgedeeld: op markten, buiten scholen en in achterstandswijken. Zelf-in-te-vullen vragenlijsten werden uitgedeeld onder vrouwelijke adolescenten tussen de 12 en 20 jaar oud. De vragenlijsten werden aan hen gepresenteerd als een onderzoek naar hun mening over de gezondheidszorg voor adolescenten en werden niet gekoppeld aan het voucherprogramma. De studie omvatte een aselecte steekproef van 3,009 adolescenten, van wie 904 in het afgelopen jaar een voucher hadden ontvangen en 2,105 nog nooit een voucher hadden ontvangen. Ontvangers van vouchers hadden een significant hoger gebruik van SRG zorg vergeleken met niet-ontvangers. Voucherontvangers hadden een grotere kennis van anticonceptiemiddelen en SOA's dan niet-ontvangers. De seksueel actieve voucherontvangers die gerecruteerd waren buiten de scholen hadden een significant hoger gebruik van moderne anticonceptiemiddelen dan niet-ontvangers. In de achterstandswijken was het gebruik van een condoom bij het laatste seksuele contact significant hoger bij voucherontvangers dan bij niet-ontvangers.

In hoofdstuk 6 wordt de analyse van de medische formulieren van 3,301 vrouwelijke adolescenten die een voucher gebruikt hadden, beschreven. De adolescenten die een voucher gebruikten presenteerden zich met SRG-problemen die medische aandacht rechtvaardigden. Het gemiddeld aantal problemen was 1,5 per consult. Eenderde van de vouchers werd gebruikt voor anticonceptiemiddelen, bijna éénderde voor klachten gerelateerd aan SOA's of een infectie van de reproductieve organen, $28 \%$ voor counseling/advies, $28 \%$ voor zwangerschapscontrole, en $18 \%$ voor een zwangerschapstest. Een nieuwe categorie van gebruikers van gezondheidszorg verscheen: seksueel actieve meisjes die noch zwanger noch moeder waren, en die kwamen voor anticonceptiemiddelen of geslachtsziektebehandeling. Het gebruik van anticonceptiemiddelen verdubbelde onder de seksueel actieve, niet-zwangere vouchergebruikers. Consult met een vrouwelijke arts jonger dan 36 jaar resulteerde in een grotere kans tot het voorgeschreven krijgen van anticonceptiemiddelen. Dit illustreert de invloed die zorgverleners hebben op het beantwoorden van de zorgbehoefte van de meisjes. 
In hoofdstuk 7 worden de resultaten gepresenteerd van de studie die werd ondernomen om te bepalen hoe de kwaliteit van de SRG-zorg werd ervaren in vergelijking tot de normaal ontvangen zorg. De zelf-in-te-vullen vragenlijst bevatte vragen die waren opgesteld om de gevoelens van de meisjes omtrent de ontvangen zorg te verkennen. Zevenhonderd van de 3,009 respondenten waren in de laatste 15 maanden naar de dokter gegaan voor een consult SRG: 221 van hen met een voucher (gebruikers-met-voucher) en 479 zonder voucher (gebruikers-zondervoucher). Hun anoniem ingevulde vragenlijsten werden gebruikt om de determinanten van hun tevredenheid te analyseren. Er werd een duidelijk verband gevonden tussen de ervaren kwaliteit van de zorg en vouchergebruik. De tevredenheid van de gebruikers-met-voucher was significant hoger dan die van gebruikers-zonder-voucher. Vouchergebruikers waren ook vaker tevreden met de ontvangst door de kliniek dan de gebruikers-zonder-voucher, vooral de seksueel actieve meisjes die nog niet zwanger of moeder waren.

De duidelijkheid van de uitleg van de artsen werd niet verschillend beleefd tussen de twee groepen. In het geheel genomen, was de tevredenheid van de gebruikers van de SRG zorg sterk gecorreleerd met de tevredenheid over de ontvangst en de duidelijkheid van de uitleg van de arts. Vouchergebruik, langere tijd van consult, kortere wachttijden, hogere leeftijd en het hebben van een vrouwelijke arts beïnvloedden de tevredenheid van de gebruikers positief.

Aangezien de zorgverlener een cruciale rol speelt m.b.t. de kwaliteit van de zorg, werd een studie uitgevoerd om te bepalen of deelname aan het programma veranderingen met zich meebracht in de kennis, houding en praktijk van de artsen. Deze studie wordt beschreven in hoofdstuk 8. Bijna alle deelnemende artsen $(\mathrm{N}=37)$ werden geïnterviewd door één van de artsen van het onderzoeksteam vóór de interventie en 23 na de interventie. Hun antwoorden bevestigen het bestaan van zorgverlenergerelateerde obstakels waar adolescenten in Nicaragua mee te maken kunnen krijgen. De eerste interviews legden serieuze tekortkomingen bloot in de kennis, houding en praktijk van artsen betreffende SRG-zaken omtrent adolescenten. De sekse en leeftijd van de arts waren niet geassocieerd met de scores die het aantal goede antwoorden weergaven. De scores vóór en na de interventie vergelijkend, is er een significante vergroting van de kennis over anticonceptiemiddelen en SOA's onder de artsen waar te nemen, de obstakels tot gebruik van anticonceptiemiddelen verminderden significant, en er konden enkele houdingsveranderingen worden waargenomen. Artsen werden zich bovendien bewust van de noodzaak hun communicatieve vaardigheden te verbeteren, en oordeelden positief over het programma.

Alle deelnemende klinieken werden vóór, tijdens en na de interventie bezocht door 
simulatiepatiënten (SPs) (vrouwelijke adolescenten) die om een voorbehoedsmiddel vroegen. $\mathrm{Na}$ ieder consult werden zij geïnterviewd met behulp van een gestandaardiseerde vragenlijst door één van de artsen van het onderzoeksteam. Het doel van deze studie was te bepalen of het functioneren van de artsen verbeterde als resultaat van deelname aan het voucherprogramma. In hoofdstuk 9 worden hun ervaringen beschreven. De SP-studie leverde belangrijke en relevante informatie op over het functioneren van de zorgverleners. De ervaringen van de SPs waren illustratief voor de moeilijkheden die een adolescent kan tegenkomen als ze om anticonceptiemiddelen vraagt. Voordat de interventie begon, ging een aanzienlijk aantal van de SPs met lege handen naar huis, hoewel ze geen van alle contraindicaties voor het gebruik van voorbehoedsmiddelen hadden. De zorg geleverd gedurende het programma verbeterde op een aantal belangrijke punten: meer SPs werden betrokken bij de keuze van het voorbehoedsmiddel en meer SPs ontvingen een voorbehoedsmiddel. De verbeteringen waren meer uitgesproken bij de zorgverleners die in het begin het de zwakste prestatie hadden. Het gezamenlijk beslissingen nemen en de condoompromotie bleven op een significant hoger niveau nadat het pilot programma was afgelopen.

In hoofdstuk 10 worden de belangrijkste algemene bevindingen behandeld. De SRG zorgbehoeften voor vele adolescenten werden beantwoord met een relatief eenvoudige interventie, gebruik makende van bestaande gezondheidsvoorzieningen. Hoewel geen andere studies in Latijns Amerika overeenkomstige resultaten hebben gerapporteerd, werden dit wel elders gedaan. Activiteiten in de gemeenschap gecombineerd met gemakkelijke toegang tot adolescentvriendelijke gezondheidszorgvoorzieningen, lijken sleutelfactoren voor succes te zijn.

Vrouwelijke adolescenten waren vaker tevreden met de verleende zorg als zij met voucher de zorg gebruikt hadden. Vertrouwelijke en gegarandeerde toegang tot zorg bleken factoren die in belangrijke mate hieraan bijdroegen. De meeste hulpverleners bleken niet goed voorbereid op de taak van consult met adolescenten, noch wat betreft technische kennis noch wat betreft hun communicatieve vaardigheden. Dit legt de nadruk op de noodzaak de training van de artsen op dit gebied te versterken. Daarnaast verklaart het waarom een voucherprogramma dat zich richt op het verbeteren van de SRG zorg voor adolescenten, training van de zorgverleners en ontwikkeling van systemen voor feedback en ondersteuning moet bevatten, wil het duurzaam effect hebben. Extra aandacht voor het verbeteren van de kwaliteit van de SRG zorg is belangrijk omdat het de zorgverleners zijn die bepalen of huidige en toekomstige behoeften worden vervuld. Dit komt door twee factoren. Ten eerste door de cruciale rol die zorgverleners hebben bij het identificeren en tegemoetkomen aan de behoeften van de meisjes, en ten tweede 
door de cruciale rol die gebruikerstevredenheid heeft in de acceptatie van gegeven adviezen en hun interesse opnieuw gebruik te maken van de zorg.

Op basis van de empirische studies waarop dit proefschrift is gebaseerd, hebben we een aantal beleidsrelevante conclusies kunnen trekken.

Ten eerste kan het vervullen van de behoefte van adolescenten aan confidentiële SRG-zorg in belangrijke mate bijdrage aan de preventie van ernstige publieke gezondheidsproblemen gerelateerd aan vroege tienerzwangerschap, ongewenste zwangerschap en geslachtsziekten.

Ten tweede levert het bereiken van seksueel actieve adolescenten die nog niet zwanger zijn waarschijnlijk de hoogste publieke gezondheidwinst op.

Ten derde kunnen door middel van een voucherprogramma bestaande gezondheidszorgvoorzieningen toegankelijk, geschikt en acceptabel worden gemaakt voor adolescenten op een relatief snelle manier en zonder enorme investeringen.

Ten vierde is het betrekken van adolescenten in de interventie cruciaal om op deze op een effectieve wijze te kunnen afstemmen op hun behoeftes.

Ten vijfde genereert een 'comprehensive' (veelomvattend) voucherprogramma, waarmee een voucherprogramma wordt bedoeld dat expliciet aandacht besteed aan het verbeteren en ondersteunen van de zorgverleners, waarschijnlijk een duurzamere verbetering in de kwaliteit van de zorg dan een 'competetive' voucherprogramma waarbij de concurrentie tussen zorgverleners centraal staat.

Ten zesde, een waardevol gebied voor verder onderzoek is het bepalen of het bereik van de interventie kan worden uitgebreid naar andere groepen adolescenten door het ontwikkelen van een systeem dat de adolescentvriendelijkheid van de bestaande klinieken vaststelt en deze accreditatie prominent laat zien buiten de klinieken.

Last but not least, de duurzaamheid van een voucherprogramma ligt in diens potentieel blijvende veranderingen teweeg te brengen in de manier waarom adolescenten gezondheidszorg gebruiken en in de manier waarop de zorgverleners hen ontvangen. Gezien de aanzienlijke directe kosten die uitgespaard worden, zowel op het individueel niveau als op het gemeenschapsniveau, als de aantallen ongewenste zwangerschappen en SOA's dalen, is de interventie waarschijnlijk zeer kosteneffectief.

Het voucherprogramma bleek een effectieve benadering te zijn om de behoeften te vervullen van vele adolescenten in Managua, en later in andere Nicaraguaanse steden - en het is waarschijnlijk dat het ook elders effectief zal blijken. Het vervullen van de behoeften van adolescenten voor SRG zorg stelt hen in staat de risico's van hun seksueel gedrag te verminderen en de verantwoordelijkheid op 
zich te nemen voor hun eigen welzijn en dat van hun partners. Daarom is de belangrijkste aanbeveling die voortkomt uit ons onderzoek om $\underline{\mathrm{nu}}$ te beginnen met het uitvoeren van voucherprogramma's voor adolescenten. Het is belangrijk om daarbij goede evaluatiestrategieën op te nemen, zodat het verschil dat toegankelijke, betaalbare, geschikte en vertrouwelijke SRG zorg kan maken op de kwaliteit van en de keuzemogelijkheden in het leven van adolescenten in ontwikkelingslanden, kan worden gevolgd en gemeten. 


\section{Resumen}

El embarazo en adolescentes es muy común en Nicaragua y los adolescentes hacen poco uso de los métodos anticonceptivos modernos. Cada año, 119 por 1000 de las adolescentes entre 15 y 19 años dan a luz. A la edad de los 19 años, el $45 \%$ de las adolescentes están embarazadas o ya han dado a luz. Esta tesis describe la evaluación de un programa de bonos competitivo para los y las adolescentes en Managua, capital de Nicaragua. El programa tenía como objetivo a aumentar el acceso y la calidad de los servicios de salud sexual y reproductiva (SSR) para los y las adolescentes. Otro de los objetivos de la intervención era reducir el índice de embarazos no deseados y los riesgos de contraer alguna infección de transmisión sexual (ITS), incluyendo el VIH/SIDA. La intervención implicó la distribución de bonos a los y las adolescentes entre 12 y 20 años, viviendo en áreas marginales de Managua. Diecinueve clínicas participaban en el programa, en donde los y las adolescentes tenían acceso gratuito a los servicios de SSR, esto a través del bono que era valido en cualquiera de las clínicas. El contexto de la intervención, las preguntas de la investigación y la estructura de la tesis se presentan en capítulo 1 .

Se revisó la literatura de Nicaragua y América Latina para entender mejor los factores que influyen en el bajo uso de los métodos anticonceptivos modernos por las adolescentes y para identificar las oportunidades para las intervenciones eficaces y este se discuta en el capitulo 2. Los resultados principales eran que la gran mayoría de la gente inicia sus relaciones sexuales durante su adolescencia, pero que muchos adolescentes carecen de la información completa y exacta sobre los riesgos involucrados y las posibilidades de prevención. Además, muchas relaciones sexuales son caracterizadas por disparidades marcadas de poder, y un porcentaje aun desconocido de embarazos en adolescentes es debido al abuso sexual. Hay dificultad en todos los niveles, desde el individual hasta el político para hablar de la sexualidad en los adolescentes de una manera constructiva. Este rechazo se origina en un número de factores entre otros: la base socio-cultural del machismo; la influencia fuerte de la Iglesia Católica; y la desaprobación generalizada del sexo recreativo para los y las jóvenes, especialmente para las muchachas. Las muchachas que desean utilizar métodos anticonceptivos tienen que vencer obstáculos relacionados con la disponibilidad, la accesibilidad, la calidad y la confidencialidad de los servicios de salud. Sin acceso fácil a información y a servicios de salud, es imposible determinar en qué medida el no uso de anticonceptivos por los y las adolescentes debe explicarse por normas y mecanismos sociales, culturales y religiosos, ó como consecuencia de la carencia del acceso a información confiable y a servicios de salud confidenciales. 
En el primer parte del capitulo 3 se proporciona una descripción de la literatura disponible sobre las intervenciones en América Latina que han tenido como objetivo de mejorar el acceso de los y las adolescentes a los servicios de salud y a los métodos anticonceptivos. Hasta este momento, de las intervenciones mencionadas como exitosas son pocas las que se han evaluado rigurosamente y las que han sido publicadas. Ninguna de estas pocas evaluaciones proporcionó evidencia de éxito en mejorar el uso de SSR o de métodos anticonceptivos por los y las adolescentes. Recientemente, el concepto de 'servicios amigables para adolescentes' se ha desarrollado. Esto ofrece un marco global que facilita el diseño de intervenciones que abarcan todos los elementos organizacionales, técnicos y comunicativos que son importantes para la entrega de servicios de salud a los y las adolescentes. Actualmente, las intervenciones basadas en este concepto se están poniendo en ejecución y se están evaluando en muchos lugares en países en vía de desarrollo.

En capitulo 3.3 se detalle la provisión de servicios de salud a adolescentes en Managua. A pesar que la representación es de aproximadamente el $25 \%$ de la población, muy pocos recursos se dedican directamente a los y las adolescentes a través del sistema existente de salud. Las normas institucionales y las prácticas en el abastecimiento de los servicios SSR a los y las adolescentes son caracterizadas por obstáculos y conceptos erróneos de los médicos, e inconsistentes con 'las mejores prácticas internacionales'. Hay una necesidad clara de intervenciones que mejoren el acceso y la calidad de los servicios de SSR para adolescentes. En Managua, las adolescentes femeninas normalmente solo comienzan a utilizar los servicios de SSR una vez que están embarazadas, mientras que los adolescentes masculinos prefieren acudir a una farmacia si tienen algún síntoma de ITS.

En 1996, el Instituto Centro Americano de Salud (ICAS) puso en ejecución un programa de bonos competitivo en Managua, para mejorar el acceso al tratamiento de ITS entre trabajadores del sexo, como medida eficaz para contribuir a la reducción de la incidencia del VIH entre este grupo que normalmente carece de los servicios adecuados para tratar sus ITS. 'Competitivo' se refiere al hecho que en el programa descrito existe varios proveedores de servicios están involucrados y que los usuarios pueden elegir entre ellos. Por eso existe una competencia entre los proveedores de los servicios para atraer a más jóvenes que usaron los bonos. El concepto de programa de bonos competitivo, y experiencias con su puesta en práctica, se presentan en el capitulo 4.1. Inspirado por el éxito de esta intervención, ICAS desarrolló, en colaboración con la Escuela de Londres de Higiene y Medicina Tropical, un programa piloto para aumentar el acceso a y la calidad de los servicios de SSR para adolescentes de escasos recursos, usando un mecanismo 
similar. El Departamento Británico para el Desarrollo Internacional (DFID) proporcionó el financiamiento, e ICAS era quien funcionaba como la agencia de bonos. Un memorandum de entendimiento fue firmado con el Ministerio de Salud, y el programa fue piloteado en Managua en el periodo 2000-2002. Es este programa piloto el tema de los estudios subyacentes de esta tesis.

Los objetivos específicos de la intervención eran: 1) facilitar el acceso a y mejorar la calidad de los servicios de SSR; 2) aumentar el uso por los y las adolescentes de los servicios SSR; y 3) aumentar el conocimiento y el uso por los y las adolescentes de los métodos anticonceptivos. Bajo el programa, los bonos fueron distribuidos a los y las adolescentes de escasos recursos entre 12 y 20 años de edad, en mercados, fuera de escuelas, en la calle y casa por casa en barrios empobrecidos. La distribución fue hecha por adolescentes contratados por ICAS, Organizaciones No Gubernamentales (ONG's), clínicas (por ejemplo, para amigos/amigas de muchachas embarazadas o parejas de pacientes adolescentes con ITS), y clubes de adolescentes asociados a clínicas. Los bonos eran transferibles y tenían una vigencia de tres meses. Los bonos dieron derecho al portador a una consulta gratuita y una visita de seguimiento en cualquiera de las 19 clínicas contratadas (4 públicas, 5 privadas y $10 \mathrm{NGO}$ ). El paquete de servicios de SSR consistió en: consejería, planificación familiar, prueba de embarazo, atención prenatal y tratamiento de ITS. Todos los usuarios de bonos recibieron un material educativo sobre salud para adolescentes; dos condones con información sobre su uso; el resto de servicios era según la necesidad individual de la/el adolescente. La selección de clínicas fue basada en su aptitud y proximidad a los sitios donde los bonos fueron distribuidos. Durante cada consulta, los doctores llenaron una ficha médica estándar basado en mejores prácticas. Las clínicas que participaban eran remuneradas con el precio previamente convenido en base al número de fichas médicas llenadas y las cuales llevaban adjunto un bono valido del programa. La capacitación para el personal de las clínicas que participaban implicó una introducción corta al programa, seguido por sesiones de entrenamiento sobre consejería, adolescencia y sexualidad, anticonceptivos, tratamiento sindrómico de ITS y abuso sexual. Todos los doctores recibieron un manual informativo que contenía datos y directrices. Los detalles de la intervención se describen en capítulo 4.3.

El monitoreo y la evaluación del programa fue realizado usando un número de instrumentos: cuestionarios auto-llenados; fichas clínicas estandardizadas; entrevistas con los doctores y con las pacientes simuladores antes, durante y después del programa; y discusiones de grupos focales con los adolescentes. El diseño del estudio de evaluación se discute en el capítulo 4.4. 
Un diseño cuasi-experimental fue utilizado para examinar el impacto de la intervención en el uso de los servicios de SSR, en el conocimiento, uso de métodos anticonceptivos y condones. Los resultados de este estudio se presentan en el capítulo 5. El muestreo del estudio fue tomado al azar de adolescentes en una muestra representativa de los mercados, los barrios, y las escuelas donde había ocurrido la intervención. Cuestionarios del tipo auto-llenado fueron distribuidos a las adolescentes femeninas de 12 a 20 años. Los cuestionarios fueron introducidos como un estudio que buscaba las opiniones sobre los servicios de salud para adolescentes, y no estaban ligados abiertamente al programa de bonos. El estudio abarcó una muestra escogida al azar de 3.009 adolescentes femeninos, de las cuales 904 eran receptoras del bono y 2.105 nunca habían recibido un bono. Las receptoras del bono tenían un uso significativo más alto de servicios de SSR, comparado con las no receptoras. Las receptoras de bonos tenían mayor conocimiento de los anticonceptivos y de las ITS que las no receptoras. En las escuelas, las receptoras sexualmente activas tenían un uso significativo más alto de anticonceptivos modernos que las no-receptoras. En los barrios de pocos recursos económicos, el uso del condón durante el último contacto sexual era significativamente mayor entre las receptoras del bono que entre las no-receptoras.

En el capitulo 6 se describe el análisis de las fichas clínicas de las 3.301 consultas con las usuarias femeninas de bonos. Las adolescentes que utilizaron un bono presentaron problemas de SSR que necesitaban atención médica. El número promedio de los problemas presentados era 1.5 por consulta. Un tercio de los bonos fue utilizado para anticonceptivos; casi un tercio para infecciones de transmisión sexual (ITS) o del tracto reproductivo $28 \%$ para consejería; $28 \%$ para chequeo prenatal, y $18 \%$ para pruebas de embarazo. Una nueva categoría de usuarias de servicios de salud surgió: muchachas sexualmente activas que no estaban embarazadas ni eran madres, y que buscaron anticonceptivos o tratamiento de ITS. Entre las usuarias sexualmente activas, que no estaban embarazadas y usaban su bono el uso de métodos anticonceptivos duplicó. Una consulta con una doctora de menos de 36 años fue asociada a una probabilidad más alta de una prescripción de métodos anticonceptivos. Esto demuestra la influencia que los proveedores tienen en su respuesta a las necesidades de las muchachas.

En capitulo 7, los resultados se presentan del estudio que se realizó para determinar cómo las jóvenes percibieron la calidad de los servicios de SSR recibido a través del programa de bonos comparado con la calidad de los servicios recibidos normalmente (sin bono). El cuestionario del tipo auto-llenado contenía algunas preguntas diseñadas para explorar las apreciaciones de las muchachas sobre el servicio recibido. Setecientos de las 3.009 que respondieron la encuesta 
habían buscado servicios de SSR en los 15 meses anteriores, 221 con bono (usuario-con-bono) y 479 sin bono (usuario-sin-bono). Sus cuestionarios llenados anónimamente fueron utilizados para analizar los determinantes de su satisfacción. Asociaciones claras fueron encontradas entre la calidad percibida de los servicios y el uso de un bono. La satisfacción de la usuaria-con-bono era significativamente más alta comparada con la usuaria-sin-bono. El uso de bonos fue también asociado a una satisfacción mayor con la recepción de la clínica, especialmente entre muchachas sexualmente activas que no estaban embarazadas ni eran madres. Sin embargo, no hubo diferencia en la percepción sobre la claridad de las explicaciones de los doctores entre los dos grupos. En su totalidad, la satisfacción de usuarios de los servicios de SSR fue altamente correlacionada a la satisfacción con la recepción en la clínica y a la claridad de las explicaciones de los médicos. Uso de un bono, consulta con duración más larga, tiempo de espera más corto, una edad mayor de médico y siendo el doctor femenino influenció positivamente en la satisfacción del usuario con los servicios recibidos.

Dado que el proveedor juega un papel crucial en la calidad del servicio, un estudio fue realizado para determinar si la participación en el programa incitó a cambios en los conocimientos, actitudes y prácticas de los médicos. Este estudio se describe en el capitulo 8. Casi todos los médicos que participaron $(\mathrm{N}=37)$ fueron entrevistados antes de la intervención y 23 fueron entrevistados después de la intervención por uno de los médicos miembros del equipo de investigación. Sus respuestas confirmaron la existencia de obstáculos relacionados a los proveedores a los cuales los adolescentes en Nicaragua se enfrentan. Las entrevistas iniciales demostraron deficiencias serias en los conocimientos, actitudes y prácticas de los médicos, relacionados a la SSR para adolescentes. Género y edad del doctor no estaban asociados con los puntajes iniciales, que eran los que reflejaron las repuestas correctas. El comparar puntajes de antes y después de la intervención reveló aumentos significativos en el conocimiento de los doctores sobre anticonceptivos y de ITS; los obstáculos al uso de anticonceptivos disminuyeron significativamente; y algunos cambios de actitud se observó. Además, los doctores estaban más concientes de la necesidad de mejorar sus habilidades de comunicación y se mostraron positivos con el programa.

Todas las clínicas que participaron fueron visitadas antes, durante y después de la intervención, por pacientes simuladoras (PS) (adolescentes femeninas) solicitando un método anticonceptivo. Después de cada consulta, las PS fueron entrevistadas con un cuestionario estandardizado por uno de los doctores miembro del equipo de investigación. El objetivo de este estudio era de determinar si el funcionamiento de los doctores mejoró como resultado de la participación en el programa de bonos. El 
capítulo 9 presenta sus experiencias. El estudio de PS sacó a luz información importante y relevante sobre el funcionamiento de los proveedores. Las experiencias de las PS eran ilustrativas de las dificultades que las adolescentes pueden encontrar al solicitar algún método anticonceptivo. Un número considerable de PS, que visitaron las clínicas antes del inicio del programa, volvieron 'con las manos vacías ', aunque todas eran usuarias elegibles para recibir anticonceptivos. El servicio proveído durante el programa del bono mejoró referente a algunos aspectos importantes: más PS fueron involucrados por el médico en la selección del método anticonceptivo, y más PS recibieron un método anticonceptivo. Las mejoras eran más pronunciadas entre proveedores que inicialmente mostraron un funcionamiento más débil. La toma de decisión compartida entre el medico y la adolescente y la promoción del condón quedaban en un nivel significativamente más alto después de que el programa piloto había terminado.

En el capitulo 10, se discuten los resultados principales. Las necesidades insatisfechas en servicios de SSR de muchas adolescentes fueron resueltas con una intervención relativamente simple y utilizando los servicios de salud existentes. Mientras que ningún otro estudio en América Latina ha divulgado resultados similares, pero si en otras partes del mundo se han registrado algunas intervenciones con resultados similares.

Actividades de educación en la calle, combinadas con el acceso fácil a los servicios médicos amigables para adolescentes, aparecen como factores principales del éxito.

El uso del bono de las muchachas adolescentes fue asociado a una satisfacción más frecuente de la usuaria. El acceso confidencial y garantizado (sin rechazo) apareció como un factor que contribuyó de una manera importante. La mayoría de los proveedores no estaban preparados para el trabajo con adolescentes, ni en términos de su conocimiento técnico ni de sus habilidades de comunicación. Esto refuerza la necesidad de fortalecer el entrenamiento médico en esta área. Además, explica porqué un programa de bonos teniendo como objetivo mejorar los servicios de SSR para adolescentes, necesita abarcar el entrenamiento de proveedores y el desarrollo de sistemas de retro-alimentación y apoyo. Atención adicional para mejorar la calidad de servicios de SSR es importante, porque son los proveedores que determinan si las necesidades actuales y futuras estarán resueltas. Esto es debido a dos factores. Primero, al papel crucial que juegan los proveedores al identificar y responder a las necesidades de las muchachas, y en segundo lugar al papel crucial 
que la satisfacción de la usuaria tiene en la aceptación del consejo dado y en la intención de volver al proveedor.

Basado en los estudios empíricos en los cuales se basa esta tesis, hemos podido sacar conclusiones relevantes para las políticas de salud.

Primero, el responder a las necesidades de los y las adolescentes en cuanto a servicios confidenciales de SSR puede contribuir de manera significativa a la prevención de problemas serios de salud pública: es decir aquellos problemas relacionados con el embarazo temprano de adolescentes; con el embarazo no deseado; y las ITS.

En segundo lugar, asistir a las adolescentes sexualmente activas y no embarazadas puede dar el mayor impacto en términos de salud pública.

Tercero, los servicios de salud existentes pueden hacerse accesibles, apropiados y aceptables a los y las adolescentes de una manera relativamente rápida, y sin enormes inversiones, con un programa de bonos.

Cuarto, la incorporación de las opiniones de los y las adolescentes es crucial, si la intervención tiene como objetivo resolver con eficacia las necesidades específicas de ellos y ellas.

Quinto, un programa 'comprensivo' de bono, es decir, un programa de bonos competitivo que presta atención explícita a mejorar y apoyar a los proveedores, probablemente generará una mejora más sostenible en la calidad de los servicios que un programa basado principalmente en la competencia entre los proveedores. En sexto lugar, una área valiosa para la investigación adicional sería determinar si la cobertura de la intervención se podría ampliar hacia los adolescentes que no tienen la suerte de recibir un bono, desarrollando un sistema para determinar el nivel de 'amigabilidad para adolescentes' de clínicas existentes, y prominentemente exhibir esta acreditación fuera de las clínicas.

Ultimo pero nolo menos, la sostenibilidad de un programa de bonos es basada en su potencial de incitar cambios duraderos y continuos en la manera en la cual los y las adolescentes utilizan los servicios de salud y en la manera como los servicios de salud reciben a los y las adolescentes. En vista de los costos directos y substanciales que se ahorran a nivel individual y de la sociedad cuando disminuyen los índices de embarazos no deseados y los casos de ITS, la intervención es probablemente altamente rentable.

El programa ha demostrado ser una manera eficaz para satisfacer las necesidades de muchos adolescentes en Managua y en otros departamentos del país, y es probable que sería muy eficaz en otros lugares. El responder a las necesidades de los y las adolescentes de servicios de SSR les permite reducir los riesgos del comportamiento sexual, y asumir la responsabilidad de su propio bienestar y la de 
sus parejas. Por lo tanto, la recomendación principal de nuestra investigación es comenzar ahora a poner en marcha programas de bonos para los y las adolescentes, e incorporar estrategias de evaluación en el diseño de estas intervenciones, para que la diferencia que puede hacer un servicio accesible, apropiado y confidencial de SSR para la calidad y las oportunidades de vida de adolescentes en países en vía de desarrollo pueda ser seguida y medida. 
Acknowledgement 



\section{Acknowledgement - Agradecimientos - Dankwoord}

Working on this intervention has been a very interesting experience. It was a true pilot in the sense that we did not know how the intervention would be received by adolescents and health care providers. This book is the result of a joint effort of many different people throughout the last six years. I would like to thank all people who participated and/or contributed to this intervention, the research and the writing up of the results, and I would like to mention some people in particular.

Hemos trabajado en esta intervención pilote con todo un equipo. Sin el trabajo duro y entusiasta de Leonora Centeno, Alejandro Dormes, Patricia Gonzales, Gloria Medina, Joel Medina, Zoyla Segura, Amelia Tijerino, Roger Torrentes, y Esteban Zuñiga, la intervención nunca había poder tener éxito. Ustedes, juntos con el otro personal en ICAS, me han aceptado en su organización, a pesar de las pocas palabras de español que hablé inicialmente. Ustedes me han apoyado a recoger millones de datos que han sido la base de todos los análisis en este libro. Ustedes no me han introducido solamente en los servicios de salud en Nicaragua, pero también en muchos otros aspectos de la vida Nicaragüense. ¡Muchas gracias a todos! Gracias a la contribución de Tomás Donaire los artículos aceptados han sido traducidos en español. ¡Espero que ustedes vayan a tener mucho éxito en influir las políticas y practicas en Nicaragua!

The central person in this process has been my co-promoter, Anna Gorter. Anna, you designed the intervention, guided us through e-mails and meetings, and followed all steps of the process. You invited me to take part in the project and introduced me into many aspects of research such as EPI-info, Pub Med, and data cleaning as well as working in Nicaragua. You also gave me room to elaborate various study designs and to develop the questionnaires. You reviewed all texts and data that I produced, and accompanied me all the way up to the finalization of this dissertation. Your speed in responding to e-mails kept on impressing me. It enabled us to take maximum advantage of the time difference between the Netherlands and Nicaragua: we have had periods that we worked together 24 hours per day on this intervention. Anna, this book would not have been there without you! Thank you for your support.

Mijn promotor André Knottnerus ben ik speciale dank verschuldigd. André, dit is de tweede keer dat je mij op een moeilijk moment in mijn leven een enorme zet in de constructieve richting hebt gegeven. Je verstaat als geen ander de kunst van het meedenken. Ik heb genoten van je zorgvuldige en trouwe begeleiding, via de telefoon toen ik nog in Managua woonde en later in Maastricht. Ik ben iedere keer 
weer onder de indruk van je scherpe blik, je grote gevoel voor humor en hoe goed je aanvoelt wat ik nodig heb om weer vooruit te kunnen. Zonder jouw steun, meedenken en wijsheid was dit boek er nooit gekomen.

Me gustaría agradecer todos los y las jóvenes, doctores, y otras personas que han compartido sus opiniones con nosotros y/o han trabajado en el proyecto de bono. He disfrutado trabajar con ustedes, y he aprendido mucho de ustedes. ¡Les desea todo lo bien! Espero que ustedes sigan trabajando para mejorar la calidad de la vida y la calidad de servicios de salud en Nicaragua para los y las jóvenes. Yo dedico este libro a los jovenes, para que tiene un futuro mejor!

Julienne, it was inspiring to meet someone like you, who succeeded in giving her life a complete new twist after turning 50. Your enthusiasm and creativity were inspiring, and I keep on trying to see difficulties I encounter as "character building exercises". Thank you for your never failing support, patience and friendship. Your help with the revision of all English texts has been indispensable.

Zonder het intiële enthusiasme van Paul Knipschild waren er nooit zoveel data verzameld, en zonder de uitstekende epidemiologie opleiding aan de London School was ik nooit in staat geweest deze data te analyseren. Voor de statistische berekeningen die ik nog niet geleerd had, was de hulp van Arnold Kester onmisbaar. Arnold, dank voor alle adviezen over de geschikte statistische toetsen en de adequate beschrijving van de resultaten.

I am grateful to the people who have been critically reviewing one or more drafts that I produced: Anton Blooten, Miriam van Bommel, Tomás Donaire, Erik van de Giessen, Justine Hanson, Susan Klassen, Richard Marquet, Joost van Montfort, Julienne McKay, Zoyla Segura and Sofia Sprechmann.

Mijn ouders ben ik dank verschuldigd voor hun enorme steun in alle fasen van dit proces. Pap, je wijze raad en belangstelling zijn enorm waardevol geweest, evenals de praktische hulp als het mogen gebruiken van je computer en de vele uren die je in bibliotheken op zoek bent geweest naar artikelen. Mam, jouw gastvrijheid en zorg voor mij en mijn mannen is en was geweldig!

Mijn dierbare vrienden en familie dank ik voor jullie steun en vriendschap. Een paar mensen wil ik speciaal noemen. Peter en Bart voor jullie gezelligheid en meeleven; Mercedes por tu cuido cariñoso para nosotros; Fred, voor de waardevolle contacten op de gemeente van Managua; Justine for the inspiring meetings of our PHD support group; Jan, voor je continue inspiratie om de balans 
in de gaten te houden en vooral ook te genieten; Guido en Linda, voor de gezellige avonden die ik bij jullie in Maastricht mocht logeren; Joost, voor alle tips over het promotietraject; de familie Hoekman, voor het de wereld rondsjouwen van vele kilo's documenten, zodat ik direct na terugkomst aan de gang kon; Miriam voor je warme meeleven, het samen op ons hoofd staan, en het beste begeleid kamerbewoon project ever; Anton en Anneke voor het welkom in Nicaragua en later in Nederland; Gabrielle en Rienk, voor het creëeren van een studeerkamer in jullie huis, toen wij nog geen plek hadden; Trudy voor je wijze en hartelijke meedenken over alle te nemen hobbels; mijn collega's in het NIVEL voor de fijne werkplek en de warme belangstelling en speciaal mijn kamergenoten Richard, Tamara en Annemarie voor alle meedenken en goede raad; en aan Mieke van Leeuwe voor de mooie layout van dit boek.

Erik, als dit niet ook jouw project geweest was, had ik er nooit met zoveel plezier aan kunnen werken. Zonder jouw kritische blik, heldere geest, goede taalgevoel, humor en Liesbethkennis, was dit boek waarschijnlijk nooit geschreven!

Houten, Juni 2006 


\section{Curriculum Vitae}

Liesbeth Meuwissen was born January 12, 1963 in Utrecht, The Netherlands. She grew up in Bilthoven and finished her secondary school at 'het Nieuw Lyceum' (VWO-B) in 1981. The commitment and fascinating stories of an uncle inspired her at young age to become a tropical doctor. She had to wait one year before she obtained a place to start studying medicine, and this year she spent at the University of Wageningen, where she met many other people who shared her international aspirations. She studied medicine at the University of Maastricht where she obtained her medical degree in 1990. In order to qualify for a posting abroad as a medical doctor she specialised for two years in general surgery and obstetrics at the 'St. Jans Gasthuis' hospital in Weert, The Netherlands. She obtained a certificate of Tropical Medicine in 1993 at the Royal Tropical Institute (KIT) in Amsterdam.

In 1993, she left with her husband for Lesotho, Southern Africa, to work as a medical officer at the St. James district hospital in the village of Mants̃onyane. Besides direct patient care, she was initially in charge of the extensive primary health care program covering 8 health centres and all outreach activities in the district. With the expectation of an increasing number of HIV infections in the region, she initiated the Mantsonyane AIDS prevention project. In 1994, she became medical superintendent of the hospital.

In 1997, she moved with her husband and two children to Niger, West Africa, where she joined a regional health program as advisor to the district health team in Tillabéri. The main aim of the program was to improve health care delivery at primary care facilities by introducing user participation in the organisation of health care, improved staff training and the establishment of a cost recovery program, by which drugs were sold and a revolving fund created.

In 2000, she moved with her family to Nicaragua, Central America. Since then, she has been involved with the voucher program for adolescents, the subject of this dissertation. She evaluated the impact of the pilot phase of the program that was implemented by the Central American Health Institute in collaboration with the London School of Hygiene and Tropical Medicine, and financed by DFID. Over this period, she studied for a Masters Degree in Epidemiology at the London School of Hygiene and Tropical Medicine via the distance-learning program. She completed the Master Degree in 2003. In December 2004, she returned with her family to the Netherlands. Since June 2005, she has worked at The Netherlands Institute for Health Service Research (NIVEL). 